Remembering Miramar, Forgetting Whātaitai 



\section{Remembering Miramar, Forgetting Whātaitai}

By

Paul Martin

A 120 point thesis submitted to the School of Architecture \& Design, Victoria

University of Wellington, in fulfilment of the requirements for the degree of Masters in

Architecture (prof)

Victoria University of Wellington

2015 

I would firstly like to thank my two supervisors Robin Skinner and Geoff Thomas who both poured so much time and encouragement into the thesis. Not only were you both helpful and encouraging but your insights were thought provoking and it was an enjoyable research project.

I would also like to thank the numerous people that helped with the gathering of historic information. Providing advice and insight into collecting Maori hisotry and well hidden documents.

Most importantly I would like to thank all my friends and family that have supported me throughout my years of study. 

Te Whanganui a Tara Wellington City has a long history dating back to legendary individuals, including Maui and Kupe. The harbour is dotted with sites associated with a history that has accumulated over several centuries. Colonial settlement concealed many of these pre-European sites with what is now Wellington City. Today many of these buildings that constitute Te Whanganui a Tara Wellington are considered heritage fabric or relics of the past.

This thesis aims to examine and define such a context of a site's past that is both concealed and concealing. The research breaks the past of the harbour down into two periods; Te Ao Tawhito (the old world) and Te Ao Hou (the new world), allowing for a segregated study of pre-European and post-European history. Many of these relics evoke, express or give insight into the past of Te Ao Hou. At times this history seems privileged due to the existence of relics. While methods such as preservation or restoration are valuable tools for a relic based design project, they do not address the matter of concealment. Two issues arise: Firstly, how could an intervention such as a mnemonic device express, evoke or give insight into the past that for numerous reasons are not presently interpretable at a site? Secondly, how could such an intervention interact with a relic that now remains on a site, as a valued vestige of the past?

Part one of the thesis consists of project one, which is a design for a Japanese bath-house on Seatoun Ridge in Motu-Kairang Miramar. This design attempts to evoke, express and give insight into an era of the past from Te Ao Tawhito. This period is not presently apparent or evoked at the site although the era of concern is well known and important. The purpose of this project is to explore analogy as a design method, which through referencing the past, allows a new building to act as a mnemonic device expressing, evoking or giving insight into Te Ao Tawhito.

Part two follows with a second project consisting of three designs for an aquarium that explore how a mnemonic intervention could exist on a site that hosts a relic. Point Gordon on the northern tip of the peninsula was once a pa during Te Ao Tawhito and a military base during Te Ao Hou. This site is well suited for the second project because a relic of the latter period remains, subsequently concealing the ancient site of the former period. This project explores a metamorphic design method that allows a site to be developed while considering the following values of a relic: its original intent, its age value or its historic meaning. The metamorphic approach used in the second project juxtaposes, weaves or wraps a mnemonic intervention into the site, allowing the relic to be valued for either of the above qualities, which it may possess. The two projects have resulted in two design methods that could guide further design projects acknowledging a site's layered histories whether interpretable or not.

The thesis discusses three issues that are important to this research. Firstly, the past is considered as an important aspect of a communities culture, identity and well-being. Secondly, relics and mnemonic interventions are discussed as having equal value and special attention should not lay with relics. Lastly, the research reflects on how questions can be more valuable than terminology. 
Image redacted from online version

Please refer to archived copy

or

the image can be found via the below reference

[FIG I] George French Angas Tinted lithograph, hand-coloured $550 \times 360 \mathrm{~mm}$ potraying women possibly occupying a whare et Tiakiwai pa,

SOURCE: Alexander Turnbull Library, Wellington, New Zealand. Reference: PUBL-0014 31. http://natlib.govt.nz/records/23048186. 1844

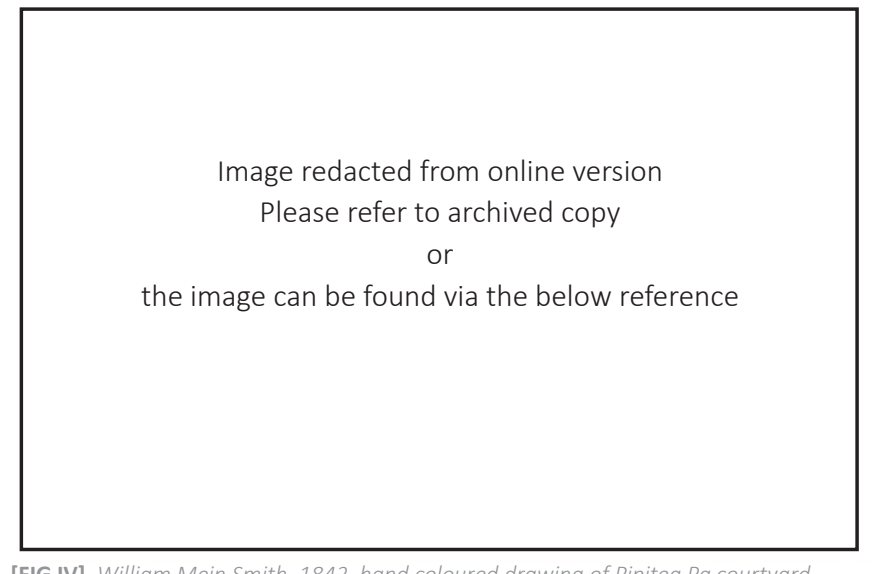

[FIG IV] William Mein Smith, 1842, hand coloured drawing of Pipitea Pa courtyard

SOURCE: Alexander Turnbull Library, Wellington, New Zealand. Reference: PUBL-0011

04-1 http://natlib.govt.nz/records/23151660
Image redacted from online version

Please refer to archived copy

or

the image can be found via the below reference

[FIG II] Charles Decimus Barroud 1852, watercolour view of Te Aro from Brooklyn SOURCE: Alexander Turnbull tibrory Wellington New Zealand Reference C C007-011 http://natlib.govt.nz/records/23101754

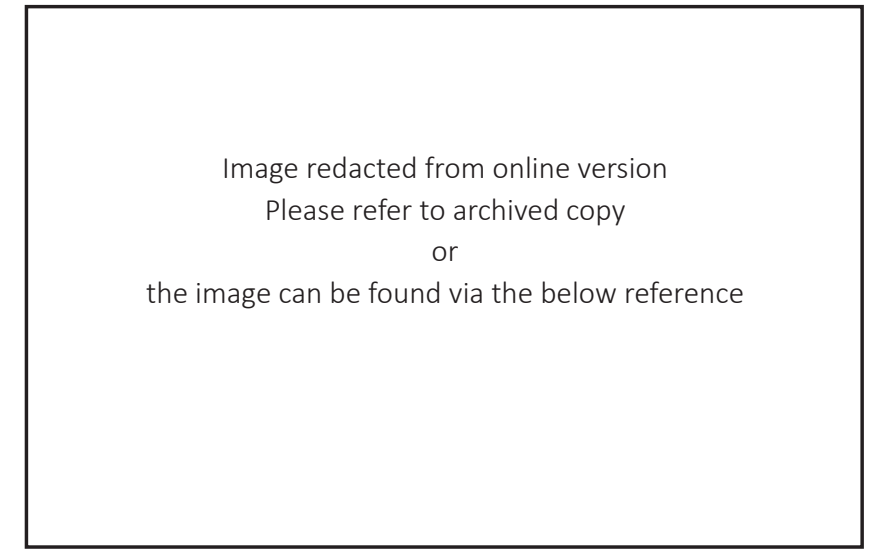

[FIG V] Charles Emilius Gold, watercolour of a Māori man poling a waka infront of Mot Kairangi Miramar Penisular

SOURCE: Alexander Turnbull Library, Wellington, New Zealand. Reference: A-288-026 http://natlib.govt.nz/records/22909953
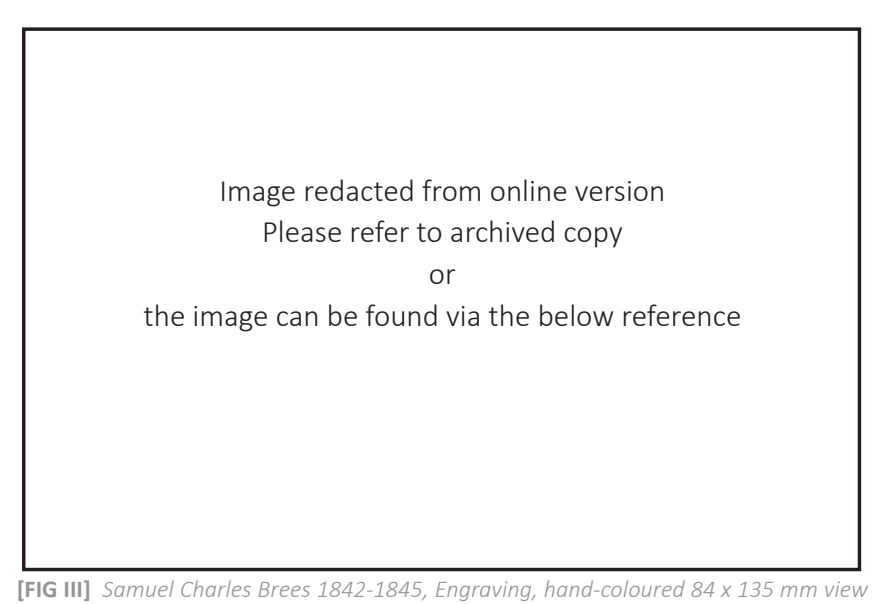
of Pipitea po

SOURCE: Alexander Turnbull Library, Wellington, New Zealand. Reference: A-109-020 http://natlib.govt.nz/records/23168219

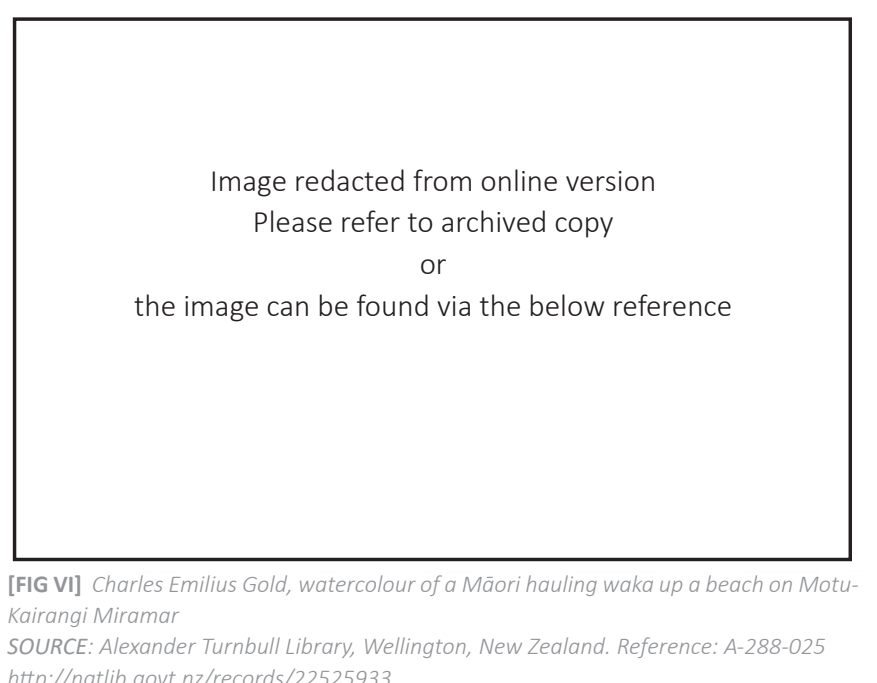




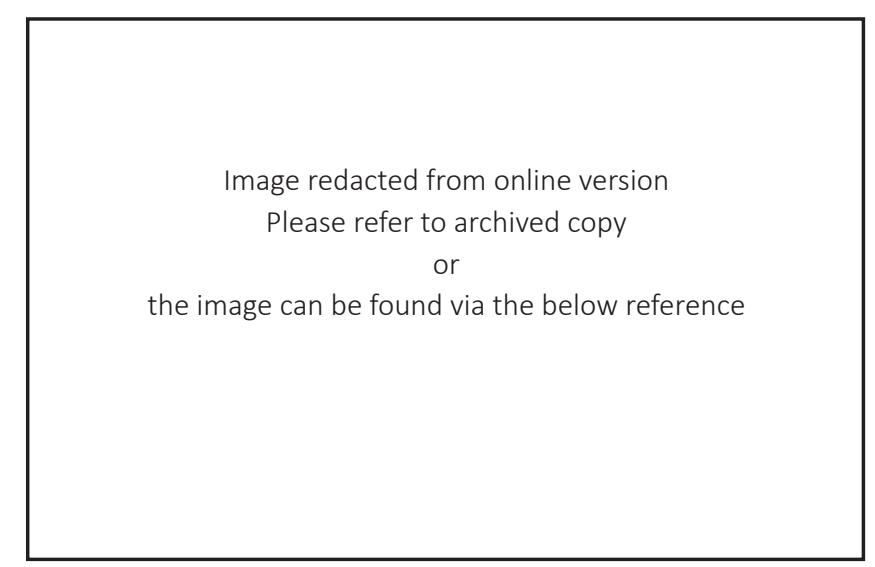

[FIG VII] William Williams, photograph 1884, of gun emplacement at Fort Ballance SOURCE: Alexander Turnbull Library, Wellington, New Zealand. Reference: 1/2-140344-C http://natlib.govt.nz/records/22917815

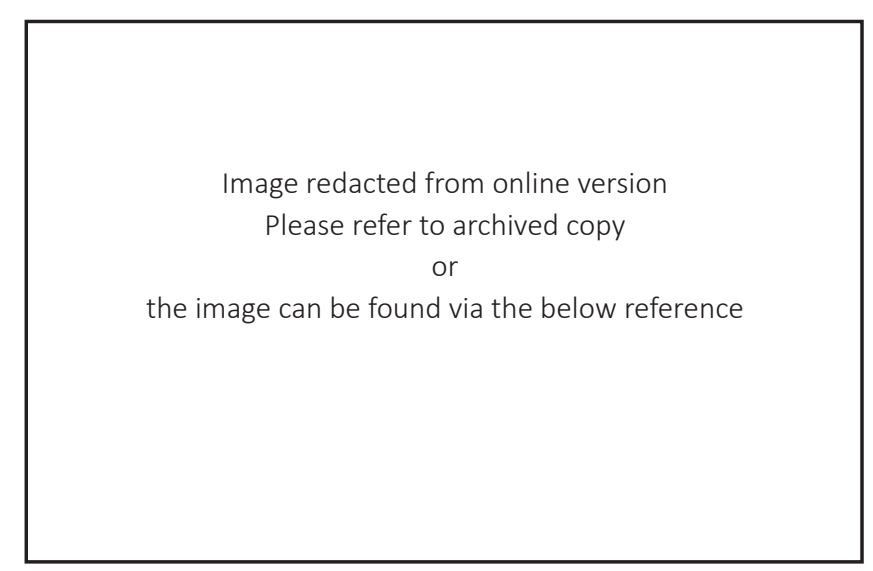

[FIG X] Sydney Charles Smith collection, photograph, 1937 showing Military personne training at Fort Dorset.

SOURCE: Alexander Turnbull Library, Wellington, New Zealand. Reference: 1/2-048328-G http://natlib.govt.nz/records/22850230

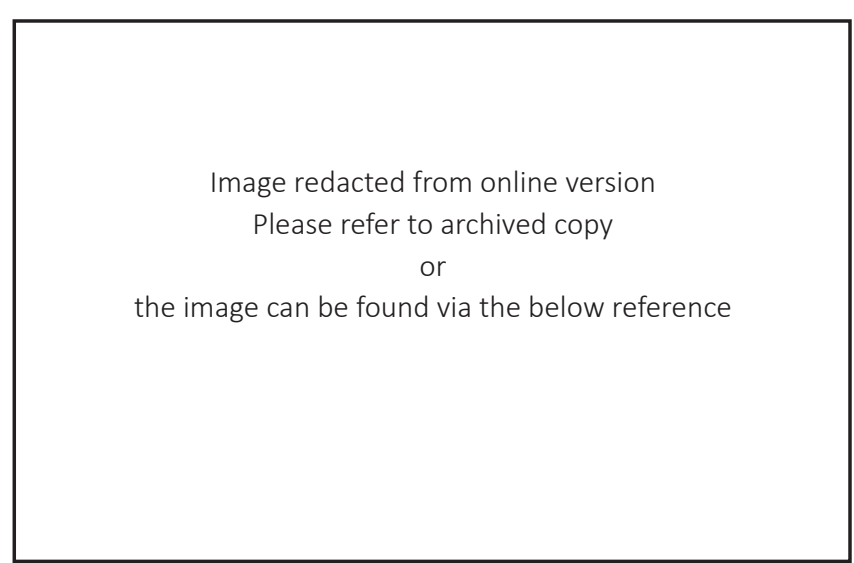

[FIG VIII] Sydney Charles Smith, photograph 1899, of the Submarine and Torpedo Mining Corps annual camp, Shelly Bay.

SOURCE: Alexander Turnbull Library Wellington New Zealand Reference: $1 / 10202366$ http://natlib.govt.nz/records/22

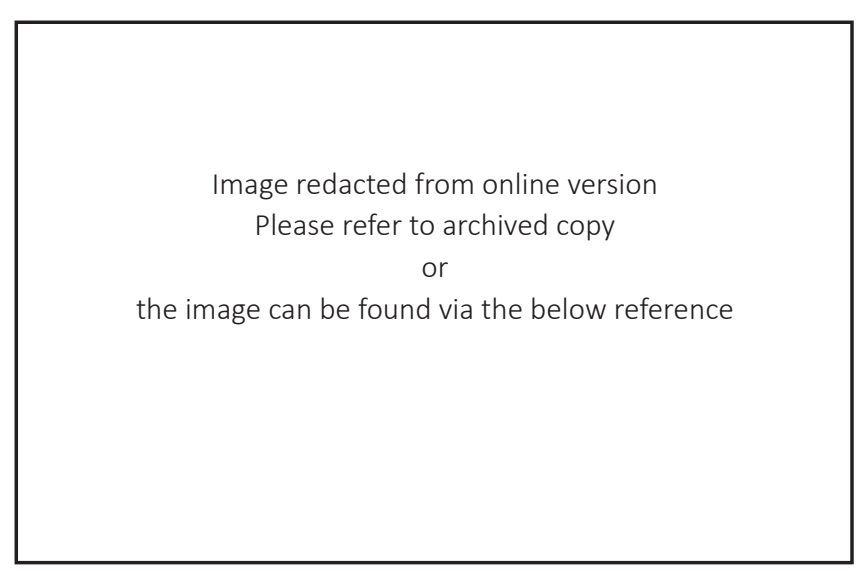

[FIG XI] Evening Post newspapper collection, photograph, 1937 showing working gur at Fort Dorset

SOURCE: Alexander Turnbull Library, Wellington, New Zealand. Reference: 1/4-048821-G http://natlib.govt.nz/records/23203467

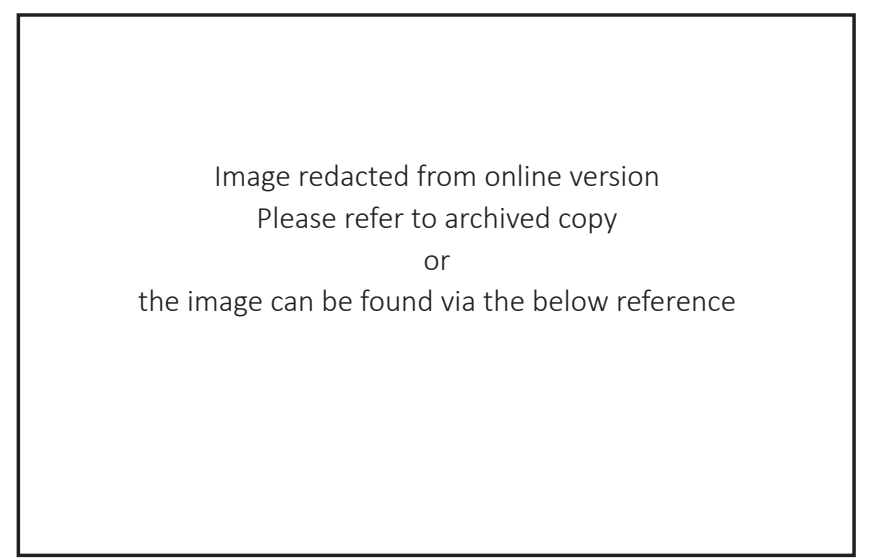

[FIG IX] Henry Charles Clarke, Wrights private collection, photograph, 1887, of Fort Ballance looking east to Scorching Bay

SOURCE: Alexander Turnbull Library Wellington, New Zealand. Reference. 1/1-020667-6 http://natlib.qovt.nz/records/23212316

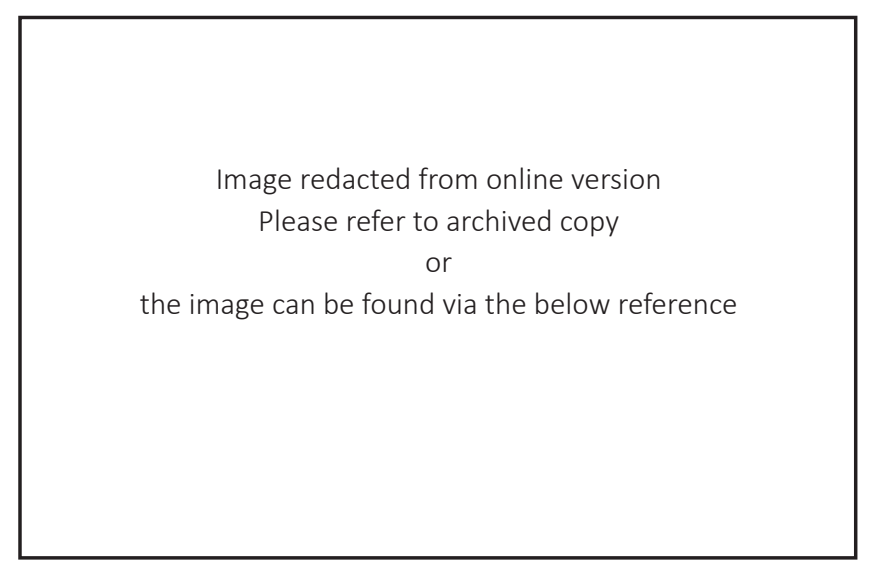

[FIG XII] William Hall Raine collection, photograph, 1942 showing Women's Army Auxiliary Corps marching at Fort Dorset, Seatoun, Wellington, during World War II

SOURCE: Alexander Turnbull Library, Wellington, New Zealand. Reference: 1/4-020868-G http://natlib.govt.nz/records/23201234 
Acknowledgements$$
\text { Abstract }
$$

opening images

\section{Prologue PAgE 14}

1.1 Background context 1.2 Problem Statement

1.3 Thesis argument

1.4 Research aim

1.5 Thesis Structure

1.6 Research Scope

1.7 Literature Review

\section{the concealed narrative}

\section{Chapter 2 PAGE 22}

Narratives of a site

2.1 Part One Introduction 2.2 The Concealed Context 2.3 The Past Through Narrative 2.4 A Peninsular of Narratives

\section{Chapter 3 PAGE 28}

the past through narrative

3.1 Architecture of narrative

3.2 case study one

3.3 case study two

3.4 case study three

3.5 analogy as design method

\section{Chapter 4 PAGE 37}

Project one: evoking the past

4.1 Researching through design

4.2 Japanese bathhouse

4.3 part one summary 


\section{Part Two}

between narratives

\section{Chapter 5 PAGE 50}

Relics of a site

5.1 Part two introduction

5.2 The concealing context

5.3 The past through relics

5.4 A peninsular of relics

\section{Chapter 6 PAGE 66}

the past through relics

6.1 Architecture of relics

6.2 case study four and five

6.3 case study six and seven

6.4 case study eight and nine

6.5 metamorphisism as design method

\section{Chapter 7 PAGE 75}

Project two: dwelling in the past

7.1 Project two introduction

7.2 Project 2a: Aquarium of continunuity

7.3 Project $2 b$ : Aquarium of light

7.4 Project 2c: Aquarium of openness

\section{Epilogue}

Epilogue PAGE 106

8.1 Project one and two reflection

8.2 research summary

8.3 conclusion and research output

\section{List of figures PAGE 108}

Bibliography PAGE 112 


\section{GLOSSARY OF MĀORI WORDS}

HAPŪ - Traditional social unit made up of whānau HEKE - Migration

IWI - Tribe, also means bone

KĀINGA - Settlement

KŌRERO - Speech, narrative or to talk

MANA - Relating to prestige, authority or spiritual power MANA WHENUA - Authority over the land (ownership or belonging)

PĀ - Fortress defended by palisades or ditches

PATAKA- Storehouse

PEPEHA - Short Saying

RANGATIRA - Relating to high rank, a leader ROHE - territory

TANGATA WHENUA - People of the land

TANIWHA - Powerful spirit monster

TAPU - Sacred, prohibited or restricted

TE AO HOU - The new world

TE AO HURIHURI - The changing world

TE AO TAWHITO - The old world

TE REO - Maori language

WAIATA - Song

WHAKAPAPA - Genealogy

WHAKATAUĀK̄̄ - Proverb

WHĀNAU - Family

WHATA - Storehouse

\section{MĀORI PEOPLE DISCUSSED IN THE THESIS}

AWANUIARANGI - Eponymous ancestor of Te Āti Awa

KUPE - Famous Polynesian navigator credited with discovering Aotearoa New Zealand

TARA IKA - Eponymous ancestor of Ngai Tara

TAUTOKI - Father of Rangitāne

TUTERMOANA - Famous descendant of Tara

WHATONGA - Grandson of Toi and Father of Tara-lka and Tautoki. depending on the tradition. Whatonga is said to have sailed from the pacific to Aotearoa New Zealand 


\section{MĀORI PLACE NAMES}

AOTEAROA- Name for New Zealand in te reo

MAKARO - Ward Island

MATIU - Somes Island

MOTU-KAIRANGI - Miramar Peninsular

TE MOANA NUI A KIWA - Pacific Ocean

TE TAI O REHUA - Tasman sea

TE UPOKO O TE IKA A MĀUI - Referring to the head of the fish (North Island) that Maui caught. The Lower North Island.

TE WAKA A MĀUI - South Island, though there are other names in Māori referring to the South Island

TE WHANGANUI A TARA - Wellington

\section{MĀORI IWI AND HAPŪ IMPORTANT TO THESIS}

\section{ANCIENT HARBOUR DWELLERS}

NGAI TARA - Named after Tara Ika, who mostly occupied the area for several generations

NGAI IRA - Succeeded Ngai Tara as the mana whenua of the harbour

\section{MANA WHENUA}

TE ĀTI AWA - Arrived during the mid-nineteeth century and have maintained mana over the harbour areas

PORT NICHOLSON BLOCK SETTLEMENT TRUST - Representatives of mana whenua 


\section{PROLOGUE}

\subsection{Background Context}

Dotted around Te Whanganui a Tara Wellington harbour and taking centre stage on Motu Kairangi Miramar peninsular are relics of military defence systems. These military bases were in response to Russian and German aggression, during the late nineteenth and early half of the twentieth century This era of unrest cost many lives abroad especially on the front lines drawn across Europe. Today the Great Wars are considered significant and important due to the sacrifice made and a sense of independence that was felt. This significant period of Aotearoa New Zealand's past is now embodied in these relics, resulting in their status as heritage fabric. This status dictates how work on the relics is to be carried out and any alterations must comply with heritage ideas and principles in order to ensure that the relics remain as a connection to the past.

However, this aim to protect the past opens a problem as these relics were not only erected during a period of global conflict but came about during a period of internal unrest. The 19th century is a pivotal moment in Aotearoa New Zealand's past as it is the coming of Pakeha and in a sense the end of Maori independence. Many of these military sites were once places of pa or kainga that embodied the past of the Maori in some way. Hence these relics that are now treasured as objects of the past are ironically also objects that conceal the past.

rihapeti Ramsden summarises this issue when musing over her ancestral Waitoa stream which is now confined to drainage pipes (294). Ramsden illustrates the issue of how the present-day environment conceals places of the Maori before European arrival. The recent publication; Tangata Whenua; an illustrated history studies the past of Aotearoa New Zealand from a Maori perspective and does so by segregating the past into three periods: Te Ao Tawhito (the old world), Te Ao Hou (the new World) and Te Ao Hurihuri (the changing world). The thesis has adopted this understanding of the past in order to refine the background context and a problem statement.

\subsection{Problem Statement}

This context presents two issues that the thesis will attempt to address. Firstly, how could an architectural intervention provide insight, express or evoke the past of Te Ao Tawhito? Secondly how could such an intervention interact with a relic of Te Ao Hou that is hosted by the same site, which is also associated with Te Ao Tawhito?

\subsection{Thesis Argument}

The thesis argues that the best way to provide insight, evoke, or express multiple eras of a site's past is through a development. Conservation rightfully takes charge when a relic's future is being explored. However, conservation generally focuses on the object as a means to express or provide insight into the past. Conservation methodologies propose to do this by either restoring or preserving architectural relics. These two methods of restoration or preservation provide the basis for many conservation projects. Although relevant, the thesis argues that these methods limit a project by not focusing on the full historical content of a site, and do not acknowledge any eras of the past that the relic may be concealing.

The thesis firstly argues that an architectural intervention may act as a mnemonic device that marks and informs inhabitants of Te Ao Tawhito past. The thesis explores an analogical method which generates a design that is a comparable space to that imagined by knowing a historic narrative. Although analogy has been used before in the discipline, the thesis presents it in response to this context and as a result of studying the problem.

The thesis then argues that a mnemonic building could intervene on a site with a relic through a metamorphic method. Similar to the analogical method, this process is also a result of the research. The method draws from conservation theory and proposes that a relic may either be valued for its age, original intent or historic content. Depending on what is valued the site could be developed by juxtaposing, weaving or wrapping an intervention around, alongside or over a relic.

\subsection{Research Aim}

The research will explore the argument by investigating two sites that do not reveal the past of Te Ao Tawhito in any form. The first site is an empty plot of land while the second site hosts a relic. The purpose of the first project is to explore how an analogical method could generate a building that evokes, expresses and provides insight into the past of Te Ao Tawhito. The second project attempts to explore a method that allows an intervention representing another era of the past to exist alongside the relic.

The research aim can be broken down into five objectives: 1.To study the past of Aotearoa New Zealand as two parts.

2.To discuss interventions and relics, as insights into the past. 3.To explore a method that responds to a site's historic narrative.

4.To explore a method that responds to a site's relic

5 To research through design both methodologies in a process that will result in a design outcome that communicates the past of Aotearoa New Zealand.

In response to the problem and in relation to the research aim the thesis asks:

How can an architectural development benefit a community by expressing, evoking and providing insight into the layered past of Aotearoa New Zealand? 


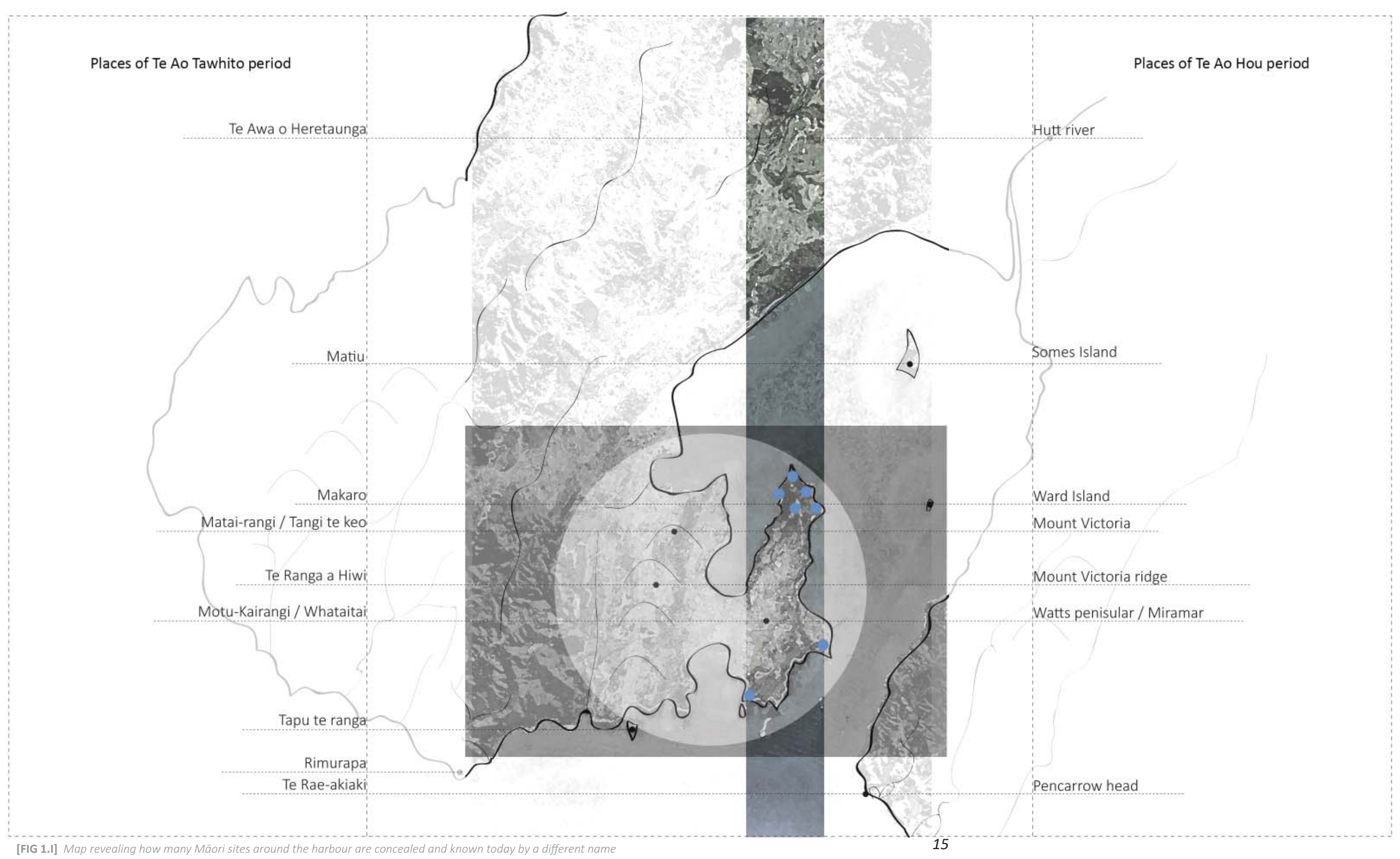




\subsection{Thesis Structure}

The thesis is broken down into two parts each concluding with a design project that explores the two possible methods allowing insight into the past. Each part explains the two periods of the past further. Part one focuses on the past of Te Ao Tawhito discussing early occupation of the harbour by the descendants of Whatonga and then the later and still present Te Ati Awa. Colonialism in part one is explored as a moment where the Maori environment changed to such a degree that it is almost unrecognisable today. Part two reflects on the past of $\mathrm{Te} \mathrm{Ao} \mathrm{Hou}$, discussing the military presence as a result of the then global conflicts.

Part one, by way of project one (Japanese bathhouse) explores the issue of evoking the past through an intervention. Part one studies the past of Te Ao Tawhito and discusses the implications and protocols of researching Maori history. History as a means to know the past is discussed and forms the nucleus for a design process. Project one focuses on a site that no longer bears any resemblance to a place it once was and enables the research of a method that could conclude with a design that creates a comparable space evoking and creating insight into the presently concealed past. Objectives one, two and three are explored and form conclusion around a possible method of analogy that guides an architectural project.

Part two similarly builds a foundation, on which project two (Aquarium schemes) capitalises. Project two explores the second issue of how an intervention (discussed in part one) can exist alongside a relic. Relics as an insight into the past are discussed along with methods which seem to dominate this context. Although valuable, these methods are constrictive providing a predetermined solution and design outcome. Such thinking is relegated but not dismissed, so as to allow for a method that guides a process to not only treat the relic, respond to it, but most importantly to allow for a space that evokes the concealed past not related to the relic Project two focuses on a site that once set the scene during Te Ao Tawhito but due to colonialism was altered in such way that the present-day site may have little resemblance of that era by hosting a relic that embodies the past of Te Ao Hou. Part two consists of objectives one, two, four and five that conclude with a possible method of metamorphism that allows the relic to be treated in such a way that it is protected, communicated and allows the site to be developed so as to allow for a space comparable to Te Ao Tawhito.

\subsection{Research Scope}

The thesis is not a definitive statement of Maori history and the two designs that reflect the past of Te Ao Tawhito are the author's interpretation. The designs do not represent Tangata whenua or mana whenua views towards the past. Although researched and studied, any description of a site's Te Ao Tawhito past is to be treated as an example of a historic narrative for the purpose of illustrating a design point. None of the four design projects herein are a substantiation of $\mathrm{Te}$ Ao Tawhito past rather an example of how historic narrative can be translated through an intervention. By studying what is available also allows a discussion on how Maori history is transmitted.

As already mentioned, the thesis will explore two possible methods that enhance an architectural project in the above context. An analogical method and a metamorphic method are considered appropriate methods for the context as a result of the research. Methods and theories associated with analogy and metamorphism are not new to architecture. Aldo Rossi and Paul Virilio, for example, both advocate notions that are named as either analogical or metamorphic. Though the methods share the same name and can be compared, the methods herein are irrespective of preexisting notions and are a result of the research conducted in the outlined context. The analogical method does draw from analogy theories but only to understand what an analogy is. The metamorphic method on the other hand, categorises a group of methods that attempt to develop or adapt a site for future uses. Each of the metamorphic methods differs by how the relic is treated, yet they each attempt to allow growth of the site.

Emphasis has been put on the conceptual stage of the design process, focusing on how and why we design. Rather than doing one final project, the thesis explores the context through four designs that not only test ideas but help to develop and inform a notion that can then be presented through the designs and discussed amongst interested people. The two methods are explored as generators of design with the four projects resulting from this generating process.

\subsection{Literature review}

The research readings can be broken down into three categories; researching the past of Te Whanganui a Tara Wellington, architectural responses to narrative and relics, and how the past can be interpreted.

Motu-Kairangi Miramar is fortunate to have severa publications on both periods of its past. The former period is less substantiated with some of the sources being disputed. Obtaining an understanding of Te Ao Tawhito past is difficult for this reason, as well as parts of the past being tapu. The literature used is useful to form a basis, and to understand the migrations of the Whatonga descendants and the latter Taranaki hapū. It gives insight into ancient harbour dwellers and their movements but should not be understood as definitive. Maori history is tapu and mana whenua should be consulted when wanting to publish accurate information about their past.

The second section of literature focuses on how architecture 
could evoke the past by interacting with narrative or a relic. These readings are of the nine case studies explored in chapter three and six. The readings give insight into the architects' intentions and provide an understanding of the ideas. The readings do not provide criticism of the works, only explanations and justifications. This allows the thesis to take ideas that seem useful and employ them in the above context.

The last group of readings informs and guides the thesis argument that focuses on historic meaning rather than artefacts. David Lowenthal and Salvador Munoz-Vinas are both advocates of a similar view and their publications The past is a foreign country and Contemporary conservation methods are extensively referred too. The thesis would direct any student interested in this area to these two books as they present a background to both the study of the past and artefacts. Although not autonomous to architecture the two books draw on architecture suggesting ideas relevant to the design field.

Lowenthal's book presents a complex argument by drawing from a wide variety of sources and examples. Although complex, the book simplifies and clarifies points making it ideal for a background reading. The arguments made in the thesis align to those made by Lowenthal and are guided by his thoughts.

Contemporary theory of conservation by Munoz-Vinas similarly presents crucial understandings regarding the theory of conservation. The book provides insight into the history of conservation and how new approaches to the past relate to classical thinking. The book also argues a perspective that the thesis draws from.

Important historic writers including Eugene Viollet-Le-Duc, John Ruskin and Alois Reigl have also been explored, however their work has been discussed by described contemporary writers so many of their ideas have been understood second hand. Other writers including, Juhani Pallasmaa, Mark Treib and Barry Curtis present similar arguments that the thesis draws from.

The research has found varied use of terminology and expressions which these readings have helped to clarify. The following terminology has been understood by the thesis based on these readings and will be used throughout.

Original intent: the original design of a relic, how the building was intended to be used, based on plans.

Age value: the value of an object based on its age including weathering and any form of damage or alteration.

Historic content: refers to the historic narrative related to an object.

Restoration: is the restoring of a building to its original intent. Although variations occur only this definition is used in the thesis.

Preservation: is the preserving of a building in its current state celebrating the marks of history and time.

Analogical method: a process of generating a design that creates a space comparable to a setting based on a historic narrative.

Metamorphic narrative: a process of introducing a new space that works with an existing relic

Mnemonic intervention: a building that reminds inhabitants of a historic narrative, the space acts as a cue.

Relic: a building that has fallen into disrepair and needs work but is categorised as heritage and protected.

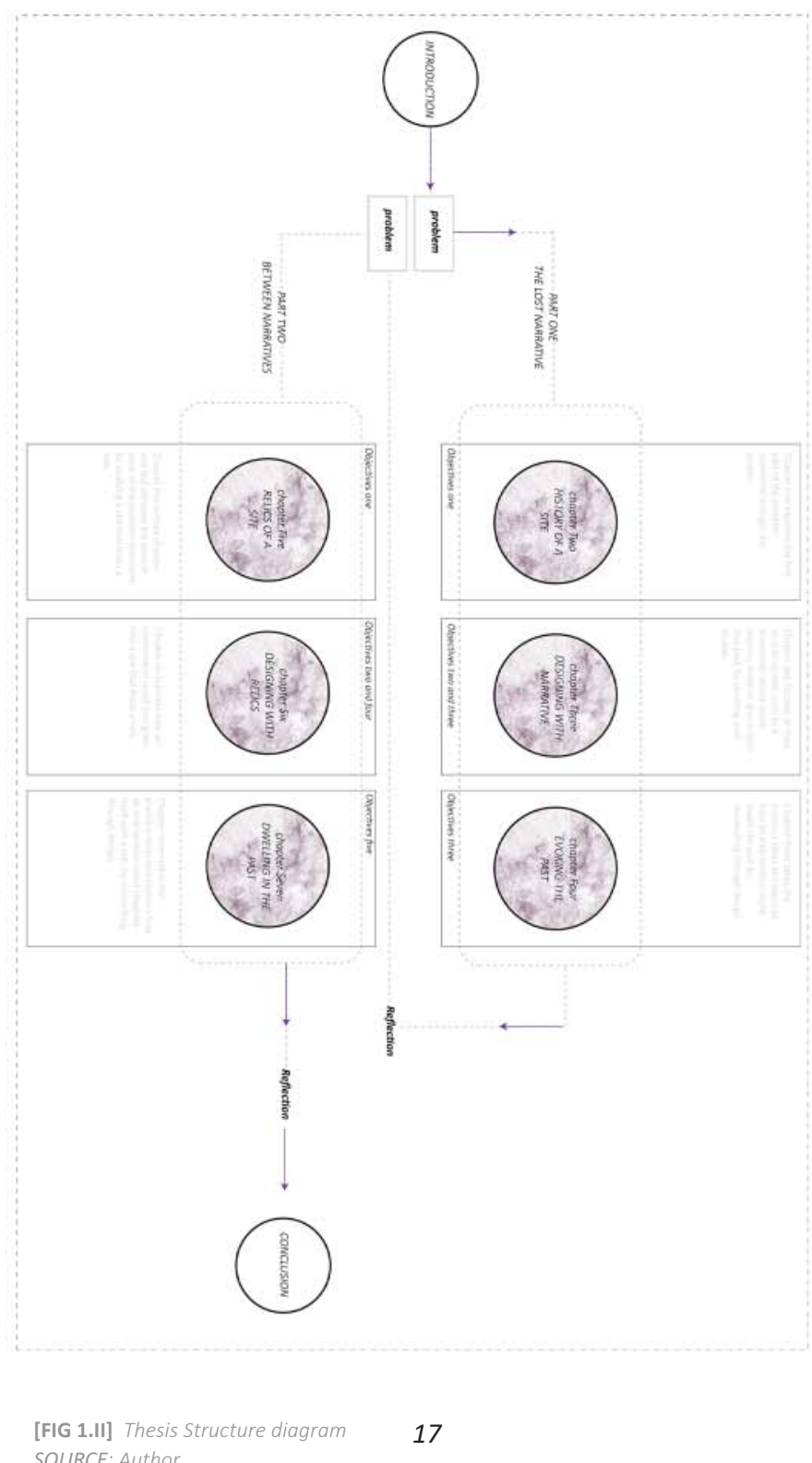


t)

$$
\begin{aligned}
& \text { 4. }
\end{aligned}
$$

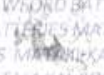

$$
\begin{aligned}
& \text { MATA } \\
& \text { - . . . . A }
\end{aligned}
$$

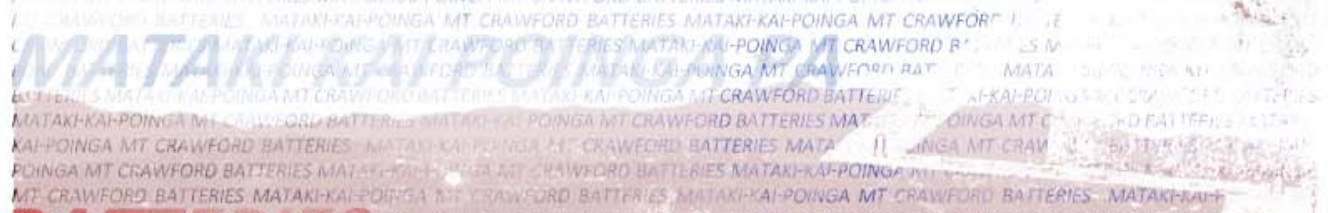

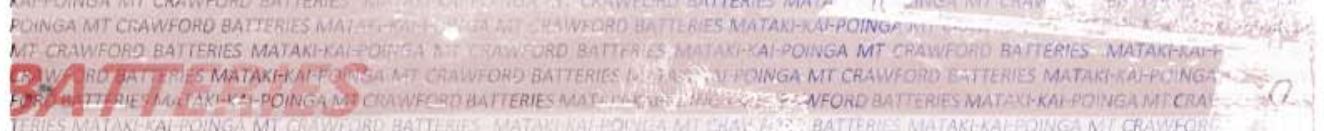

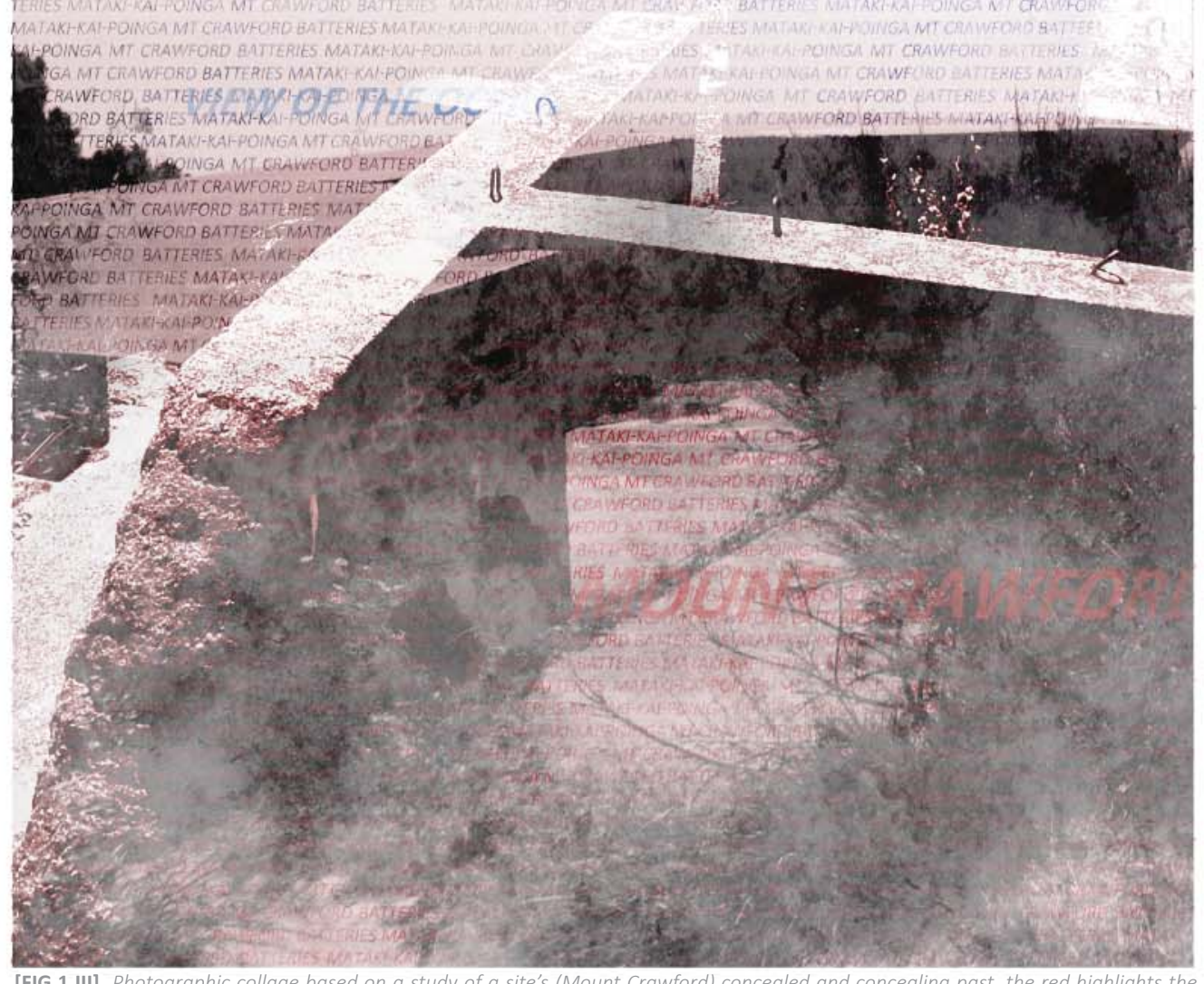

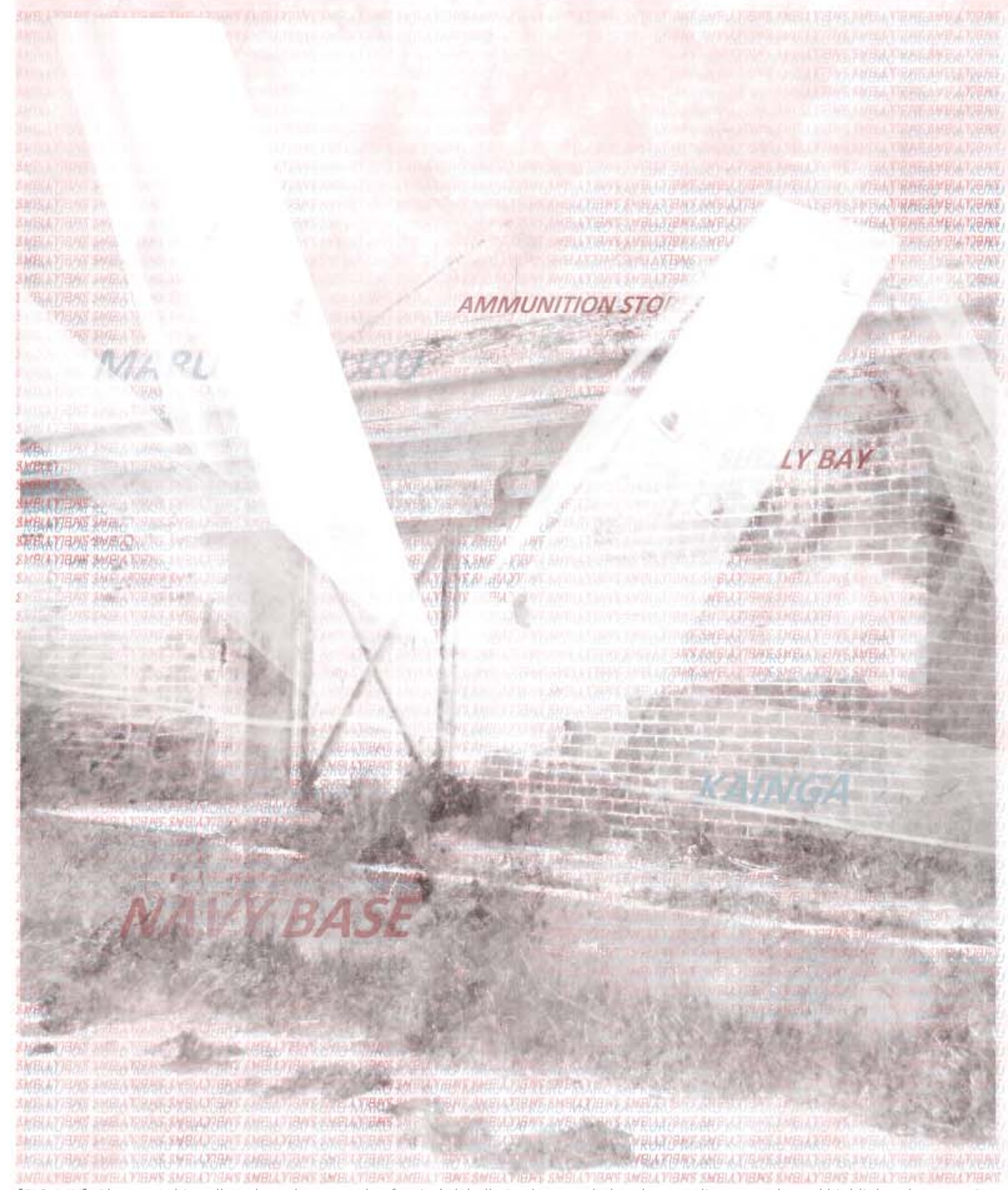
[FIG 1.IV] Photographic collage based on a study of a site's (Shelly Bay) concealed and concealing past, the red highlights the narrative SOURCE: Author 


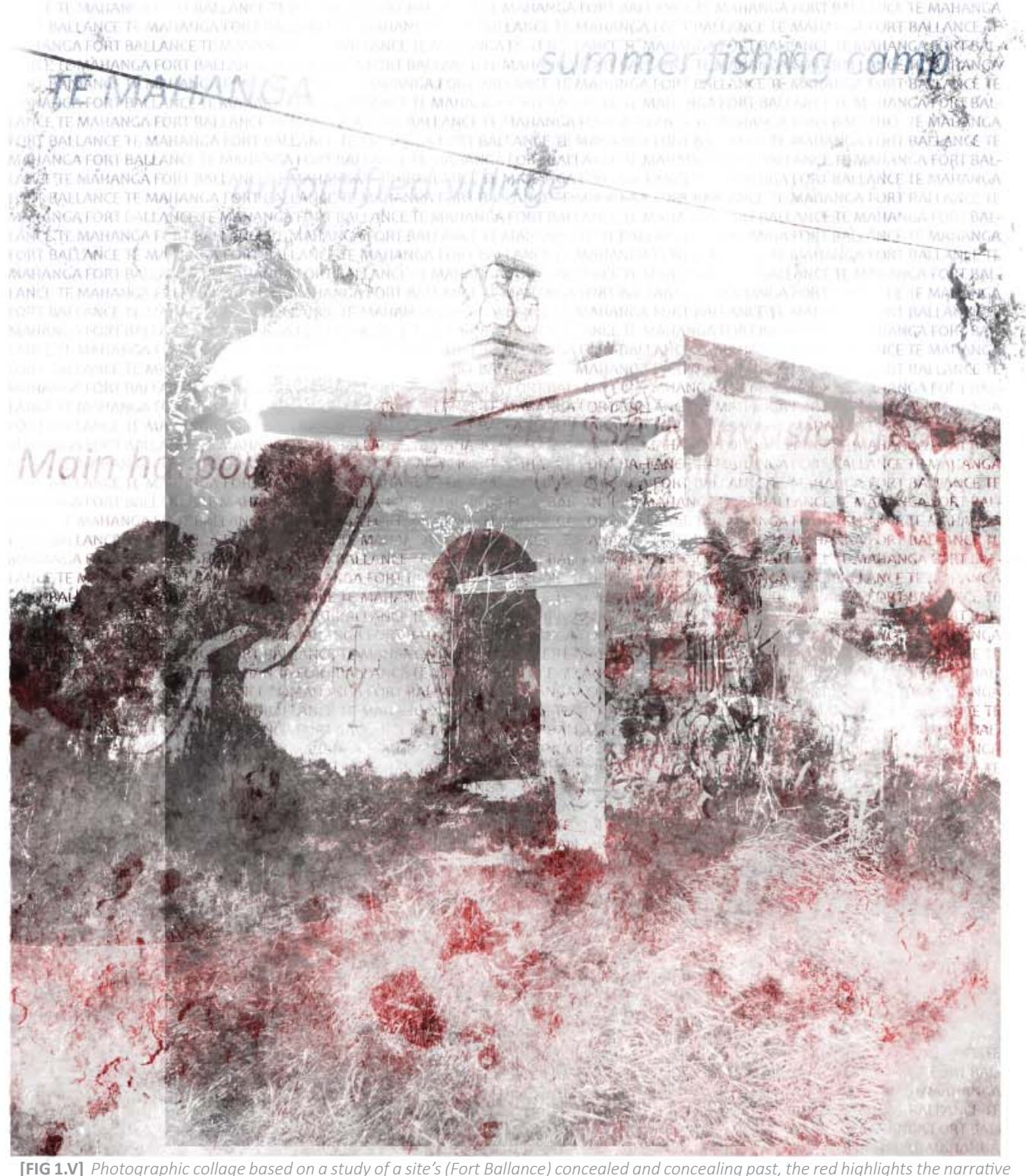

of Te Ao Hou that is

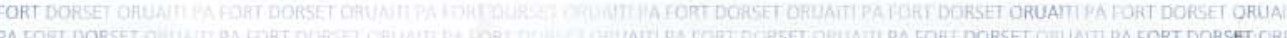

-

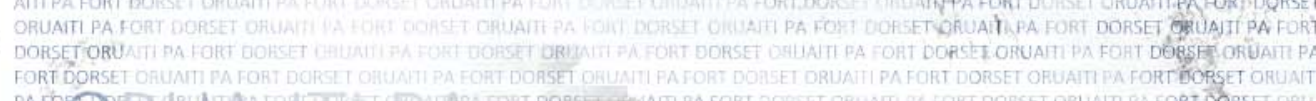
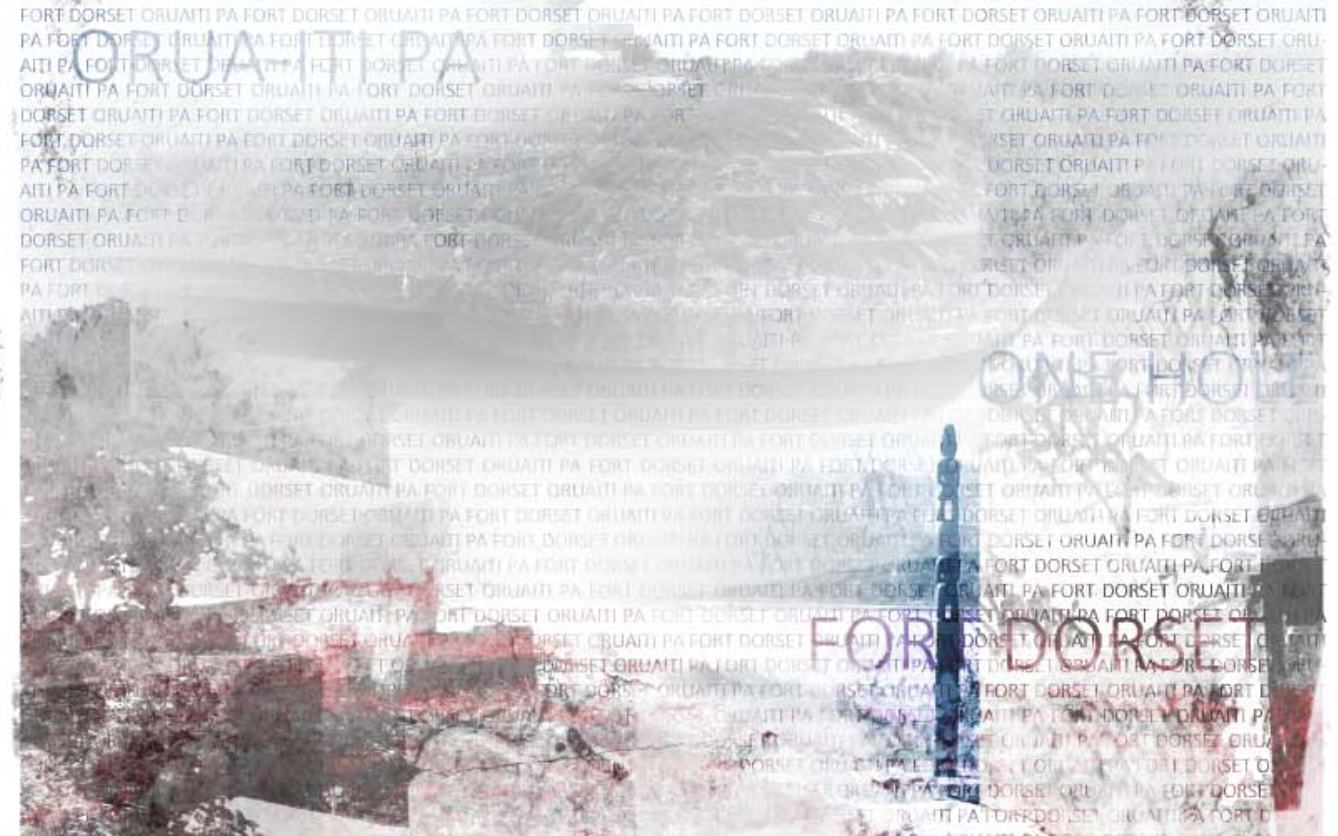

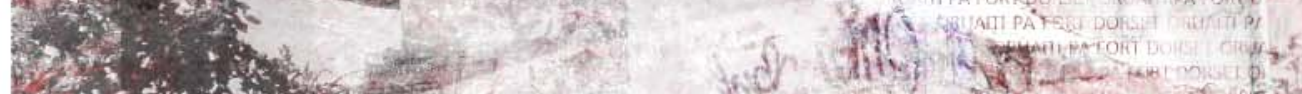

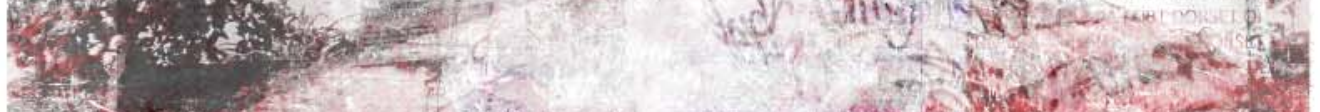

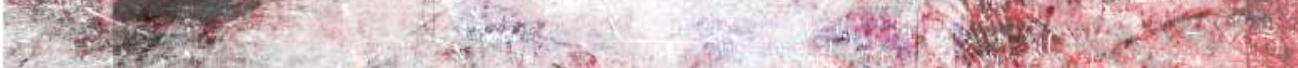
4x. W.

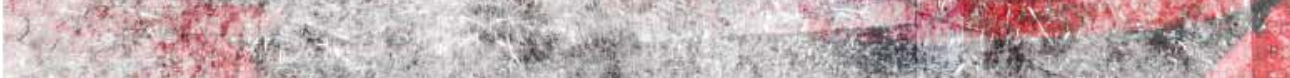

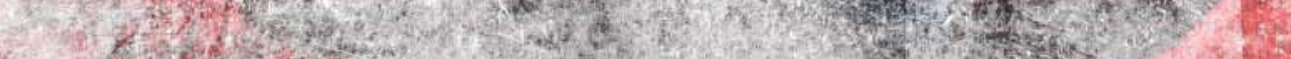

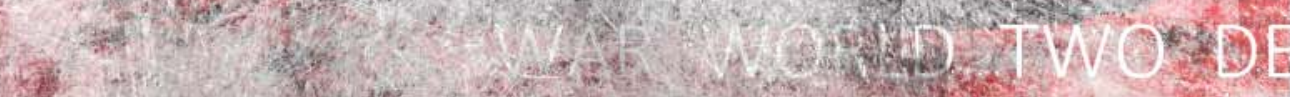
S.

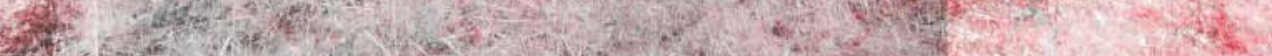

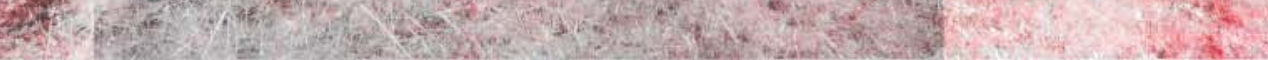
of Te Ao Hou that is marked by a relic, while the blue highlights the past of Te Ao Tawhtio (Orua-iti) which is marked by a sculpture SOURCE: Author 
Part one 


\subsection{Part One Introduction}

Part one of the thesis addresses the first issue of how an intervention could evoke, express or allow interpretation of Te

Ao Tawhito (the old world), via an architectural intervention. Before this can be addressed in project one, the context is unravelled further and followed by an examination of case studies that relate to the context and inform an approach. This chapter examines the context by addressing firstly why it exists. How Maori historic devices such as waiata, korero, whakapapa and, in the case of the thesis, place names inform a narrative of a site's past. This also raises questions about how Maori history may be studied, presented and its relevance to an architect. Finally this chapter presents the harbour and in particular Motu-Kairangi Miramar peninsular as a well-suited area of study due to extensive publications on Te Ao Tawhito past. This chapter informed the selection of three case studies, the Danteum, the Jewish Museum in Berlin and the North American Indian Museum in Washington

D.C, which will be discussed in the following chapter. These case studies were selected as they demonstrate a process of analogy, which generate a mnemonic device that attempts to evoke, express and allow interpretation of a narrative. Part one then concludes with a design project that researches and defines a design method of analogy by testing it on a site that bears no markings of Te Ao Tawhito.

\subsection{The Concealed Context}

Why this context of concealment exists can be answered by a brief study of Te Aro Pa based on Morrie Love's account in Te Äti Awa of Wellington. The significance of the pa begins in the past of Te Ao Tawhito, with four great southern heke of Northern iwi from the Taranaki and Kāwhia rohe, including Te Āti Awa, Ngāti Toa, Ngāti Mutunga and Ngāti Tama. Te Heke Tātaramoa, Te Heke Nihoputa, Te Heke Tamateuaua and Te Heke Paukena are the names of these migrations that brought about the settlement of Te Upoko o Te Ika a Maui by northern iwi. After establishing pa and Kainga along the shores of Te Whanganui a Tara Wellington such as Te Aro; Ngāti Mutunga and sections of Ngati Tama escaped pressures from neighbouring iwi (Ngati Toa and Ngati Raukawa) to Rekohu the Chatham Islands. As a result of this migration the harbour and surrounding lands were gifted to the remaining Taranaki and Te Âti Awa Rangitira, who also cemented their mana over the land with a victory against Ngati Raukawa in the battle of Kūititanga (Love, "Te Ara encyclopaedia").

Te Aro Pa, however vital and significant to Te Āti Awa, was destined for a short life because the next migration to Te Whanganui a Tara Wellington was that of the New Zealand Company which would be the first of many pakeha migrations. The Company along with their city plans would bring about radical changes to the harbour shores. The arrival of the Company saw land sales and purchases, streets laid out and the construction of Wellington City. Te Aro Pa was swallowed up by the ever growing colonial city and Maori were pushed out of the city. Today the area of the pa is overlaid by Courtenay Place and Manners Mall. Although many sites are concealed some aspects of certain sites can be visualised where the landscaped hasn't been entirely altered (see figures 2.III to 2.VII).

\subsection{The Past Through Narrative}

The past can be known through a historic narrative which is relayed by mechanisms including waiata, korero, whakapapa and place names. Lowenthal goes on to suggest that history is "things previous to memory, beyond the range of our personal experience, or dependant on accounts by others" (Lowenthal 211). Unlike memory, history is formed by a collective and is a social activity that bolsters social identity (Lowenthal 213). In this thesis the site's past is studied through history and not memory. Although memory, history and relics are intrinsic to one another, they can be studied in 


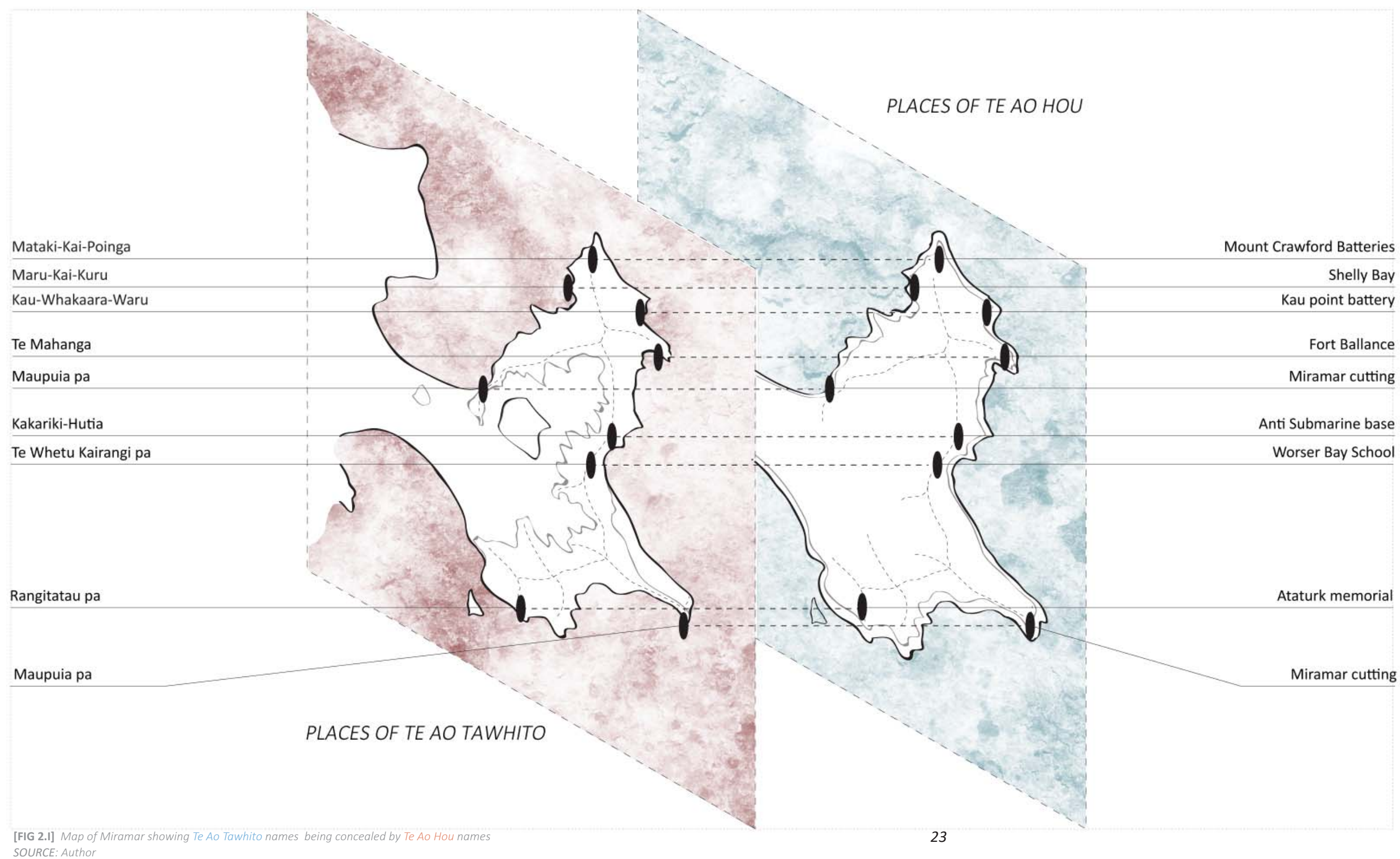


isolation, while taking into account moments when memory plays a role in history.

A historic narrative is a contemporary construction of the past whether it is based on oral or literature sources. Maori accounts of Te Ao Tawhito past were poorly recorded, biased and discarded by some early European scholars who saw oral history as inferior. Atholl Anderson explains how "the record of early contact is also extremely one sided. It is almost exclusively of the foreign gaze." (Anderson 133). Although this is true and the past of Te Ao Tawhito was deconstructed by some Pakeha scholars, others acknowledge it, allowing recent Maori academics to challenge, correct, and restructure an understanding of Te Ao Tawhito past.

Whakapapa, waiata, and korero inform and build many historic narratives but there are protocols and issues that need to be acknowledged such as indigenous property and tapu. These issues do not prevent the publication of the past, but ensure that tangata whenua are protected. A report issued by the Ministry of Social Development suggests that "korero is imbued with the tapu of that person, which must be respected when their words are combined with othe individuals" (Crengle Par. 29) Maori history is also intrinsic to the tangata whenua, and considered alive and as a spiritual entity, that it needs to be treated appropriately.

Although stringent guidelines need to be followed and considered, an opportunity arises with a study of place names. Te Whanganui a Tara Wellington harbour is described in publications such as The land of Tara, The great harbour of Tara, and Miramar peninsula. These publications provide a wealth of knowledge but at the same time are not entirely accurate as J.M McEwen points out flaws with some of Elsdon Best's sources and interpretations. However, with this in mind these publications are useful as they provide insight regarding a site's past. Knowing place names of Te Ao Tawhito period is crucial for an architect, who wants to acknowledge this past. The thesis suggests that such a background understanding would allow any architect to include (if appropriate) Maori history and culture into a design

As mentioned place names will be used to study and inform architects of Te Ao Tawhito past. An essay in the publication, Tone Tupu ora: indigenous knowledge and sustainable urban design discusses the use of mapping Maori Narrative. The Author Wiki Walker explains how "an initiative was established aimed at obtaining tangata whenua (Maori) 'spatial narratives' which could be included in the strategic spatial planning and urban design process." (84). The thesis is not about the collection of a sites Maori history, instead how spatial narratives could inform a design.

Although effort has been put into the study of the past, mana whenua should always be acknowledged and interviewed extensively when constructing an understanding of the past. Interviewing individuals falls out of the present research scope resulting in a basic study that focuses on place names. This study should not be read as accurate or representative of mana whenua. Instead the research focuses on how the past could be interpretative, evoked, or expressed by a mnemonic intervention. Why, who and what are important questions that need to be addressed in order to ask how an intervention can evoke, express or allow interpretation of the past.

\subsection{A Penisular of Narratives}

As previously mentioned Motu Kairangi Miramar has been selected as an area to study for two main reasons. Firstly, in 2014 the northern tip of Motu-Kairangi Miramar was announced as a heritage park due to the remains of numerous military bases in action during Te Ao Hou period and the known locations of kainga and pa inhabited during Te Ao Tawhito period. Secondly, the area was also central to Maori of Te Ao Tawhito period. Many of the events associated with the peninsular do have a relationship with other sites, events and individuals including the well known catch by Maui, the flight of the taniwha Ngake, the discovery by Kupe, the exploration of Whatonga, the establishing of pa and Kainga by the eponymous ancestor Tara-lka which was followed by other occupations by different hapū.

As this part focuses on the first issue of how an intervention could evoke the past of Te Ao Tawhito, a clearing on Seatoun ridge has been chosen. Although outside of the proposed heritage area, and hosting no relic the site is ideal due to an associated narrative that is accessible and extensive. Seatoun ridge was once the site of a pa known as Te Whetu Kairangi. Te Whetu Kairangi Pa has been documented allowing an interpretation of its history based on its place name to form the nucleus of a design project. 
Miramar central

Seatoun

Rongotai

Kilbirne

Strathmore Park

Worser Bay

Karaka Bay

Maupuia

Shelly Bay

Breaker Bay

Mount Crawford

Moa Point

Weta Workshops

Miramar Hub

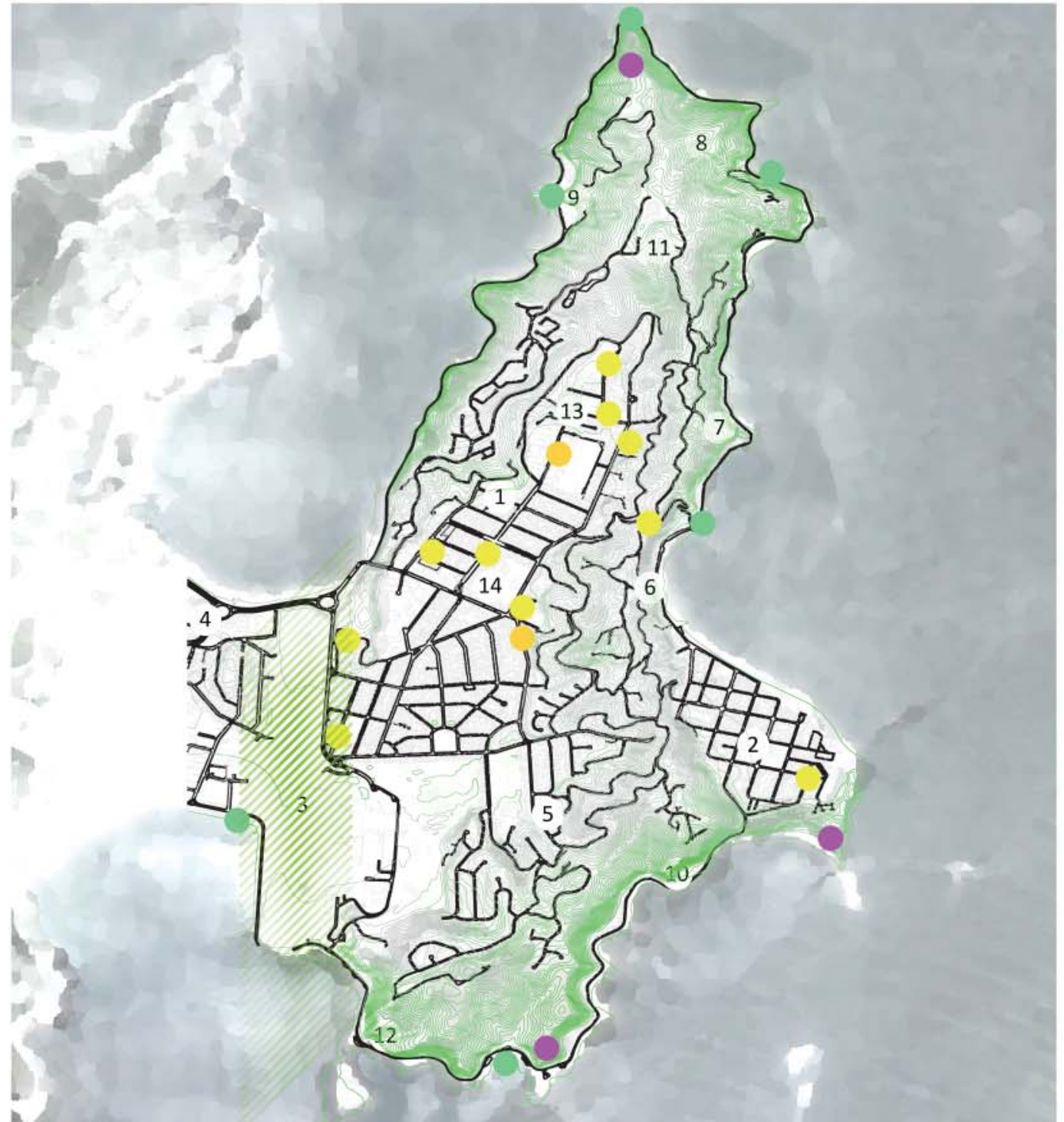

25
Educational institutes

recreational facilities

public gardens and scenic parks

marine facilities

memorials public transport

walkways

Heritage sites of Te Ao Tawhito Heritage sites of Te Ao Hou

defence area

residential

comercial

industrial

retail 

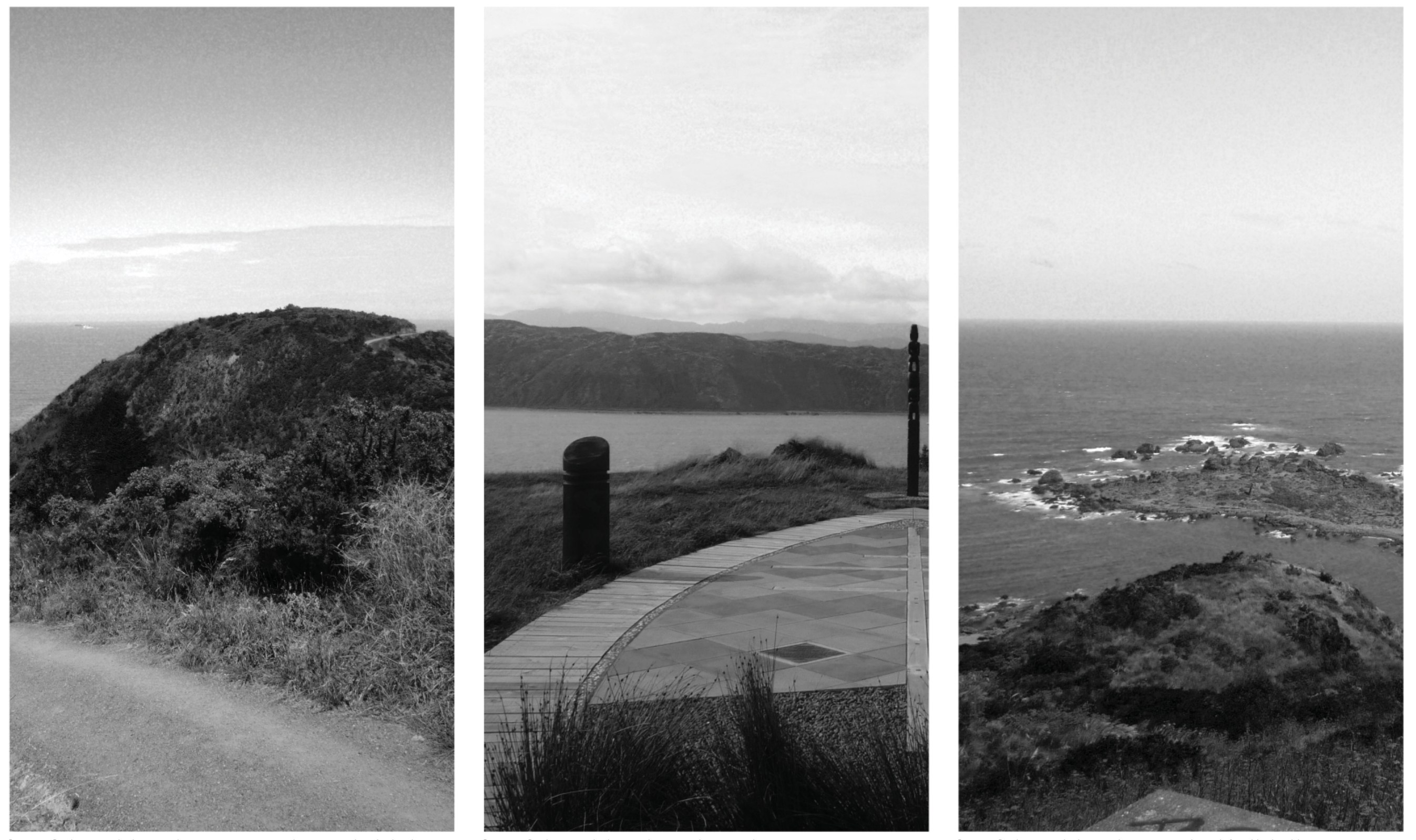

[FIG 2.V] Photograph showing how Hue te Taka is defined by boulders 


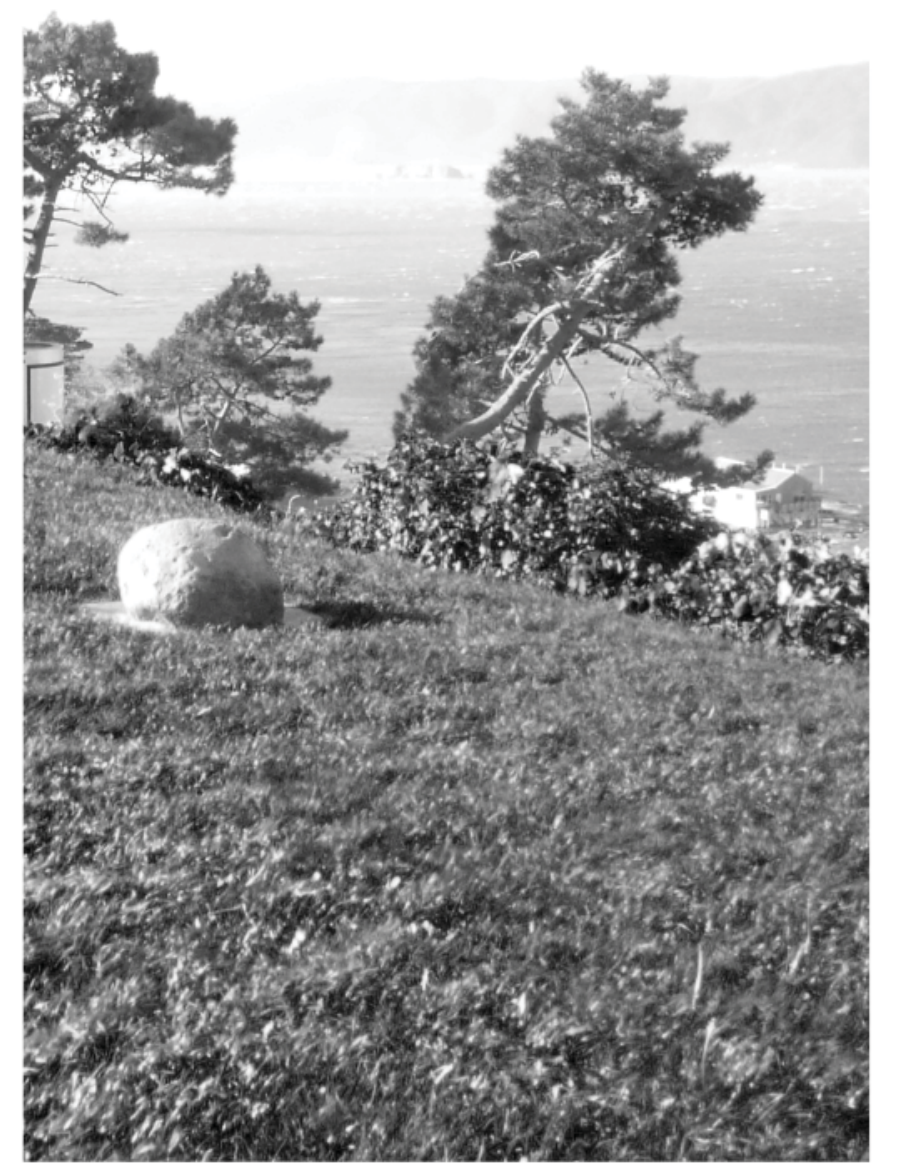
Kairangi pa
SOURCE: Author
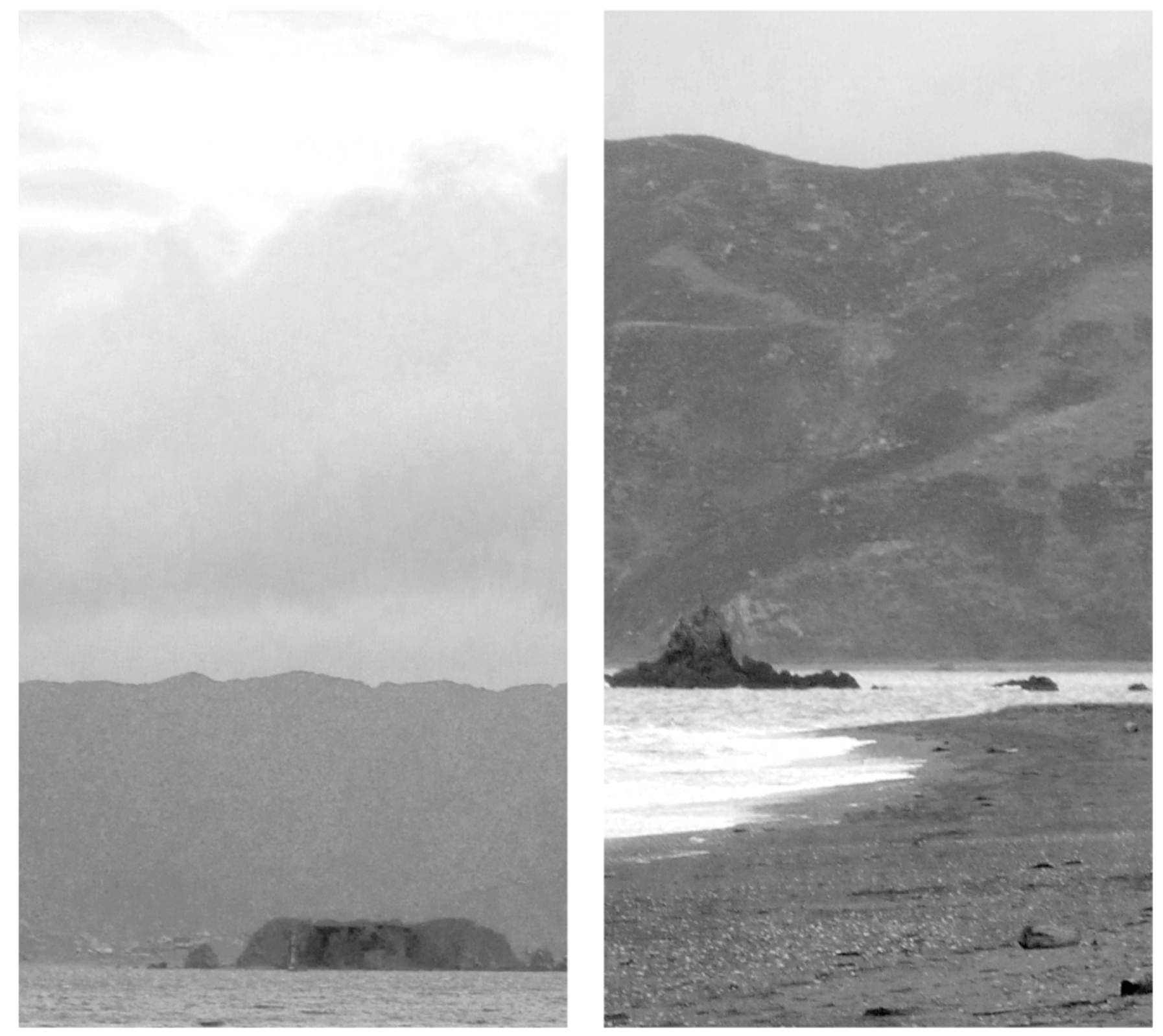

[FIG 2.VII] Photograph showing how Makaro island has
intervention and its solid silohuette stands out against the sea SOURCE: Author
27 [FIG 2.VIII] Photog
SOURCE: Author 


\section{1 architecture of narrative}

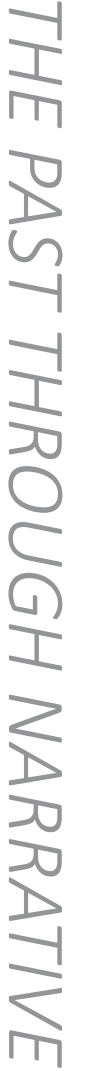

\section{CHAPTER THREE}

If the past is known through history could there be a relationship to the past through an intervention that is not a relic but a construction of the history in some way? Sites around Motu-Kairangi Miramar peninsular are associated with the past of Te Ao Tawhito and this is known through historic narratives. An intervention on a site would now be the only way to mark and express the past of Te Ao Tawhito, and this chapter explores the extent of such an intervention. Take Te Aro Pa for example, in order to be stimulated during a site visit one would first have to know the history. Except knowing the past of Te Aro Pa is almost irrelevant as a site visit will only conjure disappointment as a result of the unrelated and dominating traffic lights, roads and kiosks that dissect the place into almost oblivion. A visit will not be entirely disappointing, because interventions have marked the site, including: Te Aro Park, the Wharewaka (to a degree) and the archaeological excavation. All create a space of reflection and assert the past.

Three key points have been raised: Firstly, the history in question must be known prior, either through the study of whakapapa, korero, literature or movies (to name a few). Secondly, the interpretation of the past is subjective, and the meaning derived will be different for particular audiences such as mana whenua, tangata whenua, and even tangata tiriti, although all could acknowledge the site's importance to varying degrees. Thirdly, even though the site has changed, interventions can mark the area and create spaces for contemporary use that express and evoke the past. Te Aro Park, the archaeological site and the Wharewaka are public areas that mark the past. Of all three, the Wharewaka as architecture is argued as the more successful as it creates a public space for all, asserts Maori presence and the programme of launching waka is continued and becomes a part of daily life. The Wharewaka is not intended to be a marker of Te Aro pa although it provides a link to Te Ao
Tawhito Maori who dwelled along the shorelines (Love, "A Wharewaka for Wellington" 91). The park, as a landscape suffers for usability but none the less marks the area and creates potential use. The archaeological site with its limited interpretation becomes a sad display of the lost past, failing to evoke or express a narrative of the past.

The Wharewaka as a development compared to the archaeological site is an example of preservation that illustrates the progress versus preservation debate. Of the two, the Wharewaka engages with the past by allowing individuals to not only learn of the past but to incorporate the past into the present. The development of a site through an architectural intervention to evoke the past is discussed further and argued through the following case studies: The Jewish Museum in Berlin by Daniel Libeskind, The Danteum in Rome by Giuseppe Terragni and the North American Indian museum in Washington D.C. Each of the case studies demonstrates the three key points further and discusses how the spaces act as a mnemonic device of the past. This chapter then concludes with a discussion on the analogical design method already mentioned, which creates spatial settings based on narratives that a knowing individual may relate to. 


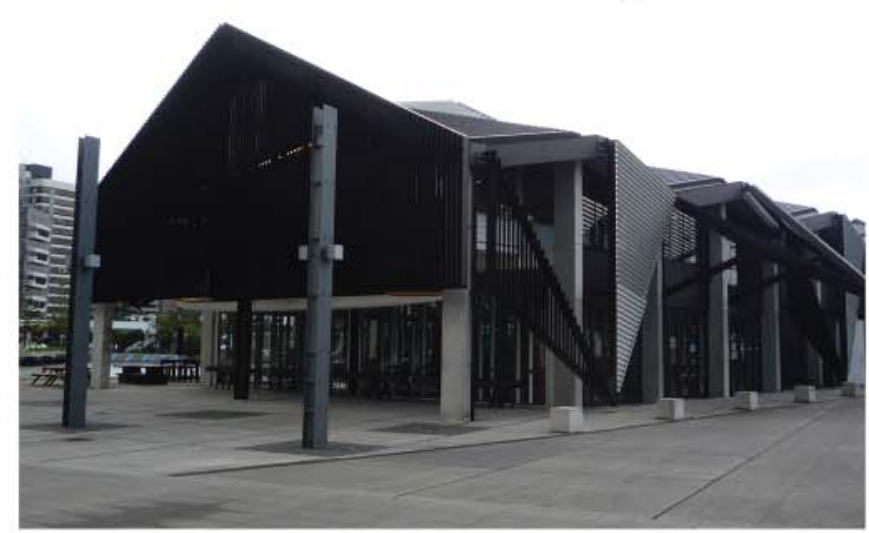

[FIG 3.I] Photograph of the south elevation of the Wharewaka SOURCE: Autho

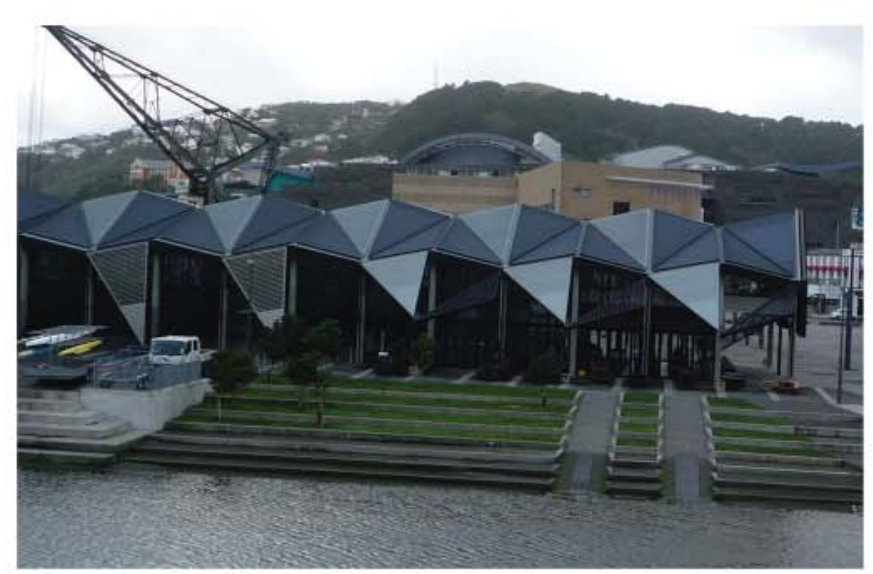

[FIG 3.IV] Photograph of the West side of the Wharewaka opening out onto the lago SOURCE: Authar

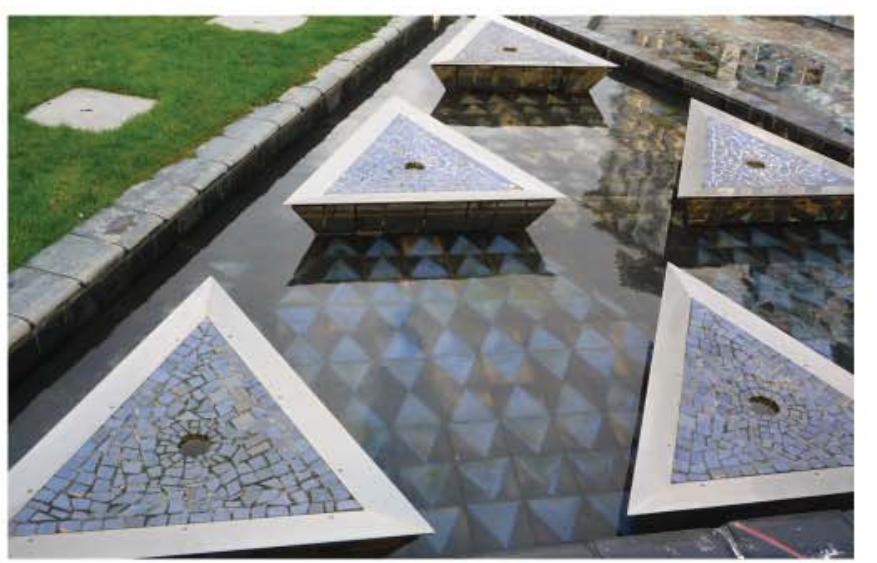

[FIG 3.II] Photograph of the Te Aro Park ponds SOURCE: Author

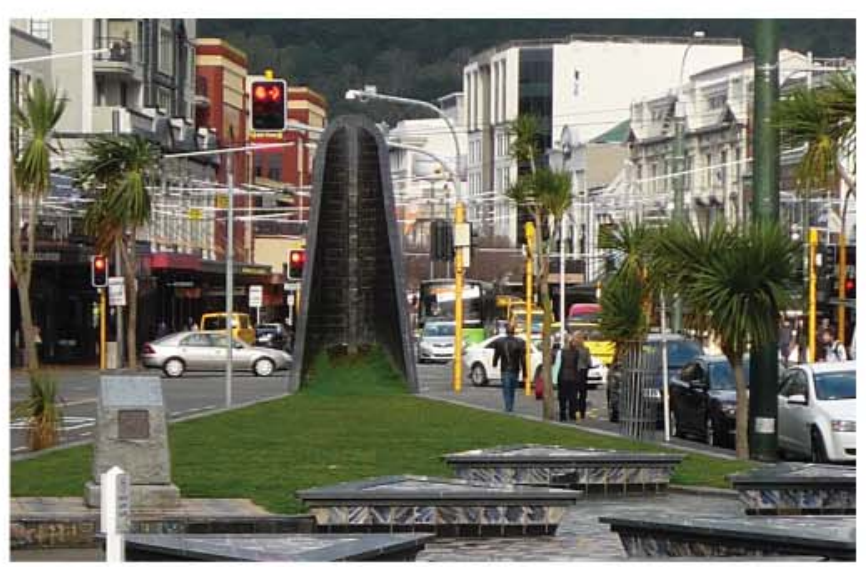

[FIG 3.V] Photograph showing the vertical element of Te Aro Park SOURCE: Author

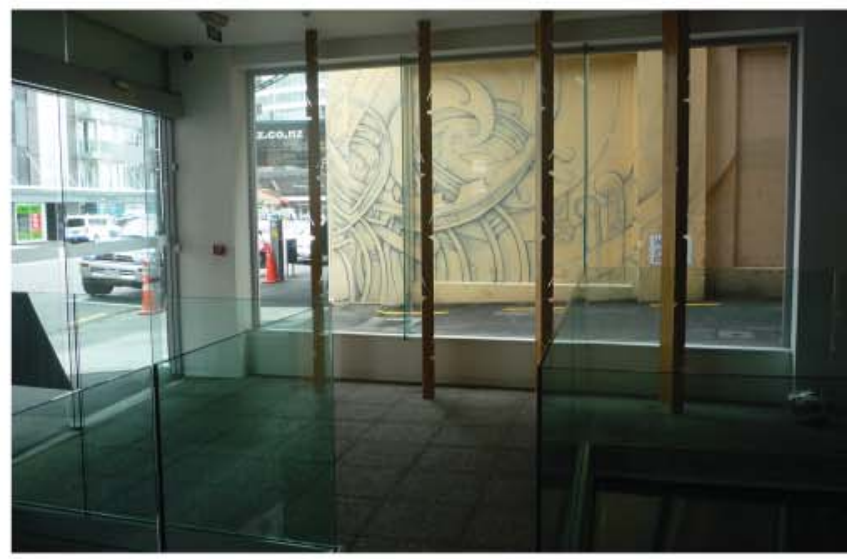

[FIG 3.III] Photograph of the the archeaological site that unearthed two raupo dwellings SOURCE: Author

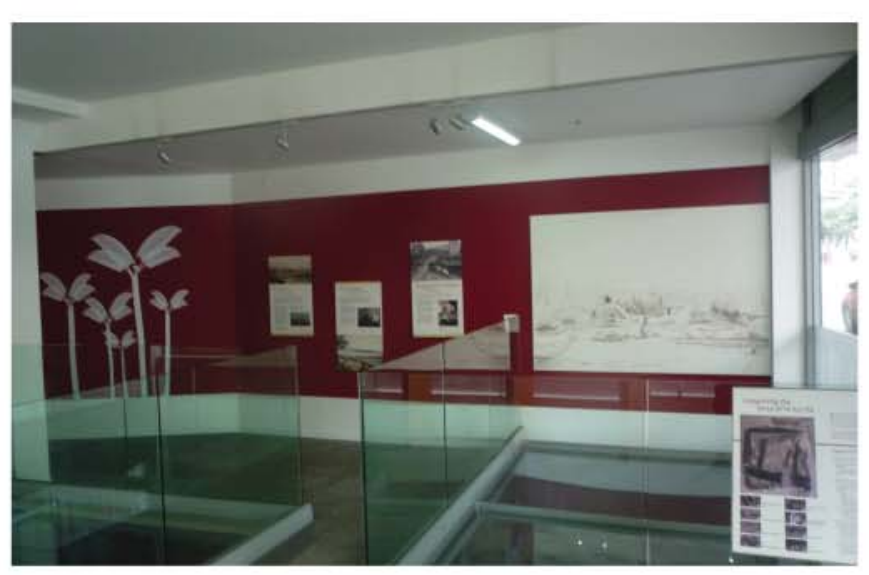

[FIG 3.VI] Photograph of the the archeaological site that unearthed two raupo dwellings SOURCE: Author 


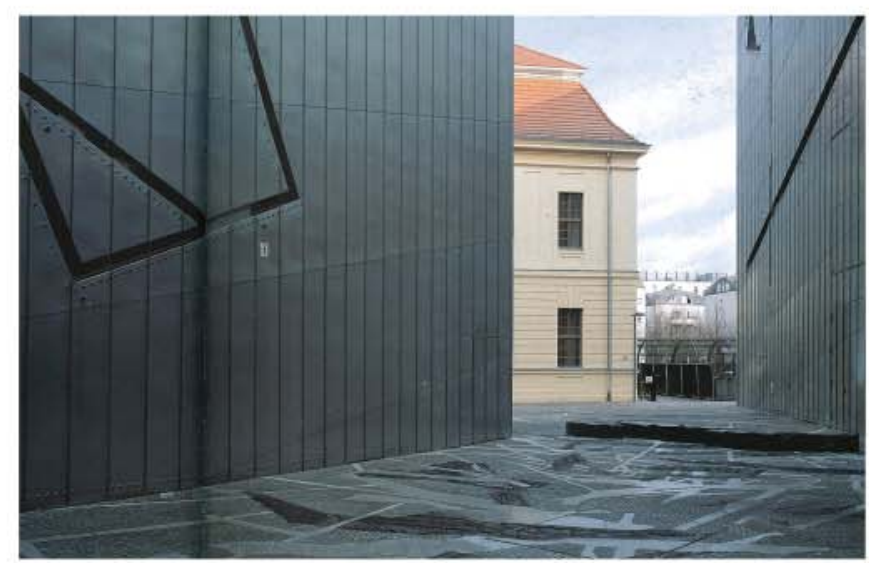

[FIG 3.VII] Image showing the relationship the museum has with its neighbouring buildings

SOURCE: Schneider, Daniel Libeskind, Jewish Museum Berlin. photographer Stefan Müller

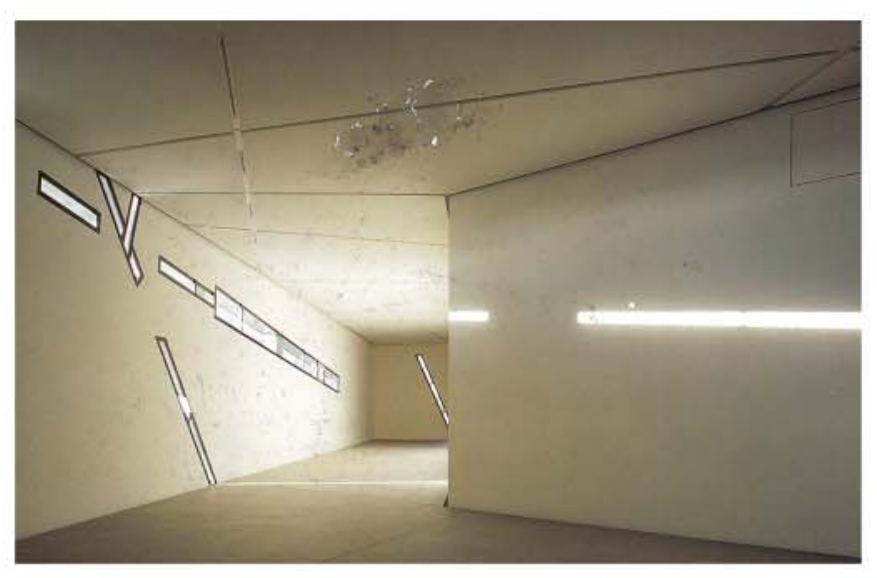

[FIG 3.X] Image showing the interior space which is scarred by the slashing windows

SOURCE: Schneider, Daniel Libeskind, Jewish Museum Berlin. photographer Stefan Müller

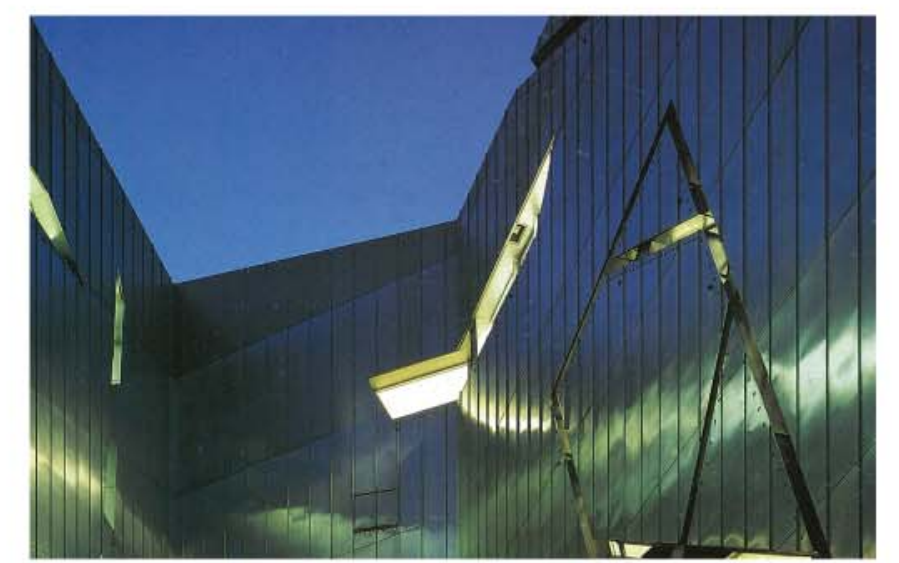

[FIG 3.VIII] Image showing the cladding lit up

SOURCE: Schneider, Daniel Libeskind, Jewish Museum Berlin photographer Stefan Müller

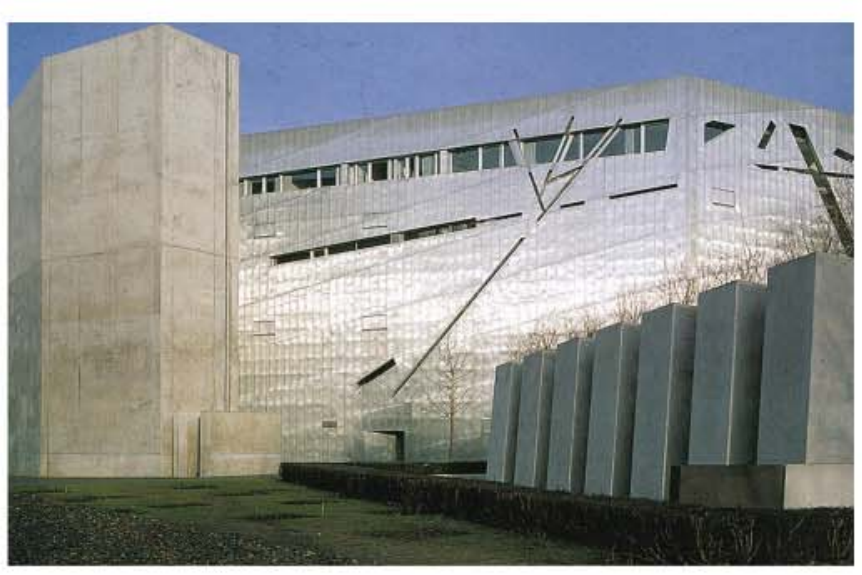

[FIG 3.XI] Image showing the eterior of the holocaust tower and exile garden

SOURCE: Schneiden Daniel tibeskind jewish Museum Berlin. photographer Stefon Mi

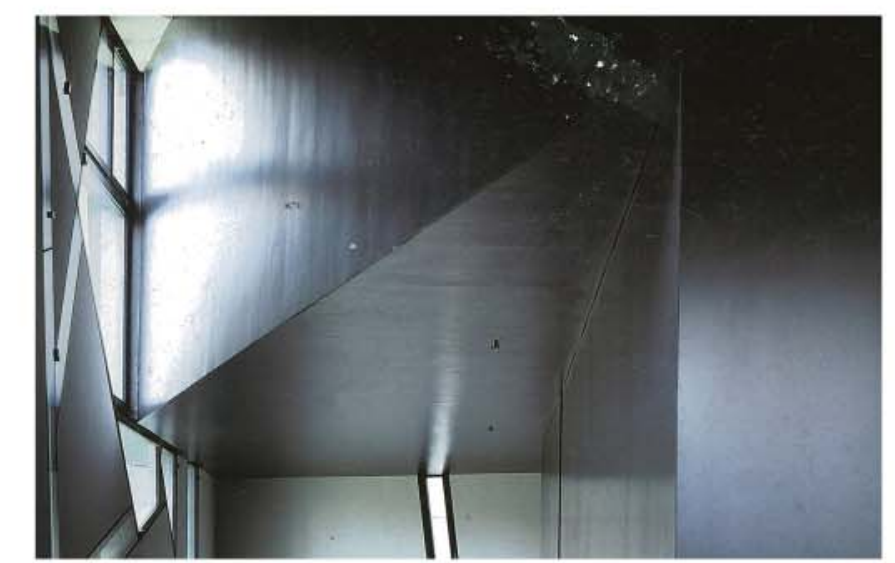

[FIG 3.IX] Image showing the interior space which is scarred by the slashing windows SOURCE: Schneider, Daniel Libeskind, Jewish Museum Berlin. photographer Stefan Müller

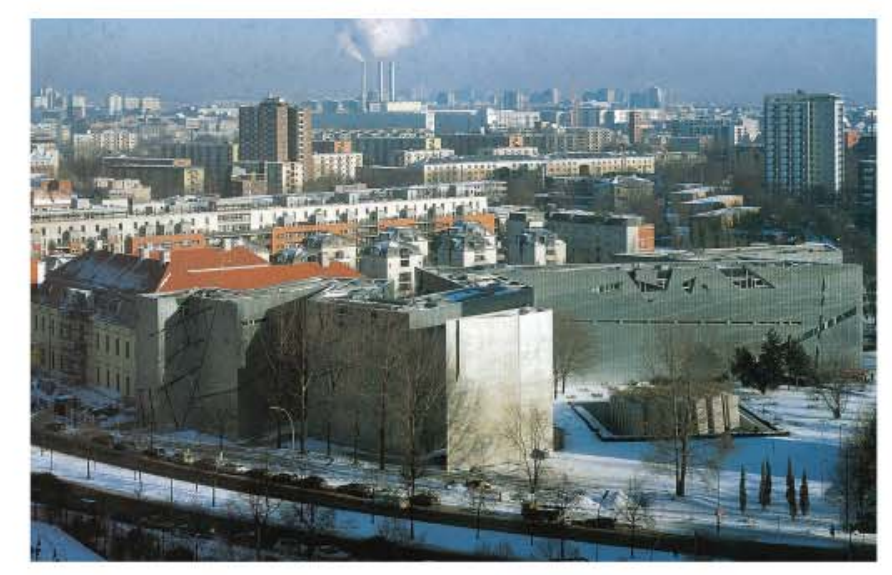

[FIG 3.XII] Image the zig zagging building in the context of the city

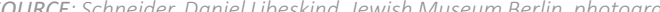




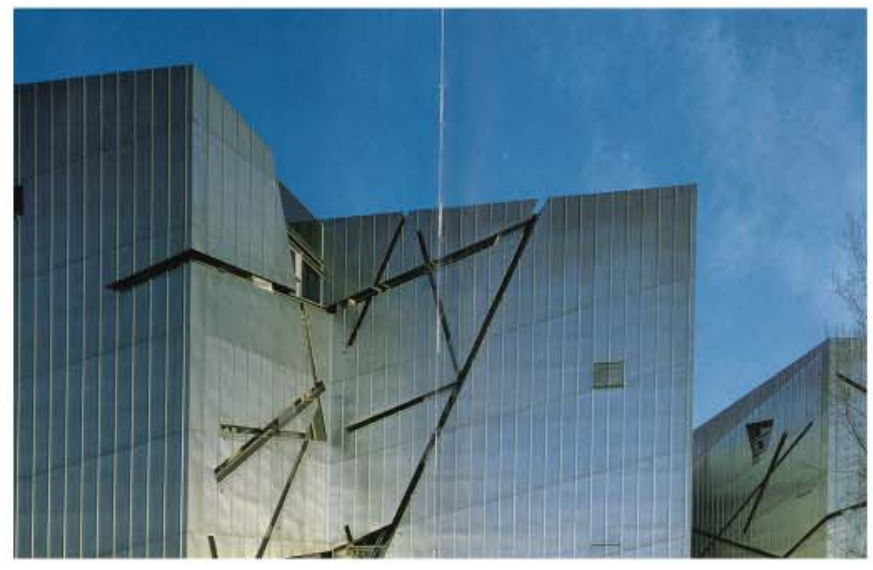

[FIG 3.XIII] Exterior cladding of the museum

SOURCE: Schneider, Daniel Libeskind, Jewish Museum Berlin. photographer Stefan Müller

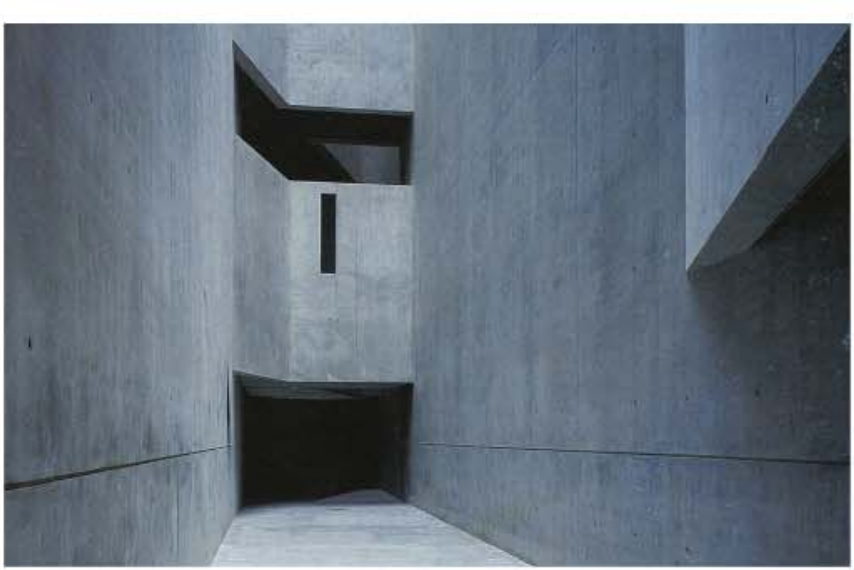

[FIG 3.XV] Inside one of several voids

SOURCE: Schneider, Daniel Libeskind, Jewish Museum Berlin. photographer Stefan Müller

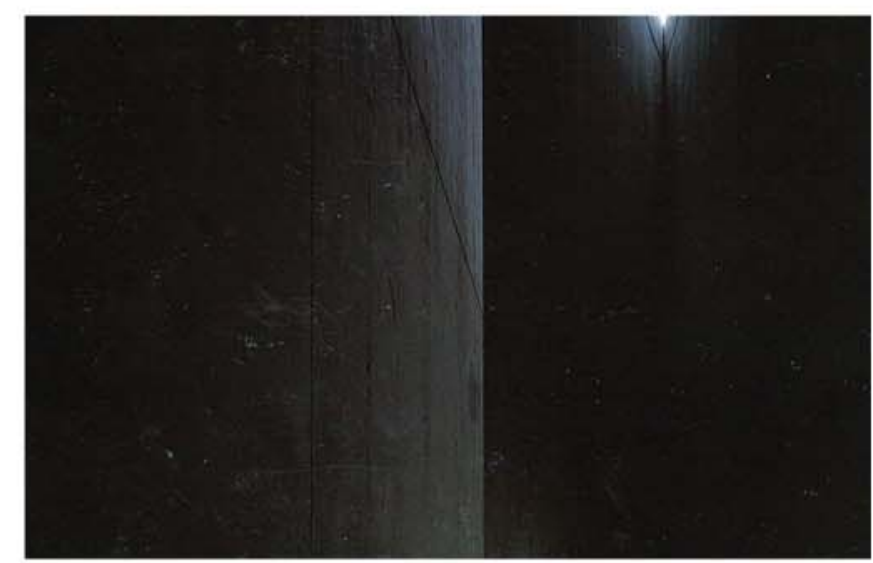

[FIG 3.XIV] Inside the holocaust tower

SOURCE: Schneider, Daniel Libeskind, Jewish Museum Berlin. photographer Stefan Müller

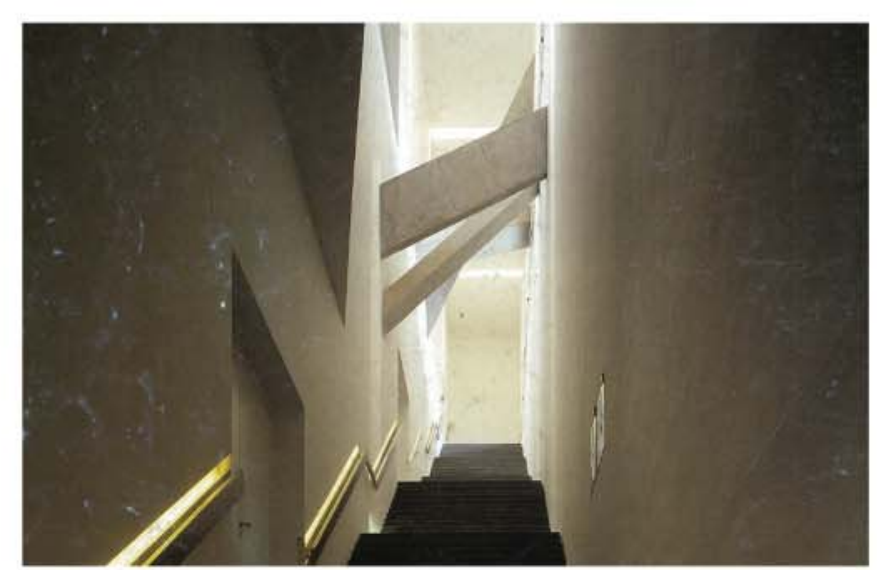

[FIG 3.XVI] Climbing the compressed staircase

SOURCE: Schneider, Daniel Libeskind, Jewish Museum Berlin. photographer Stefan Müller
3.2 Case study one

This case study reveals the importance of knowing the past prior to visiting and how abstract spaces can intervene on a site becoming not only markers of the past but also a place to evoke the past for the occupant. The rise of Hitler saw many ideals being practised such as the purification of the Aryan race which was attempted through the extermination of certain groups including the disabled and people of Jewish faith. This museum demonstrates the importance of knowing the narrative prior to visiting the space. The spaces of interest attempt to remember those people exiled, executed and made homeless. The museum, although now home to artefacts of this troubled past, was at first left empty. It was initially the spatial arrangement that evoked the past and drew visitors to the site. Historic narratives such as movies, pictures and books have informed society of this atrocious past. The museum is important to people as it is a place that reverberates this particular past and is spatially arranged to evoke the sensation of being exiled, executed and left homeless. Rather than viewing artefacts that are linked to the past, the past itself is experienced and so remembered. What is important to note is that if one does not know the history then the experience would not be that of exile while wandering the exterior garden. The tower of the holocaust although formally daunting, casting the occupant into darkness is similarly pointless unless the visitor is already aware of the past. The museum is not a physical or literal creation of the past but rather evokes an existing understanding of the past, within the observer. The architecture is a backdrop, it is a landscape, it is a cue it is an activation of the historic narrative and it subtly and at times boldly awakens the ideas and knowledge within the occupant. The garden of exile, the holocaust tower and the meandering hallways of the museum illustrate that without prior knowledge the spaces could be related to any narrative or to none at all. 


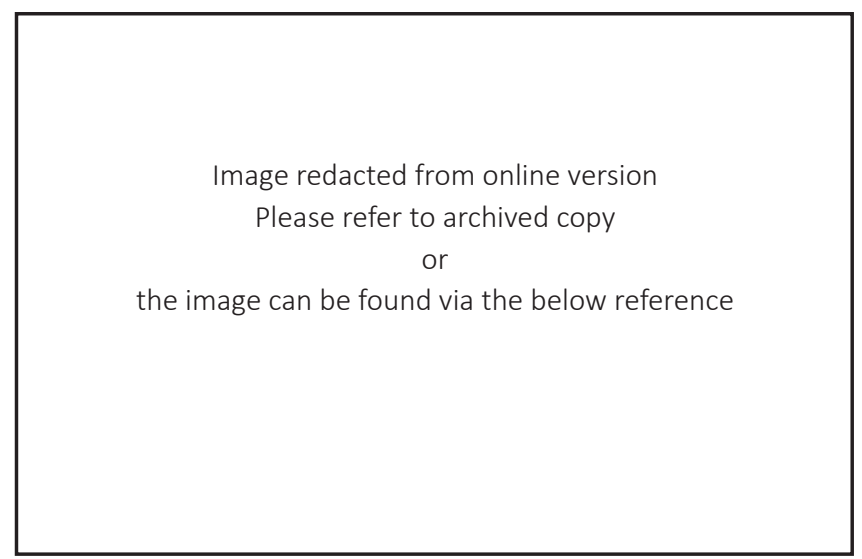

[FIG 3.XVII] an interior perspectve of the inferno space water colour by architect SOURCE: Schumacher, Terragni's Danteum. plate seven

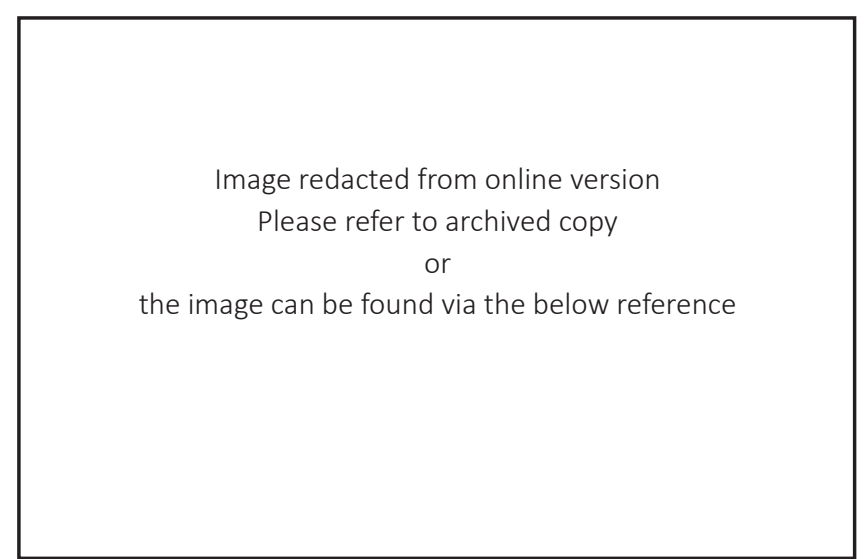

[FIG 3.XX] an interior perspectve of the paradise space water colour by architect SOURCE: Schumacher, Terragni's Danteum. plate eleven

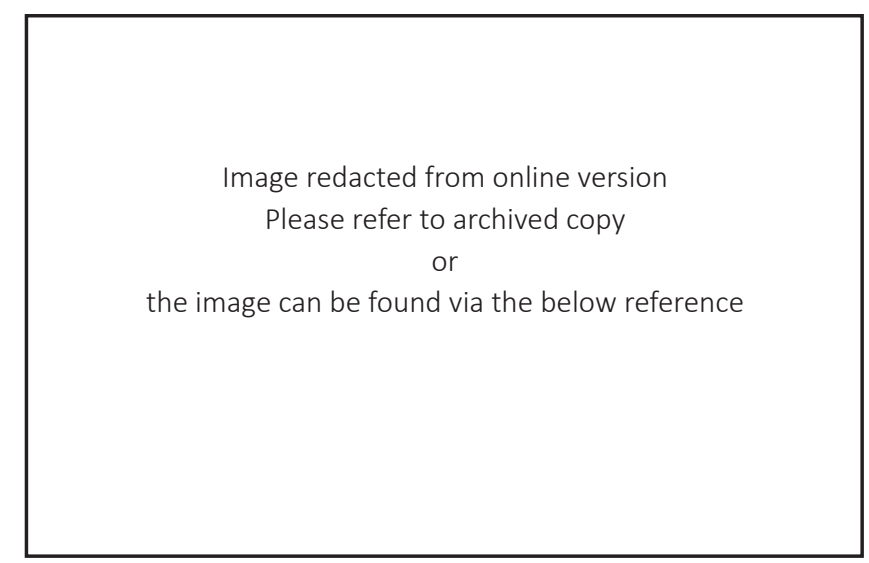

[FIG 3.XVIII] an interior perspectve of the purgatory space, water colour by architect SOURCE: Schumacher, Terragni's Danteum. plate nine

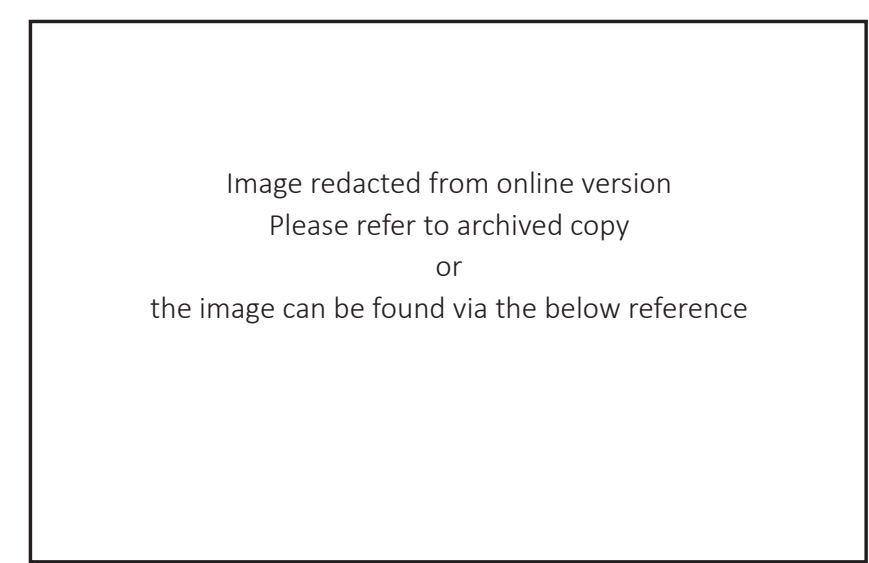

[FIG 3.XXI] the rear facade

SOURCE: Schumacher, Terragni's Danteum. plate two

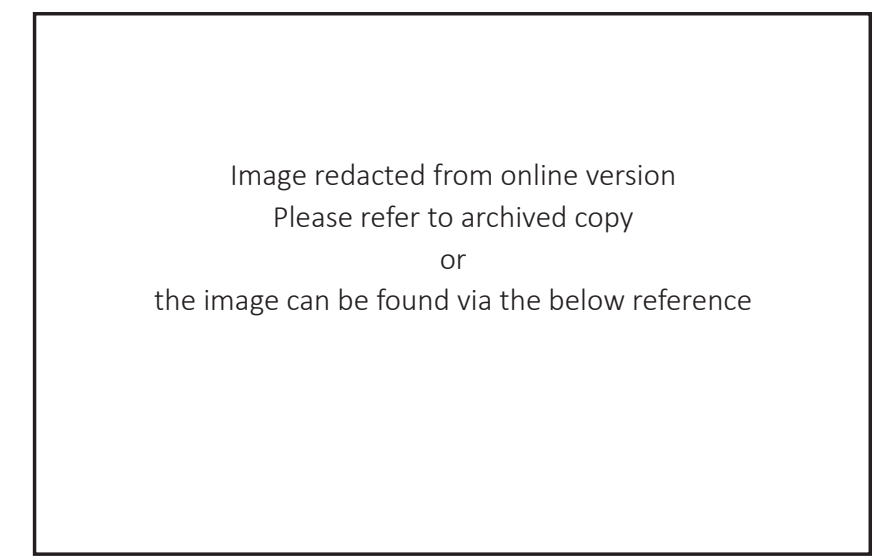

[FIG 3.XIX the sculpture exterior, free standing wall, water colour by architect SOURCE: Schumacher, Terragni's Danteum. plate three

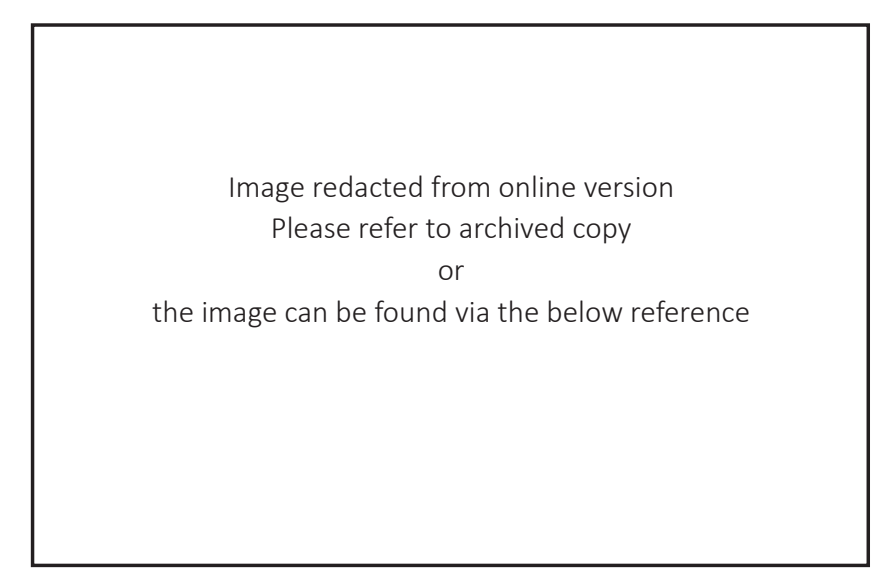

[FIG 3.XXII] an interior perspectve of the empire room water colour by architect SOURCE: Schumacher, Terragni's Danteum. plate twelve 
Image redacted from online version

Please refer to archived copy

the image can be found via the below reference

[FIG 3.XXIII] the entrance court, water colour by architect

\section{Image redacted from online version}

Please refer to archived copy

or

the image can be found via the below reference
Image redacted from online version

Please refer to archived copy

the image can be found via the below reference

[FIG 3.XXIV] side allyway with a relationship to the colosseum SOURCE: Schumacher, Terragni's Danteum. plate four

\section{Image redacted from online version}

Please refer to archived copy

the image can be found via the below reference

[FIG 3.XXVI] Danteum floor plan

[FIG 3.XXV] Danteum mode

SOURCE: Schumacher, Terragni's Danteum. page 48
SOURCE: Schumacher, Terragni's Danteum. page 52

\subsection{Case study two}

Although never built the second case study illustrates how a spatial arrangement may reflect collective ideas and interpretations of a narrative. History in many ways is the collective agreement of the past, therefore any monument or mnemonic device would be an emblem of that society and its view to both the past and future (Schumacher 39).

On the eve of War World Two, Italy was preparing itself for expansion whilst simultaneously summoning the ancient might of the once dominating Roman Empire. Thomas Schumacher explains how Mussolini and Fascist ideas were publicized, practised and justified through the arts including architecture (38). An audience may read a narrative from certain perspective and portray it likewise in a reflective manner. Dante's Divine Comedy was a parable that allowed the Italian fascists to read the history of Italy, which illustrated their fascist ideals, and justified their actions. The Danteum was designed to connect the twentieth century Italian to the past that justified Italy's might, glory and domination over others. The design was unlike any project of the time "superseding political symbolism and patriotism" (Schumacher, 39). The building not only asserted the regime but was designed to house the works of Dante, works about Dante and students of Dante. "The sequence of spaces is Terragni's conflation of concepts found in the Divine Comedy (creating a setting for the poem) and an interpretation of Mussolini's new Roman Empire." (Schumacher, 46). The design achieves this by reflecting the cantos of the poem and the three canticles of Dante's journey: inferno, purgatory and paradise. The second point made above is evident in the Danteum design. Collectively the fascists of Mussolini's Italy interpreted the narrative of Dante as a source for empirical divinity that was captured, remembered and evoked in the design. Although never built, the design illustrates how a spatial arrangement may reflect collective ideas and a specific and subjective interpretation of a narrative. 


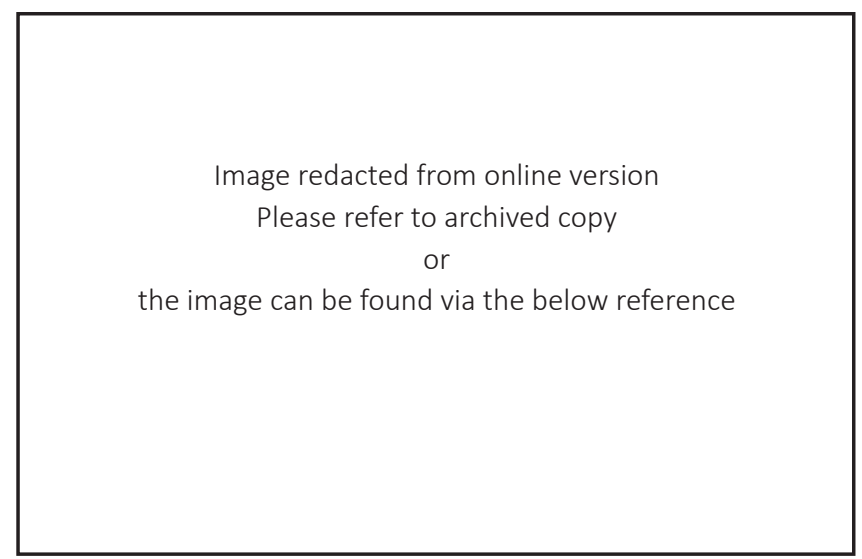

[FIG 3.XXVII] facade of the North American Indian Museun SOURCE: Spruce, the land has memory. page

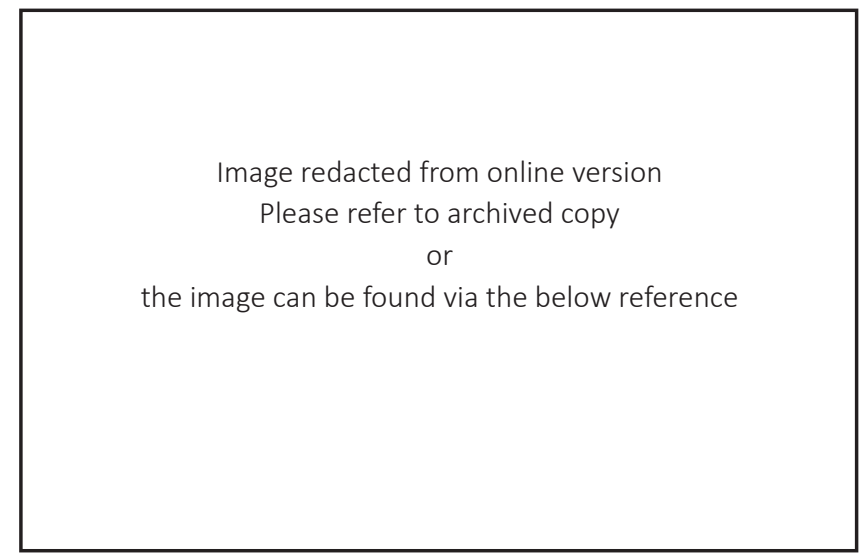

[FIG 3.XXX] Open fires are an important part of the culture SOURCE: Spruce, the land has memory. page 5

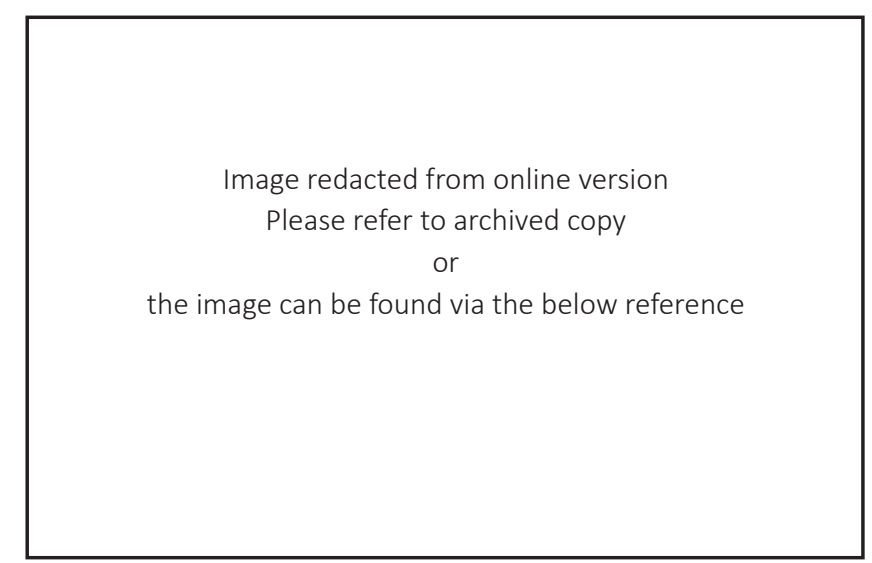

[FIG 3.XXVIII] facade of the North American Indian Museum reflects desert cliffs SOURCE: Spruce, the land has memory. page XIV.

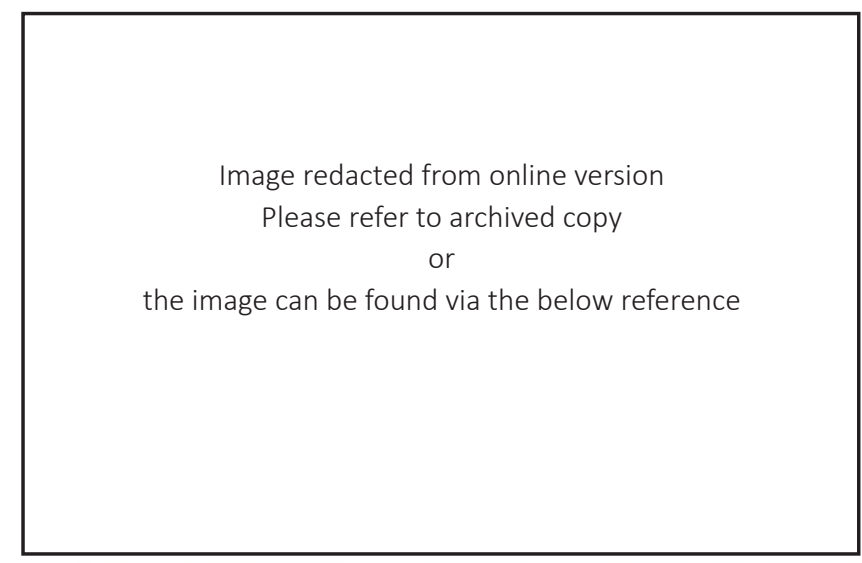

[FIG 3.XXXI] the facade evokes the expasive plains of the america SOURCE: Spruce, the land has memory. page 13

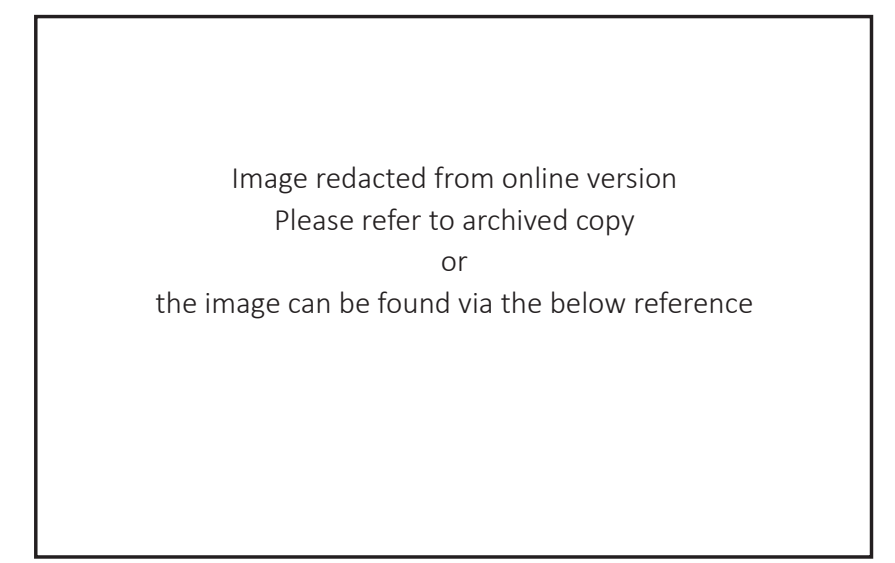

[FIG 3.XXIX] Crystal windows create rainbows, that evoke a sense of the spirit world SOURCE: Spruce, the land has memory. page 4

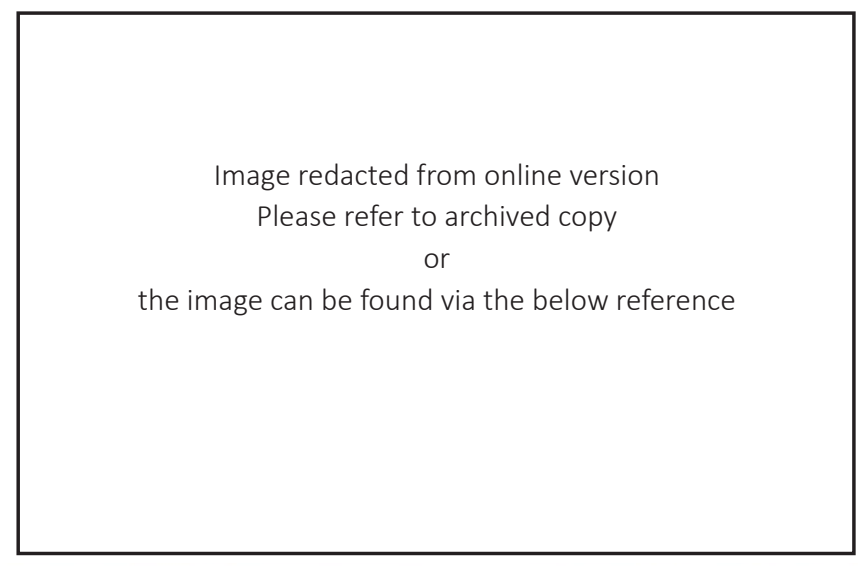

[FIG 3.XXXII] Wet lands evoke wildlife enhancing a celebration of the animal world SOURCE: Spruce, the land has memory. page 14 
Image redacted from online version

Please refer to archived copy

the image can be found via the below reference

[FIG 3.XXXIII] Rocks anchor the site and point to important direction SOURCE: Spruce, the land has memory page 32

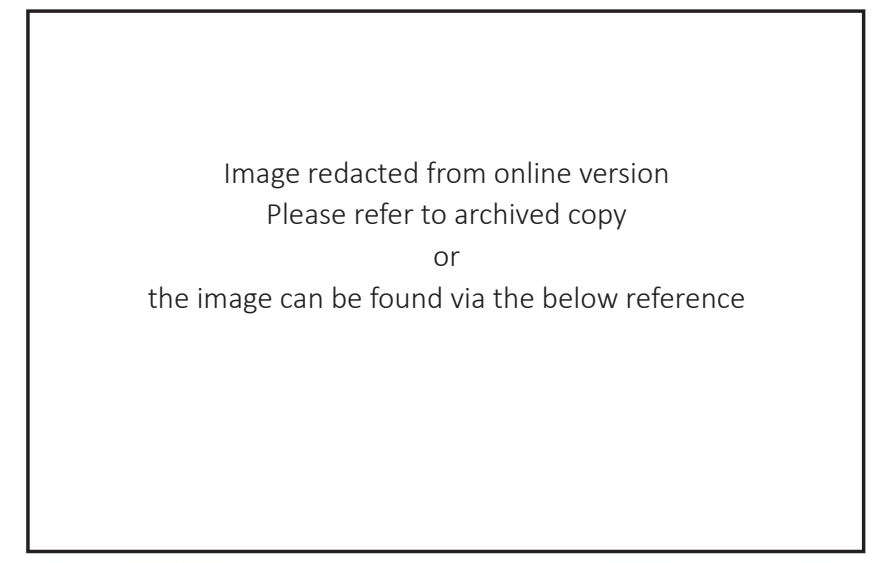

[FIG 3.XXXV view from the garden area

SOURCE: Spruce, the land has memory. page 20
Image redacted from online version Please refer to archived copy

the image can be found via the below reference

(FIG 3.XXXIV Aerial view of the museum

SOURCE: Spruce, the land has memory page 19

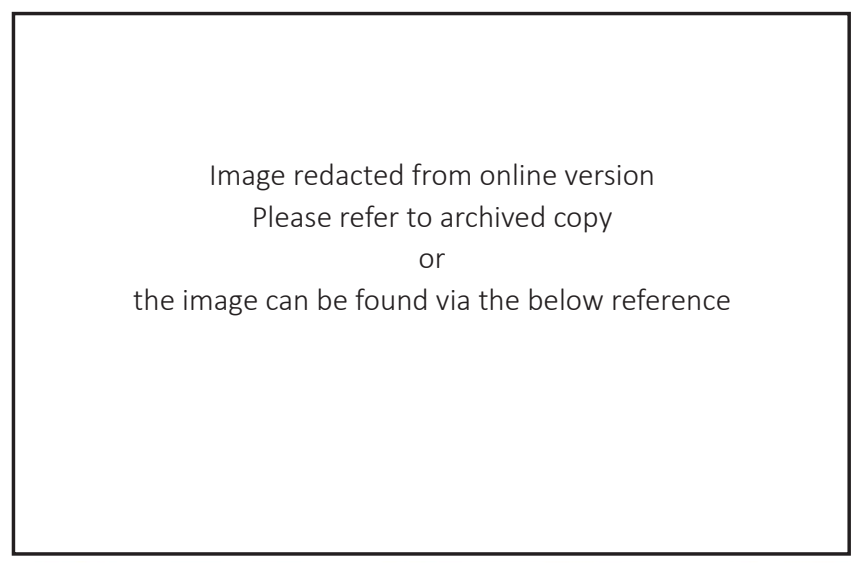

IFIG 3.XXXVI view of the waterfol

SOURCE: Spruce, the land has memory. Page 31

\subsection{Case study three}

The third key point previously raised that an intervention can mark a place now overlaid with a city is illustrated by the North American Indian Museum in Washington D.C. Now the heart of U.S.A politics and history, the area was once home to the indigenous people. Deprived from their lands through colonisation, the museum attempts to reassert the once roaming people of the area (Jones 1 ). The museum not only tells the past of the indigenous but acts as a place to stand in the words of Johnpaul Jones "we wanted to announce our continued presence: we are still here" (Jones1). After generations of assimilation and annihilation, the indigenous Americans expressed their history and culture through the museum. The American Indian way of life revolves around an understanding of the four worlds; the natural world, the spirit world, the animal world and the human world. The Museum represents these worlds in such profound ways that when one walks into the museum they are walking into "An American Indian place" (Jones 3 ). To create this place which is not only like the world of the indigenous ancestors but in many ways it is an indigenous world. The building formally references cliffs of the desert plains, and the animal world with a garden and pond. The building also houses programmes such as open fire cooking and storytelling allowing the museum to be alive and continue native customs. The museum most importantly included "consultation with hundreds of native elders, artists and educators" (Jones 1). Thus the local community were able to reconnect with their environment overlaid by the present city 


\subsection{Analogy as design method}

Knowing the history before visiting, what the narrative means to a particular audience and the expressing of the narrative in the changed land/cityscape are important points when establishing a connection to the past. Each of the three case studies above illuminated only one of the points, however further discussion of each precedent can reveal all three points valid to the design.

Any intervention would need to assume that the occupant is aware of the site's association with the past, and the past in question is indeed relevant to a large group of people. An intervention should therefore not attempt to objectify the past, but rather create a space of reflection that has similarities to the setting ascribed in the historic narrative. For example the site of project one was once Te Whet Kairangi $\mathrm{Pa}$, which could be objectified through signage or sculpture. However, as the pa is considered important and well known an intervention should express and evoke the past in a reflective manner

The intervention would represent contemporary views with a reading of the past that would be biased in some way. This is not a negative point, but rather acknowledges that the past is used in the present to affirm and express identity. Understanding the past subjectively and applying meaning helps design decisions. Te Whetu-Kairangi pa could be described as a communal place for early inhabitants where one could retreat during a moment of peril. Although wars are no longer common place, the site could be developed as community space for people to retreat to from the hustle and bustle of the city.

An intervention could abstractly express the past such as the layout in the Danteum, or it could create similar spaces as illustrated in the Jewish museum, or it could literally translate the narrative such as the creation of the four worlds in the North American Indian Museum.

All three case studies share a similar goal to communicate ideas of the past known through a narrative to contemporary audiences. All of the precedents present a known narrative and act as a mnemonic device by registering an occupant with a narrative via literal, abstract or spatial means. The thesis suggests that such a mnemonic space could be generated by a method of analogy which attempts to create a comparable space to that imagined out of a narrative. Barbara Stafford illustrates a contemporary understanding of analogy as an "artful theory of invention and as a practise of intermedia communication" (Maria Stafford 8). Hence a mnemonic device could be understood as a communicator of Te Ao Tawhito past. As no relics exist to communicate or even affirm the past an analogous intervention could fill this void. Analogy as a design method will be employed in project one to explore how such an approach could guide a design process and generate an outcome. Stafford goes on to explain how analogy is the "desire to achieve union with that which one does not possess" (2) and to form a dialect bridging "the seen and unseen" (8). Although the past of Te Ao Tawhito may be possessed by individuals through history, it is not consistently seen or experienced in the present environment. Developing a method based on analogy will be a worthwhile exploration. 
4.1 Researching through design

Nestled along Seatoun ridge, above Worser Bay is a sleepy residential area surrounding a primary school. The area is like many places around the country with bungalows and picketed gardens attributing to a peaceful and charming atmosphere. Apart from a stone appointed to the centre of a clearing, nothing in the area indicates the site's long and rich past prior to Europeans. After the great catch by Maui, the flight of the taniwha Ngake, the discovery by Kupe followed by the journey of Whatonga, came the settlements of Tara-lka. Tara along with Whatonga and his half brother Tautoki arranged and constructed a pa that became known as Te Whetu-Kairangi. For several generations the pa was a refuge of Ngai Tara and it saw the development of the harbour people. The thesis interprets the pa as significant for the role it played for the pioneering harbour dwellers and certain characteristics such as its solitude, relationship to the stars, and protection of resources including the nearby spring and its communal value, are all interpretations made by the author. These interpretations are intended to reveal how history may be translated into contemporary space. The pa is not precisely located although a general area has been noted by discussed sources.

A Japanese bathhouse will develop the site for the benefit of the locals while simultaneously marking, expressing and evoking the past. The bathhouse programme was selected due to its own distinct characteristics in order to explore if a site's past could be excavated by adding new spatial layers rather than preserving the area. The design explores the bath complex as a terraced, labyrinth like space that is a literal, abstract and spatial imagining of the pa.

\subsection{Japanese Bathhouse}

Japanese bathing consists of five key stages or areas: entrance, changing, rinsing, bathing and relaxing (smith). These stages that constitute the design also relate to the past of Te Ao Tawhito through formal and functional analogies. Water is not only vital to bathing but it also has a spiritual element. Likewise the spring of Tara was nearby and protected by Te Whetu-Kairangi Pa. The rinsing area and water storage abstractly echoes that of a pātaka or whata. Best refers to the pa as having three palisades that reverberate literally through the three main corridors. These corridors also fold over each other forming a labyrinth that creates a disorientating experience similar to a described experience of one attacking the pa. After bathing however one learns of the space and then on leaving, the place is revealed allowing one to know and belong to the area. The views out have also been vertically orientated so the viewer is greeted by the stars and clouds in a sense of solitude and isolation.

\section{CHAPTER FOUR}




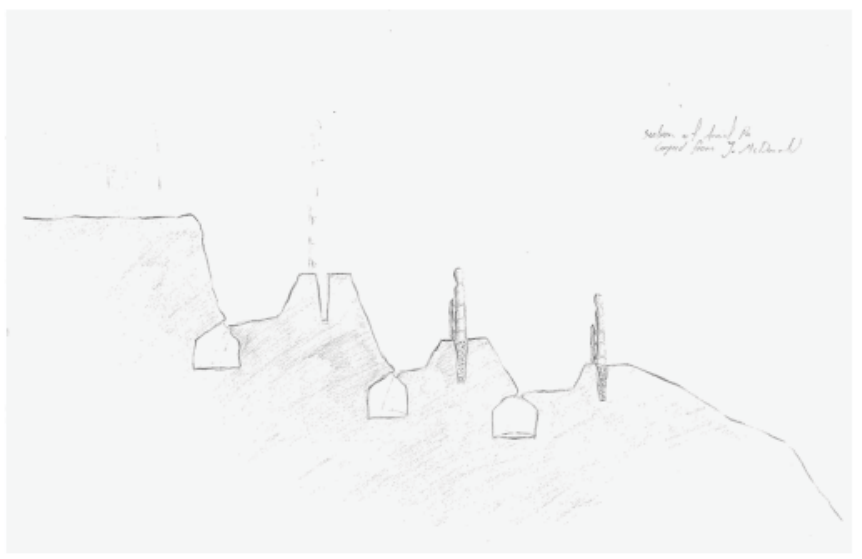

[FIG 4.I] study of pa based on Elsdon Best

SOURCE: Authors studying of existing drawings (EIsdon Best: The pa Maori)

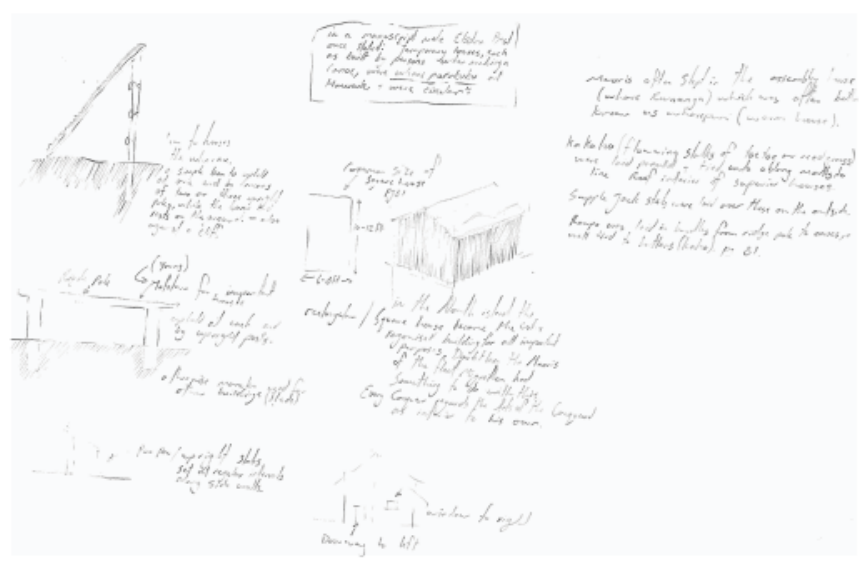

[FIG 4.IV] study of pa based on Elsdon Best

SOURCE: Authors studying of existing drawings (Elsdon Best: The pa Maori

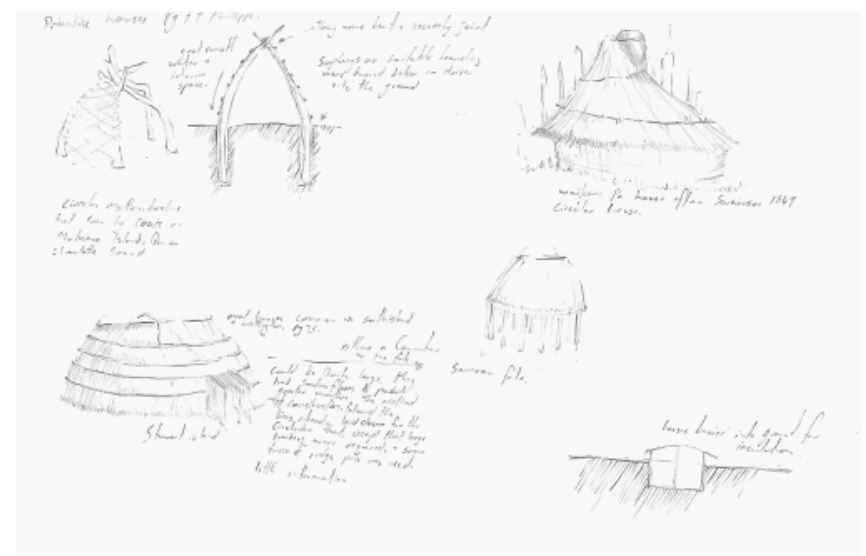

[FIG 4.II] study of pa based on Elsdon Best

SOURCE: Authors studying of existing drawings (Elsdon Best: The pa Maor)

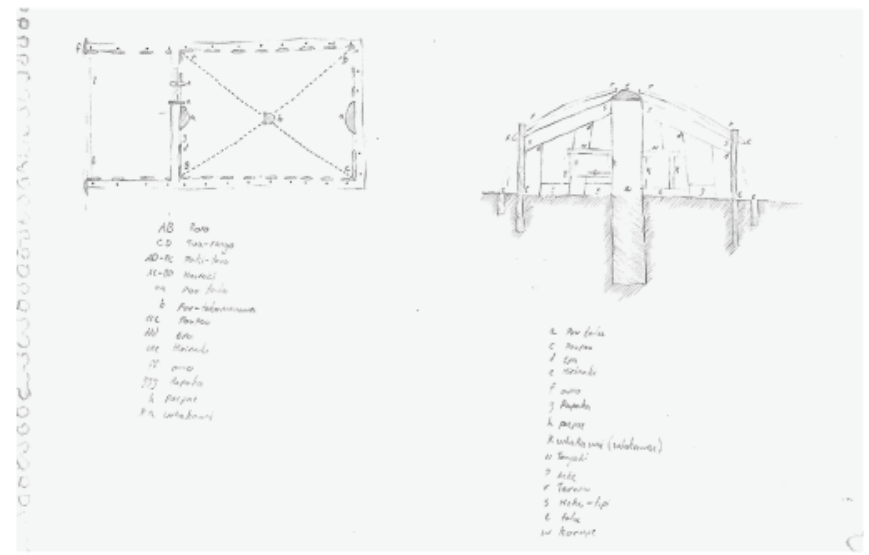

[FIG 4.V] study of pa based on Elsdon Best

SOURCE: Authors studying of existing drawings (EIsdon Best: The pa Maori

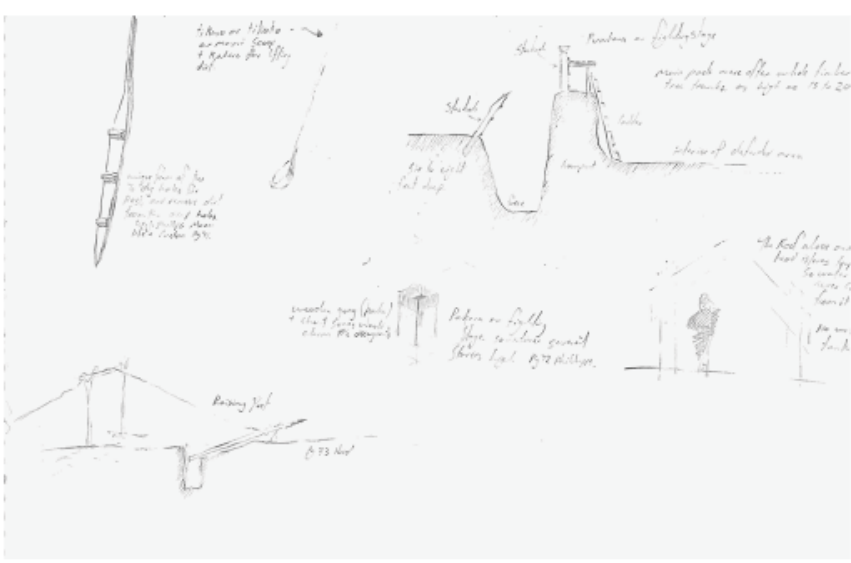

[FIG 4.III] study of pa based on Elsdon Best

SOURCE: Authors studying of existing drawings (Elsdon Best: The pa Maori)

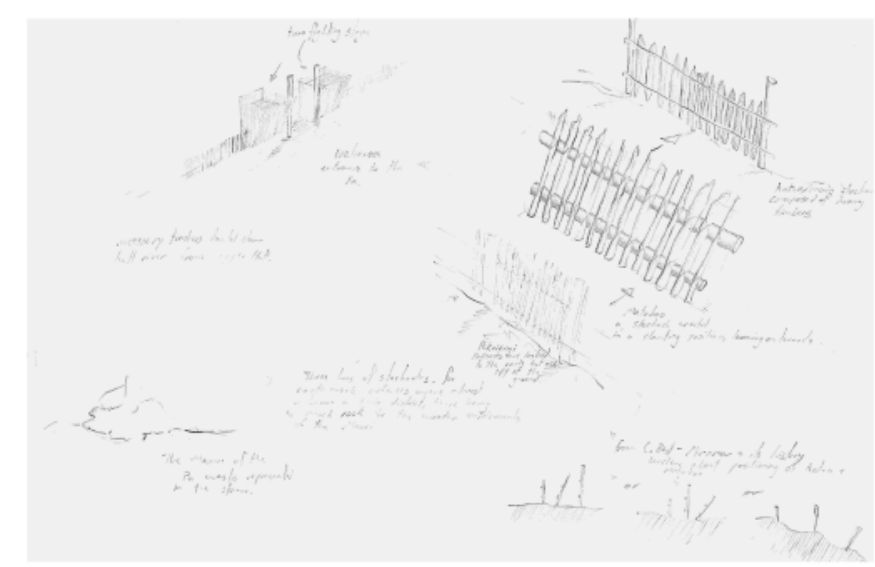

[FIG 4.VI] study of pa based on Elsdon Best

SOURCE: Authors studving of existing drawings (Elsdon Best: The pa Maori) 


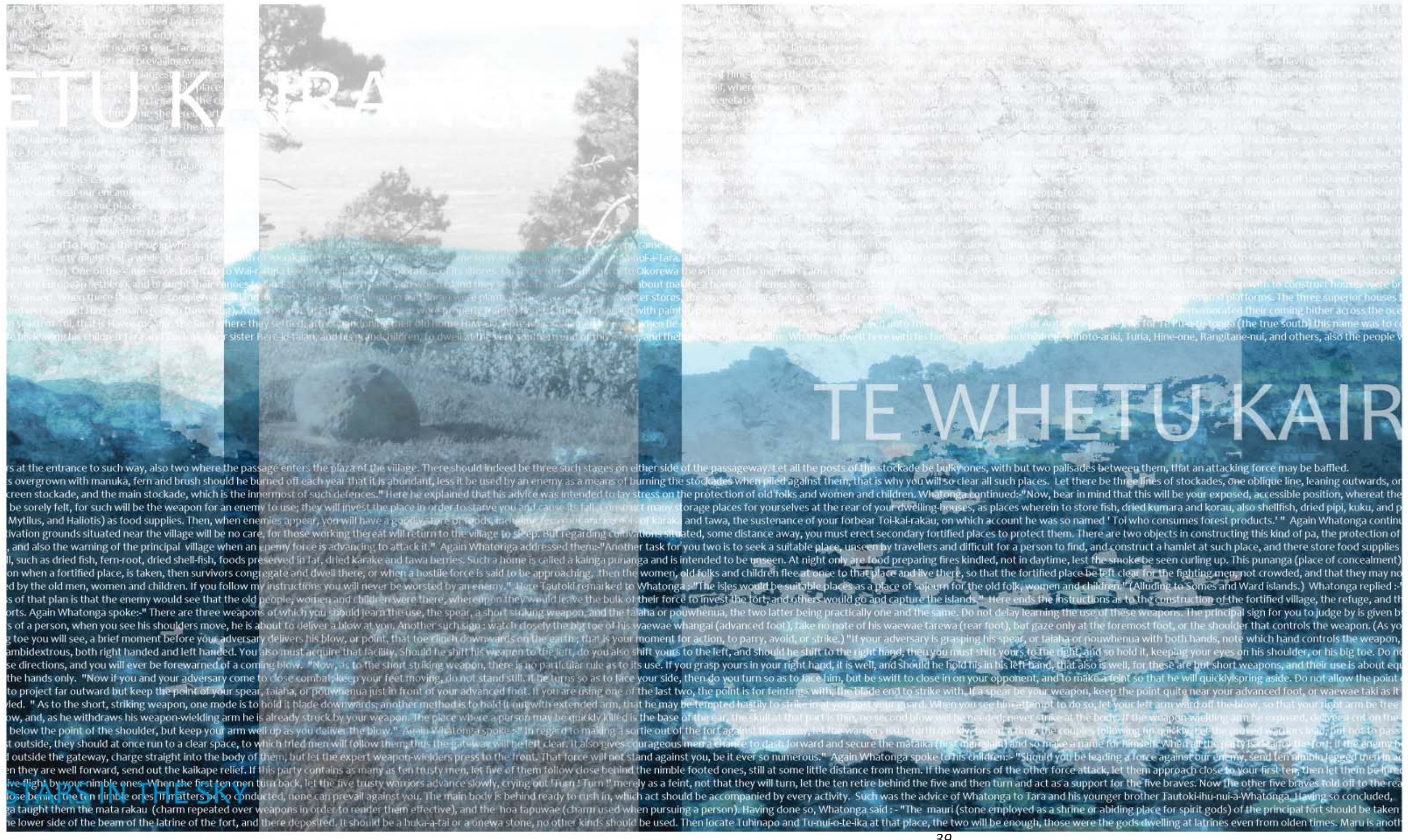

[FIG 4.VII] a photographic collage of the sites past, that will form the nucleus to the

39

SOURCE: Authors 


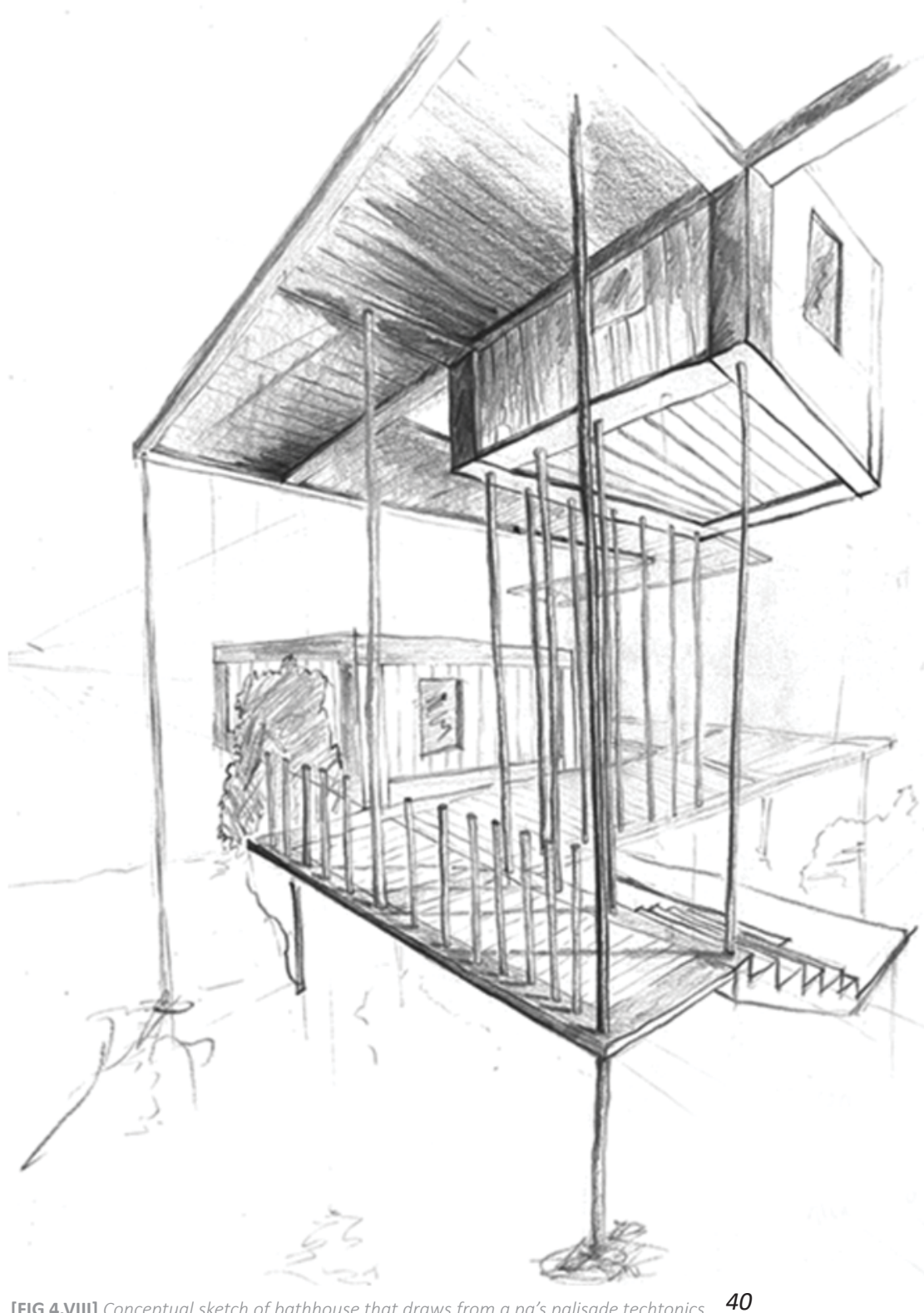

[FIG 4.VIII] Concep
SOURCE: Authors

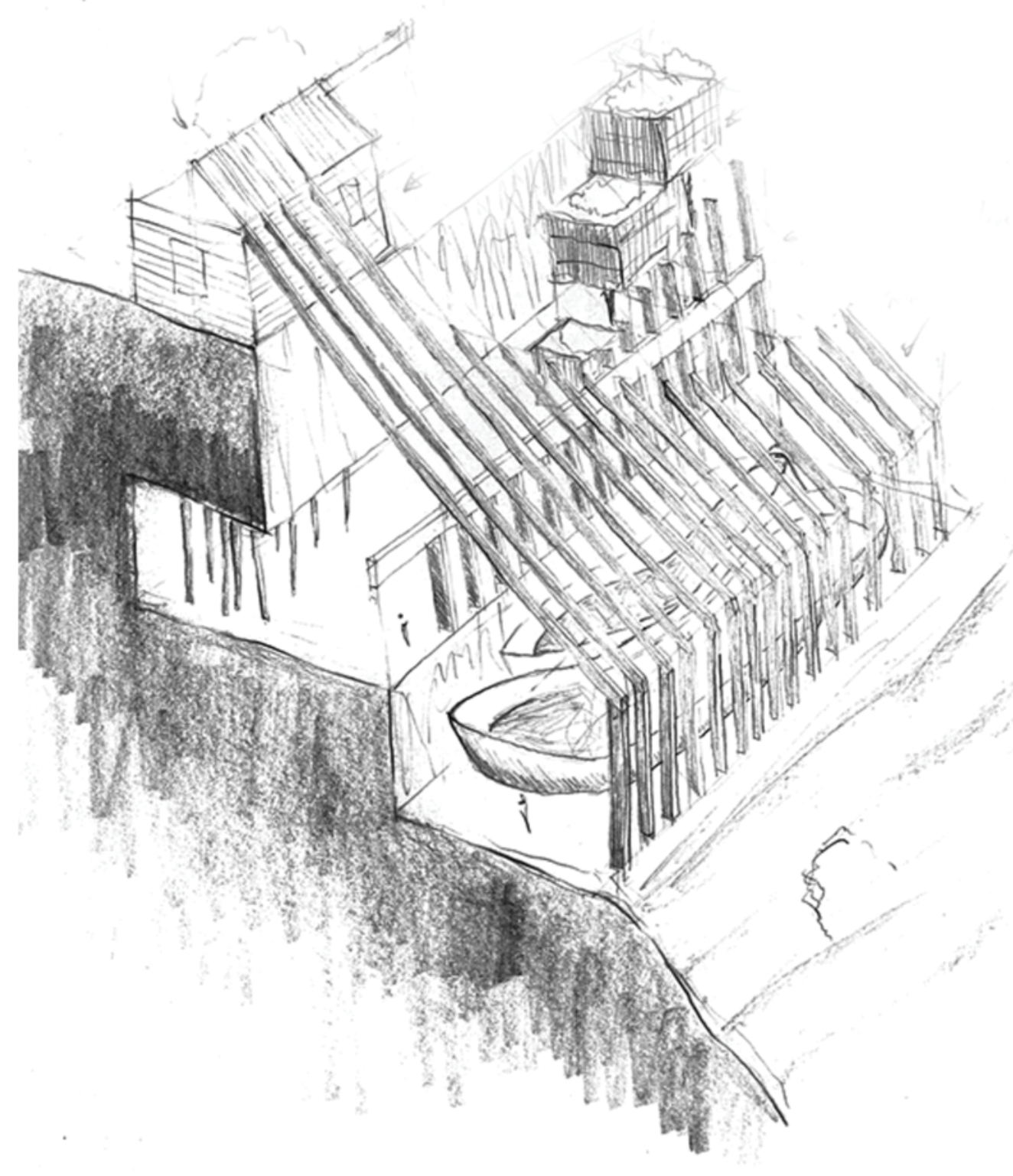

[FIG 4.IX] Conceptual sketch of bathhouse that draws from how a pa cuts into the earth 

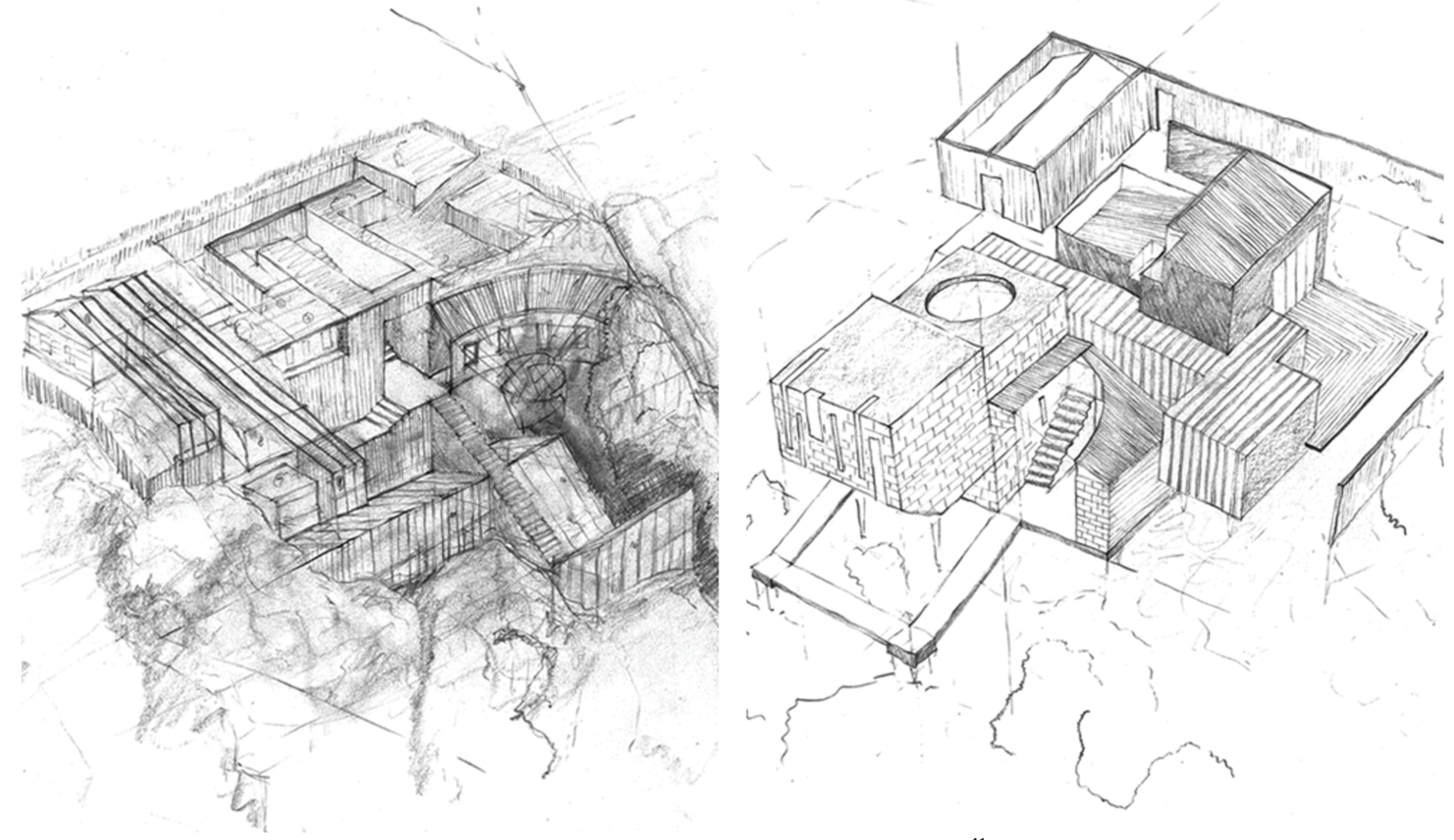

[FIG 4.X] Conceptual sketch of bothhouse that draws from haw a pa cuts into the earth

[FIG 4.XI] Conceptual sketch of bathhouse 41 a draws from how a pa is a labyrinth like 


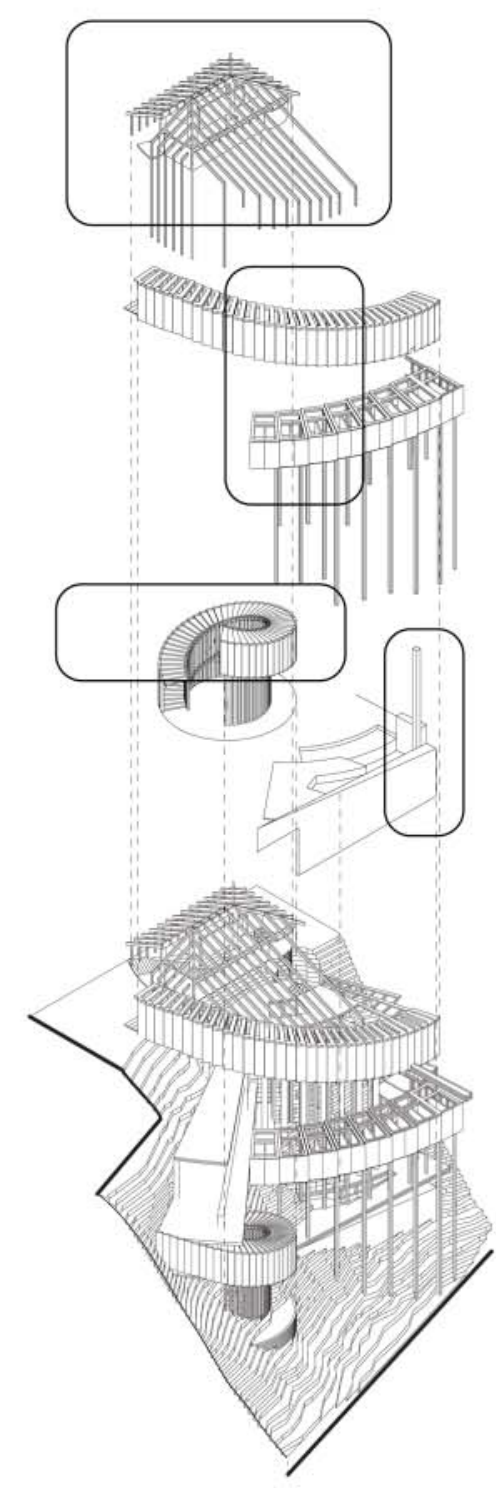

KEY

A- Entrance

B- Office space

C- Courtyard

D- Palisaded corridor

E- Disabled access

F- Reception

G- Cafe

H- kitchen

I- Staff room

J- Outdoor deck area

K-Changing rooms

L- Rinsing area

M- Sauna

$\mathrm{N}$ - Toilets exit

O- Baths

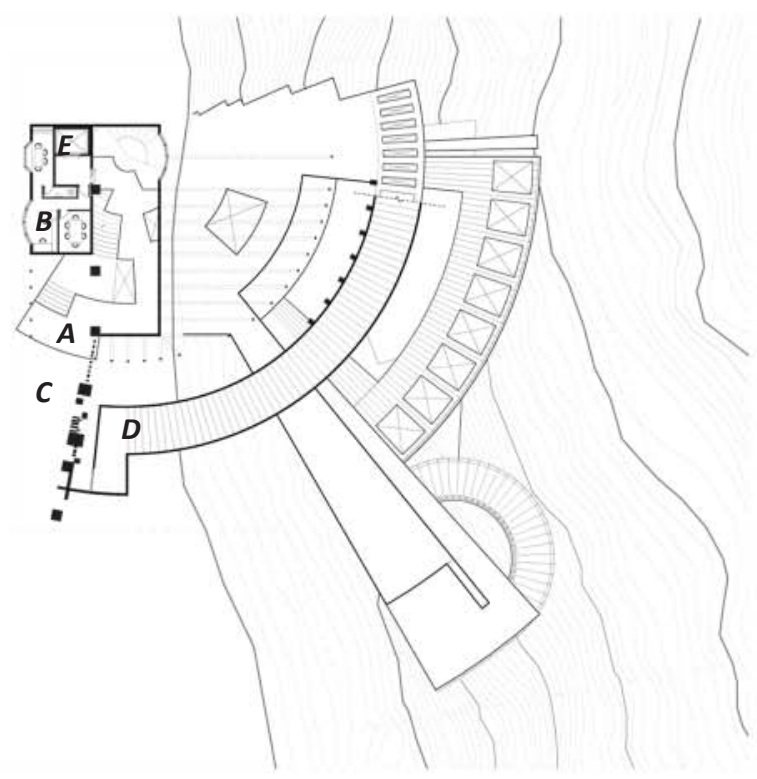



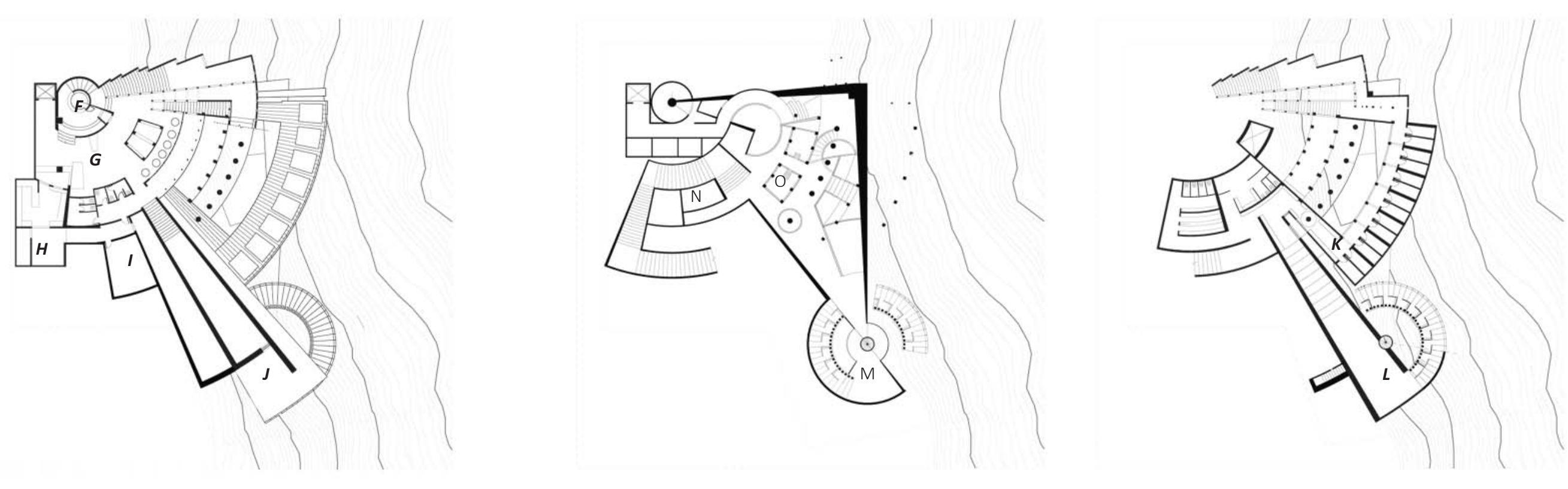


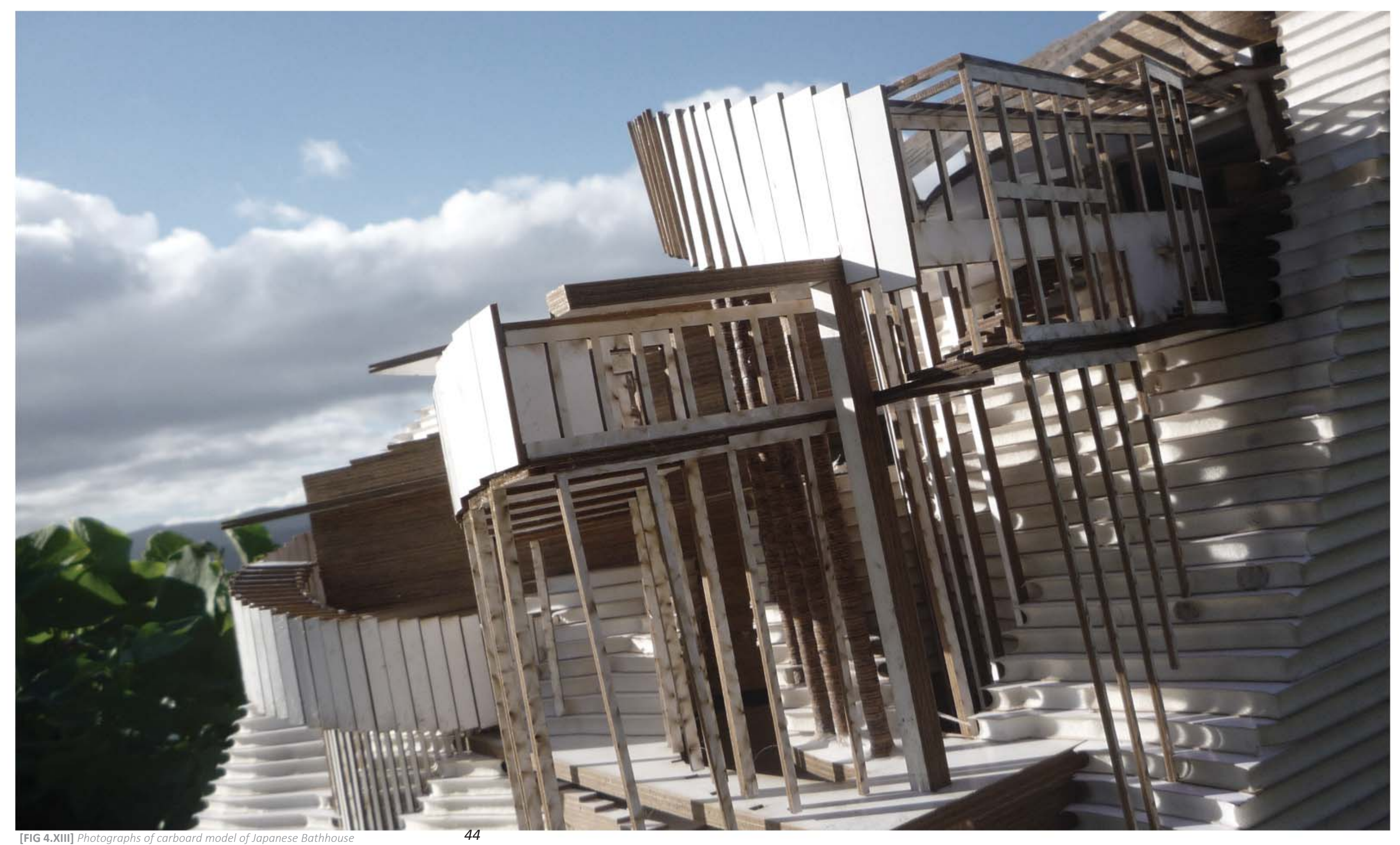




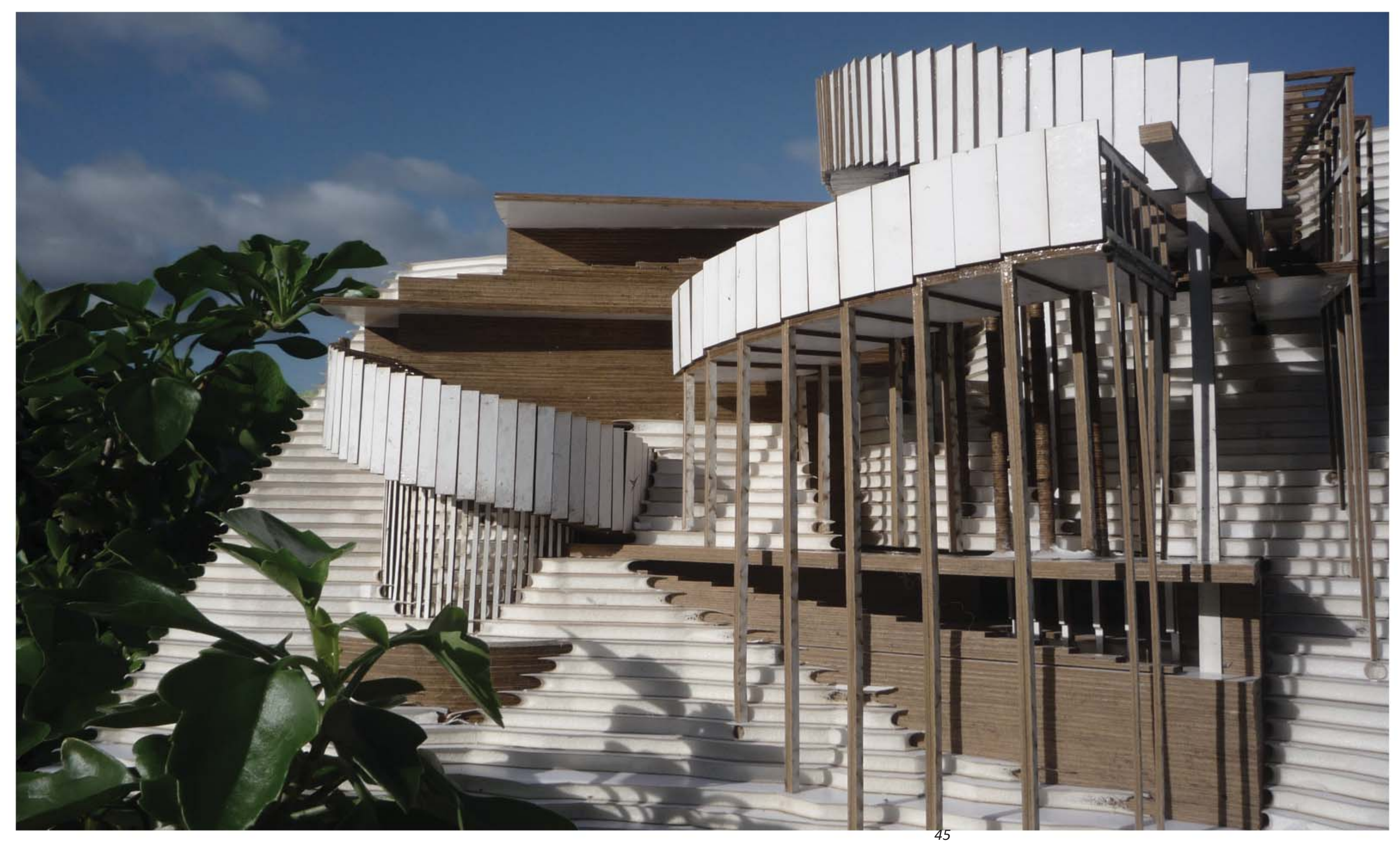



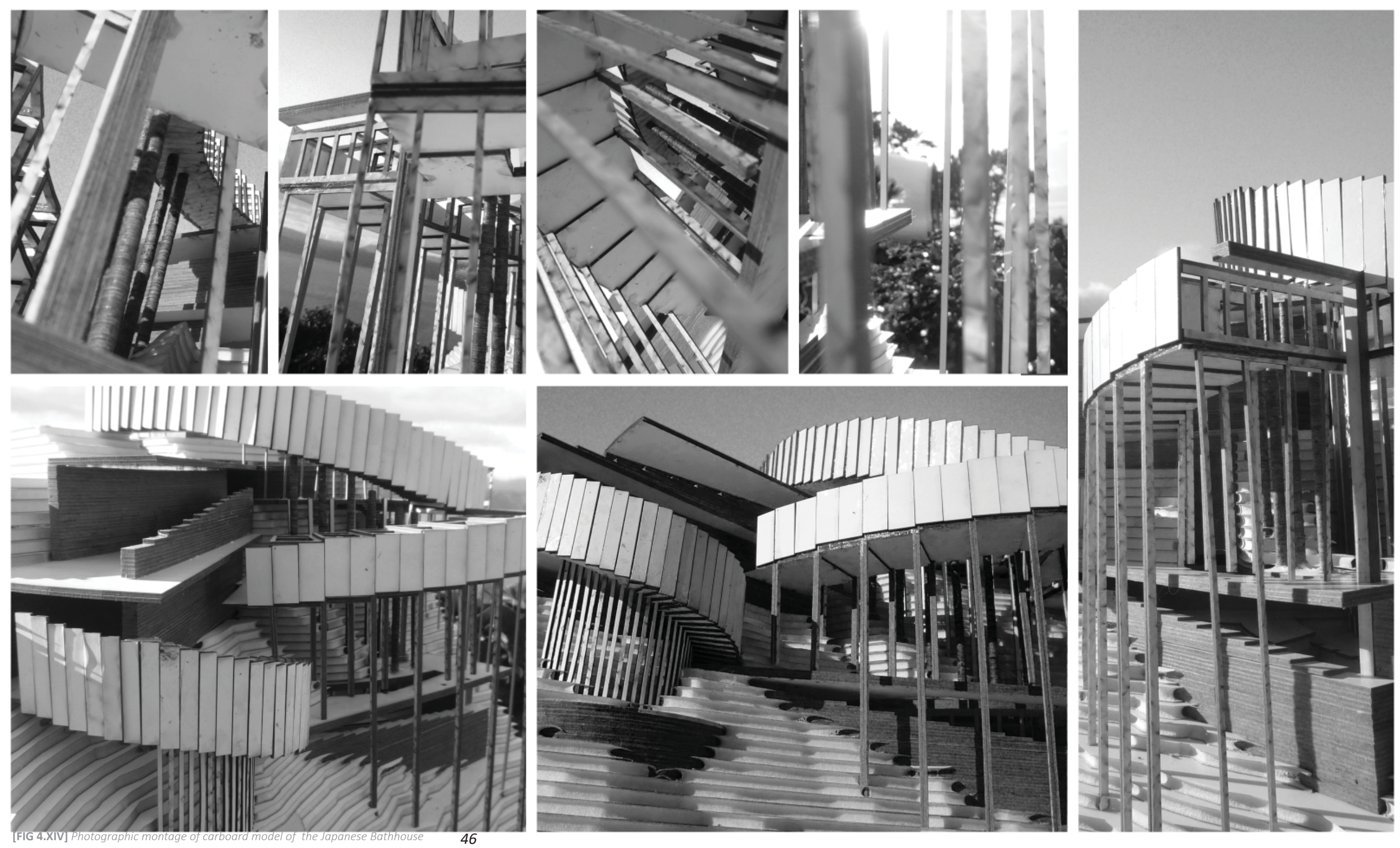

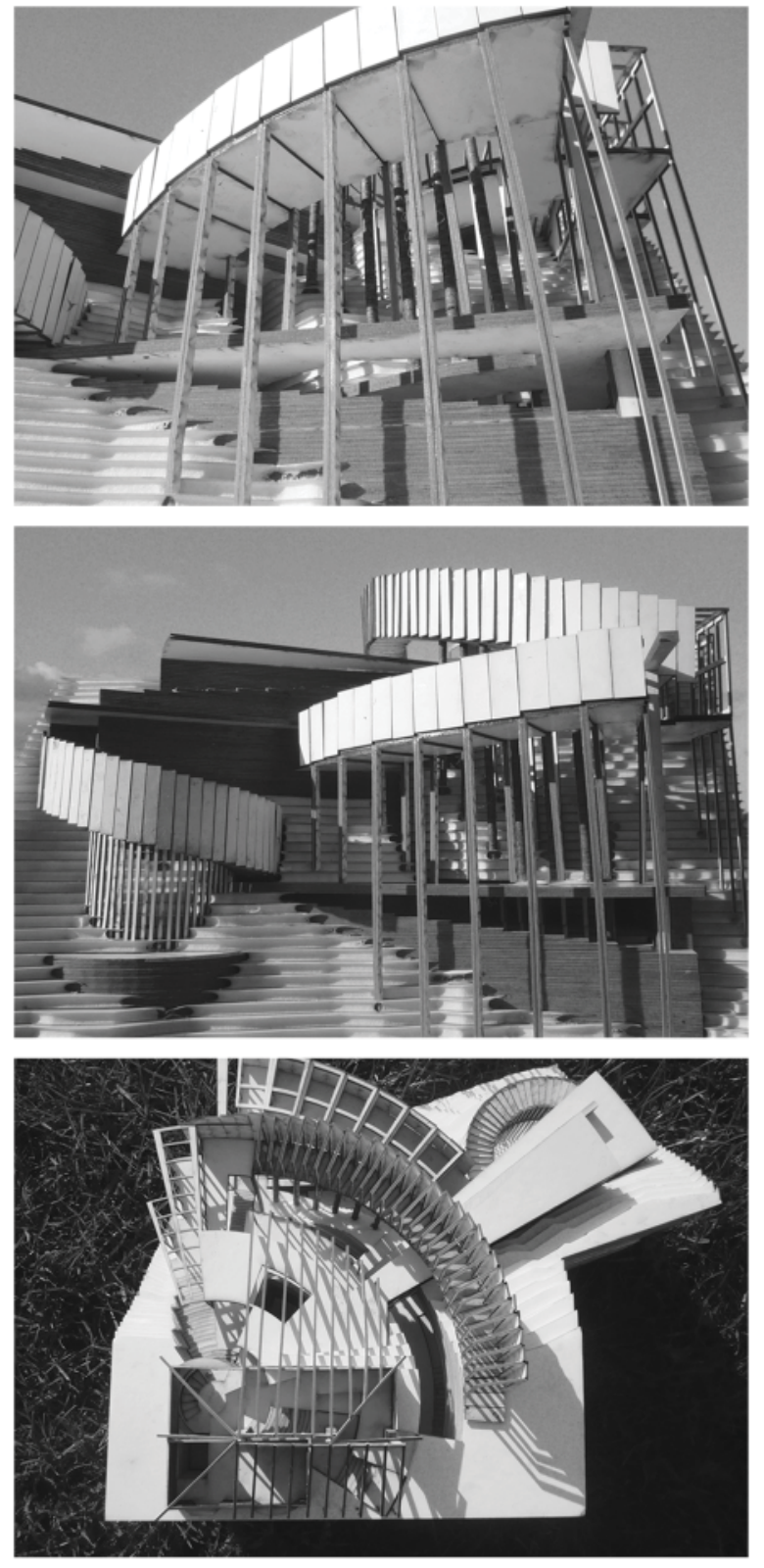
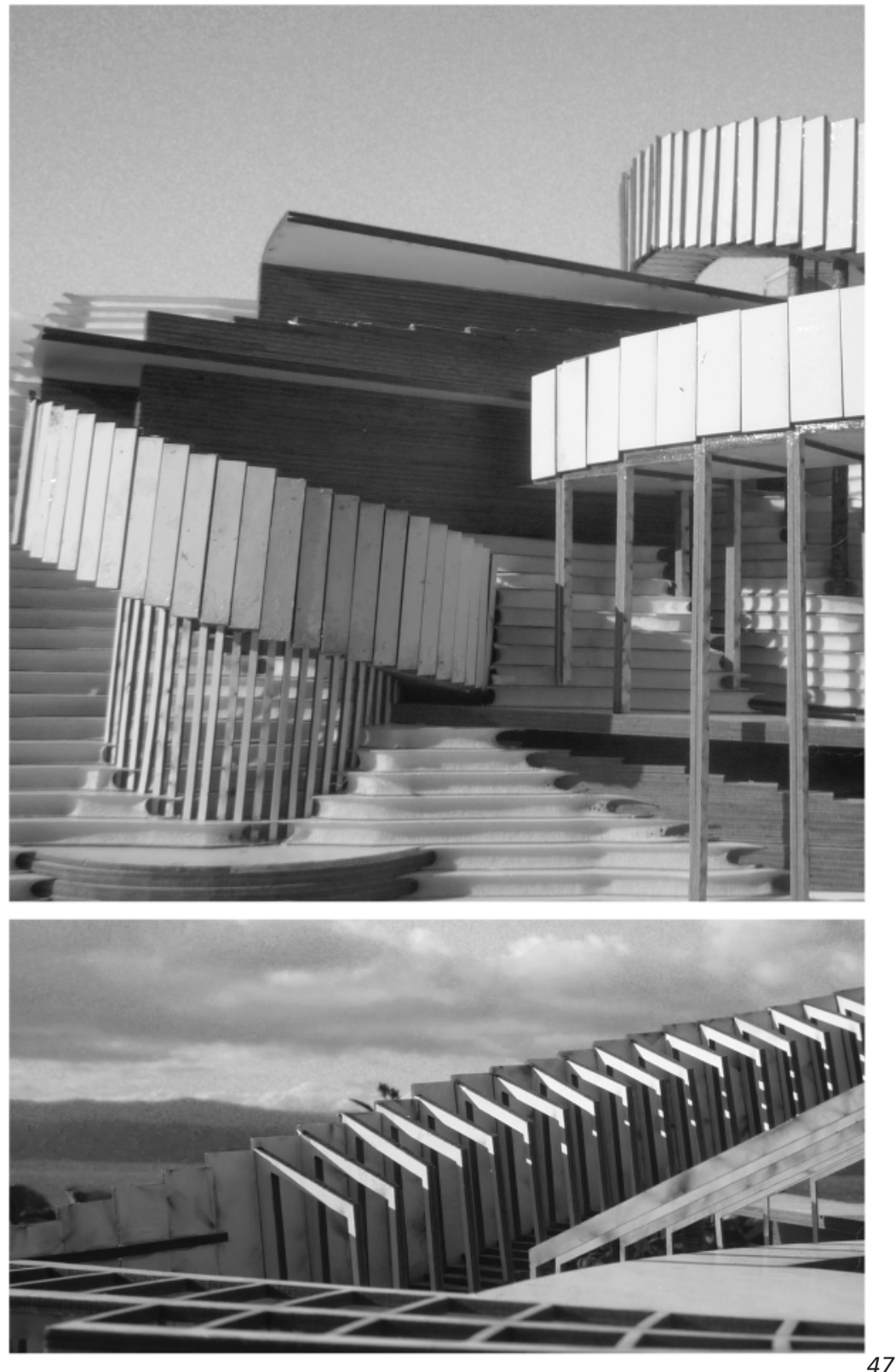

\subsection{Part one summary}

Part one dealt with objectives one, two and three and brought together ideas in the Japanese bathhouse. The bathhouse project is not to be read as a proclamation of the site's history; rather it is an example of the following argument: an architectural intervention can evoke a site's past via the analogical method which evokes, expresses and provides insight into the past of a site. The use of place names as the main source for a site's past was illustrated along with the forming of an interpretation. The project revealed the importance of programme; although unintentional, the programme of bathing in a Japanese manner has similar qualities to those interpreted of Te Whetu Kairangi pa, such as community, rehabilitation, and solitude.

Part one found that analogy as a design method opens three possible avenues of design, Firstly, the creation of a space that literally recognises physical elements of the lost setting such as the three corridors reflecting the three palisades. Secondly, a design which abstractly creates a space such as the rinsing and water storage area evokes the past of the spring and possible whata. Lastly, the design spatially created a setting that is expressive of moments such as a sense of solitude and relationship with the stars, possibly once experienced.

Part one also found that although the past of Te Ao Tawhito is limited to place names and at times a small description, through an interpretation key words can be formed. Such as isolation, starry sky, solitude, labyrinth, and rehabilitation which are enough to generate a design through a method of analogy.

Lastly, part one found a strong link between the programme and the past. If there is a connection then occupants may be able to reflect on the past when carrying out similar tasks. A bather soaking in the hot water and gazing upwards into the starry sky above may allow their mind to meander to a time where the first Maori may have done something similar. 
Part Two Between narratives 


\subsection{Part Two Introduction}

Part two of the thesis addresses the second issue of how a mnemonic intervention could interact with a relic that now remains on a site. Before this can be addressed in project two, the context is unravelled further and followed by an examination of six case studies that relate to the context and inform a method. This chapter explores the context by studying Point Gordon which is now part of a heritage park and up for development. The area was once a pa known as Te Mahanga during Te Ao Tawhito period. However military occupation dramatically changed the site to such a degree that the pa is no longer legible and the site now hosts the remains (largely intact) of Fort Ballance. Relics can be valued and treated in regard to their original intent, age value or historical content which is further discussed. This discussion leads onto chapter six which explores six case studies that each allows a site to be developed by treating the relic in any of these three manners. These case studies were selected as they allow a mnemonic intervention to exist on a site by interacting with a relic. The case studies inform a method of metamorphism which is explored in project two, which concludes part two by exploring how an intervention could evoke, express and provide insight into both Te Ao Tawhito and Te Ao Hou pasts.

\subsection{The Concealing Context}

Just as interventions, including the archaeology site and Te Aro Park, found along Te Ara o Nga Tupuna (The Path of Our Ancestors) mark, evoke and provide insight into the past of Te Ao Tawhito. So too is the colonial settlement of early Wellington marked and evoked by relics which provides insight into certain eras of Te Ao Hou period, that are located around the harbour. A short history similar to Loves Te Ati Awa, of Port Nicholson's military defence (colonial name of Te Whanganui a Tara Wellington) will reveal the essence of part two. Following colonisation by the British and after settlements had become established, Aotearoa New Zealand became over paranoid about Russian invasion which threatened the shores of major cities during the late nineteenth century. Although unlikely to be attacked by the Russians the threat became serious during War World One and Two. Point Gordon is part of a series of interconnected bases that formed a system of defence during this period of unrest. Point Gordon consisted of Fort Gordon, a mining station, and Fort Ballance, which was the main defence base until relieved by Fort Dorset.

Today Motu Kairangi Miramar is marked by the remains of these military installations which present an opportunity for an architectural intervention. Fort Dorset like Fort Ballance conceals a pa of Te Ao Tawhito, although Orua-iti Pa has been marked by a sculpture through an upgrade of the area. Many of these military bases conceal any physical trace of what would otherwise express the past of Te Ao Tawhito, there is a growing trend to acknowledge both periods of the harbours past. Fort Dorset/Orua iti was developed as a reserve and the relics preserved with a focus on their age value while the past of Te Ao Tawhito was marked with a sculpture. Although the past of Te Ao Tawhito and Te Ao Hou is now being marked, the thesis argues that a mnemonic architectural intervention will provide more insight for visitors by expressing and evoking the past.

\subsection{The past through relics}

Although the past is known through history, memory and relics, it is perceived physically in the environment through relics. David Lowenthal continues by explaining that "tangible relics survive in the form of natural features and human artefacts. Awareness of such relics enhances knowledge gained through memory and history. But no physical object or trace is an autonomous guide to bygone times: they light up the past only when we already know they belong to it" 


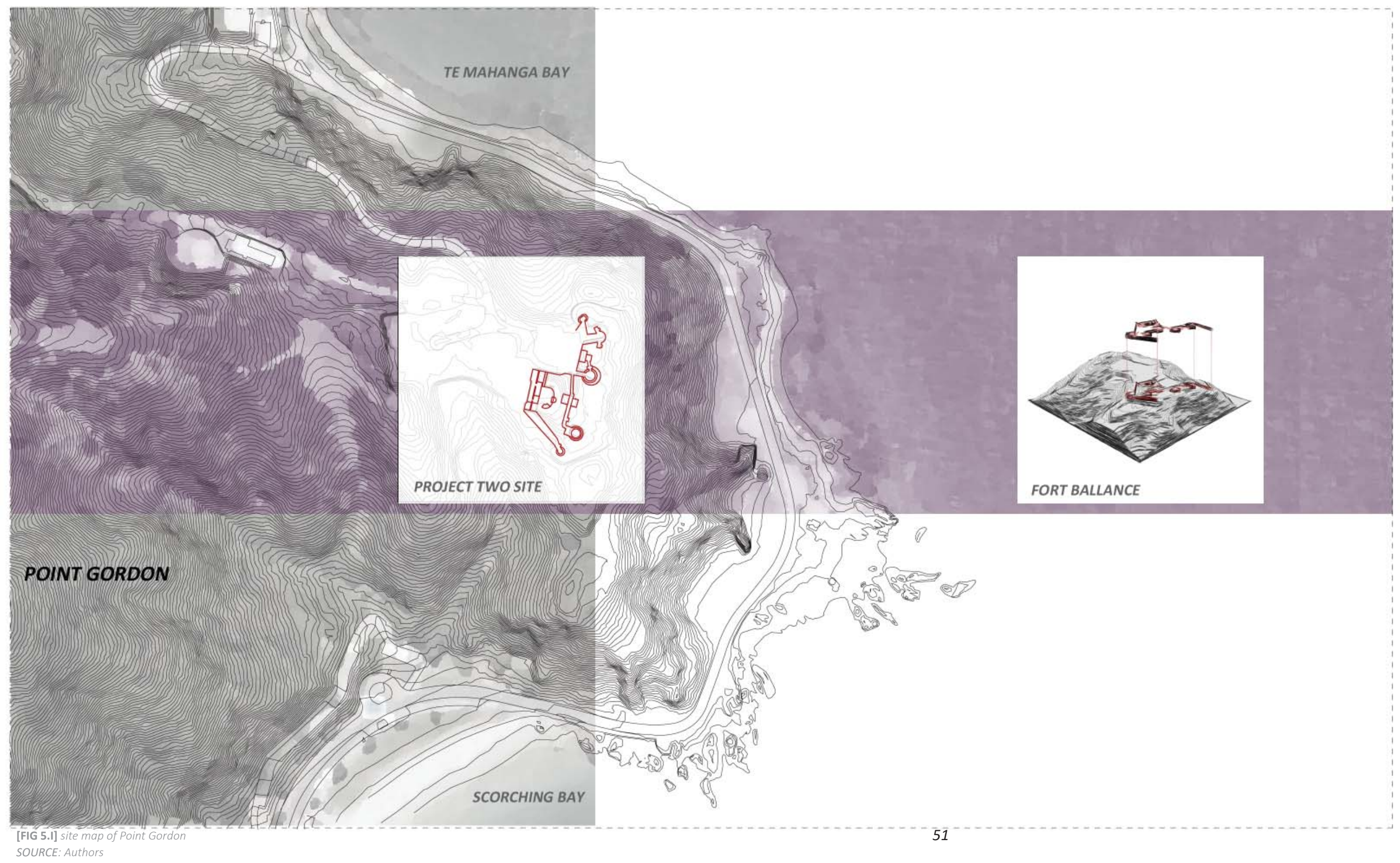


(238). It could be argued that it is the narrative of the past that individuals find the most interesting. Although that is not to suggest that individuals do not value or appreciate the object, rather the thesis argues that historic content should be prioritised.

Whare whakairo are perfect examples of beautiful objects that are imbued with narrative and iwi history. One could not suggest that the whare whakairo, Te Hau ki Turanga, presently housed in Te Papa is not in any way an object of awe or quality. However, more importantly is the meaning of Te Hau ki Turanga to the Rongowhakaata iwi. In genera whare whakairo are analogies of whakapapa and the world around the iwi (Royal par 1). Te Hau Ki Turanga will soon be returned because of its importance to iwi as a source of their past, rather than as an object from the past.

Military relics are similar to whare whakairo, in a sense they too embody ideas and values about the past. However relics are not only appreciated for their historical content but also their age value and original intent. Although the military relics could ignite individual understanding and interpretation of the past in relation to the great wars, they are valued for objective qualities. Lowenthal suggests that "what we save is property and artefacts rather than ideas or culture." (Lowenthal 406).

The thesis suggests that any work carried out on a relic could be in response to its original intent, age value or historical content. These ideas will form the basis of project two and be discussed further in the following chapter. Each value correlates to a method of restoration, preservation or adaptation. These methods will also be discussed.

\subsection{A penisular of Relics}

Point Gordon is a well-suited site for the study as it is easily accessible with information published on both Te Ao Tawhito and Te Ao Hou periods associated with the site. It is also part of plans to make the area publicly accessible. Although Point Gordon hosts Fort Gordon and a mining station the study only focuses on Fort Ballance. Peter Cooke's Ramparts of the sea provide extensive background information which has been accompanied by heritage and archaeological reports.

The base was broken down into 12 Areas (figure 5.2 to 5.13), and the existing fabric was studied analysing natural damage, human related damage and alterations. This study of the base resulted in three possible methods of metamorphism, juxtaposing, weaving, and wrapping, that could allow for an intervention to be placed on the site that evokes, expresses and provides insight into Te Ao Tawhito past. 

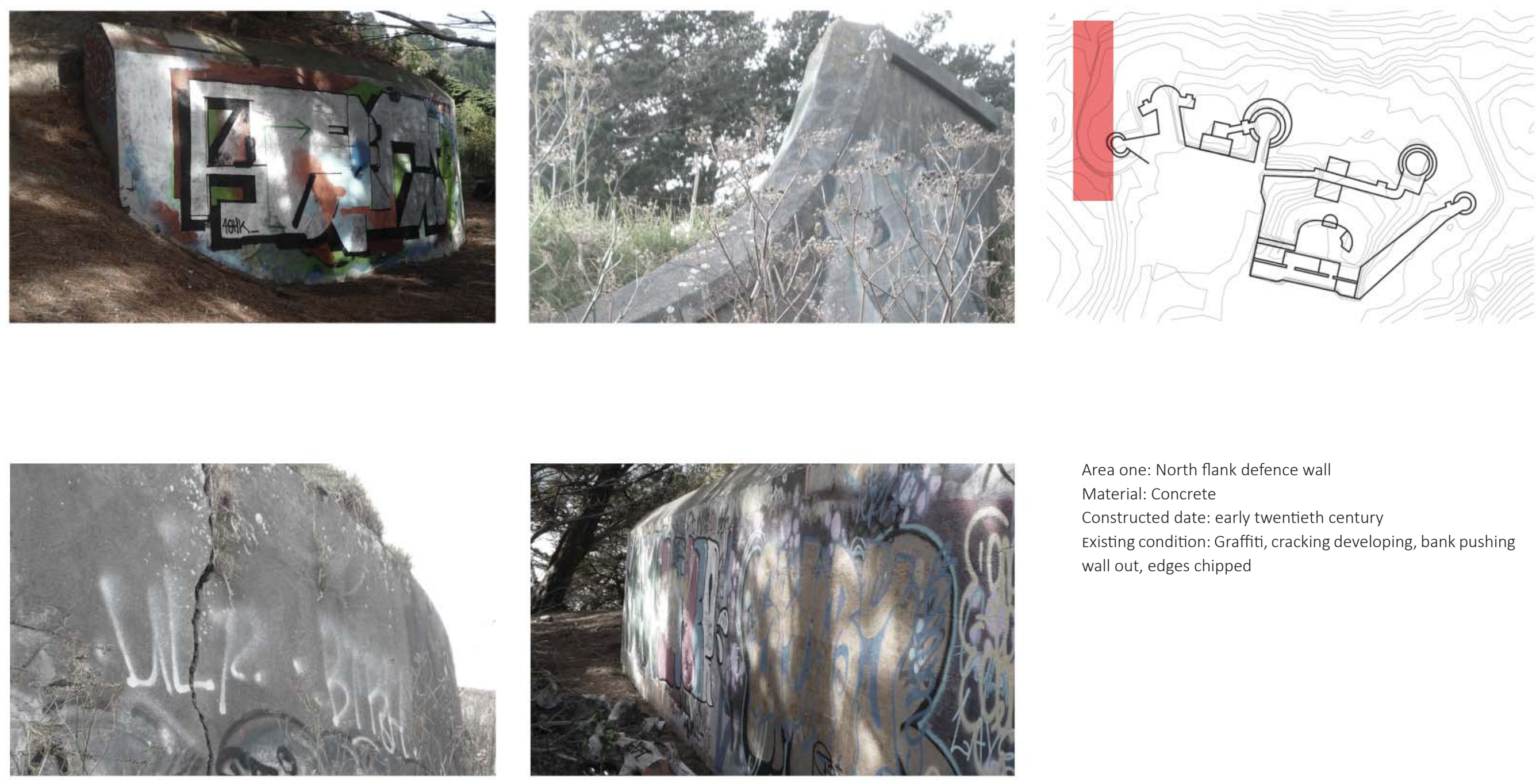

Area one: North flank defence wal

Material: Concrete

Constructed date: early twentieth century

Existing condition: Graffiti, cracking developing, bank pushing

wall out, edges chipped 

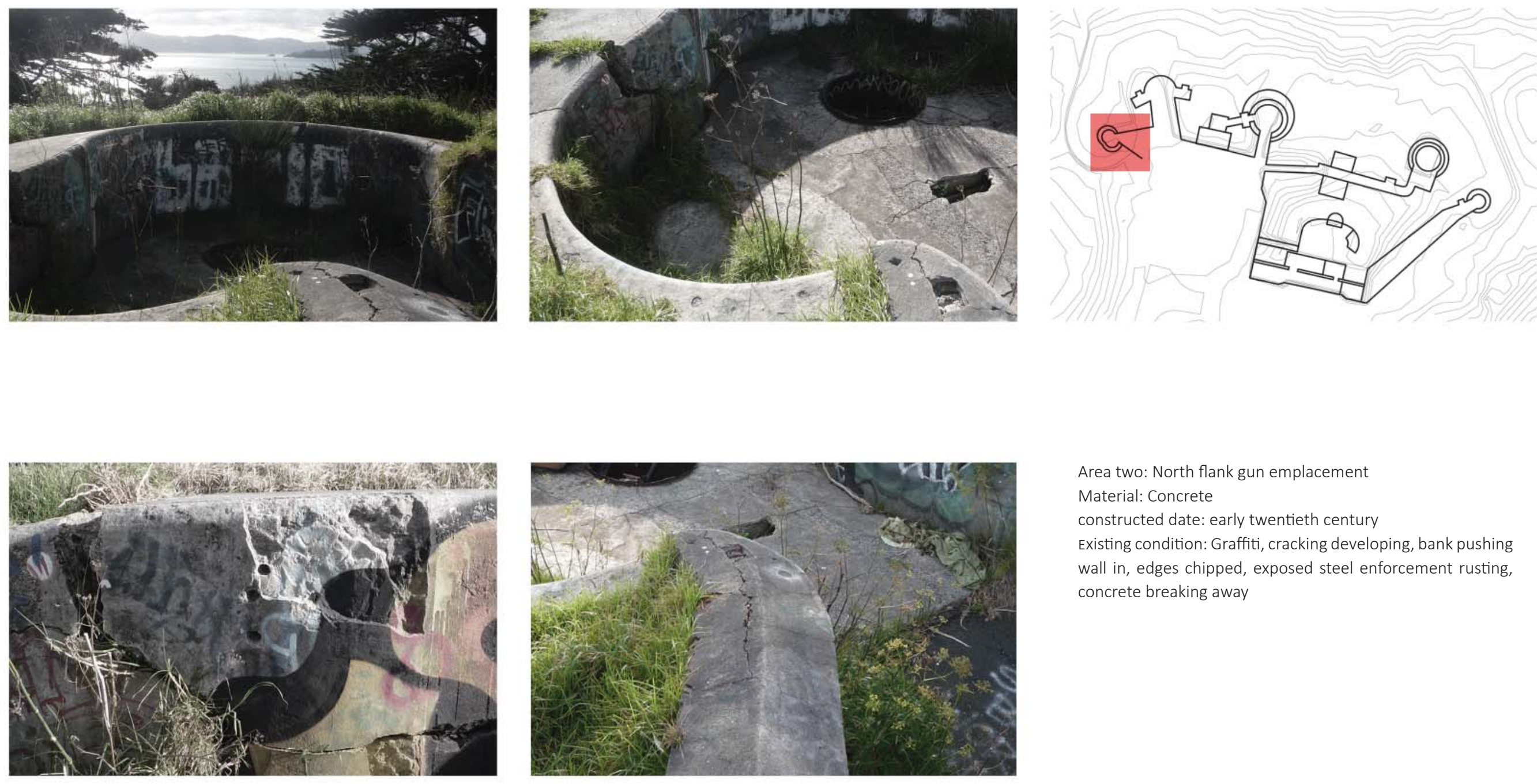

Area two: North flank gun emplacement

Material: Concrete

constructed date: early twentieth century

Existing condition: Graffiti, cracking developing, bank pushing

wall in, edges chipped, exposed steel enforcement rusting,

concrete breaking away 

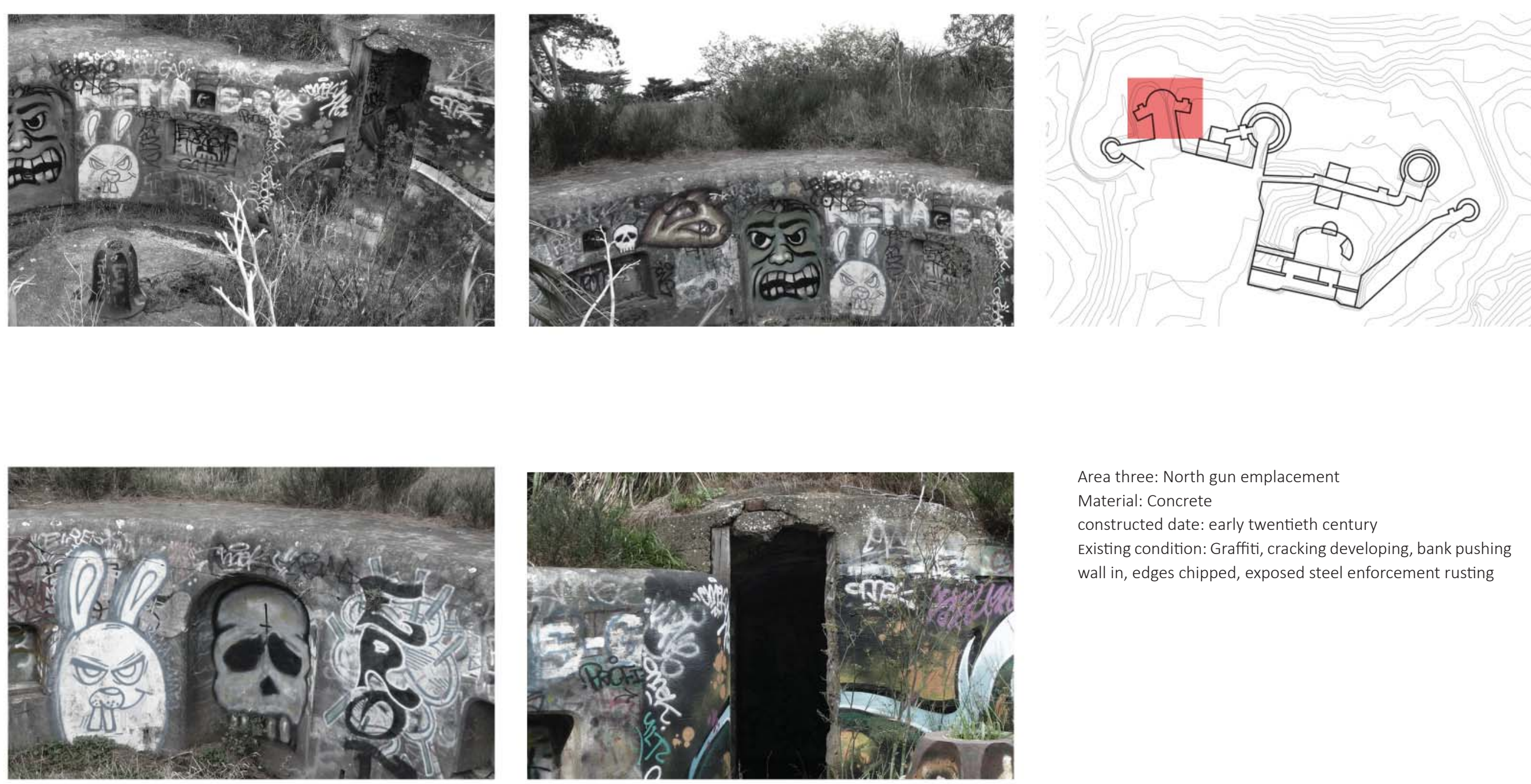

Area three: North gun emplacement

Material: Concrete

constructed date: early twentieth century

Existing condition: Graffiti, cracking developing, bank pushing

wall in, edges chipped, exposed steel enforcement rusting 

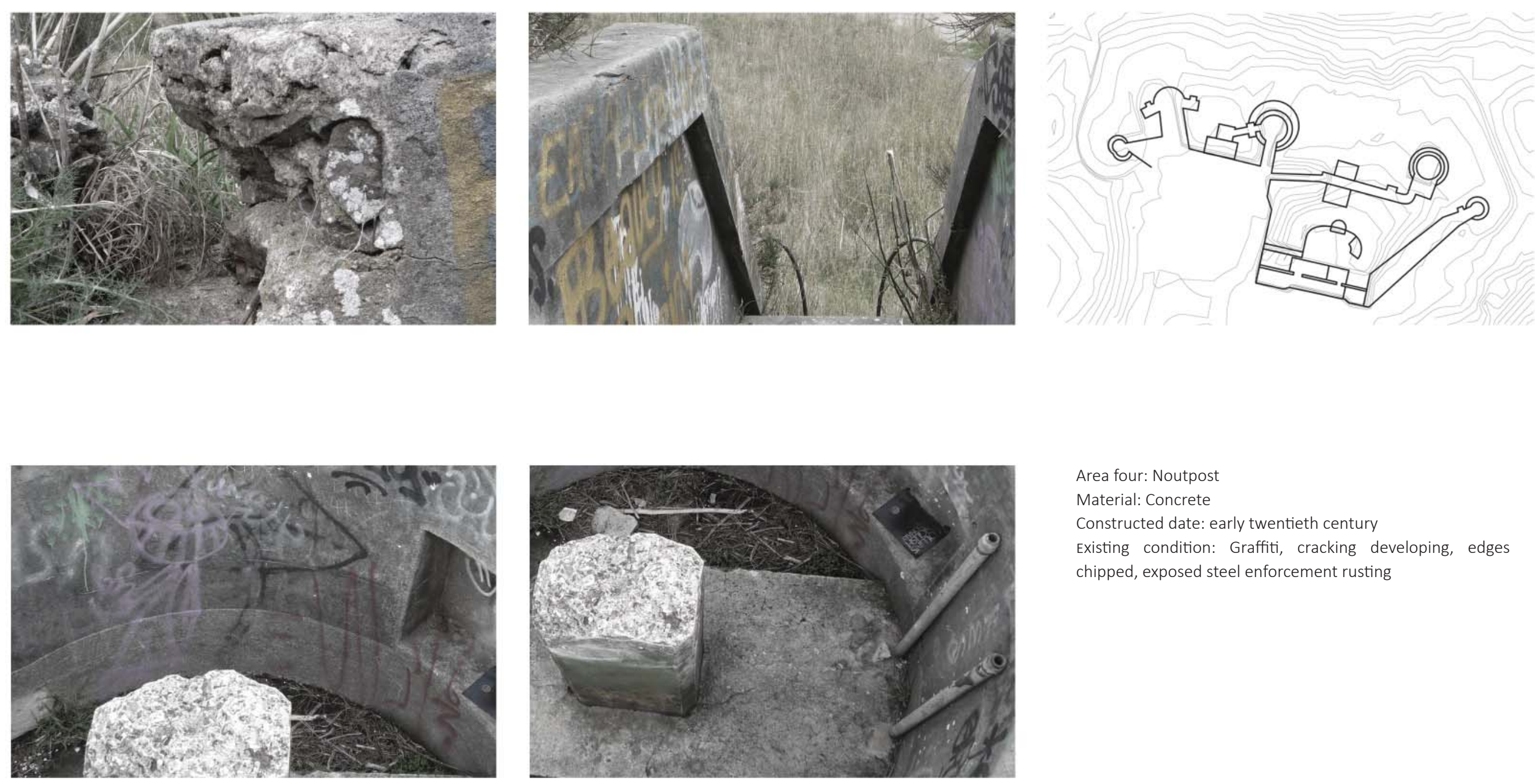

Area four: Noutpost

Material: Concrete

Constructed date: early twentieth century

Existing condition: Graffiti, cracking developing, edges

chipped, exposed steel enforcement rusting 

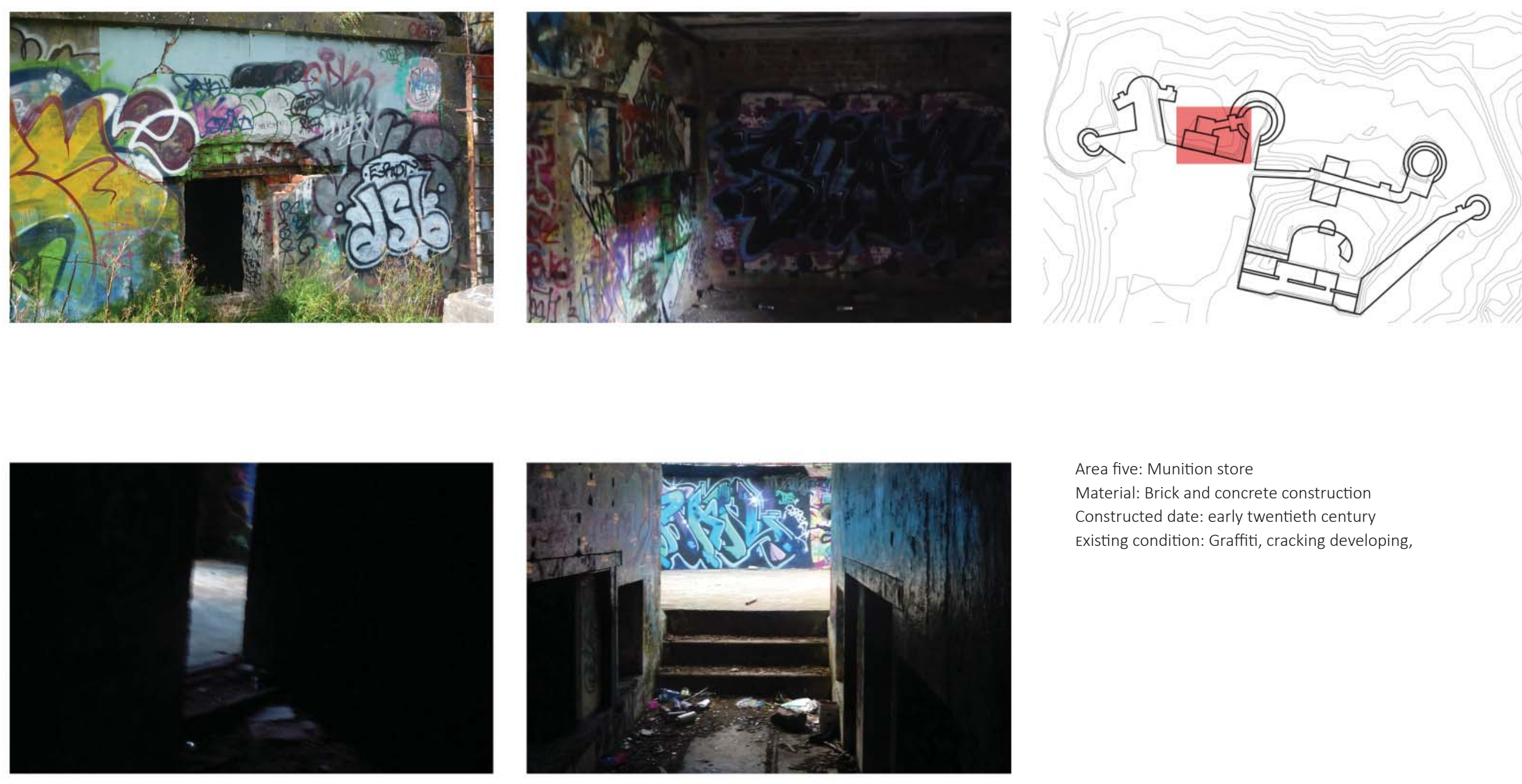

Area five: Munition store

Material: Brick and concrete construction

Constructed date: early twentieth century

Existing condition: Graffiti, cracking developing, 

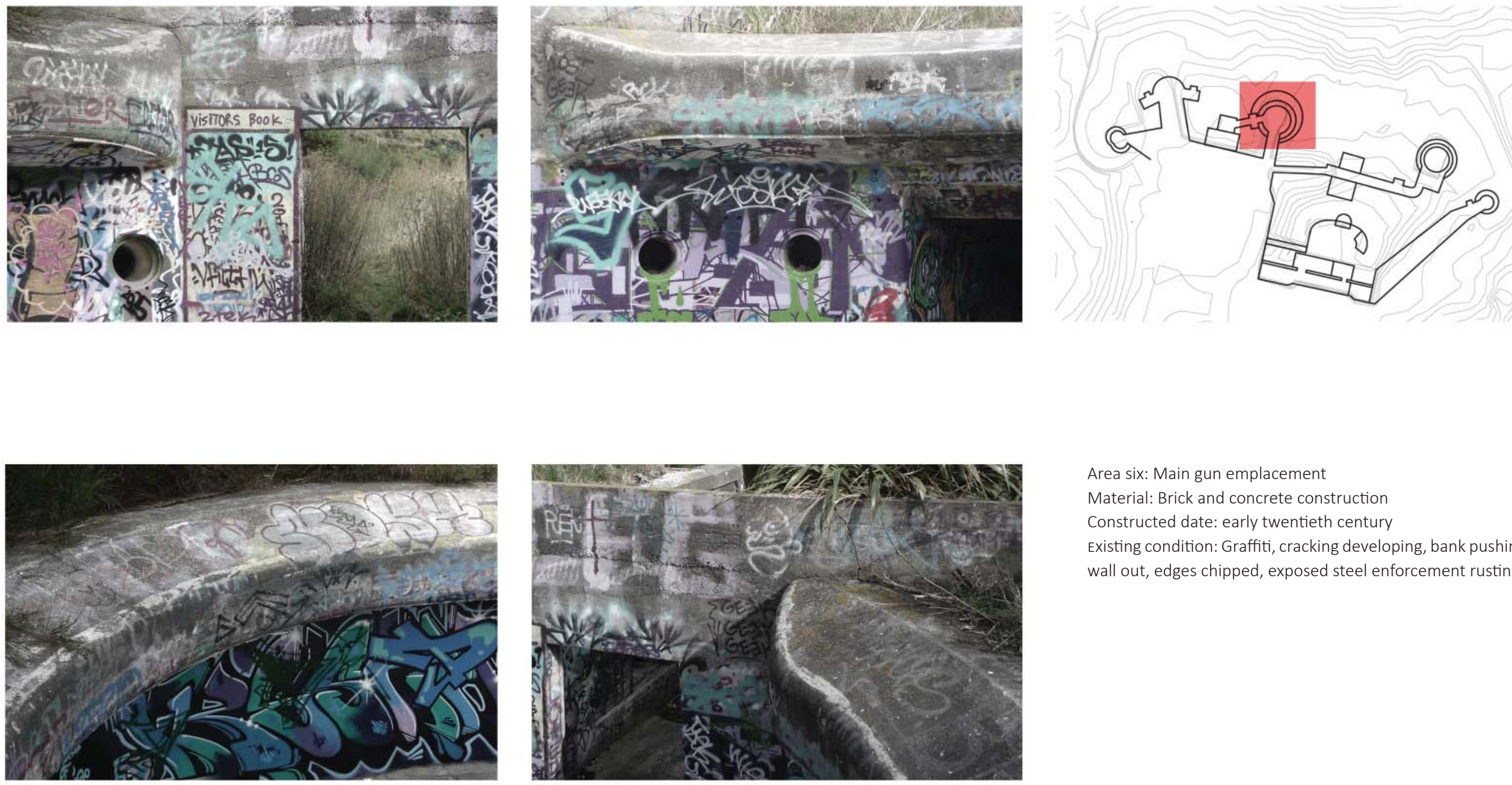

Area six: Main gun emplacement

Material: Brick and concrete construction

Constructed date: early twentieth century

Existing condition: Graffiti, cracking developing, bank pushing

wall out, edges chipped, exposed steel enforcement rusting 

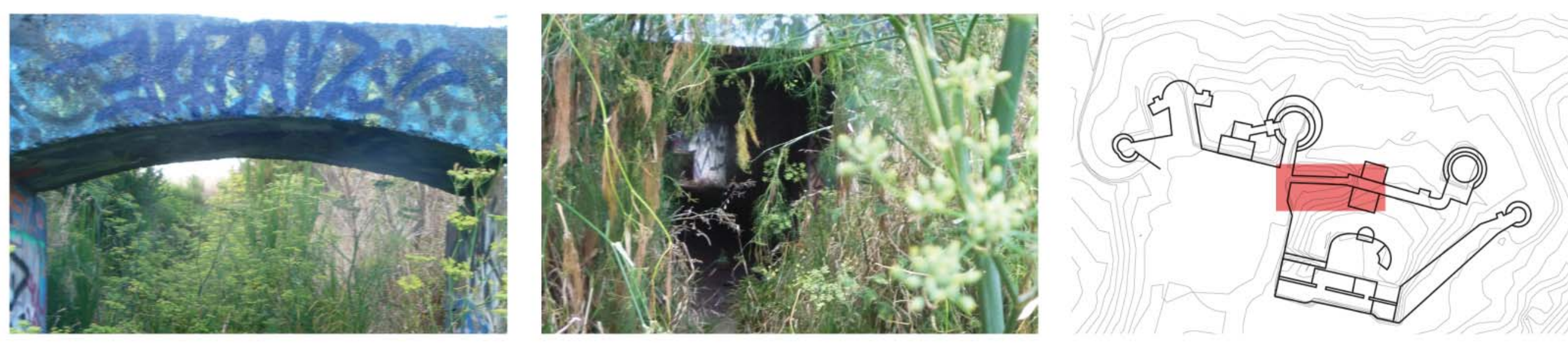

Area seven south Munition Store

Material: Brick and concrete construction

Constructed date: early twentieth century

Existing condition: Graffiti, cracking developing, edges

chipped, exposed steel enforcement rusting, damp and

mouldy 

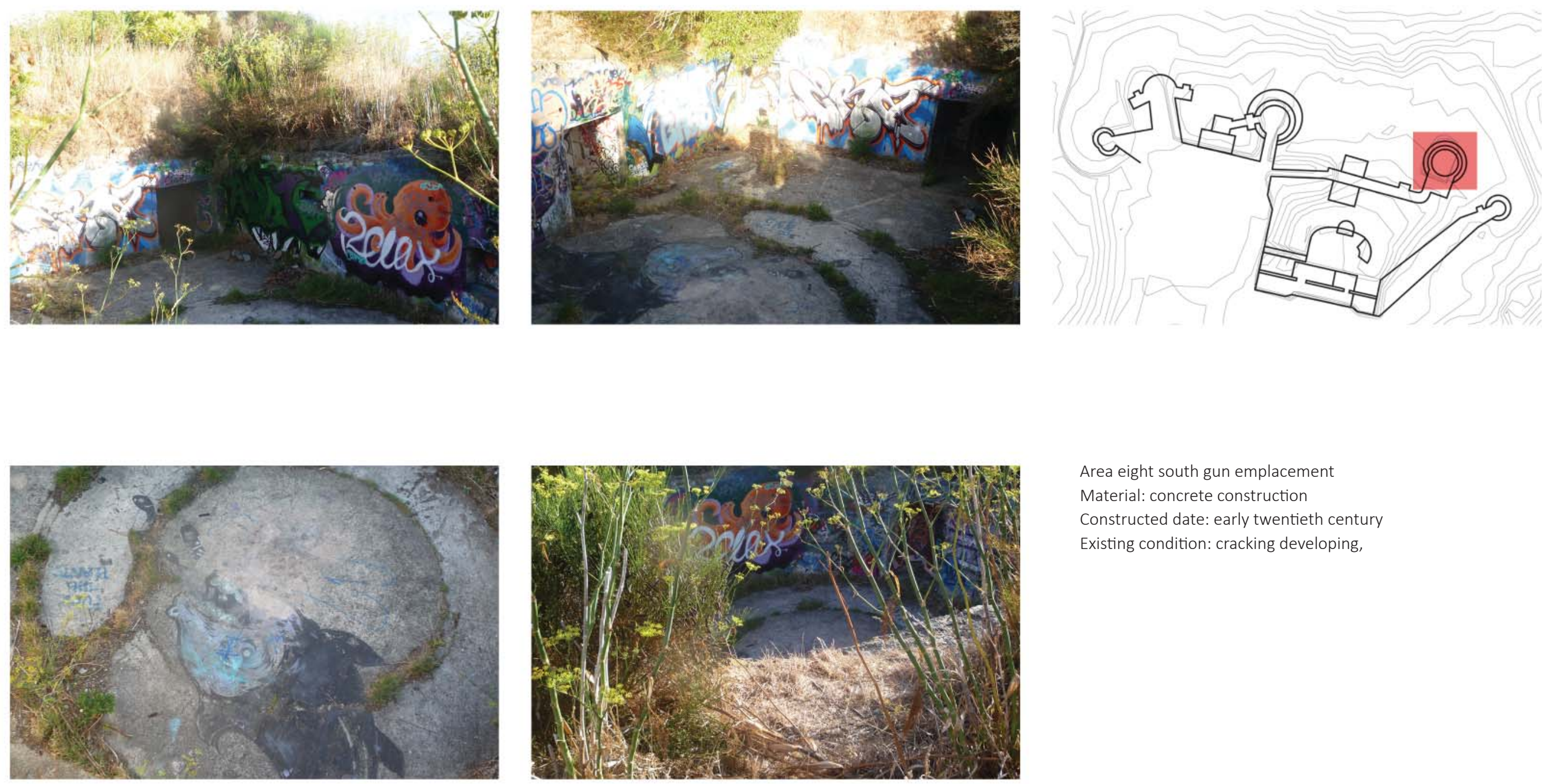

Area eight south gun emplacement

Material: concrete construction

Constructed date: early twentieth century

Existing condition: cracking developing 

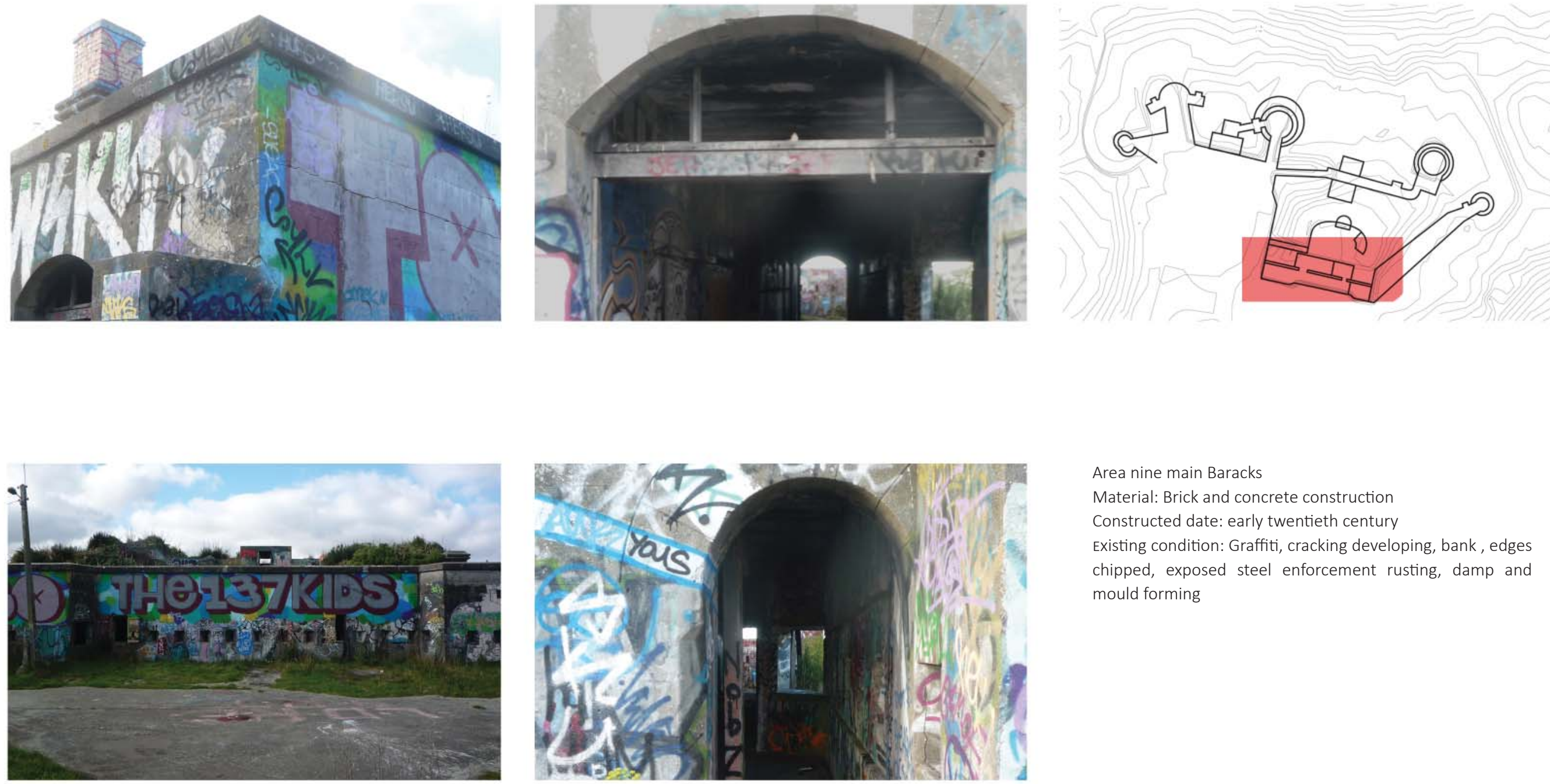

Area nine main Baracks

Material: Brick and concrete construction

Constructed date: early twentieth century

Existing condition: Graffiti, cracking developing, bank, edges

chipped, exposed steel enforcement rusting, damp and

mould forming 

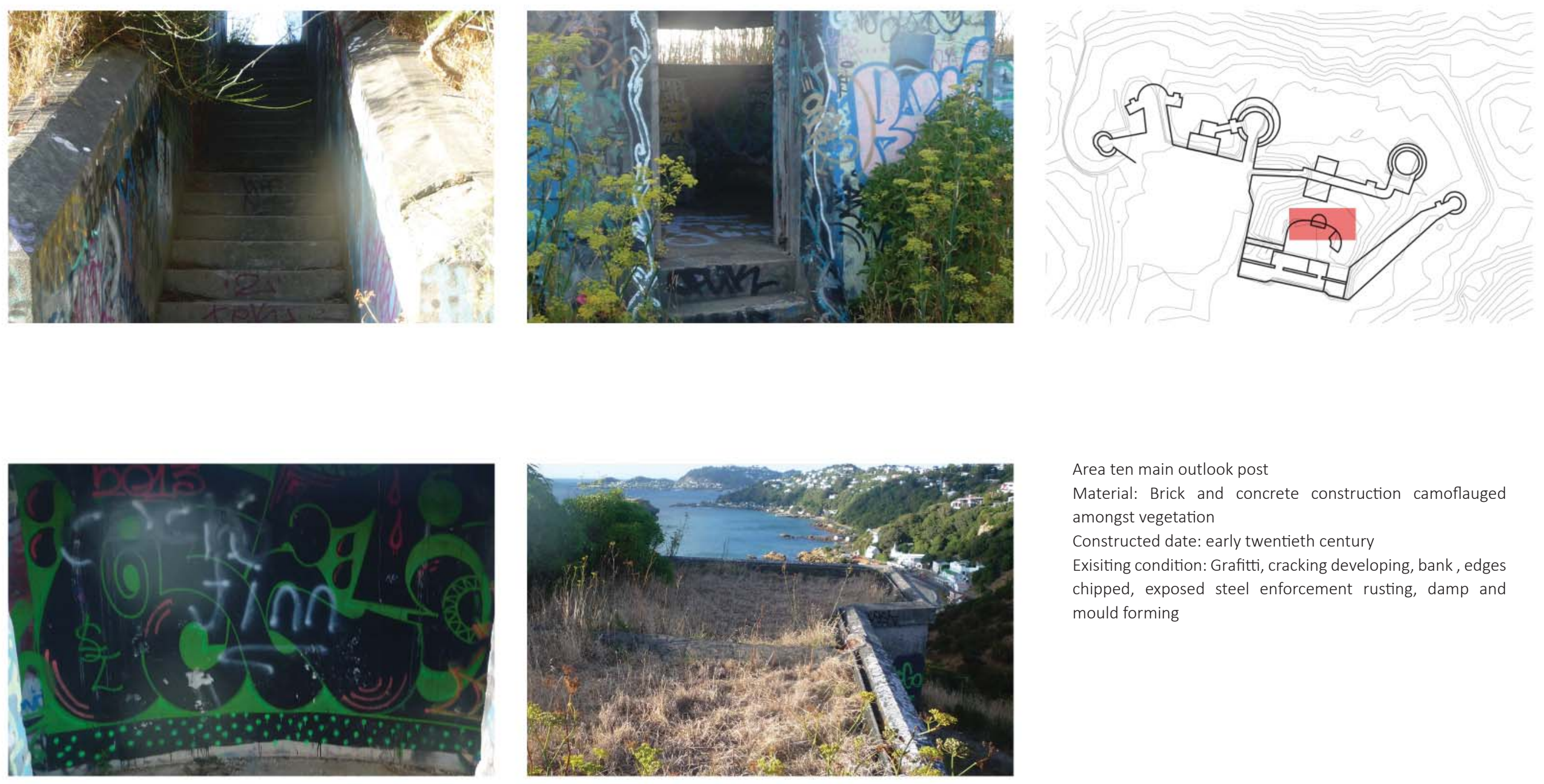

Area ten main outlook post

Material: Brick and concrete construction camoflauged amongst vegetation

Constructed date: early twentieth century

Exisiting condition: Grafitti, cracking developing, bank, edges chipped, exposed steel enforcement rusting, damp and mould forming 

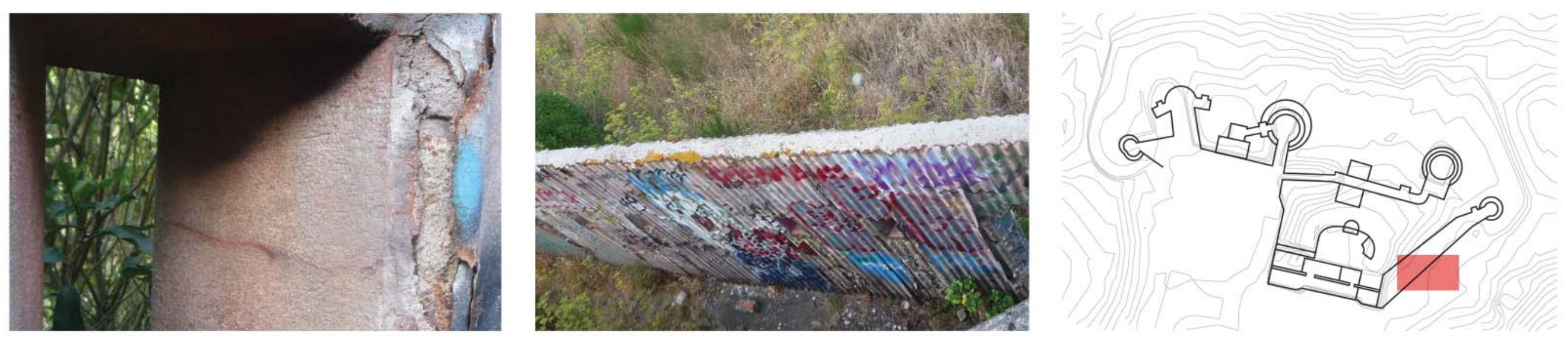

Area eleven corrugated loop hole wall

Material: concrete and corrugation

Constructed date: early twentieth century

Existing condition: Graffiti, cracking developing, edges

chipped, exposed steel enforcement rusting, damp and

mould forming 

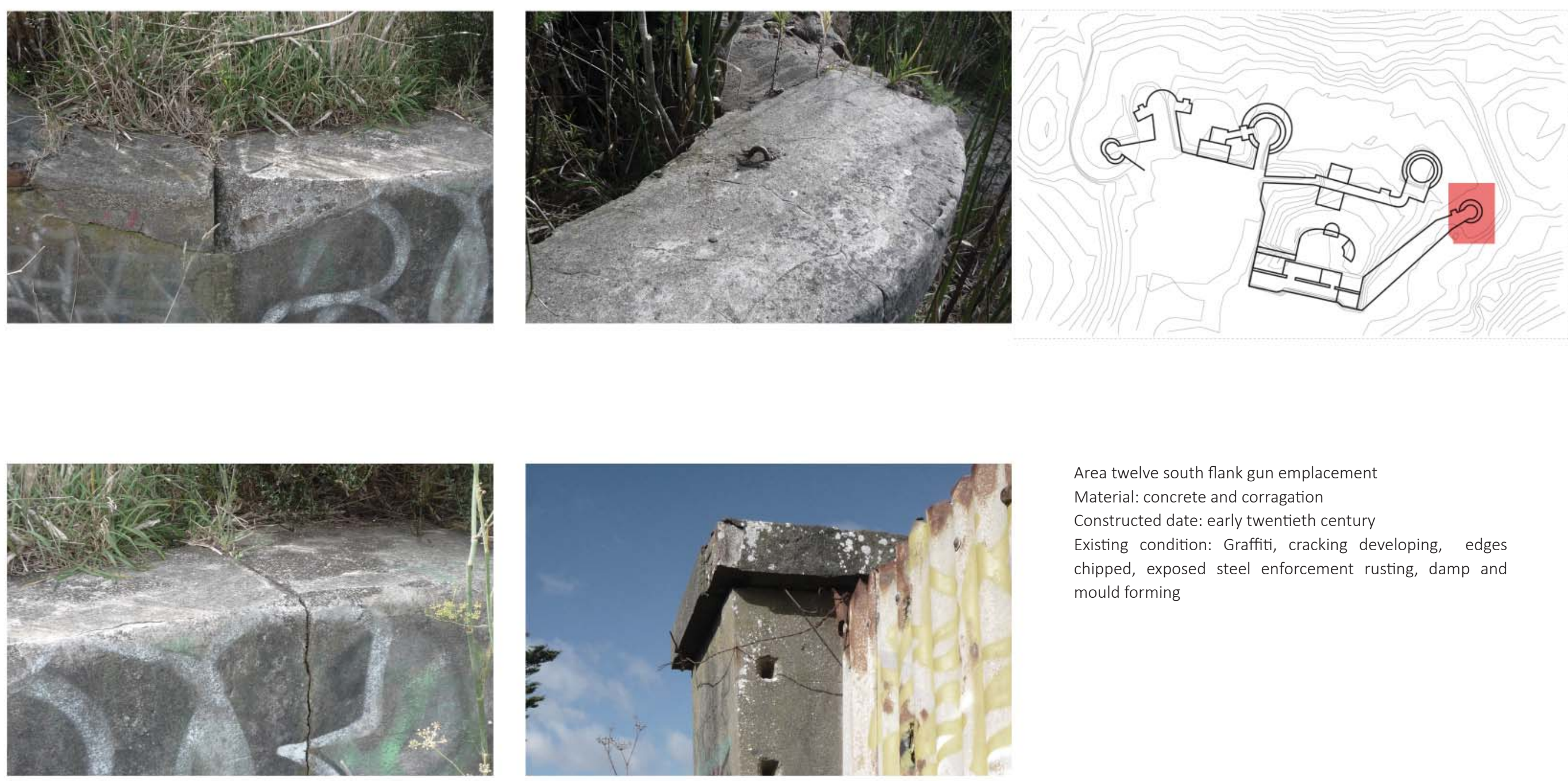

Area twelve south flank gun emplacement

Material: concrete and corragation

Constructed date: early twentieth century

Existing condition: Graffiti, cracking developing, edges

chipped, exposed steel enforcement rusting, damp and

mould forming 


\section{1 architecture of relics}

Relics associated with history are most likely to be deemed as heritage, where the object gains a status far beyond its original purpose. Valuing an object for itself and treating it independently has resulted from decades of theoretical discourse and conservational practice. This approach not only leaves the impression of the object as immutable, but it also fails to communicate its historic or cultural value, similar to the incarceration of the whare whakairo, Te Hau ki Turanga. Not only is the relic's historical content repressed but the past the relic conceals has little if no chance of being noticed. The process of restoration and preservation do not attempt to communicate the historical content associated with the relic, but rather focus upon the relic itself.

This chapter begins with an historic overview of conservation theory and is followed by a discussion of the three values relic may be prized for. Each of the three values are explored in project two that consists of three schemes, where Fort Ballance is valued for its age in the first scheme, with the second focusing on its original intent and the final scheme reflecting on its historical content. This position opens up design opportunities that allow a mnemonic intervention to develop the site. Metamorphic design methods will be explored as a process to guide a site's development that hosts a relic. This methodology is examined through six case studies that develop a site by retaining the existing fabric but allowing a contemporary programme.

Although ideas towards the maintenance of buildings Eugene Violette-Le-Duc, Salvador Munoz-Vinas credits their publications as the conception of conservation and heritage theory. Ruskin suggested a more restrictive idea that advocated buildings to be left in their existing condition and stated that "the signs of history are one of the most valuable features of an object" advocating age value (Munoz-Vinas page 20). On the other end of the spectrum is Violette-leDuc's more permissive ideas which claimed that "the most perfect state of a conservation object is its original state" advocating original intent (Munoz-Vinas page 20). Although other ideas exist, these two essentially form a spectrum along which other theories seem to oscillate between. Both Lowenthal and Munoz-Vinas however present a third major treatment of relics; communication that explores adaptation of the relic. They argue that the ideas or historical content of the object is more important and should be the focus of any conservation project.

Of worthy mention are the charters of Athens and Venice, which set out guidelines that influence conservation of relics. The Wellington City Council Heritage Policy (2010), the ICOSMOS charter (2010), and Heritage New Zealand Pouhere Taonga are agencies, polices and guidelines that control, protect and advocate understanding of heritage, heritage itself and work on heritage. These organisations do acknowledge intangible history referring to the relic's values or ideas. However they still advocate the protection of the relic preferring minimum intervention and an exploration of preservation or restoration methods, alongside signage for communicatory purposes.

Munoz-Vinas goes on to raise an important point by quoting Daniel McGilvray who suggests that there are "only three alternatives when dealing with an existing historic resource: we can keep it, we can change it, or we can destroy it" (30). If Fort Ballance is kept then the options of restoring it as a military base or preserving it as a ruin arise. If Fort Ballance is demolished, the history of the city's military defence systems would remain in historic sources and at the very least Te Mahanga Pa won't be fully concealed, although its form will not reappear. Fort Ballance could also undergo change, it could undergo metamorphosis, allowing people to engage with the past. Rather than suggesting that the past is being conserved through the preservation or restoration of a relic, 
the thesis suggests that the past can be communicated through the development of a site. Why and who for will be discussed further in the conclusion although how a relic can be adapted will be explored in project two, and discussed in the following sections. The six following case studies explore how an intervention could relate to a relic. The Metamorphic design method allows a site to change so the past is communicated, along with a treatment of the relic.
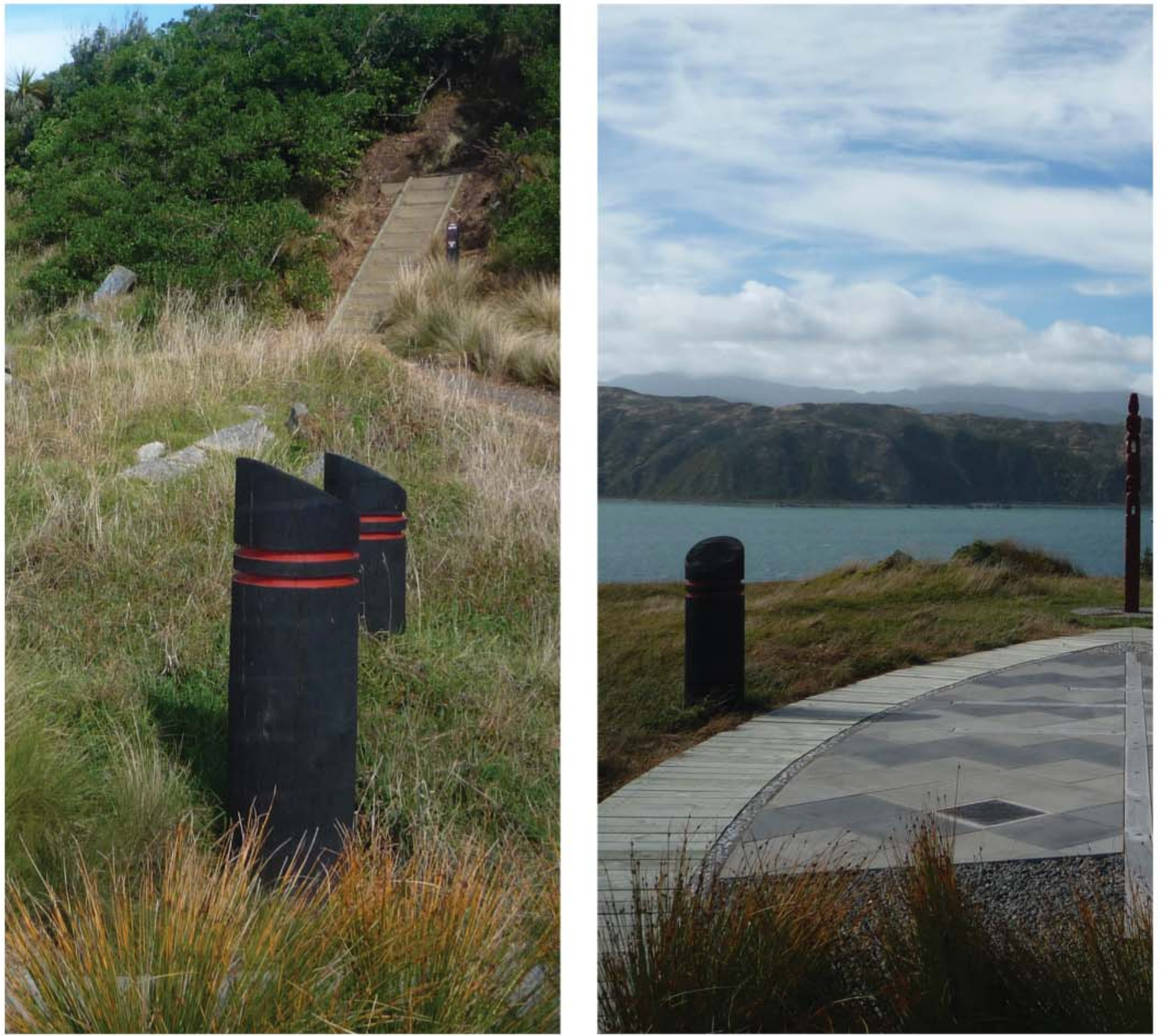

[FIG 6.I] phot 


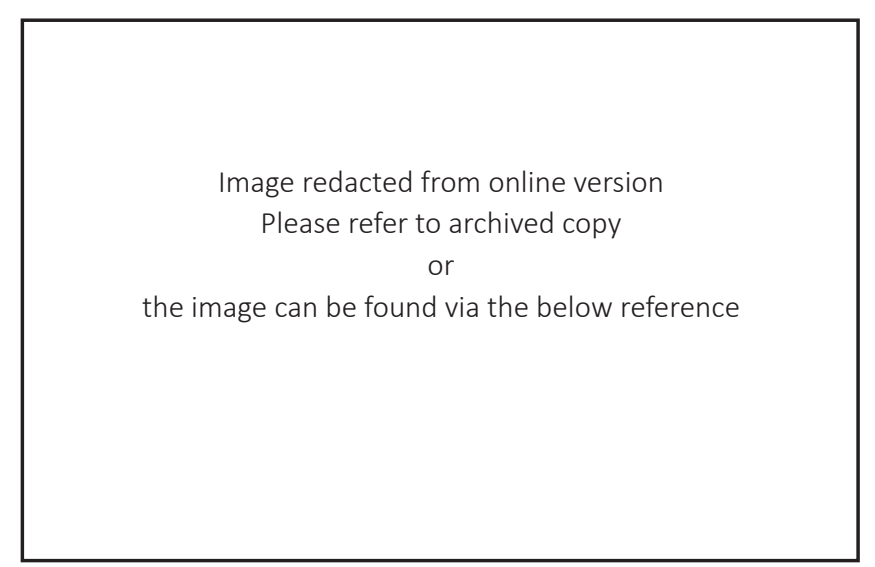

[FIG 6.II] the Higgins Hall by Steven Holl

SOURCE: Bollack page 151

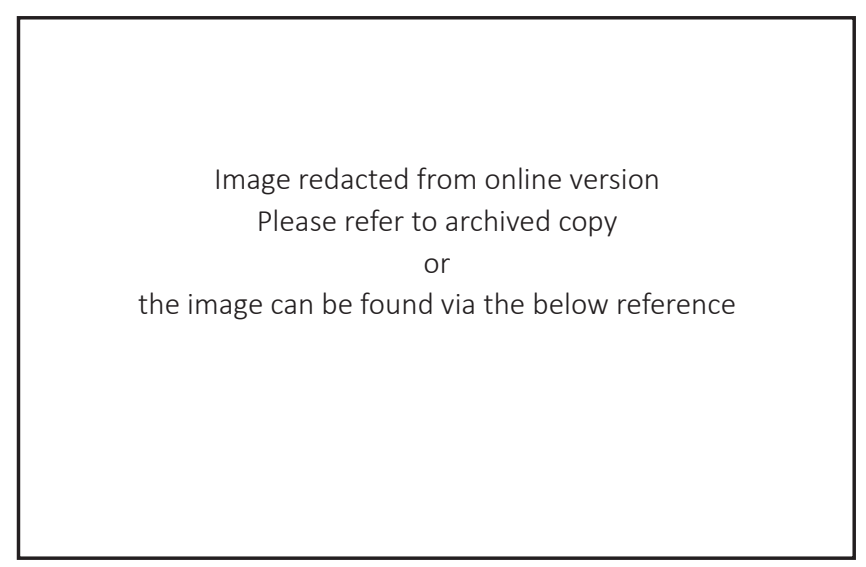

[FIG 6.VI] the Bridge of Aspiration by Wilkinson Eyre Architects

SOURCE: Bollack page 167

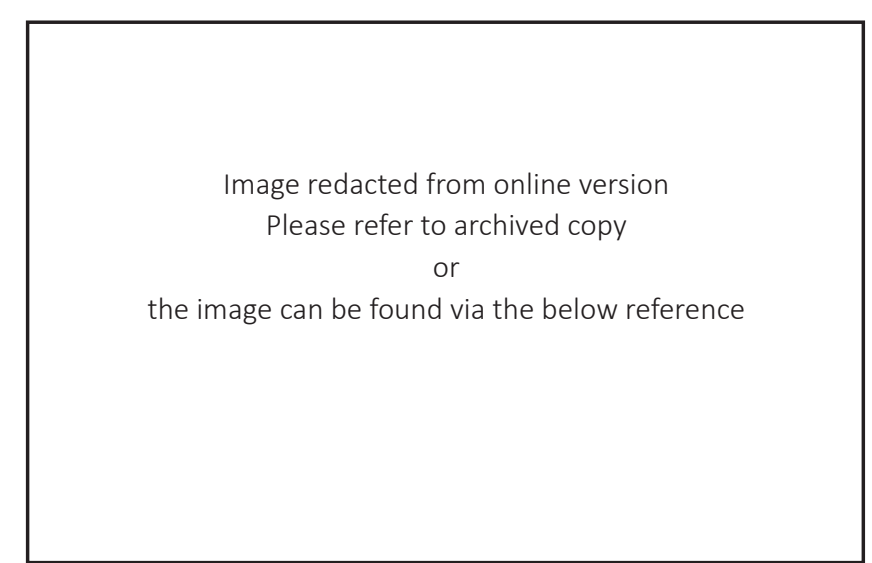

[FIG 6.III] the Higgins Hall by Steven Holl

SOURCE: Bollack page 153

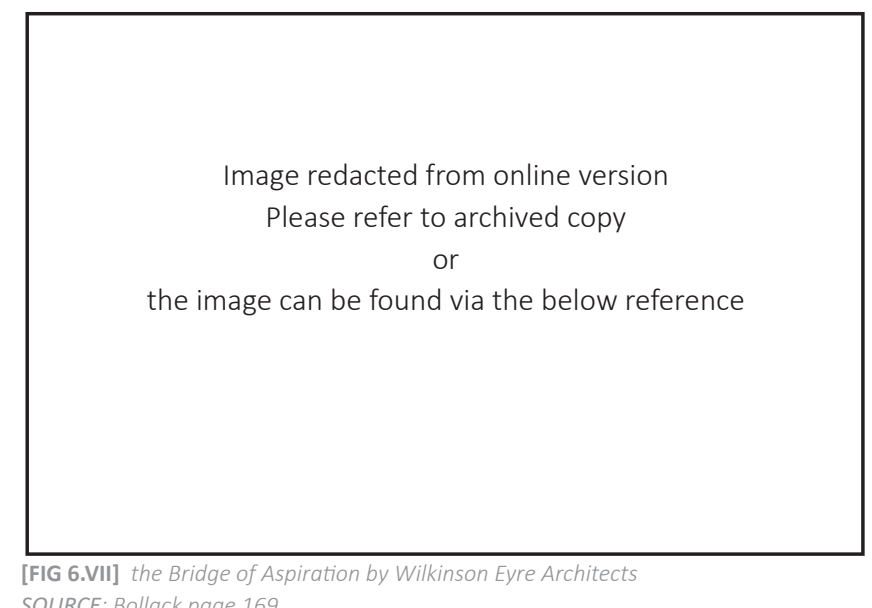

SOURCE: Bollack page 169

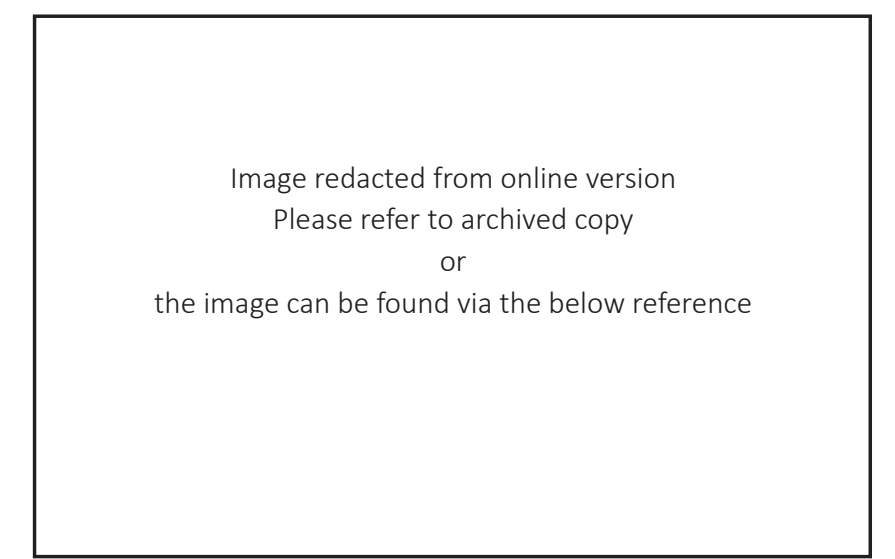

[FIG 6.IV] the Higgins Hall by Steven Holl

SOURCE: Bollack page 153

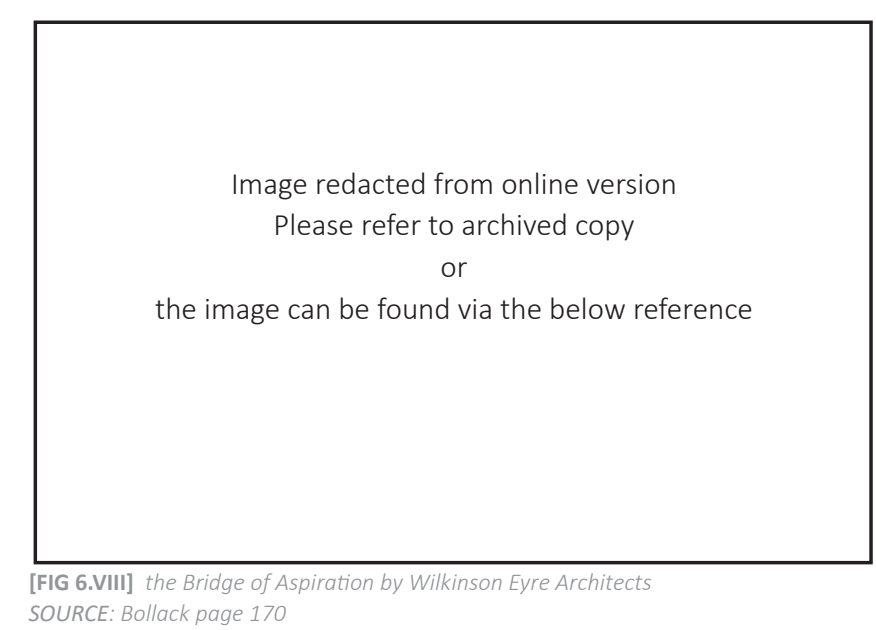

SOURCE: Bollack page 170 
Image redacted from online version

Please refer to archived copy

the image can be found via the below reference

[FIG 6.V] the Higgins Hall by Steven Hol

SOURCE: Bollack page 154

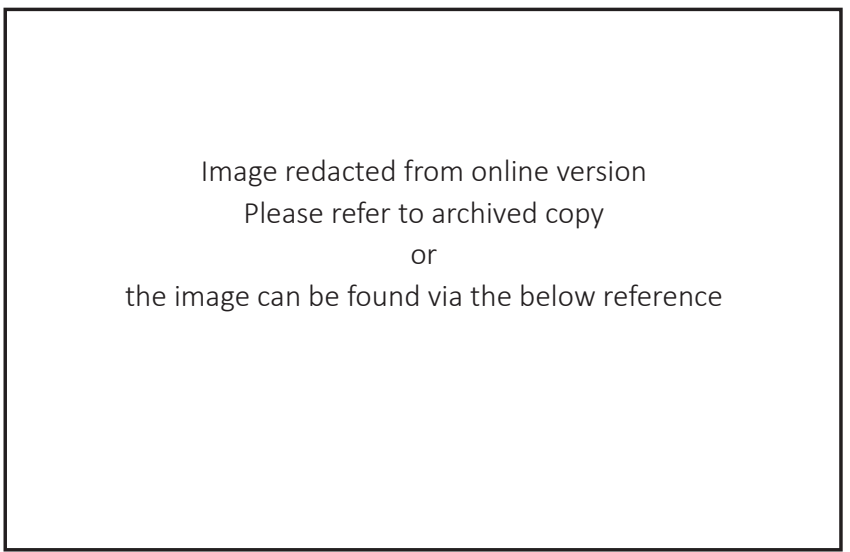

[FIG 6.IX] the Bridge of Aspiration by Wilkinson Eyre Architects

SOURCE: Bollack page 170

\subsection{Case study four and five}

If a relic is valued for its age value, then it will most likely be preserved in a state of ruin. This perspective should however not prevent a mnemonic architectural intervention from existing on the site. The process of juxtaposition would allow a new space to co-exist with a relic that has been valued for its age. The following two case studies are the Higgins Hall at the Pratt Institute in Brooklyn, New York by Steven Holl Architects and the Royal Ballet School Bridge of Aspiration in London by Wilkinson Eyre Architects. Both the bridge and hall are new interventions that juxtapose against an existing fabric. Although they are not juxtaposing against a ruin, they are relevant as they display how an intervention could integrate itself into a site and interact separately with an existing building.

The site of the Higgins Hall was gutted by a fire in 1996 with the loss of a central complex that connected what still remains of two Romanesque buildings constructed in the early second half of the nineteenth century by two different architects. Steven Holl designed a light, transparent structure that juxtaposes against the heavy solid facades of the existing building (figures 6.2 to 6.5 ). The addition expressed the differing floor levels of each building and reaffirmed the function of the new building as a connecting area between the two buildings (Bollack 150).

The Bridge of Aspiration connects two buildings, The Royal Ballet School and the Royal Opera House, dissected by a narrow street. The purpose of the bridge is to allow private access for the dancers between the two buildings and be an expression of the dancing institution. The buildings posed two problems firstly being distinct styles from one another, and secondly, the floor levels are at different heights. These issues were resolved by the juxtaposition of the bridge which creates a third and almost separate space (Bollack 166).
Typically juxtaposing buildings results in a clear separation of the new and old, although both precedents were visibly connected as a result of the site conditions, there remained a visual separation. Bollack goes onto suggest that what is characteristic of juxtaposing architecture is "an unobvious dialogue between two buildings, the original remain fully legible, no blurring of boundaries and no transfer of architectural elements" (Bollack 141). Through a means of separation, distinct or contrasting styles, materials, colours and textures Bollack suggests that "this formal separation of two worlds adds to the value of each" (Bollack 141). The ide of juxtaposing a new building against a relic is of interest as it suggests that a new building could exist on the site through a separate relationship that contrasts with the original potentially adding subtle understandings towards the past. An intervention at Point Gordon that juxtaposes against Fort Ballance, would allow the relic to be preserved in a state that shows its age value. 


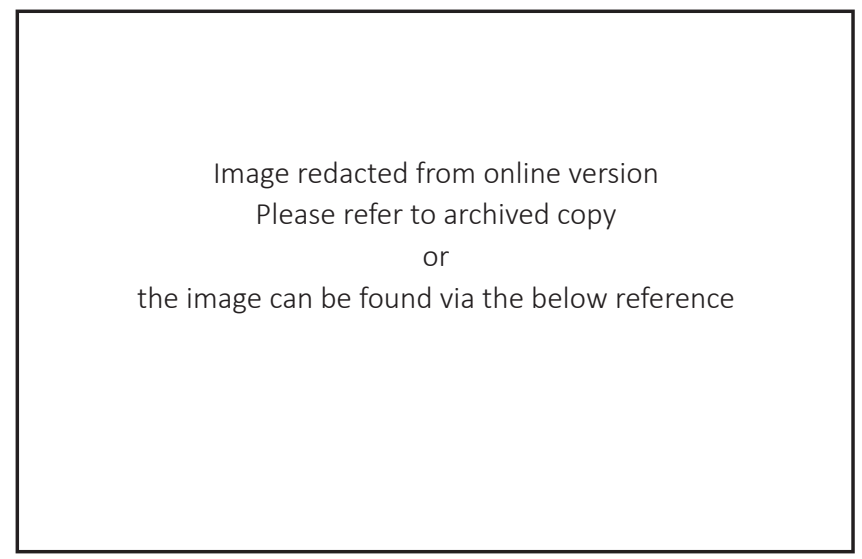

[FIG 6.X] The Mill City Museum by Meyer, Scherer and Rockcastle SOURCE: Bollack page 206

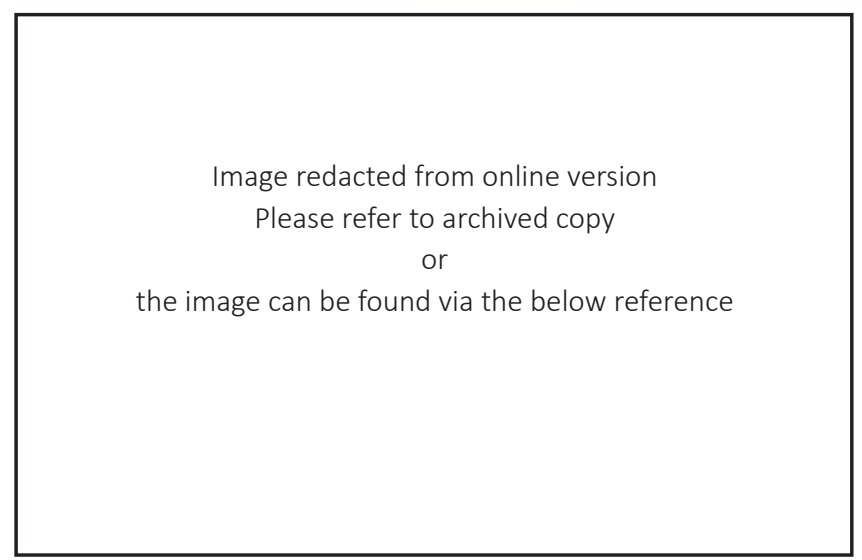

[FIG 6.XIV] The Neues Museum by David Chipperfield architects SOURCE: Bollack page 216

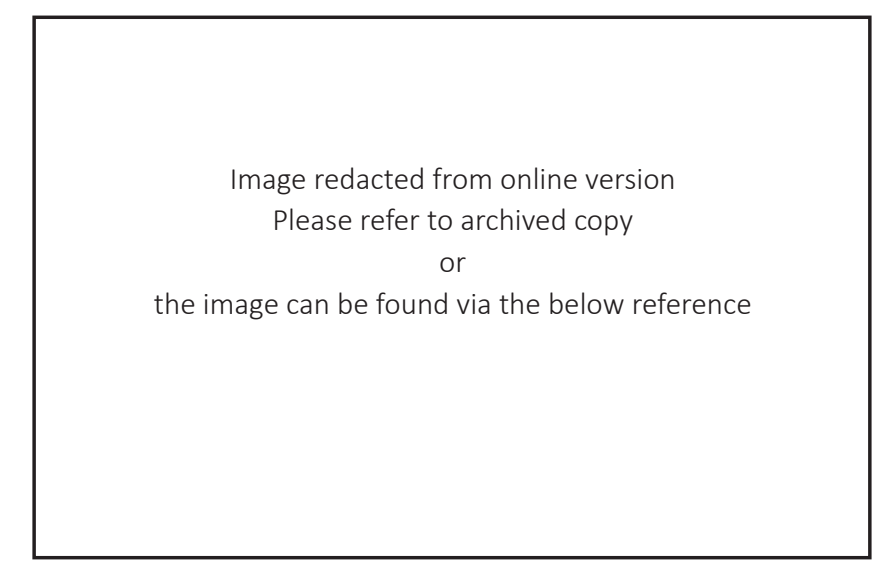

[FIG 6.XI] The Mill City Museum by Meyer, Scherer and Rockcastle SOURCE: Bollack page 208

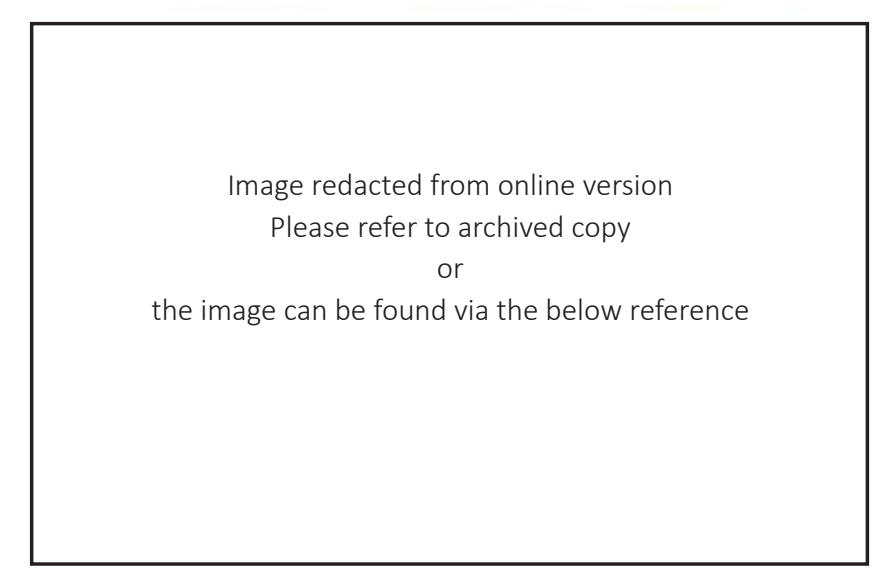

[FIG 6.XV] The Neues Museum by David Chipperfield architects SOURCE: Bollack page 21

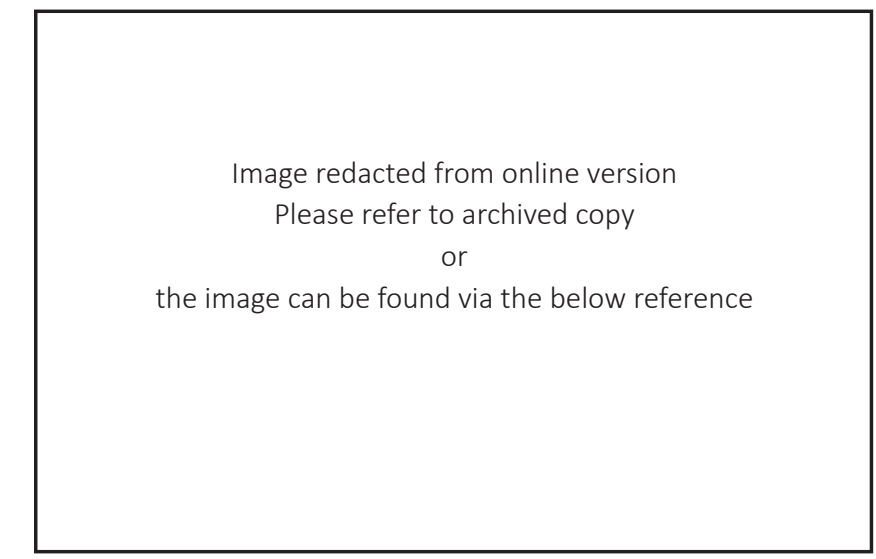

[FIG 6.XII] The Mill City Museum by Meyer, Scherer and Rockcastle SOURCE: Bollack page 209

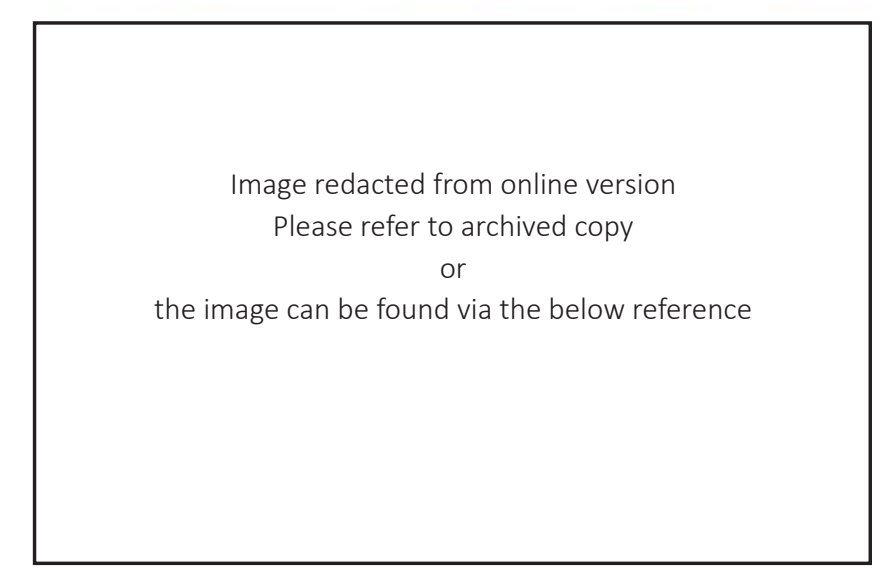

[FIG 6.XVI] The Neues Museum by David Chipperfield architects SOURCE: Bollack page 218 
Image redacted from online version

Please refer to archived copy

or

the image can be found via the below reference

[FIG 6.XIII] The Mill City Museum by Meyer, Scherer and Rockcastle SOURCE: Bollack page 210

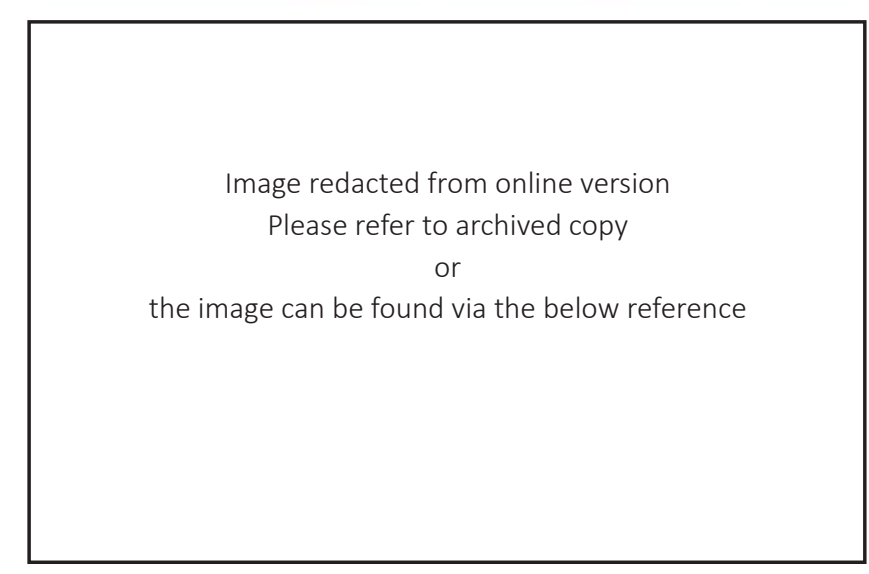

[FIG 6.XVII] The Neues Museum by David Chipperfield architects SOURCE: Bollack page 220

\subsection{Case study Six and Seven}

If a relic is valued for its original intent, then it will most likely be restored. A process of restoration has developed from returning a relic back into its original state to a more suggestive approach. This approach replaces missing or damaged pieces with distinguishable elements that can be read as new but allow the relic to be understood, as it once was. A process of weaving would allow a mnemonic intervention to suggest what Fort Ballance may have looked like, valuing the relic for its original intent. The following two case studies are the Mill City Museum in Minneapolis, Minnesota by Meyer, Scherer and Rockcastle and the Neues Museum in Berlin, by David Chipperfield architects. Both are examples of how a relic can be restored by weaving new spaces into and around the existing fabric.

The Mill Museum was previously the Gold Medal Flour Mill designed by C.C. Washburn in 1874 until it was closed down in 1965. The mill was burnt down in 1991 and three years later the ruinous site was selected to be the home for a new city development and the construction of a museum started soon after. By weaving into the existing fabric there is a clear distinction between the old and new. The design recreates what spaces may have physically been like. This allows an inhabitant to read the building in its existing deteriorated state, its original state and enable the occupant to distinguish what is new (Bollack 204).

The Neues Museum was devastated by severe bombing during War World Two. Bollack quotes David Chipperfield who explains that "(the Neues Museum was)... a new building from the remains of the old, a new building that neither celebrates nor hides its history but includes it. A new building that was made of fragments or parts of the old but once again conspiring to completeness" (214). The design is seen as a new building that values the building for its age value, but allows the site to be occupied.
An intervention could be integrated into the site by weaving into Fort Ballance, allowing it to be read as a military base and although separate from the intervention, both the relic and the mnemonic device would be blurred forming a single experience though the parts are disguisable. The fort will be treated as historic document and the intervention will allow a reading of its original state and its weathered state. 


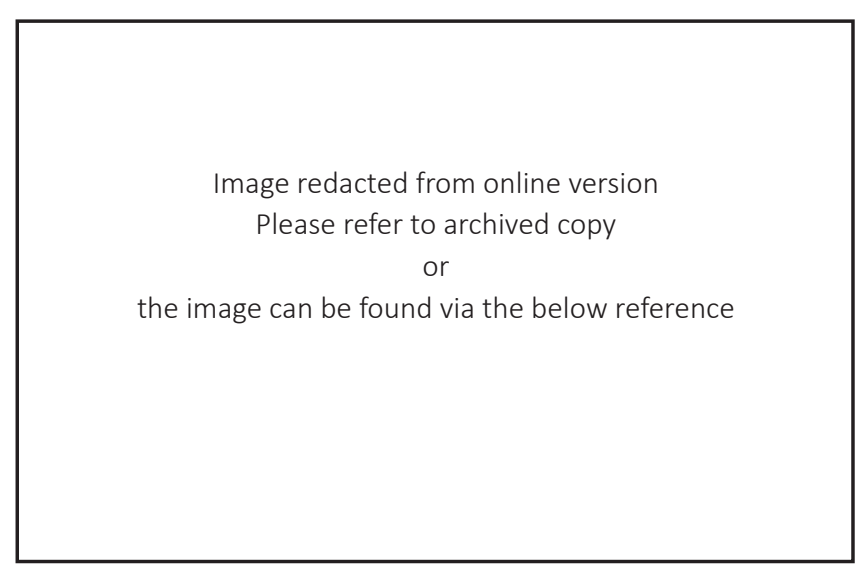

[FIG 6.XVIII] The Santa Caterina Market by Enric Miralles and Benedetta Tagliabue SOURCE: Bollack page 128

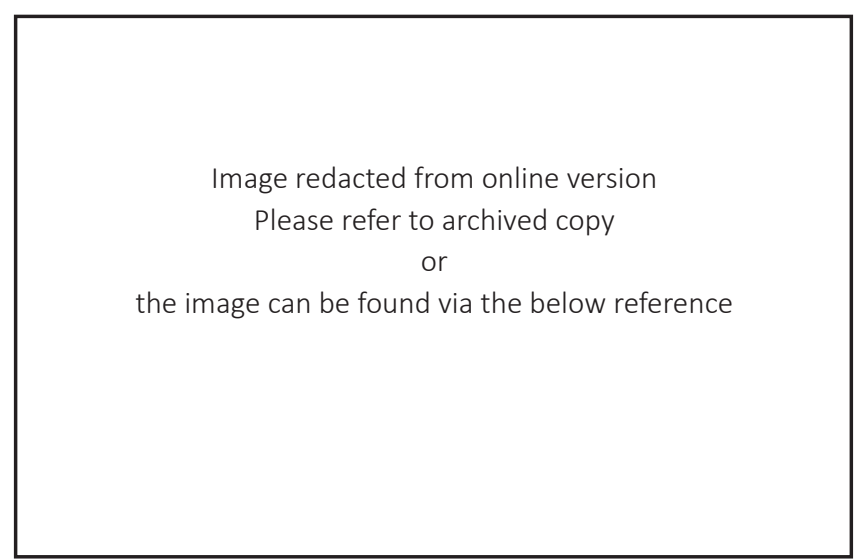

[FIG 6.XXII] The Wohlfahrt-Laymann House by Meixner, Schulter, Wendt architects SOURCE: Bollack page 135

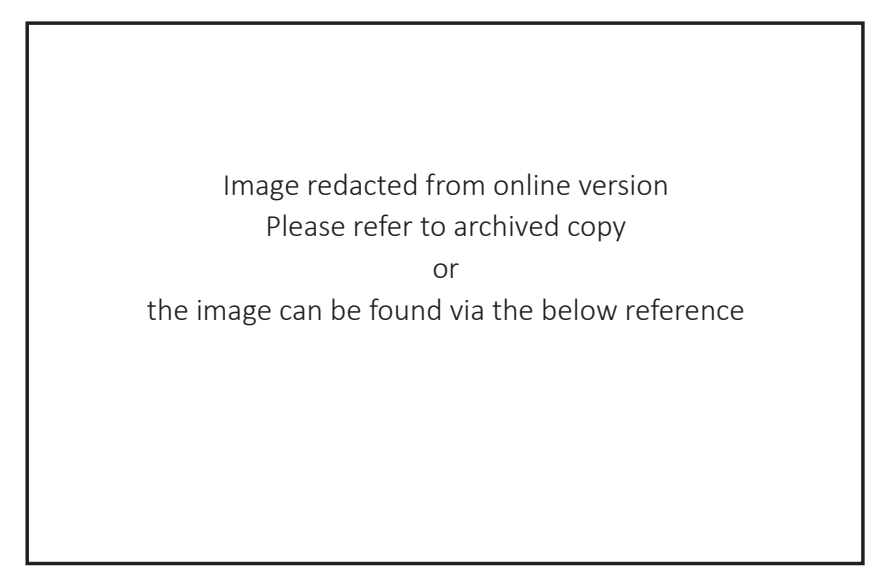

[FIG 6.XIX] The Santa Caterina Market by Enric Miralles and Benedetta Tagliabue SOURCE: Bollack page 128

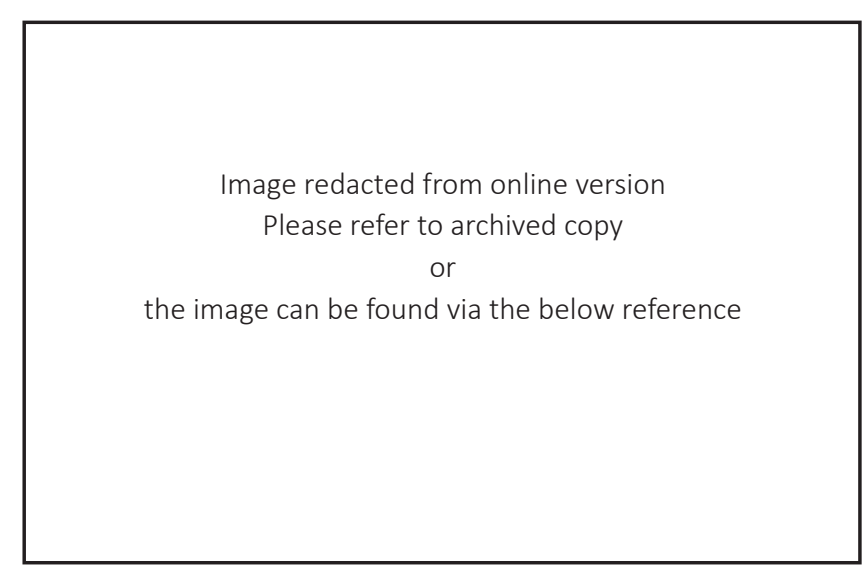

[FIG 6.XXIII] The Wohlfahrt-Laymann House by Meixner, Schulter, Wendt architects SOURCE: Bollack page 13

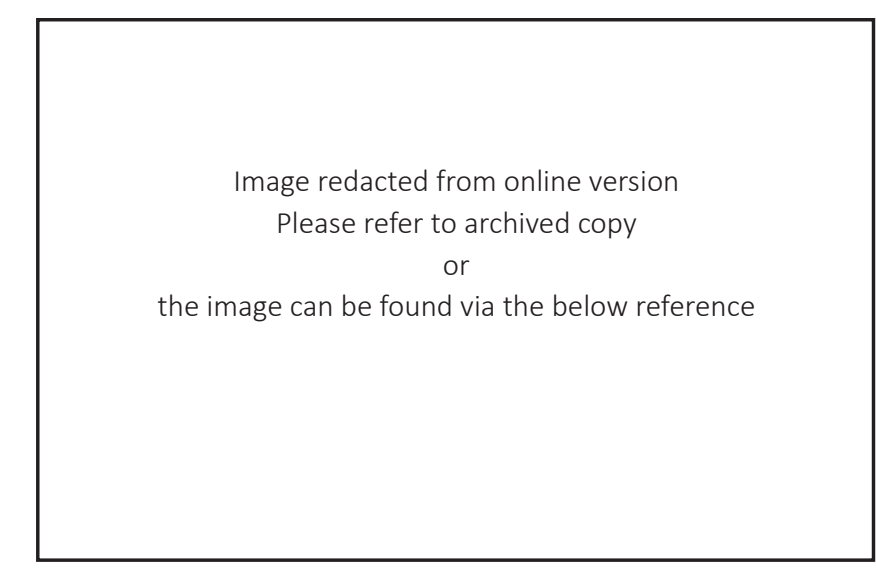

[FIG 6.XX] The Santa Caterina Market by Enric Miralles and Benedetta Tagliabue SOURCE: Bollack page 132



[FIG 6.XXIV] The Wohlfahrt-Laymann House by Meixner, Schulter, Wendt architects SOURCE: Bollack page 138 
Image redacted from online version

Please refer to archived copy

the image can be found via the below reference

[FIG 6.XXI] The Santa Caterina Market by Enric Miralles and Benedetta Tagliabue SOURCE: Bollack page 132

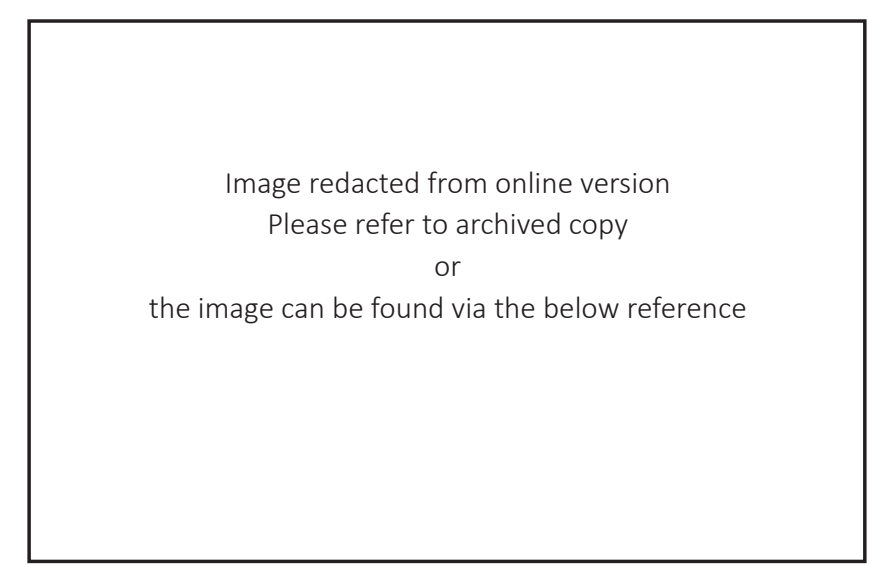

[FIG 6.XXV] The Wohlfahrt-Laymann House by Meixner, Schulter, Wendt architects SOURCE: Bollack page 138

\subsection{Case study Eight and Nine}

If a relic is valued for its historical intent then it could be reused or adapted to serve in a similar fashion. Just as the mnemonic intervention focuses on linking the past through

a programme, so to would adapting a relic. This process would allow the relic to be used for contemporary needs that are comparable to those that the relic once served. Fort Ballance as a harbour defence could now be adapted to suit a programme that also defended the harbour such as a fisheries headquarters. The following two case studies are, the Wohlfahrt-Laymann house in Frankfurt Germany by Meixner, Schluter, Wendt Architects and the Santa Caterina Market in Barcelona, Spain by Enric Miralles and Benedetta Tagliabue architects. These examples are of how an intervention could wrap over the relic adapting it for a similar use. Although both case studies do not discuss historic content of the existing fabric they do provide an insight into how a building could be adapted so as to express the historical content.

The Wohlfahrt-Laymann house in Frankfurt, Germany constructed between 2004 and 2006 saw the adaptation of a 1930s house. The designers from Meixner, Schluter, Wendt Architects decided against building a new building and opted to increase space and energy efficiency by extruding out from the existing building and using it as a starting point for a design project. By wrapping around the existing building the architects kept it but created a new space. People are reminded of the old house through fragments that are displayed. The programme is kept, and so is the house itself, though it is now read differently. The market similarly creates a new space where voids are created between the new and the old forming an interesting reading of the existing fabric.

Wrapping will allow an intervention to change Fort Ballance to such a degree that it is still recognisable but is understood in relation to the intervention and the past. Fort Ballance will not be preserved or restored but will form the basis of an adaptation. The fort will be a starting point from which further spaces are extruded and added.

\section{5 metamorphism design method}

The metamorphic design method acknowledges the relic as a valuable vestige of the past but is not deterred from developing the site. The method allows the site to be used in relation to the relic with emphasis on an understanding and communication of the past. The understanding of a site's past and its meaning to individuals or communities is considered of the most value and importance. While whakapapa, korero, stories, film and art relay and inform the individual or community of the past, mnemonic interventions and relics enforce, express and remind individuals or communities of that past and our interpretation of it. The method, therefore allows a site associated with both Te Ao Tawhito and Te Ao Hou eras to be celebrated, and remembered through both a mnemonic intervention and relic. 
Project two explores the three ways a relic can be valued, age value, original intent, or historic content. Although the three schemes that make up project two, value the relic in different ways, the method of metamorphosis will allow a mnemonic intervention to exist in some way at the site and in all cases allowing the site to evoke the past within people

\section{CHAPTER SEVEN}


7.2 Project Two A: Aquarium of continuity

The intention of scheme $A$ is to explore how the analogical method can generate a spatial experience similar to the understood narrative of Te Ao Tawhito past. The next phase will explore how this intervention could be integrated into the site, where the relic's age value is of concern. The scheme will explore a metamorphic method of juxtaposition.

Figures 7.1 and 7.11 show how there are two main phases of the design process where these methods are employed. Although separate figure 7.111 reveals that the process is dynamic moving backwards and forwards between the methods.

The outcome of scheme $A$ is shown in the drawings of figure 7.IV and 7.V and the photographs of the models in figure 7.VI The scheme consists of two whare like structures that create two possible entries into the aquarium. The entrances form kainga/atea like spaces, where people can base themselves, with each of these spaces facing either Scorching Bay or Te Mahanga Bay. These spaces are separated by the aquarium which consists of three levels, two for public viewing and the other set aside for staff use. The occupants will migrate from one base to the other continually moving, backwards and forwards referencing the Maori concept of moving from bay to bay to ensure marine life is not depleted. The past of Te Ao Tawhito is evoked in people when they experience the idea of continuity and is expressed by the kainga like structures. The aquarium provides insight into the past of Te Mahanga as it reveals Maori perspectives towards the moana of the past and present.

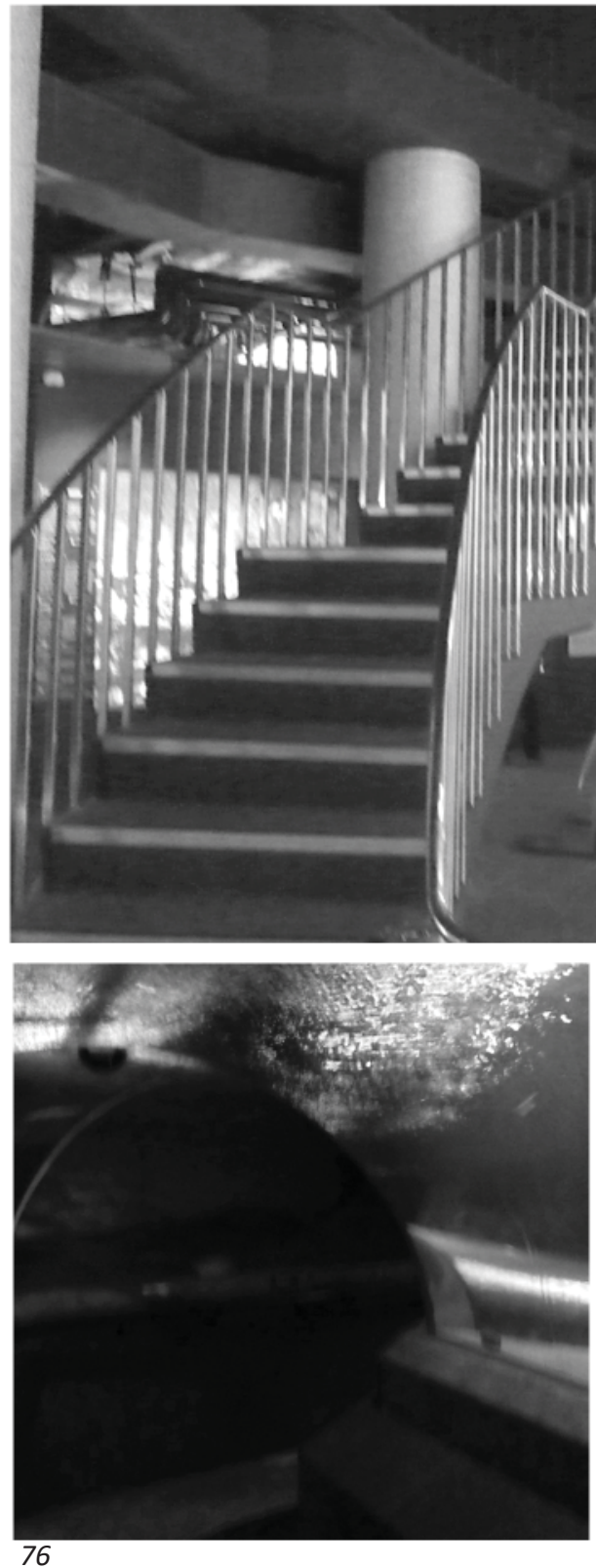

76
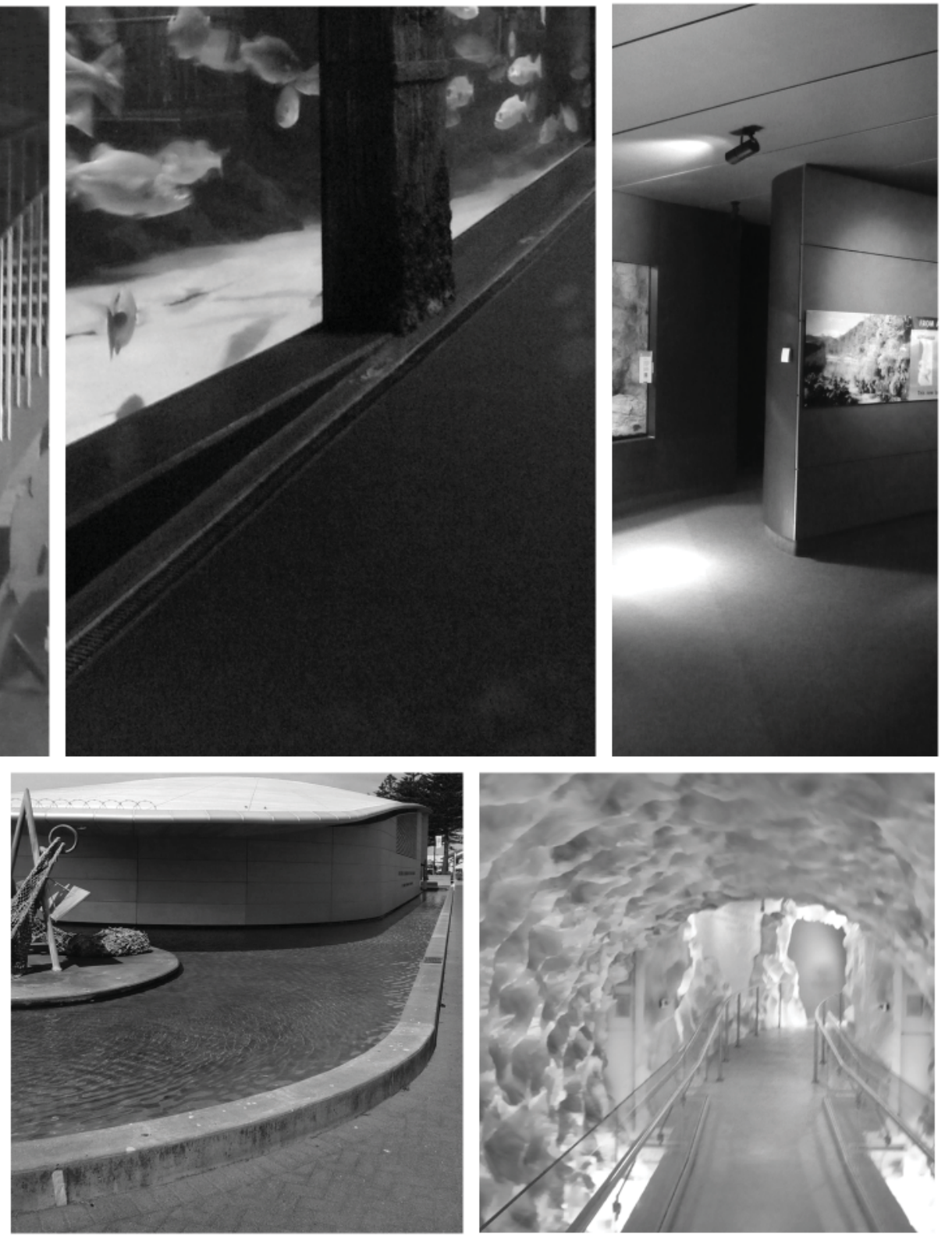

[FIG 7.I] The study of Kelly Tarlton and the Napier aquaria resulted in an analogy of the circulation SOURCE: Authors site trip 

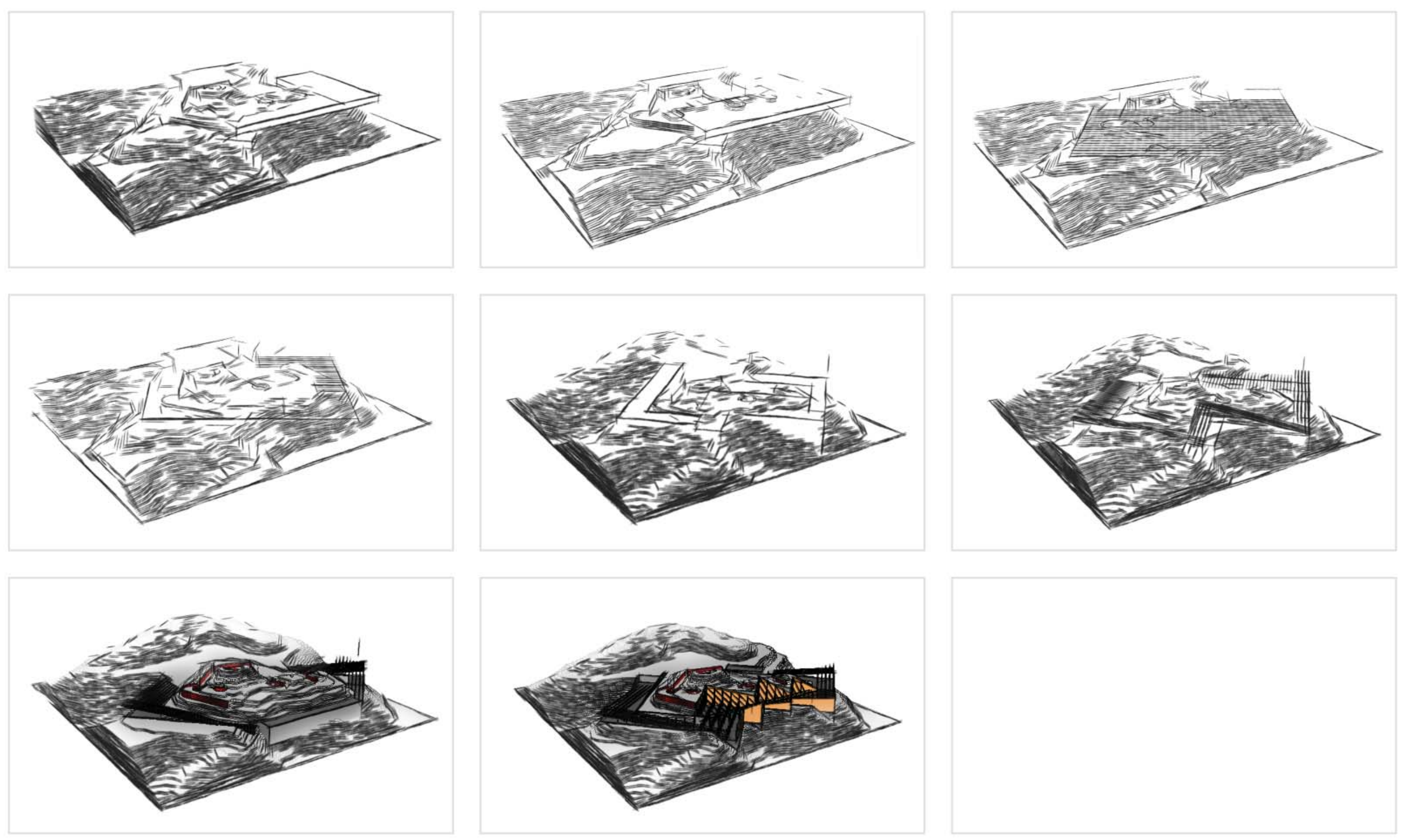

[FIG 7.III the mnemonic device is juxtaposed with the relic, the above images show an iterative process of juxtaposing the intervention with the relic

SOURCE: Authors, model on sketch up 

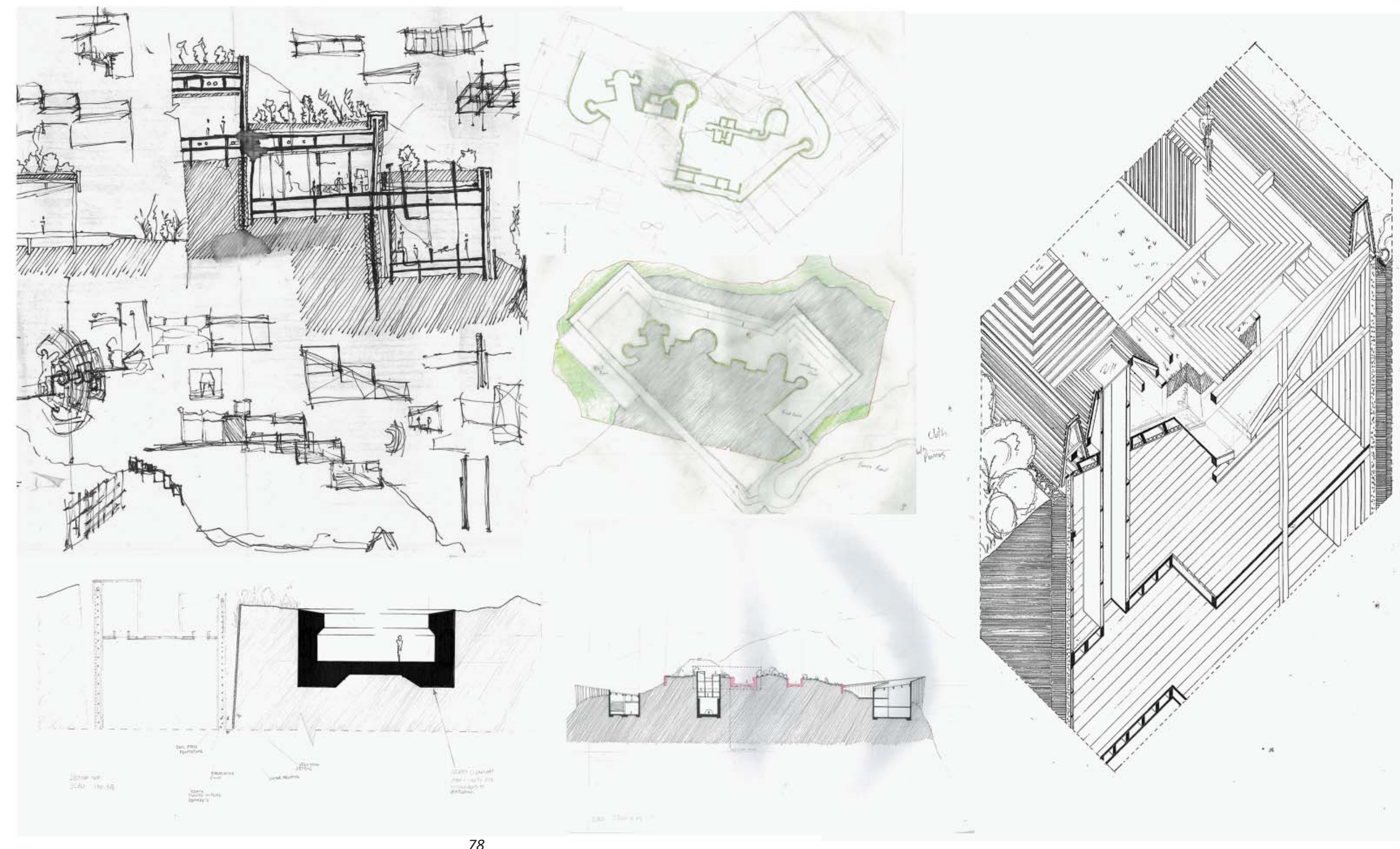


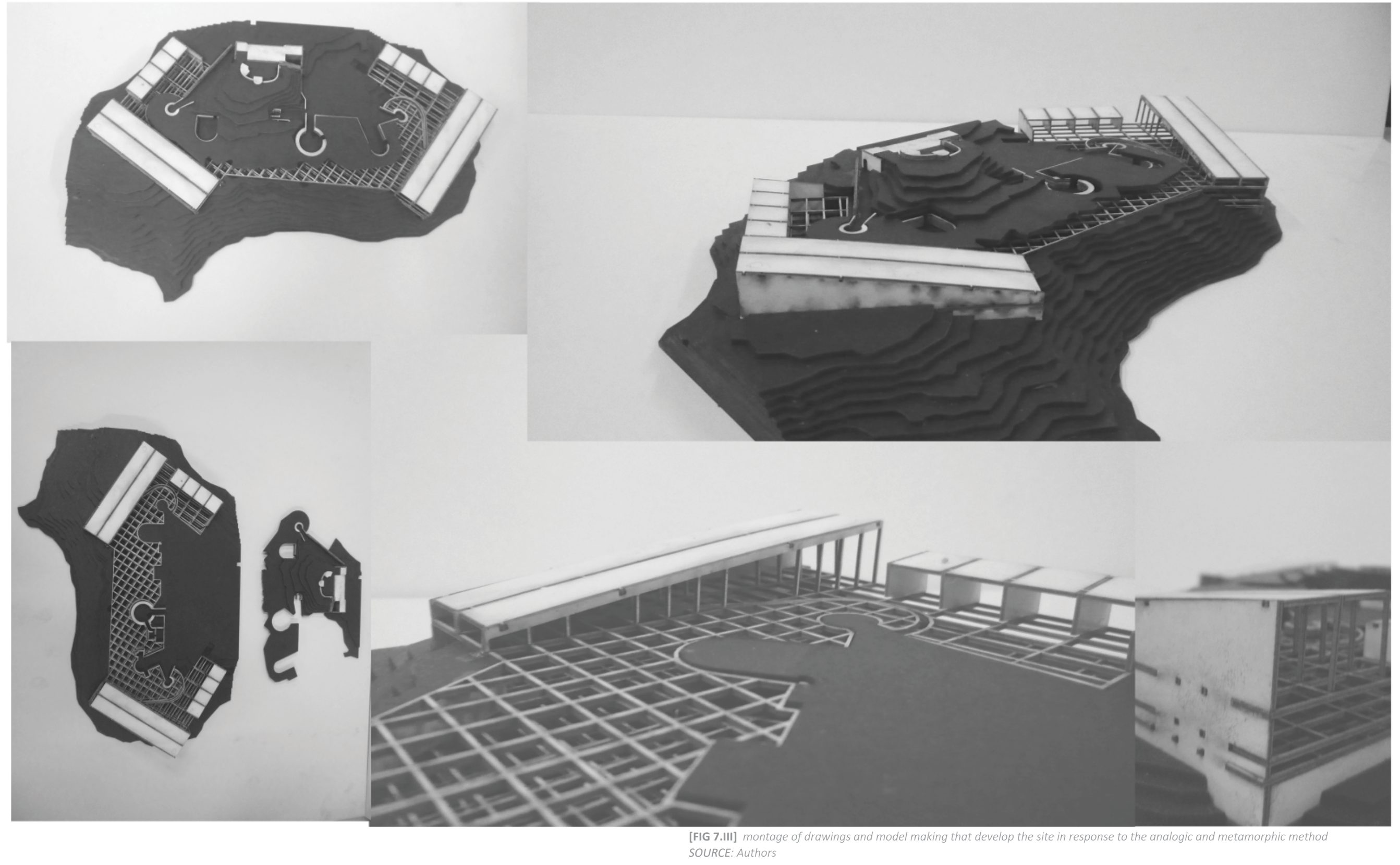



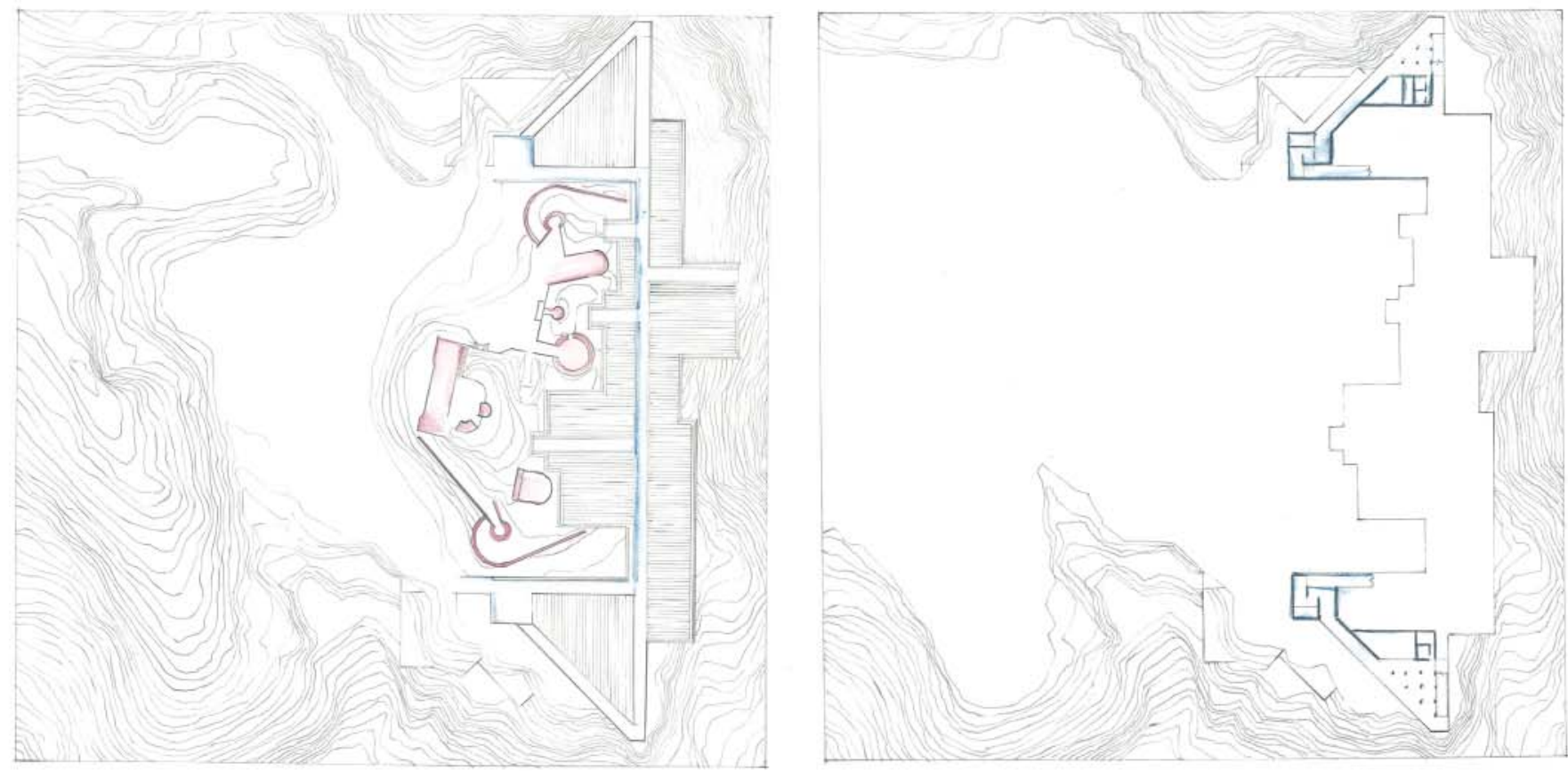

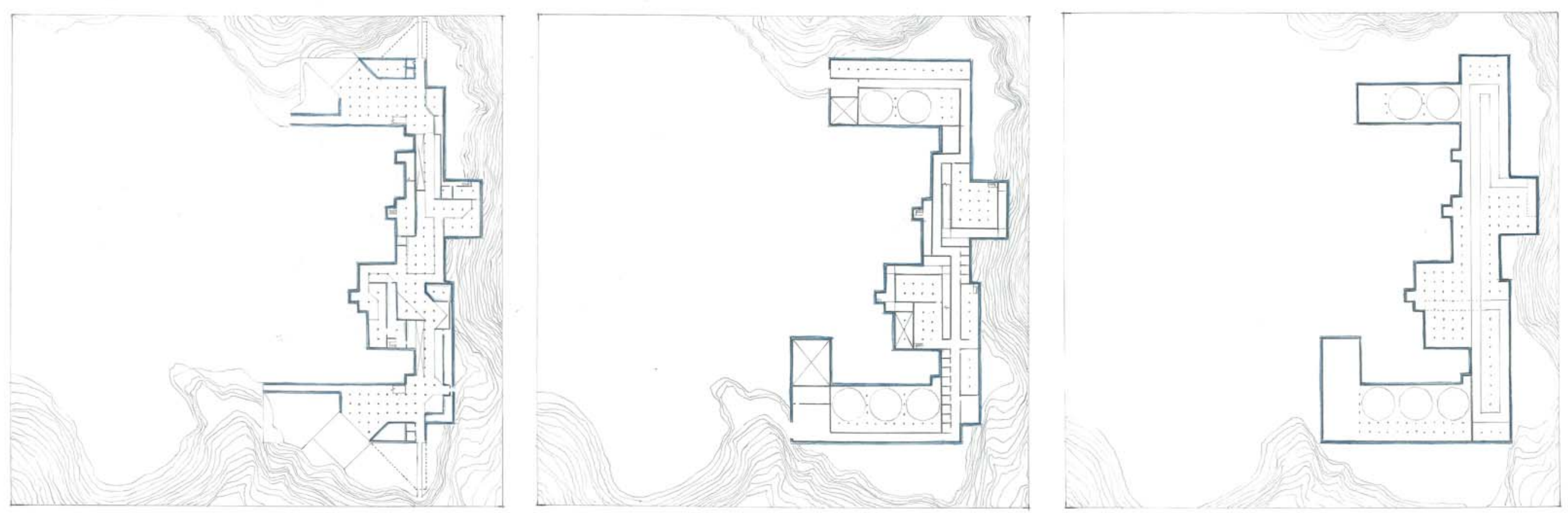


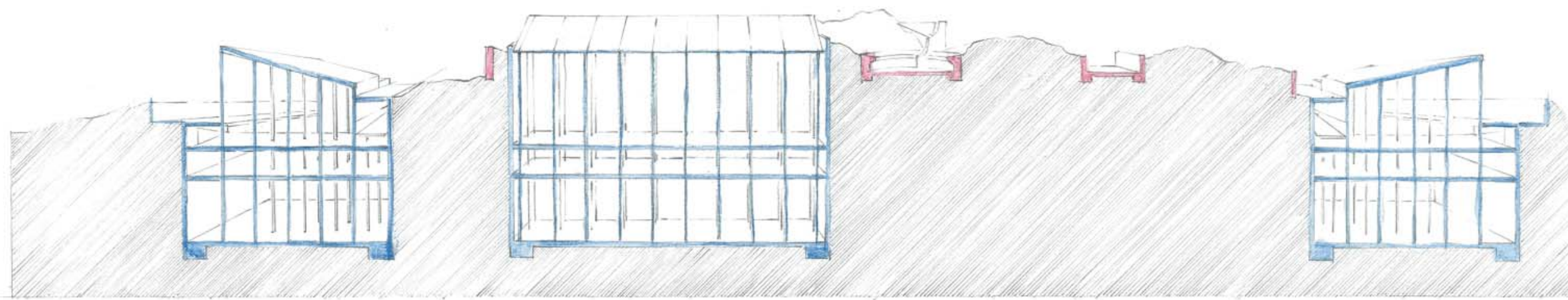




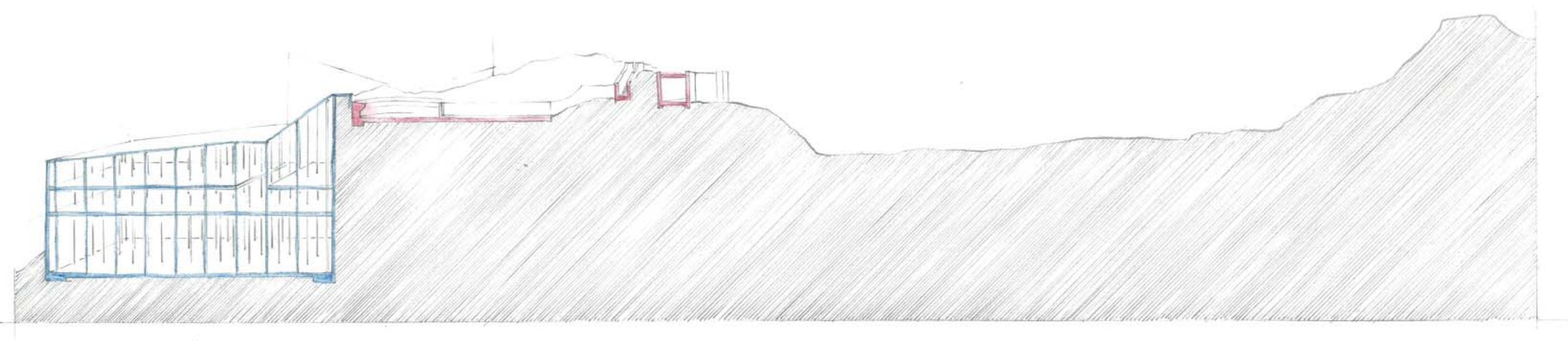



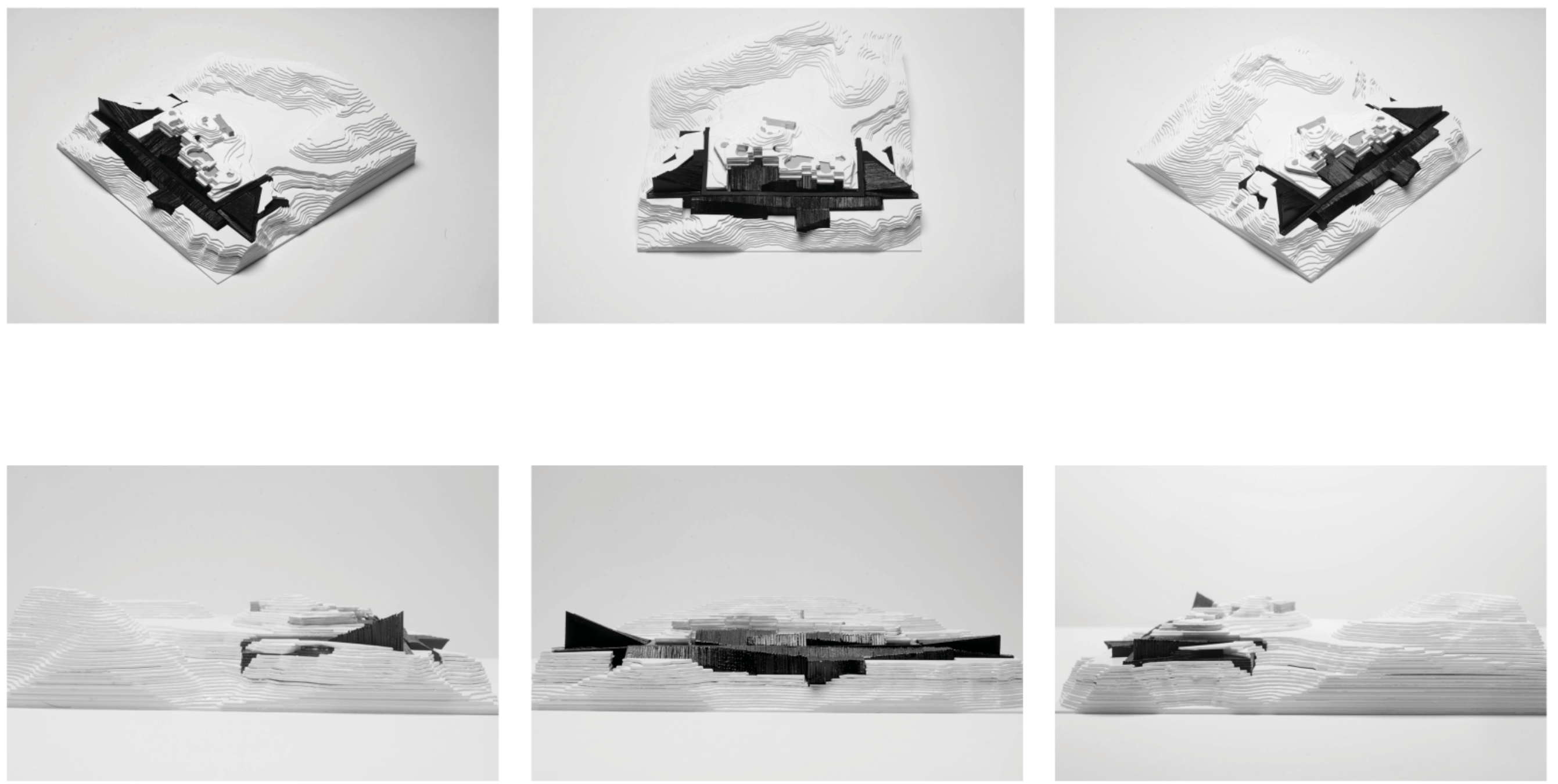

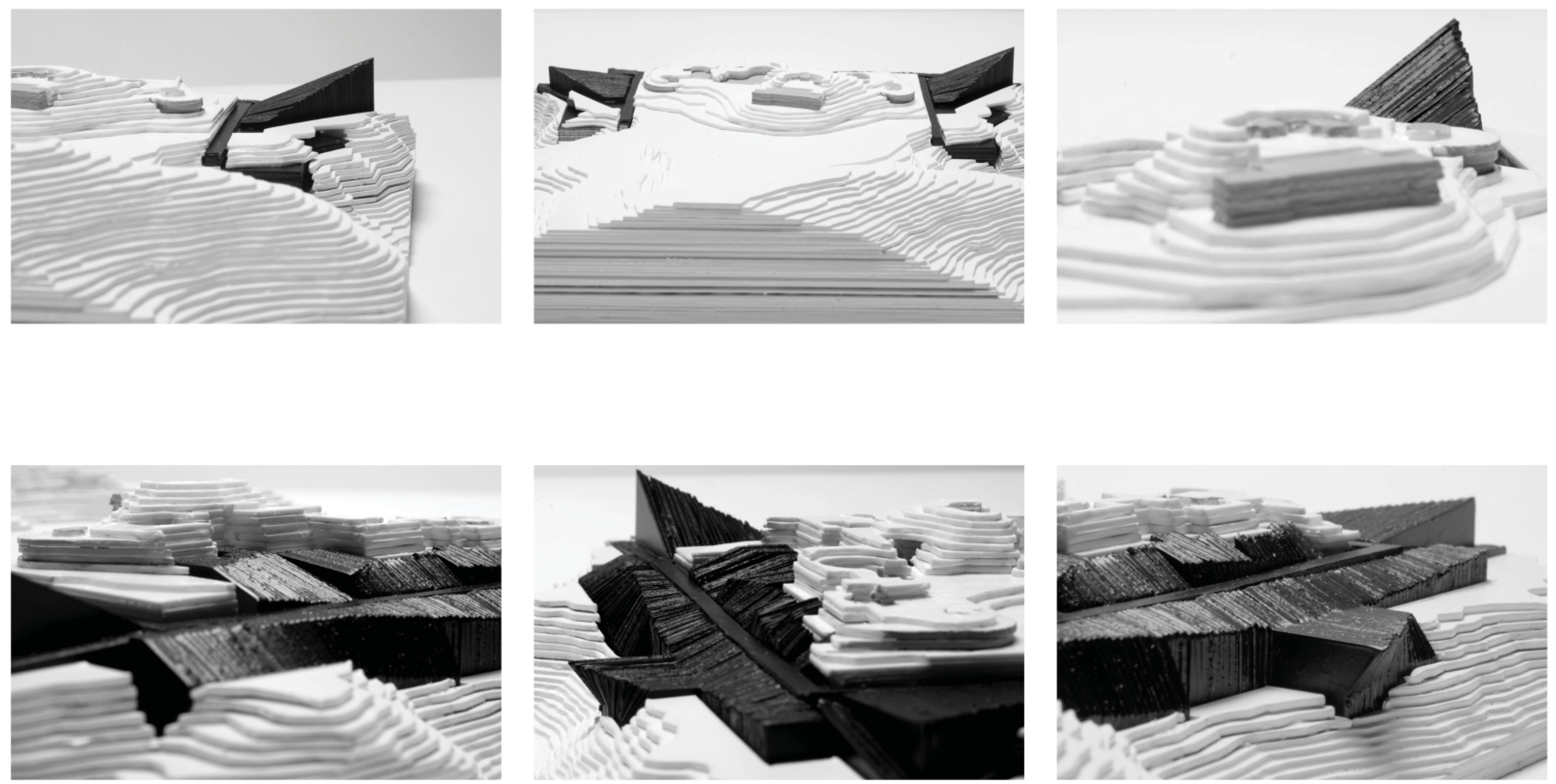


\subsection{Project Two B: Aquarium of Light}

The intention of scheme B is to explore how the analogical method can generate a literal space similar to the one understood in the narrative of Te Ao Tawhito past. This intervention will then be integrated into the site by a process of weaving. The metamorphic method allows the relic's original intent to be valued.

Just as in scheme A, figures 7.VII and 7.VIII show how there are two main phases of the design process where these methods are employed. With figure 7.IX also revealing how the process is dynamic moving backwards and forwards between the methods.

The outcome of scheme $B$ is shown in the drawings of figures 7.X and 7.XI and the photographs of the models in figure 7.XII. The scheme consists of three large terraces that weave into the site and the relic. The earth where Maori once dug into and built on is treated as historic and the glass facade which mimics the form of terracing also encases earth like terracing. Visitors to the site will be greeted by these glass facades which literally resemble terracing. The visitor is introduced to the layers of the past from the present (Aquarium) to Te Ao Hou (Fort Ballance) to Te Ao Tawhito (Te Mahanga). Lighting is an important part of aquarium design and is linked to the idea of how Maori knowledge comes from the darkness. Visitors are led to the bottom level, in darkness and as people circulate back upwards through the levels, so to does the lighting increase. This play on light provides an insight into the place possibly where and how ideas were learnt and remembered. Te Ao Tawhito is also expressed by the glass terracing.

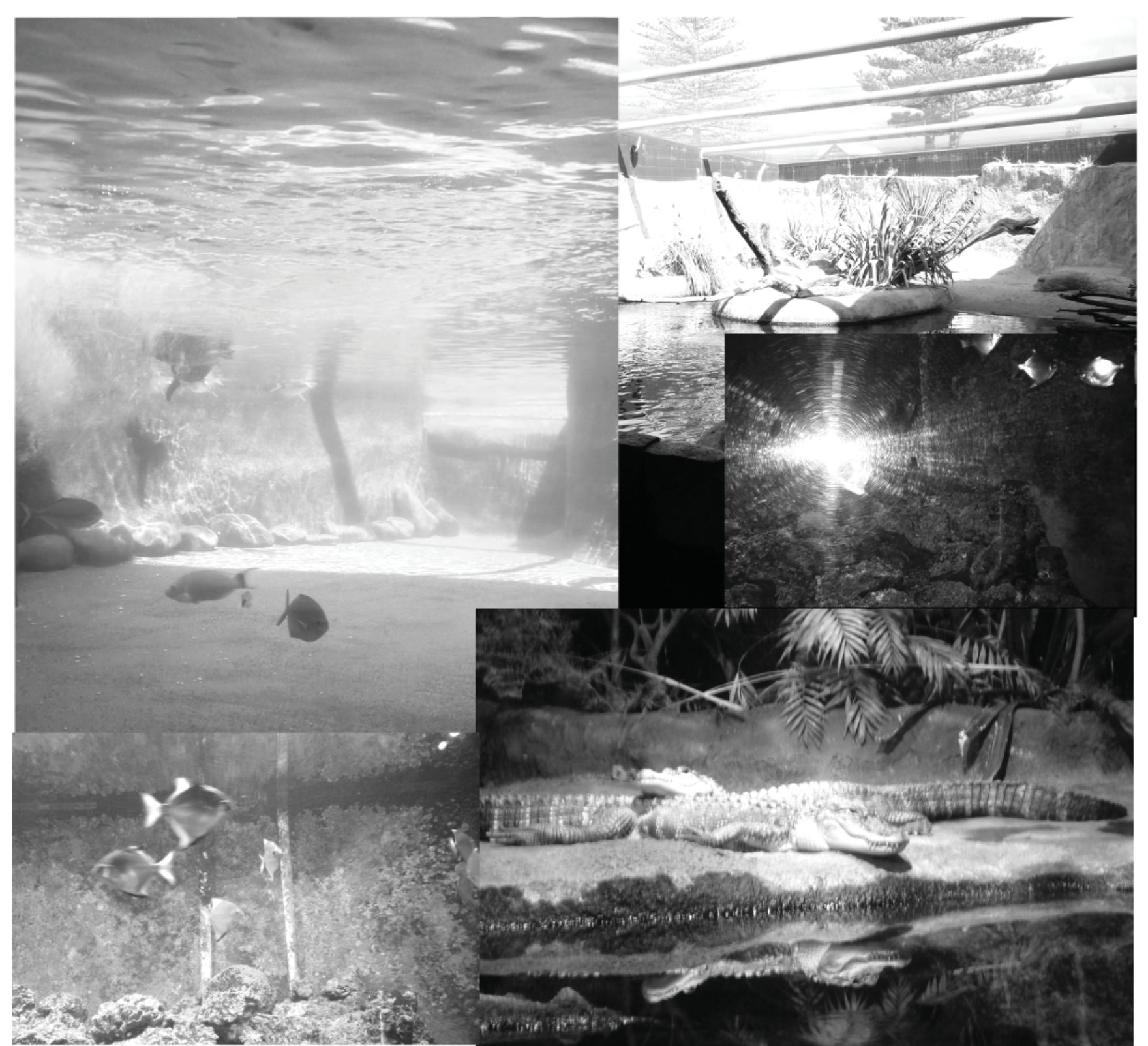



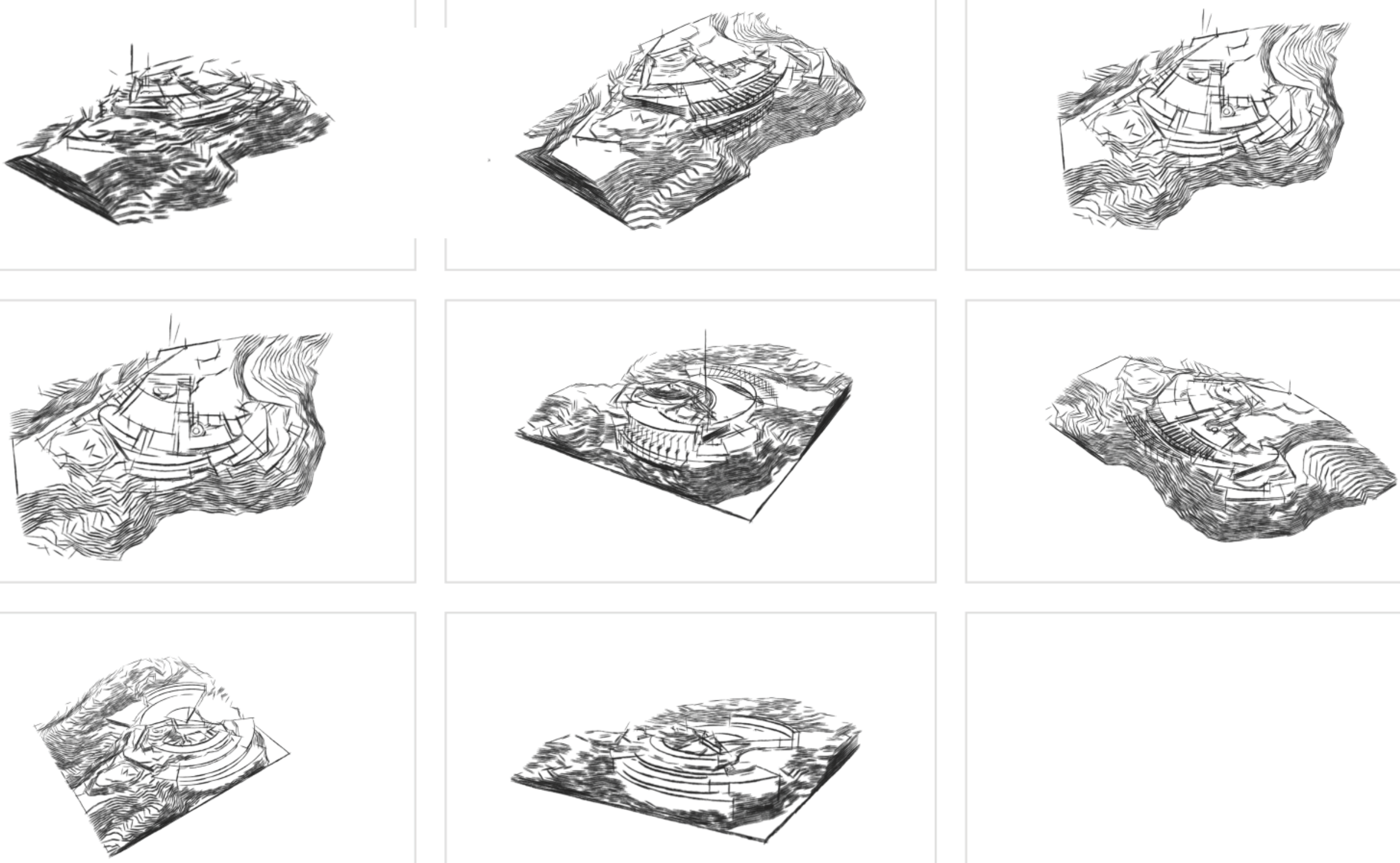


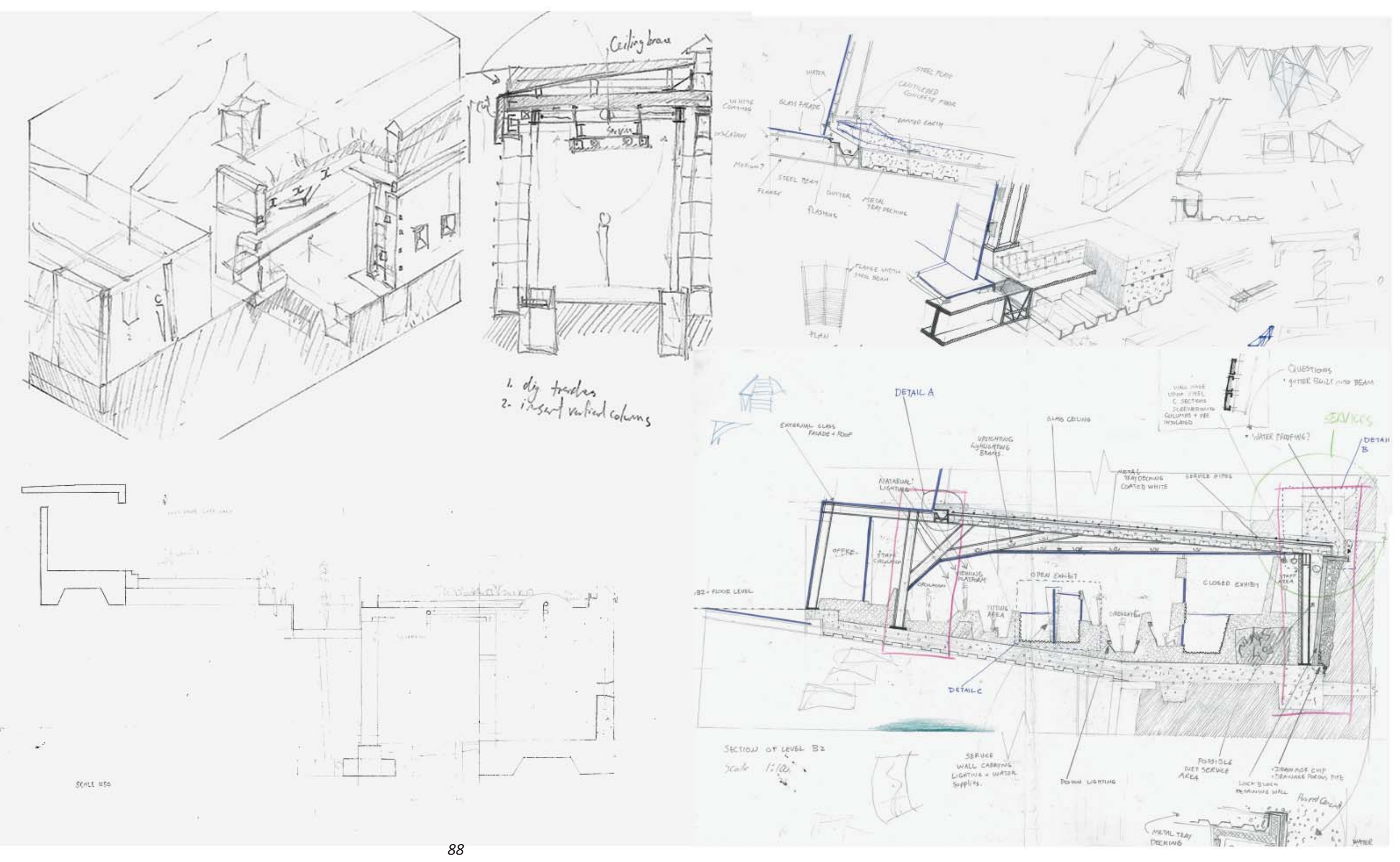



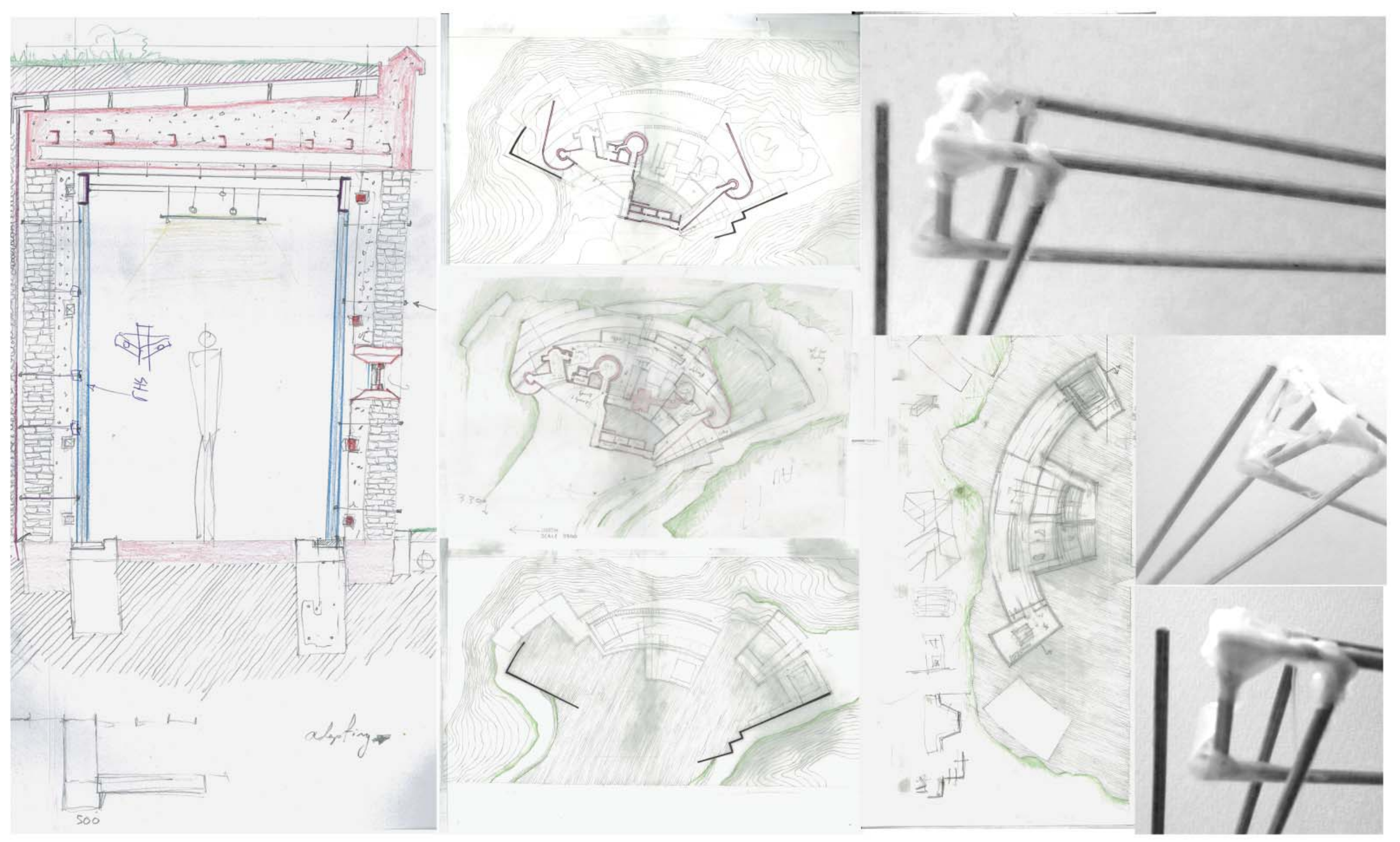

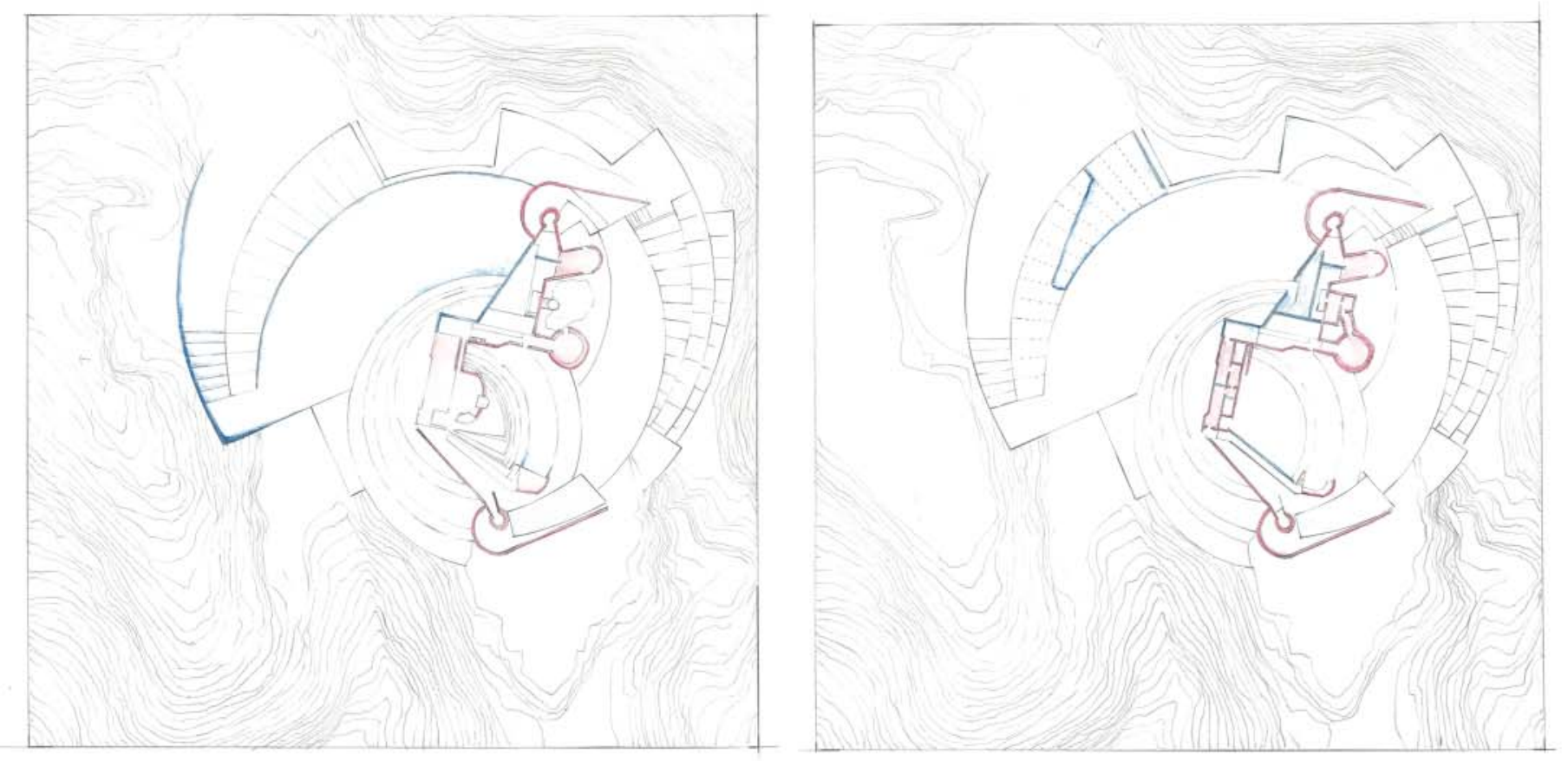

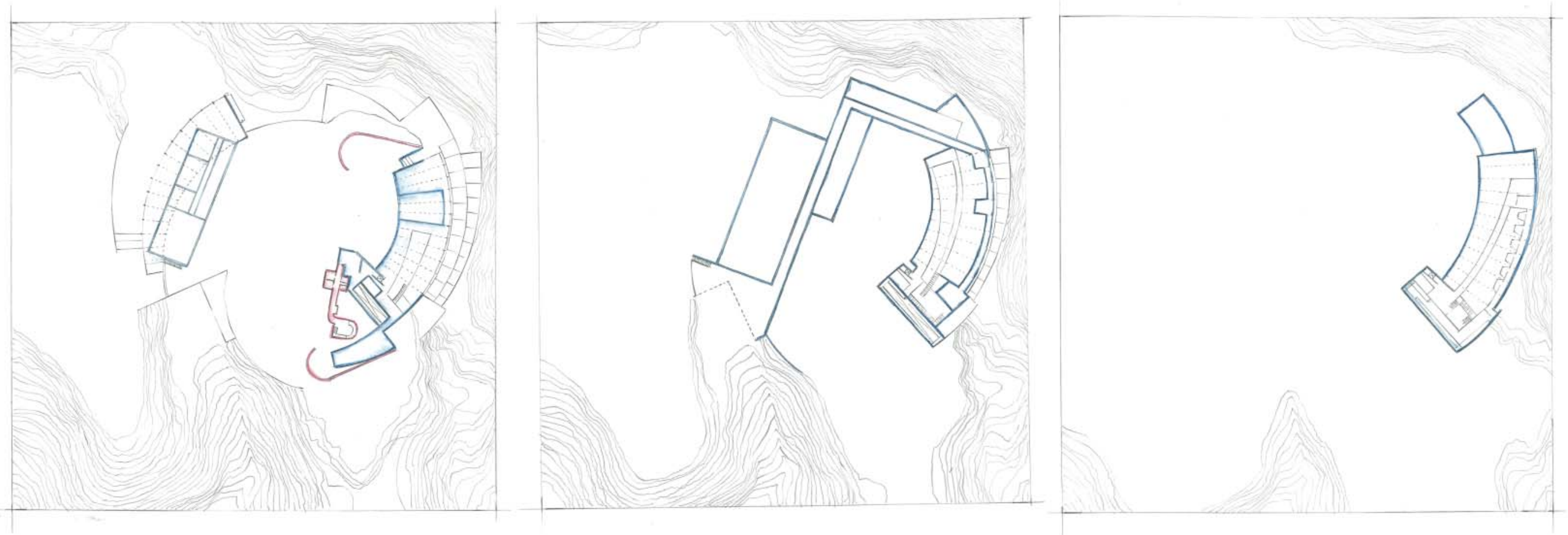


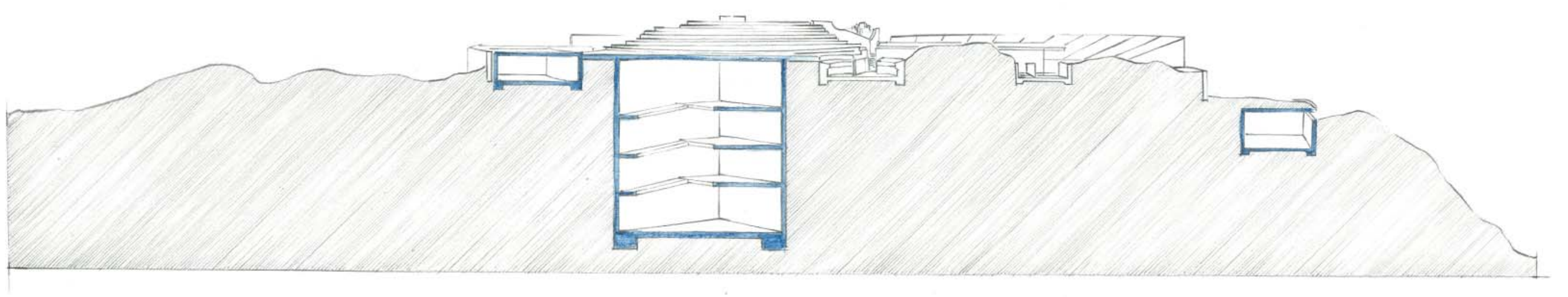




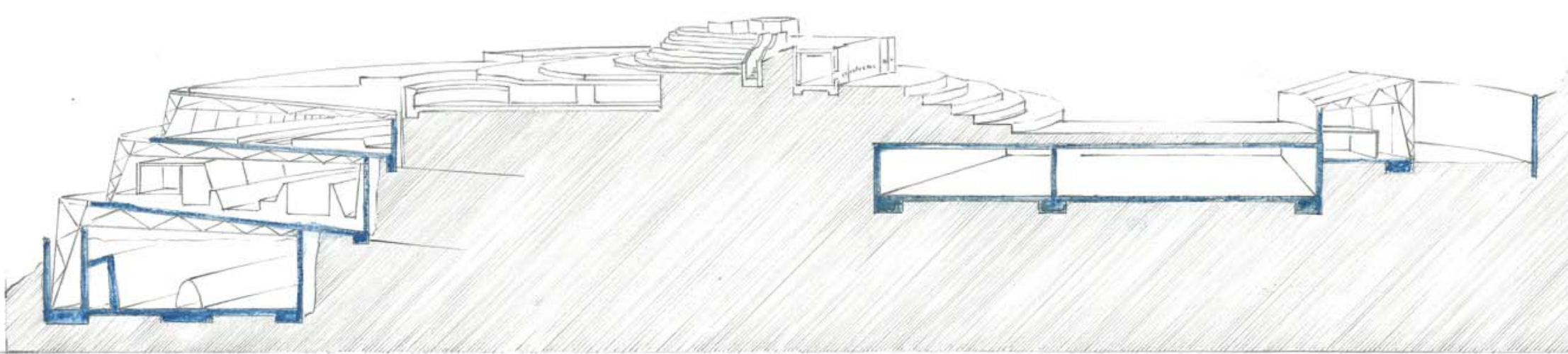



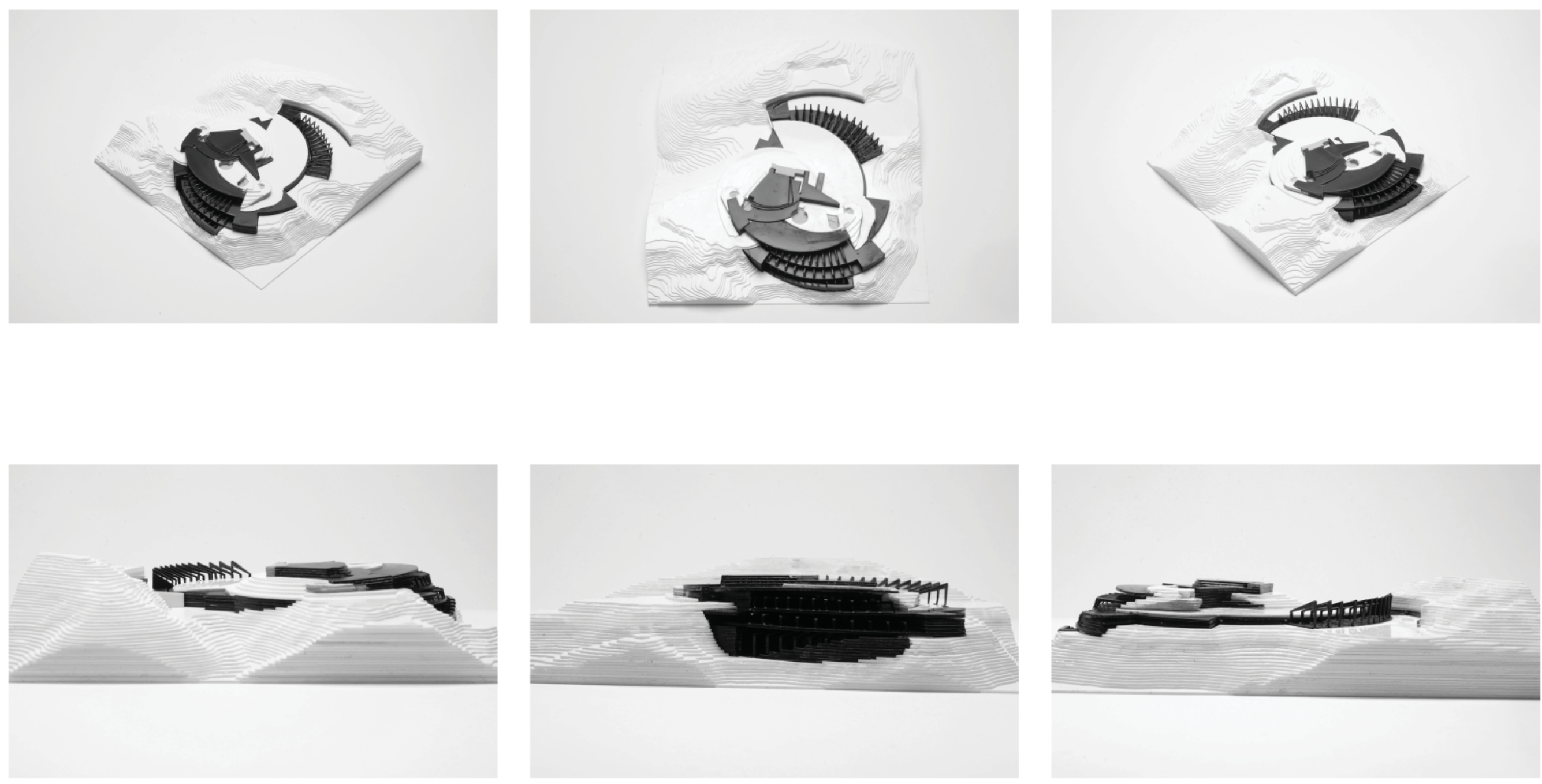

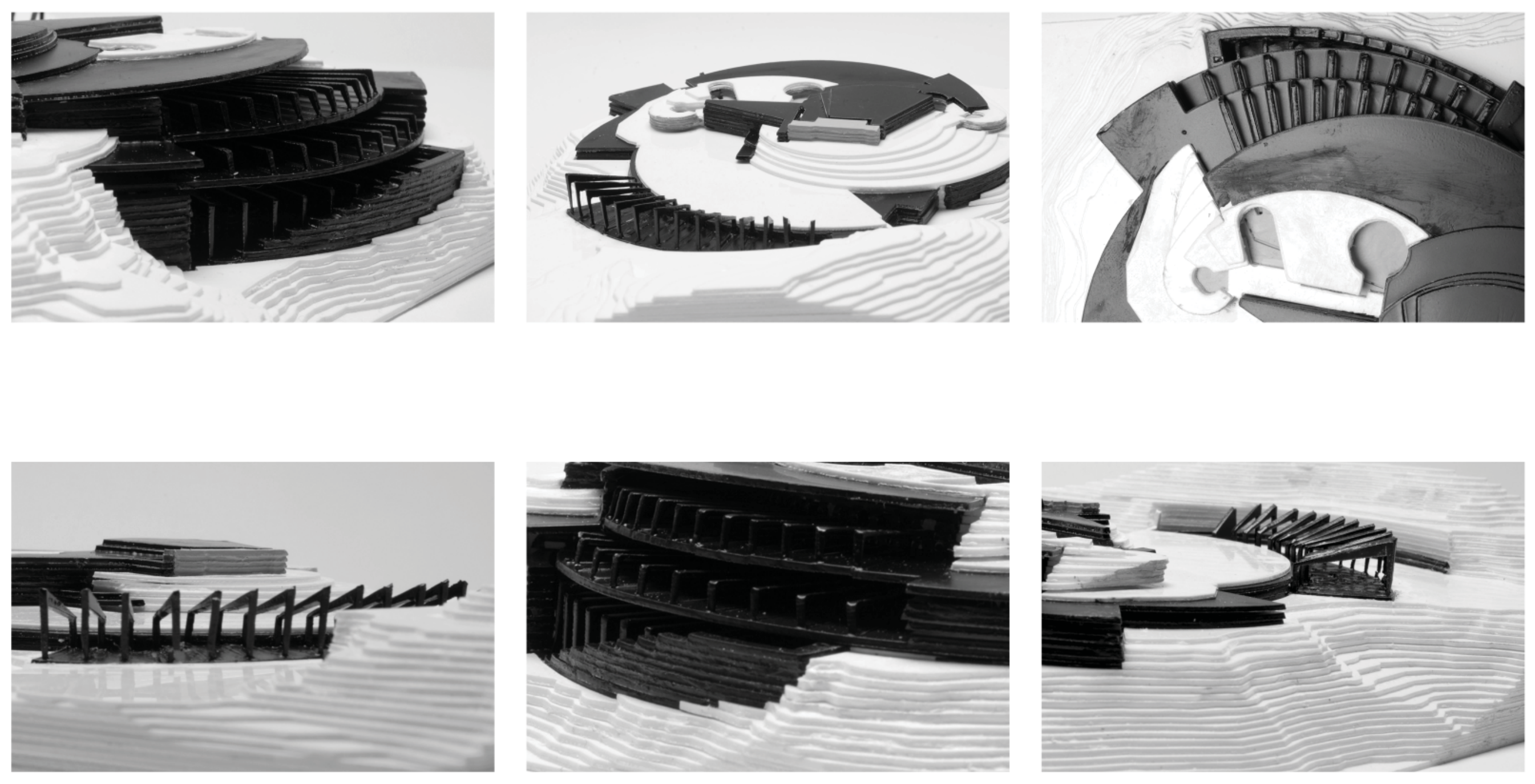
The intention of scheme $\mathrm{C}$ is to explore how the analogical method can generate an abstract space similar to the one understood in the narrative of Te Ao Tawhito past. This intervention will then be integrated into the site by a process of wrapping. This metamorphic method will allow the historic content of the relic to be valued and interpreted.

Figures 7.XIII and 7.XIV show how there are two main phases of the design process where these methods are employed. Although the separate figure 7.XV reveals that the process is dynamic moving backwards and forwards between the methods.

The outcome of scheme $C$ is shown in the drawings of figure 7.XVI and 7.XVII with the photographs of the models in figure 7.VIII. The scheme is an abstract terracing of the site that wraps over Fort Ballance and responds to the gun emplacement pits. These pits form atea like spaces where people can congregate to discuss matters of the marine environment or where aquarium and educational talks wil be held. The past of Te Ao Tawhito is evoked by these open spaces that express the concealed pa. The aquarium provides insight into the idea of openness and the importance of communal input.

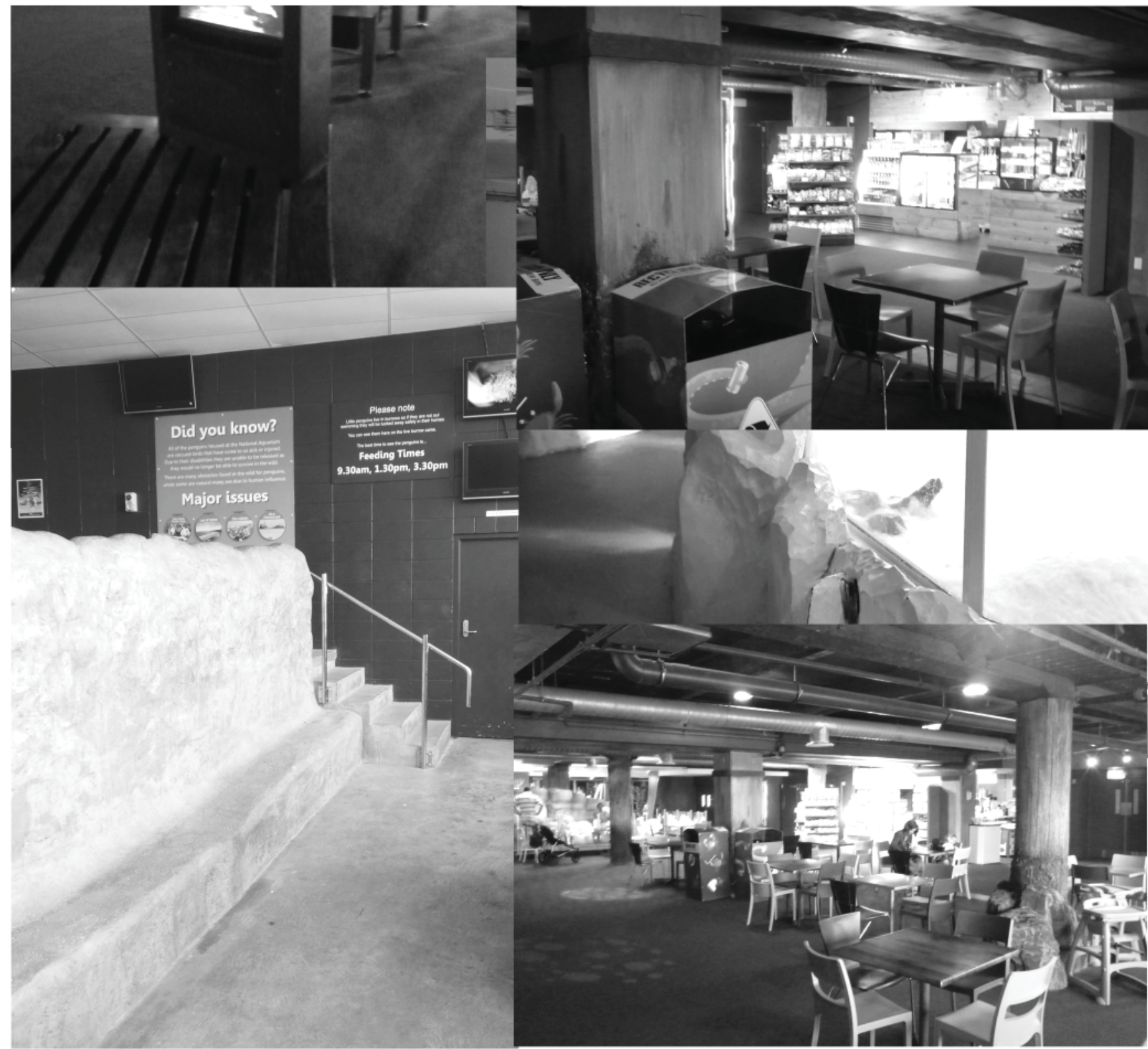



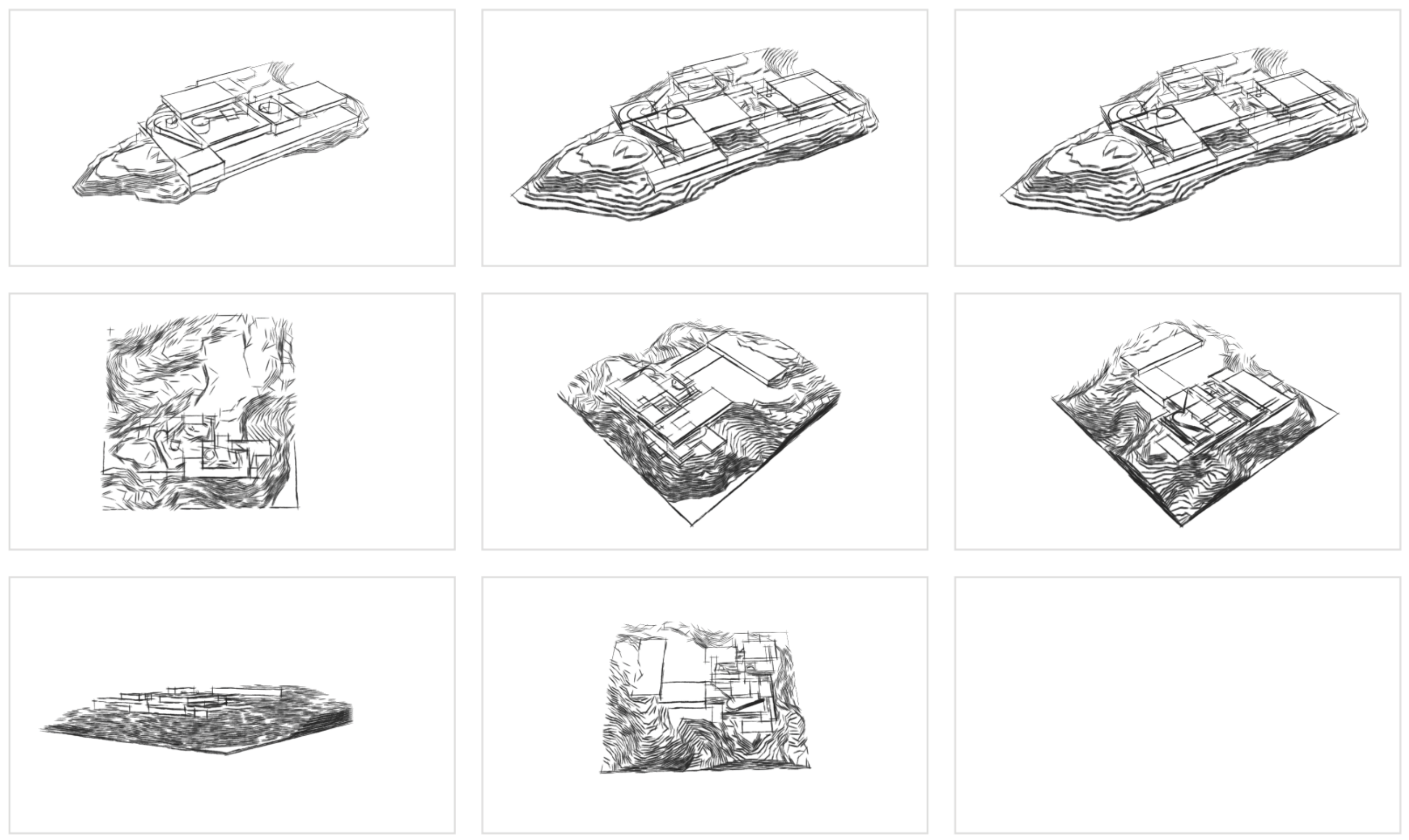

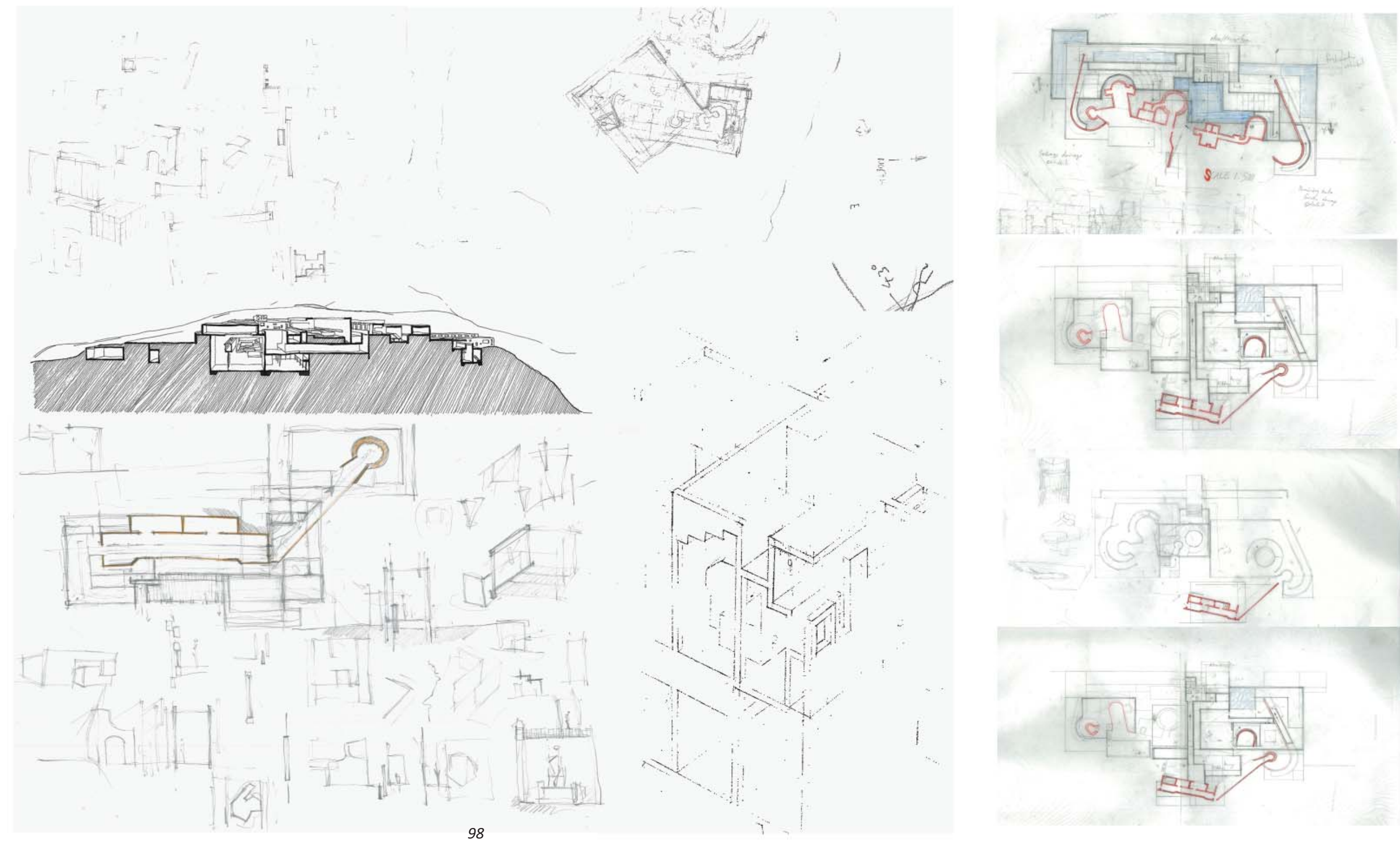
$+\frac{\pi}{1+10}$
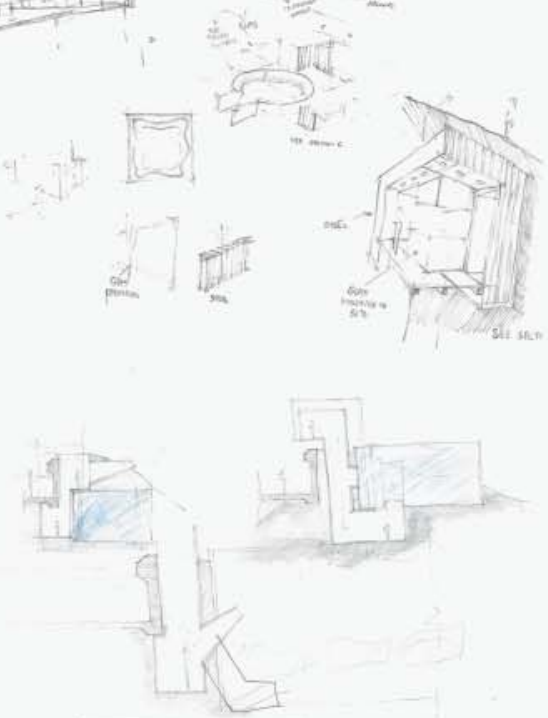

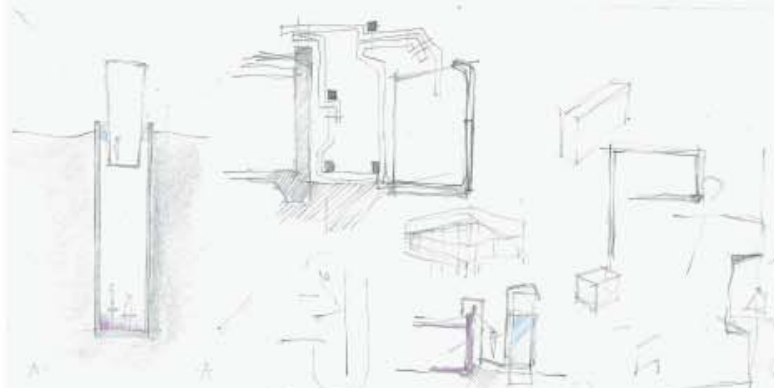

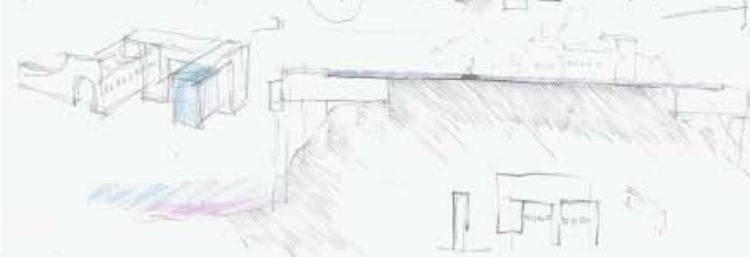

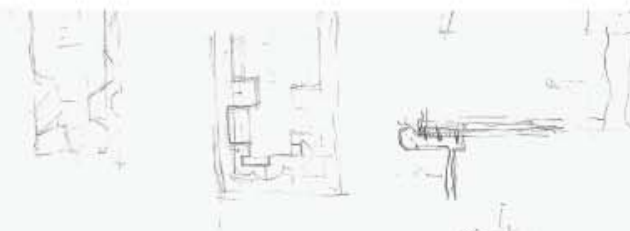
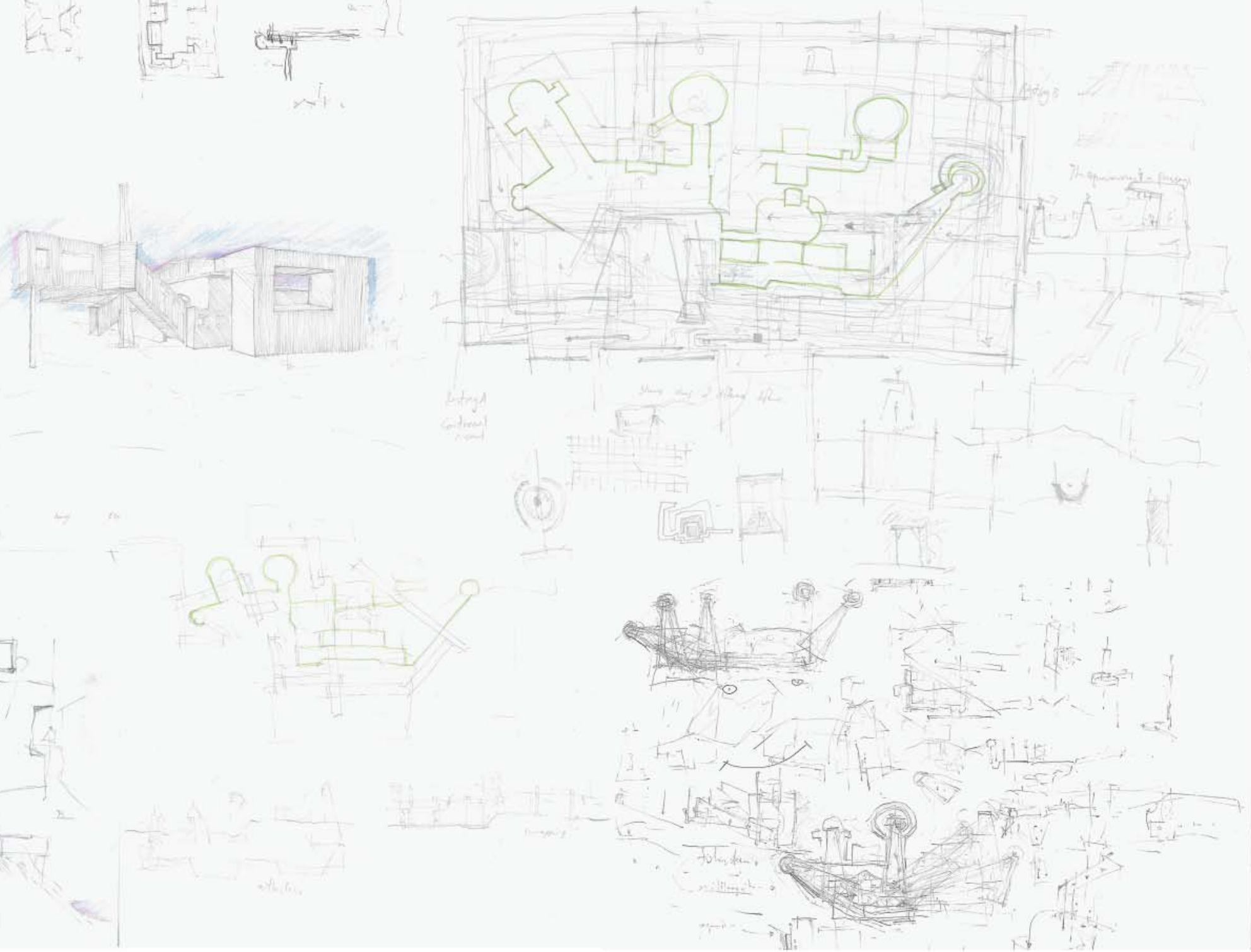

[FIG 7.XV] montage of drawings and model making that show how the site is developed as a result of the analogic and metamorphic methods SOURCE: Authors 


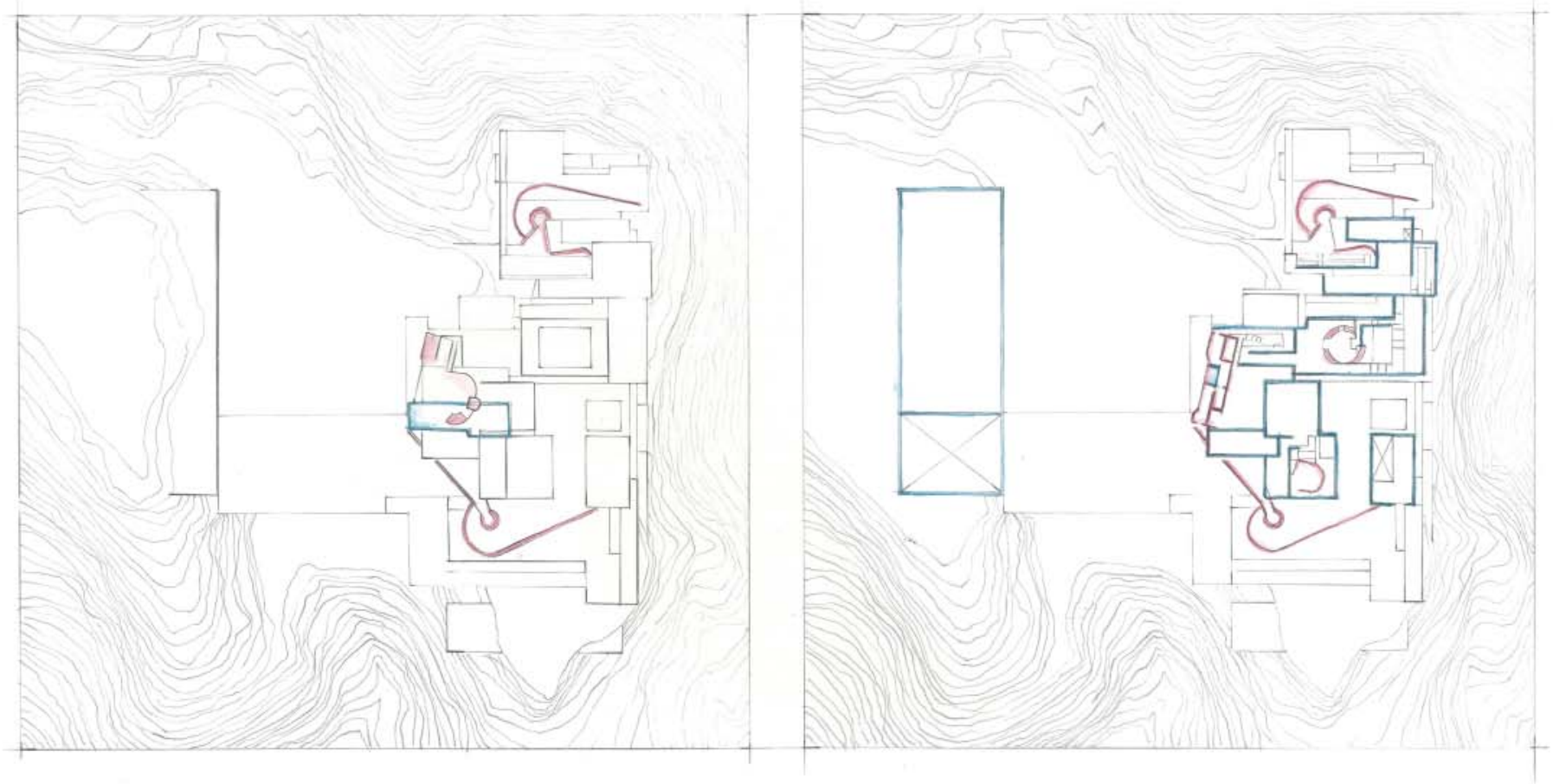



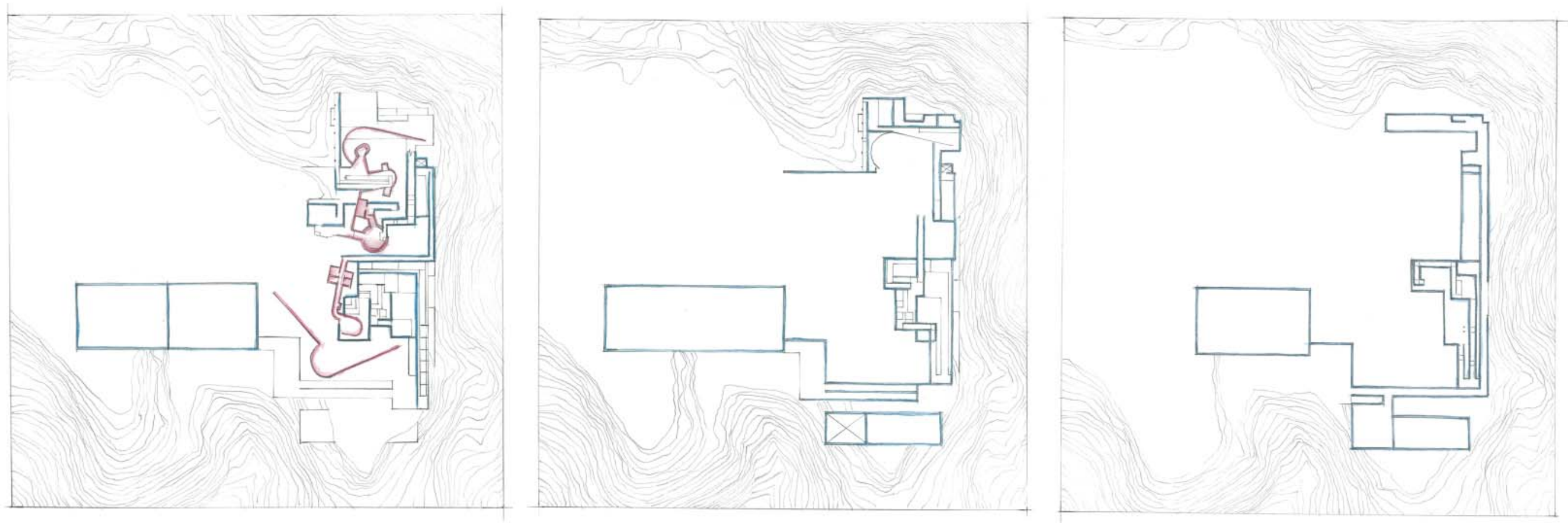


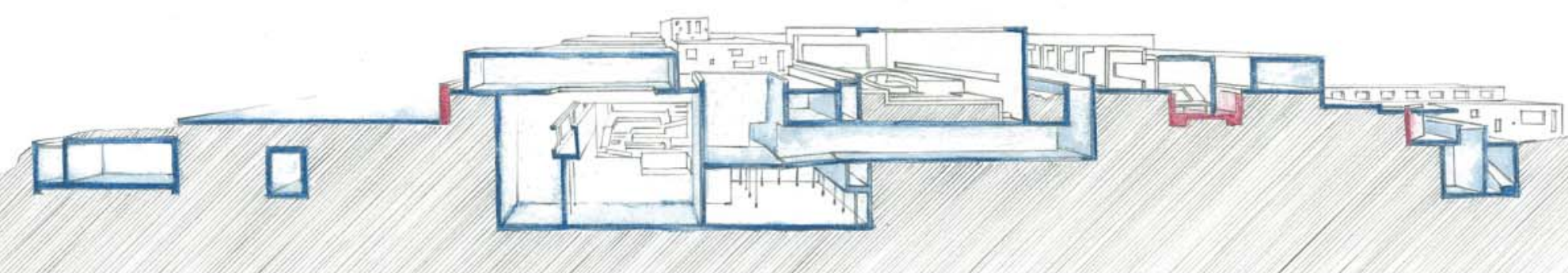




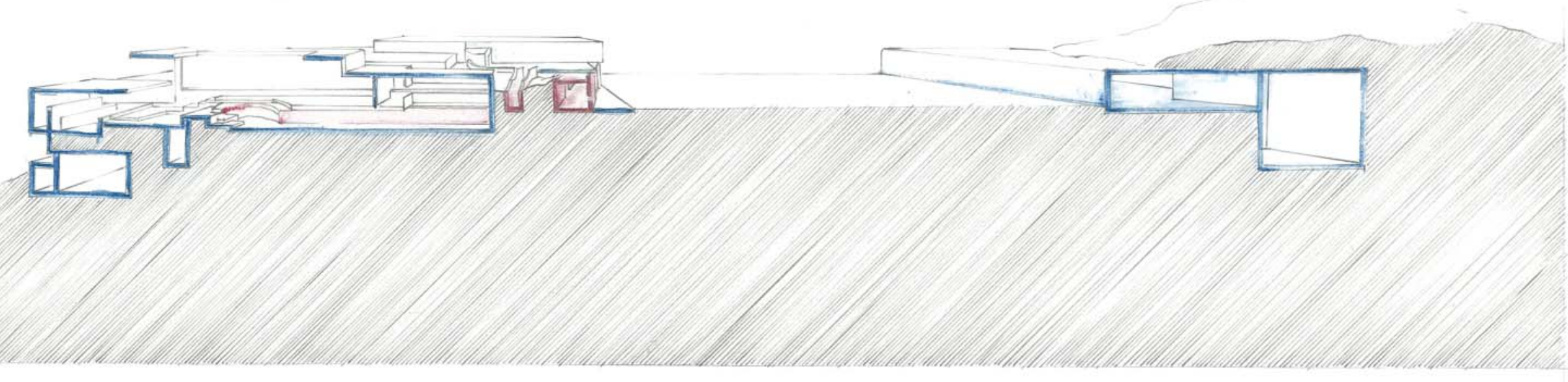



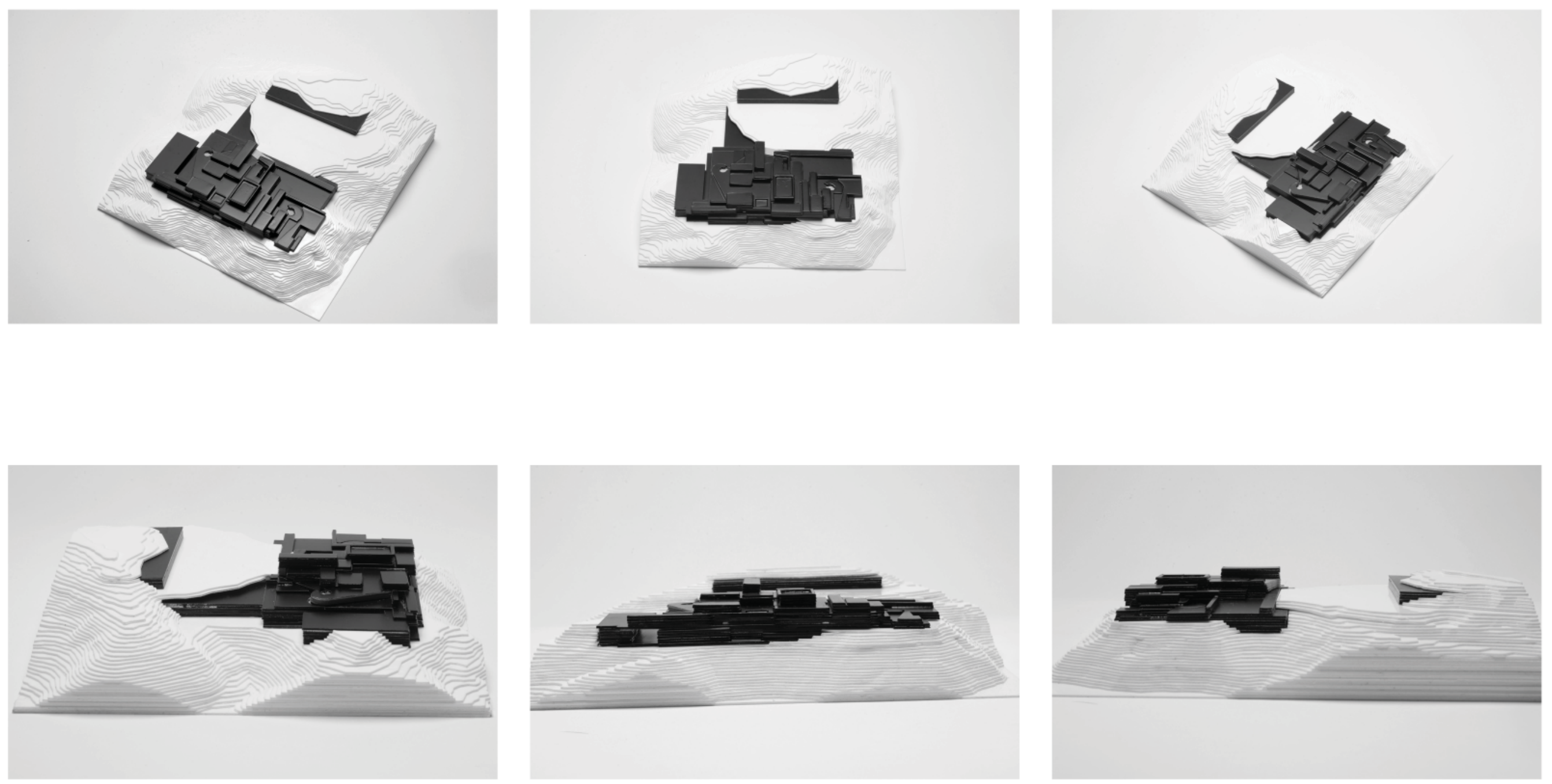

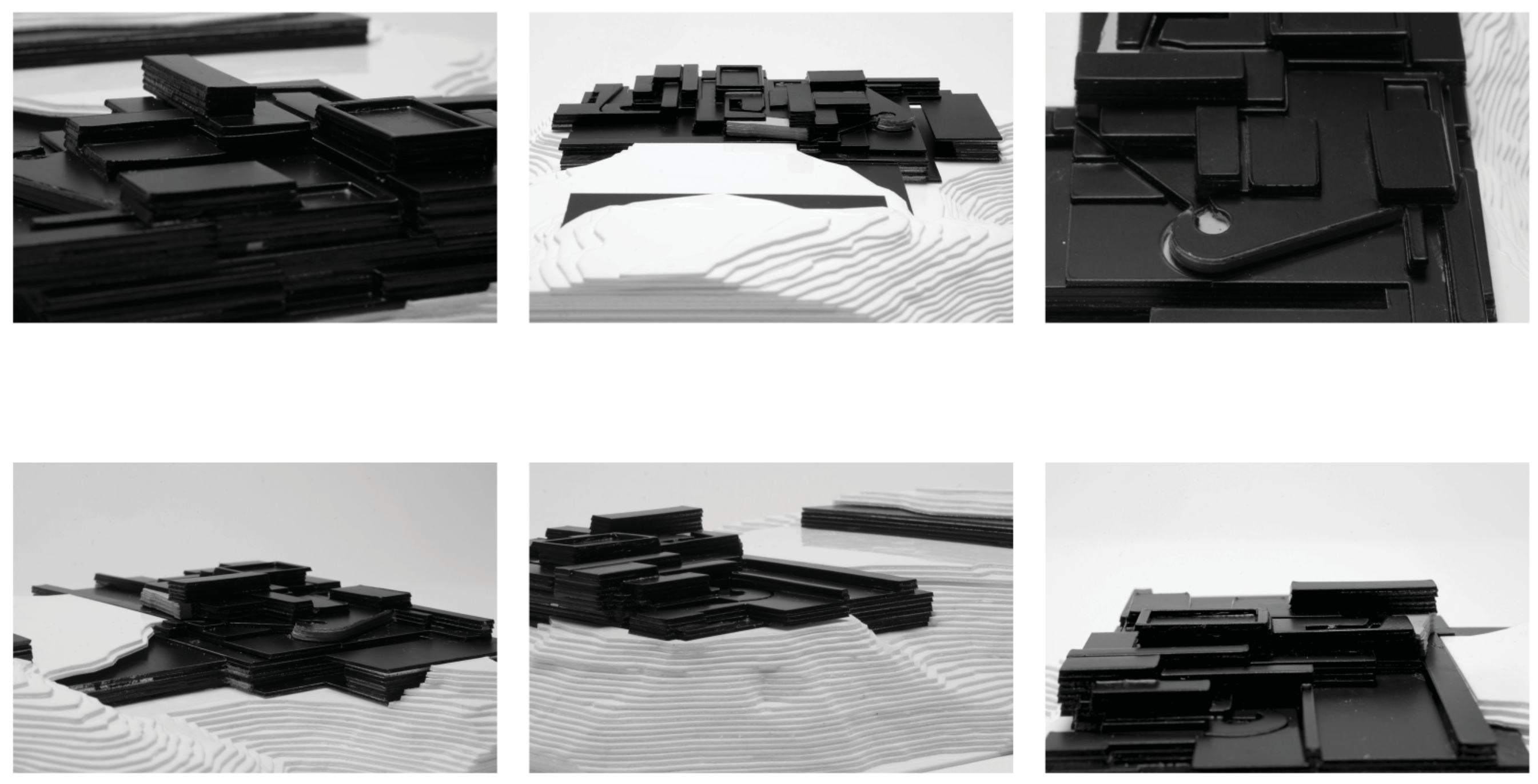


\section{EPILOGUE}

\subsection{Project One and Two Reflection}

When responding to a site's contextual values such as its associated past, any project must ask the basic questions; who is the past associated with, what aspects of the past is being expressed and interpreted, why is it being interpreted, when is it being interpreted and expressed and how will it be interpreted and expressed? Each question can be independently asked, although they are not exclusive of each other. Also numerous disciplines and entities may be involved in a project where each group may have more input into one of the answers. The first four questions were asked and answered by this thesis so as to allow for an appropriate study of how to develop a site with a historical context. The thesis acknowledges that this research has no authority to answer who, what, why, and when; but by doing so the outcome of the study is posited towards those who may be asking these questions. Project two is an example where the three developments of Point Gordon were a result of answering these questions. These answers will be discussed here in order to discuss their relevance to the question of how.

In 2014 the chair of The Port Nicholson Block Settlement Trust, the Mayor of Wellington and the minister of culture and heritage all signed a memorandum, agreeing upon a vision for the Miramar heritage area, including Point Gordon. As representatives of the community the three indicated that the area will be allocated for public use that will allow for interpretation of Te Whanganui a Tara Wellington's past. The thesis suggests that the area is for members of the public to use, but an opportunity arises for private investment to back a public facility that could provide insight into the past and maintain the area, such as an aquarium.

The thesis opted to develop the site as an aquarium, seeing as the city currently lacks one and over the last few years numerous investors have proposed concepts to the council. The aquarium is also a public facility that could be financially independent and which would also provide protection for the area, including any potential users of the site.

The aquarium was selected because of the site's past and its location. Practically being close to the sea is important. Point Gordon was once Te Mahanga Pa during Te Ao Tawhito (the old world) period, and Elsdon Best describes the place as a summer fishing retreat. The name could be translated as twin or snare in English possibly referring to the two bays below and a method of fishing (Best, the great harbour of Tara). Although such techniques are not preeminent for today's society or industry, many Maori principles of the marine environment are. Te Whanganui a Tara Wellington harbour is under threat from human affairs, including pollution and overfishing. The aquarium will not only address contemporary issues but evoke, express and provide insight into Te Ao Tawhito period.

This project is theoretical, however the question of when is still relevant. As previously mentioned numerous aquaria have been proposed for the city. An article in 2014 revealed draft proposals being sent to the council for backing. The project is relevant to the city and is presently being discussed.

All of these answers to who, what, why and when are valid and indicate that any project should be a collaboration between public representatives, investors and specialists. In reality the answers would result from a discussion. However these answers are plausible, allowing the research to focus on how a site could be developed that has a strong historical context. Project one argued that an architectural intervention could evoke, express and provide insight into the past of Te Ao Tawhito period. A method of analogy allowed a process to develop a site so to create a space that was analogous of the past and acted as a mnemonic device. Project two took this idea of creating a mnemonic space and explored how it could interact with a relic, so as to develop a site. A method of metamorphism allowed a process to develop a site with matters of concealment.

The questions of who, why, what, and when are interrelated to the question of how, and are important to reflect on. If those questions reveal the site to be understood as historically important with some eras of the past affected by concealment, then the discussion of how is relevant. Projects one and two provide insight into a process that could evoke, express and interpret the past through a development.

\subsection{Research summary}

The past is a broad field of study and there are many implications and issues when dealing with it, such as its relevance and source. The thesis has tried to study the past so as to explain a context and set the basis for the subsequent design projects. By setting parameters certain points may arouse argument, which has been noted, but more importantly the convergence of a complex issue into a context statement has allowed the thesis to focus on the research question

How can an architectural development benefit a community by expressing, evoking and providing insight into the layered past of Aotearoa New Zealand?

This question was informed by two issues relating to how an intervention could not only evoke a concealed past but then $\mathrm{co}$ - exist with a relic. By understanding the context in 
a certain way, not only were two fundamental issues raised but this allowed the research to navigate a complex issue. Such navigation has resulted in three key issues worthy of reflection and discussion:

1. The past as an important aspect of identity, culture and wellbeing

2. Relics and mnemonic interventions could be consider markers of the past

3. The use of questions over terminology

\section{Reflection one:}

A study of the past is important as it allows us to not only know where our culture and identity come from, but how the future could be approached. The past of Te Ao Hou dominates the environment through relics, and this expresses a colonial identity with a culture that is not bothered by or is unaware of the indigenous people. Although organisations claim to evoke and express the past of Te Ao Tawhito, it is generally rarely done and left to Maori organisations. As a local Pakeha, the author argues that the past of Te Ao Tawhito is important to the regional identity and culture. After studying early harbour defence systems and Maori occupation there surely cannot be any preference to either of these periods. Both periods are just as important for the welfare of the region. There is definitely bias towards Te Ao Hou history as many Maori and Pakeha can relate to it, and many of the events such as the great wars are annually remembered through events such as ANZAC day. However in noting this, it could also be suggested that Maori narrative is beginning to become mainstream. With more awareness raised in regards to Maori culture and narrative associated with sites around the harbour, architects have a responsibility to express and evoke the past of Te Ao Tawhito. The past is what we make it with Lowenthal suggesting that "just as we are products of the past, so is the known past an artefact of ours" (216).
Second point of reflection

Relics do not relay the past to people, but merely evoke the past known by people. This is similar to mnemonic interventions which also evoke the past intrinsic to a possible user. Therefore the thesis reflects that relics (heritage fabric) should not be protected in the current manner. If a site's past is important to a collective group then a relic only enhances this relationship. The relationship to the past is not gained through a relic, or a mnemonic intervention rather as the thesis suggests; relics and mnemonic interventions are considered to be devices that express and evoke the past around the harbour. Therefore many of these sites assocaited with Te Ao Tawhito period that are concealed by a relic may be expressed. Lowenthal suggests that "our sense of the historical past comes less from history books than from the everyday things we see and do from childhood on." (211). This concurs with the perception so far explained and argued for.

\section{Third point of reflection}

When studying a site that hosts a relic it is possible to fall into a trap of what terminology to use and to focus on terminologies such as original intent, age value, restoration or preservation. Although these ideas are important and may be relevant on a case by case study they should not be preeminent when working on a site that hosts a relic. The thesis argues that questions are more appropriate such as: should a relic be kept, destroyed or changed? Or is the site's relic concealing a past that is valued today? Is the site suitable for a possible development that relates to the past such as the aquarium in project two? These questions can be applied in a case by case basis.

\subsection{Conclusion and research output}

In conclusion the thesis suggests that history is important and should be a part of people's routines instead of being alienated as a vestige or fragment of the past. The thesis suggests a notion that history is of the utmost value, and any work should attempt to communicate and enhance it.

The research output consists of the two methods which are illustrated by the three schemes of project two. Rathe than designing a building that responds to the context, the thesis opted to explore how methods could be employed by stakeholders where a sites historic and cultural value is contested. The thesis offers an option of development which mirrors the past allowing an expression of both Te Ao Tawhtio and Te Ao Hou pasts. 


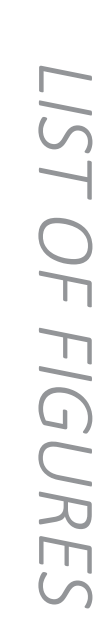

\section{OPENING IMAGES}

IFIG I] George French Angas Tinted lithograph, hand-coloured $550 \times 360 \mathrm{~mm}$ potraying women possibly occupying a whare at Tiakiwai pa. SOURCE: Alexander Turnbull Library Wellington New Zealand Reference: PUBL-0014-31. http://natlib.govt.nz/records/23048186. 1844

[FIG II] Charles Decimus Barraud, 1852, watercolour, view of Te Aro, from Brooklyn SOURCE: Alexander Turnbull Library, Wellington, New Zealand. Reference: c-007-011. http://natlib.govt.nz/records/23101754

[FIG III] Samuel Charles Brees 1842-1845, Engraving, hand-coloured 84 × 135 mm view of Pipitea pa

SOURCE: Alexander Turnbull Library, Wellington, New Zealand. Reference: A-109-020 http://natlib.govt.nz/records/23168219

[FIG IV] William Mein Smith, 1842, hand coloured drawing of Pipitea Pa courtyard SOURCE: Alexander Turnbull Library Wellington, New Zealand Reference: PUBL-0011-04-1 http://natlib.govt.nz/records/23151660

[FIG V] Charles Emilius Gold, watercolour of a Mãori man poling a waka infront of Motu-Kairangi Miramar Penisular

SOURCE: Alexander Turnbull Library, Wellington, New Zealand. Reference: A-288-026 http://natlib.govt.nz/records/22909953

[FIG VI] Charles Emilius Gold, watercolour of a Māori hauling waka up a beach on Motu-Kairangi Miramar SOURCE: Alexander Turnbull Library, Wellington, New Zealand. Reference: A-288-025 http://natlib.govt.nz/records/22525933

[FIG VII] William Williams, photograph 1884, of gun emplacement at Fort Ballance SOURCE: Alexander Turnbull Library, Wellington, New Zealand. Reference: 1/2 140344-G http://natlib.govt.nz/records/22917815

[FIG VIII] Sydney Charles Smith, photograph 1899, of the Submarine and Torpedo Mining Corps annual camp, Shelly Bay.

SOURCE: Alexander Turnbull Library, Wellington, New Zealand. Reference: 1/1020236-G http://natlib.govt.nz/records/22769110

[FIG IX] Henry Charles Clarke, Wrights private collection, photograph, 1887, of Fort Ballance looking east to Scorching Ba .

SOURCE: Alexander Turnbull Library Wellington New Zealand Reference: $1 / 1$ 020667-G http://natlib.govt.nz/records/23212316

[FIG X] Sydney Charles Smith collection, photograph, 1937 showing Military personne training at Fort Dorset.

SOURCE: Alexander Turnbull Library, Wellington, New Zealand. Reference: 1/2 Q48328-G http//natlib govt nz/records/22850230

[FIG XI] Evening Post newspaper collection, photograph, 1937 showing working guns at Fort Dorset 048821-G http://natlib.govt.nz/records/23203467
[FIG XII] William Hall Raine collection, photograph, 1942 showing Women's Army Auxiliary Corps marching at Fort Dorset, Seatoun, Wellington, during World

SOURCE: Alexander Turnbull Library Wellington, New Zealand. Reference: 1/4220868-G http://natlib govt nz/records/23201234

\section{PROLOGUE}

[FIG 1.I] Map revealing how many Māori sites around the harbour are concealed and known today by a different name SOURCE: Author

[FIG 1.II] Thesis Structure diagram SOURCE: Author

[FIG 1.III] Photographic collage based on a study of a site's (Mount Crawford) concealed and concealing past, the red highlights the narrative of Te Ao Hou that is marked by a relic, while the blue highlights the past of Te Ao Tawhtio (Matak Kai Poinga) which is not marked at the site SOURCE: Author

[FIG 1.IV] Photographic collage based on a study of a site's (Shelly Bay) concealed and concealing past, the red highlights the narrative of Te Ao Hou that is marked by a relic, while the blue highlights the past of Te Ao Tawhtio (Maru kai Kuru) which is not marked at the site SOURCE: Author

[FIG 1.V] Photographic collage based on a study of a site's (Fort Ballance) concealed and concealing past, the red highlights the narrative of Te Ao Hou that is marked by a relic, while the blue highlights the past of Te Ao Tawhtio (Te Mahanga which s not marked at the site SOURCE: Author

[FIG 1.VI] Photographic collage based on a study of a site's (Fort Dorset) concealed and concealing past, the red highlights the narrative of Te Ao Hou that is marked by a relic, while the blue highlights the past of Te Ao Tawhtio (Orua-iti) which is marked by a sculpture SOURCE: Autho

\section{CHAPTER TWO}

[FIG 2.I] Map of Miramar showing Te Ao Tawhito names being concealed by Te Ao Hou names SOURCE: Author

[FIG 2.II] Site study of Motu-Kairangi Miramar Penisular SOURCE: Autho

[FIG 2.III] Photograph showing that Rangitatau Pa can be perceived in the landscape SOURCE: Author 
[FIG 2.IV] Photograph showing how a sculpture marks Orua-itipa SOURCE: Author

[FIG 2.V] Photograph showing how Hue te Taka is defined by boulders SOURCE: Author

[FIG 2.VII] A clearing on Seatoun ridge hosts a rock that possibly may mark Te WhetuKairangi pa SOURCE: Author

[FIG 2.VII]Photograph showing how Makaro island has had little if no human intervention and its solid silohuette stands out against the sea.

SOURCE: Author

[FIG 2.VIII] Photograph showing of Te Aroaro o kupe, where the famous navigator was SOURCE: Author

\section{CHAPTER THREE}

[FIG 3.1] Photograph of the south elevation of the Wharewaka SOURCE: Author

[FIG 3.II] Photograph of the Te Aro Park ponds SOURCE: Author

FIG 3.III] Photograph of the the archeaological site that unearthed two raup dwellings

SOURCE: Author

[FIG 3.IV] Photograph of the West side of the Wharewaka opening out onto the

lagoon
SOURCE: Author

[FIG 3.V] Photograph showing the vertical element of Te Aro Park SOURCE: Author

[FIG 3.VI] Photograph of the archeaological site that unearthed two raupo dwellings

SOURCE: Author

[FIG 3.VII] Image showing the relationship the museum has with its neighbouring buildings SOURCE: Schneider, Daniel Libeskind, Jewish Museum Berlin. page 39 photographer Stefan Müller

[FIG 3.VIII] Image showing the cladding lit up SOURCE: Schneider, Daniel Libeskind, Jewish Museum Berlin. photographer Stefan Müller

[FIG 3.IX] Image showing the interior space which is scarred by the slashing windows SOURCE. Schneider Daniel Libeskind, lewish Museum Berlin. photographer Stefan Müller

[FIG 3.X] Image showing the interior space which is scarred by the slashing windows SOURCE: Schneider Daniel Libeskind Jewish Museum Berlin. page 30 photographer Stefan Müller

[FIG 3.XI] Image showing the exterior of the holocaust tower and exile garden SOURCE: Schneider, Daniel Libeskind, Jewish Museum Berlin. page 28 photographer Stefan Müller
[FIG 3.XII] Image the zig zagaing building in the context of the city SOURCE: Schneider, Daniel Libeskind, Jewish Museum Berlin. page 18 photographer Stefan Müller

IFIG 3.XIII] Exterior cladding of the museum

SOURCE: Schneider, Daniel Libeskind, Jewish Museum Berlin. photographer

[FIG 3.XIV] the holocaust tower

SOURCE: Schneider, Daniel Libeskind, Jewish Museum Berlin.

photographer Stefan Müller

FIG 3.XV] ph iside one of several voids

SOURCE. Schneider Daniel libeskind, Lewish Museum Berlin.

photographer Stefan Müller

[FIG 3.XVI] Climbing the compressed staircase

SOURCE: Schneider, Daniel Libeskind, Jewish Museum Berlin

photographer Stefon Aluter

[FIG 3.XVII] an interior perspectve of the inferno space water colour by architect SOURCE: Schumacher, Terragni's Danteum. plate seven

[FIG 3.XVIII] an interior perspectve of the ipurgatory space water colour by architect SOURCE: Schumacher, Terragni's Danteum. plate nine

[FIG 3.XIX] the sculpture exterior, free standing wall, water colour by architect SOURCE: Schumacher, Terragni's Danteum. plate three

[FIG 3.XX] an interior perspectve of the paradise space water colour by architect SOURCE: Schumacher, Terragni's Danteum. plate eleven

[FIG 3.XXI] the rear facade

SOURCE: Schumacher, Terragni's Danteum. plate two

[FIG 3.XXII] an interior perspectve of the empire room water colour by architect SOURCE: Schumacher, Terragni's Danteum. plate twelve

[FIG 3.XXIII] the entrance court, water colour by architect SOURCE: Schumacher, Terragni's Danteum. plate five

[FIG 3.XXIV] side allyway with a relationship to the colosseum SOURCE: Schumacher, Terragni's Danteum. plate four

[FIG 3.XXV] Danteum mode

SOURCE: Schumacher Terragni's Danteum page 48

[FIG 3.XXVI] Danteum floor plan

SOURCE: Schumacher, Terragni's Danteum. page 52

[FIG 3.XXVII] facade of the North American Indian Museum SOURCE: Spruce, the land has memory page introduction

[FIG 3.XXVIII] facade of the North American Indian Museum reflects desert cliffs SOURCE: Spruce, the land has memory. page XIV.
[FIG 3.XXIX] Crystal windows create rainbows, that evoke a sense of the spirit world SOURCE: Spruce, the land has memory page 4

[FIG 3.XXX] Open fires are an important part of the culture

[FIG 3.XXXI] the facade evokes the expasive plains of the america SOURCE: Spruce, the land has memory page 13

[FIG 3.XXXII] Wet lands evoke wild life enhancing a celebration of the animal world SOURCE: Spruce, the land has memory page 14

[FIG 3.XXXIII] Rocks anchor the site and point to important directions SOURCE: Spruce, the land has memory. page

[FIG 3.XXXIV] Ariel view of the museum SOURCE: Spruce, the land has memory. page 19

[FIG 3.XXXV] view from the garden area SOURCE: Spruce, the land has memory. page 20

[FIG 3.XXXVI] view of the waterfall SOURCE: Spruce, the land has memory.

\section{CHAPTER FOUR}

[FIG 4.I] study of pa based on Elsdon Best SOURCE: Authors studying of existing drawings

[FIG 4.II] study of pa based on Elsdon Best SOURCE: Authors studying of existing drawings

[FIG 4.III] study of pa based on Elsdon Best SOURCE: Authors studying of existing drawings

[FIG 4.IV] study of pa based on Elsdon Best SOURCE: Authors studying of existing drawing

[FIG 4.V] study of pa based on Elsdon Best SOURCE: Authors studying of existing drawings

[FIG 4.VI] study of pa based on Elsdon Best SOURCE: Authors studying of existing drawings

[FIG 4.VII] a photographic collage of the sites past, that will form the nucleus to the following design explorations SOURCE: Authors

[FIG 4.VIII] Conceptual sketch of bathhouse that draws from a pa's palisade techtonics SOURCE: Authors 


\begin{tabular}{|c|c|}
\hline [FIG 4.IX] & $\begin{array}{l}\text { Conceptual sketch of bathhouse that draws from a how a pa cuts into } \\
\text { the earth } \\
\text { SOURCE: Authors }\end{array}$ \\
\hline [FIG 4.X] & $\begin{array}{l}\text { Conceptual sketch of bathhouse that draws from how a pa cuts into the } \\
\text { earth } \\
\text { SOURCE: Authors }\end{array}$ \\
\hline [FIG 4.XI] & $\begin{array}{l}\text { Conceptual sketch of bathhouse that draws from how a pa is a labyrinth } \\
\text { like structure } \\
\text { SOURCE: Authors }\end{array}$ \\
\hline [FIG 4.XII] & $\begin{array}{l}\text { Layout of Japanese floor plans and an exploded axonometric } \\
\text { SOURCE: Authors }\end{array}$ \\
\hline [FIG 4.XIII] & $\begin{array}{l}\text { Photographs of carboard model of Japanese Bathhouse } \\
\text { SOURCE: Authors }\end{array}$ \\
\hline [FIG 4.XIV] & $\begin{array}{l}\text { Photographic montage of carboard model of the Japanese Bathhouse } \\
\text { SOURCE: Authors }\end{array}$ \\
\hline & CHAPTER FIVE \\
\hline [FIG 5.I] & $\begin{array}{l}\text { site map of Point Gordon } \\
\text { SOURCE: Authors }\end{array}$ \\
\hline [FIG 5.II] & $\begin{array}{l}\text { study of Fort Ballance } \\
\text { SOURCE: Authors }\end{array}$ \\
\hline [FIG 5.III] & $\begin{array}{l}\text { study of Fort Ballance } \\
\text { SOURCE: Authors }\end{array}$ \\
\hline [FIG 5.IV] & $\begin{array}{l}\text { study of Fort Ballance } \\
\text { SOURCE: Authors }\end{array}$ \\
\hline [FIG 5.V] & $\begin{array}{l}\text { study of Fort Ballance } \\
\text { SOURCE: Authors }\end{array}$ \\
\hline [FIG 5.VI] & $\begin{array}{l}\text { study of Fort Ballance } \\
\text { SOURCE: Authors }\end{array}$ \\
\hline [FIG 5.VII] & $\begin{array}{l}\text { study of Fort Ballance } \\
\text { SOURCE: Authors }\end{array}$ \\
\hline [FIG 5.VIII] & $\begin{array}{l}\text { study of Fort Ballance } \\
\text { SOURCE: Authors }\end{array}$ \\
\hline [FIG 5.IX] & $\begin{array}{l}\text { study of Fort Ballance } \\
\text { SOURCE: Authors }\end{array}$ \\
\hline [FIG 5.X] & $\begin{array}{l}\text { study of Fort Ballance } \\
\text { SOURCE: Authors }\end{array}$ \\
\hline
\end{tabular}

\section{[FIG 5.XI] study of Fort Ballance SOURCE: Authors \\ [FIG 5.XII] study of Fort Ballance SOURCE: Authors \\ [FIG 5.XIII] study of Fort Ballance SOURCE: Authors \\ CHAPTER SIX}

[FIG 6.I] photographs of the Oruaiti sculpture express how there is a changin attitude to the past.

SOURCE: Authors

[FIG 6.II] the Higqins Hall by Steven Hol SOURCE: Bollack page 15

[FIG 6.III] the Higgins Hall by Steven Holl SOURCE: Bollack page 153

[FIG 6.IV] the Higgins Hall by Steven Hol SOURCE: Bollack page 153

[FIG 6.V] the Higgins Hall by Steven Holl SOURCE: Bollack page 154

[FIG 6.VI] the Bridge of Aspiration by Wilkinson Eyre Architects SOURCE: Bollack page 167

[FIG 6.VII] the Bridge of Aspiration by Wilkinson Eyre Architects SOURCE: Bollack page 169

[FIG 6.VIII] the Bridge of Aspiration by Wilkinson Eyre Architects SOURCE: Bollack page 170

[FIG 6.IX] the Bridge of Aspiration by Wilkinson Eyre Architects SOURCE: Bollack page 170

[FIG 6.X] The Mill City Museum by Meyer, Scherer and Rockcastle SOURCE: Bollack page 206

[FIG 6.XI] The Mill City Museum by Meyer, Scherer and Rockcastle SOURCE: Bollack page 208

[FIG 6.XII] The Mill City Museum by Meyer, Scherer and Rockcastle SOURCE: Bollack page 209

[FIG 6.XIII] The Mill City Museum by Meyer, Scherer and Rockcastle SOURCE: Bollack page 210

[FIG 6.XIV] The Neues Museum by David Chipperfield architects SOURCE: Bollack page 216
[FIG 6.XV] The Neues Museum by David Chipperfield architects SOURCE: Bollack page 217

[FIG 6.XVI] The Neues Museum by David Chipperfield architects SOURCE: Bollack page 218

[FIG 6.XVIII The Neues Museum by David Chipperfield architects SOURCE: Bollack page 220

[FIG 6.XVIII] The Santa Caterina Market by Enric Miralles and Benedetta Tagliabue SOURCE: Bollack page 128

[FIG 6.XIX] The Santa Caterina Market by Enric Miralles and Benedetta Taqliabue SOURCE: Bollack page 128

[FIG 6.XX] The Santa Caterina Market by Enric Miralles and Benedetta Tagliabue SOURCE: Bollack page 132

[FIG 6.XXI] The Santa Caterina Market by Enric Miralles and Benedetta Tagliabue SOURCE: Bollack page 132

[FIG 6.XXIII] The Wohlfahrt-Laymann House by Meixner, Schulter, Wendt architects SOURCE: Bollack page 135

[FIG 6.XXIII] The Wohlfahrt-Laymann House by Meixner, Schulter, Wendt architects SOURCE: Bollack page 136

[FIG 6.XXIV] The Wohlfahrt-Laymann House by Meixner, Schulter, Wendt architects SOURCE: Bollack page 138

[FIG 6.XXV] The Wohlfahrt-Laymann House by Meixner, Schulter, Wendt architects SOURCE: Bollack page 138

\section{CHAPTER SEVEN}

[FIG 7.II Kelly Tarlton and the Napier aquaria were study resulting in analogy of circulation SOURCE: Authors site trip

[FIG 7.II] the mnemonic device is juxtaposed with the relic, the above images show an iterative process of $\mathrm{juxtaposing} \mathrm{the} \mathrm{intervention} \mathrm{with} \mathrm{the} \mathrm{relic}$ SOURCE: Authors, model on sketch up

[FIG 7.III] montage of drawings and model making that develop the site in response to the analogic and metamorphic method SOURCE: Authors

[FIG 7.IV] Floor plans of the scheme that juxtaposes against the relic SOURCE: Authors

[FIG 7.V] Sections of the scheme that juxtaposes against the relic SOURCE: Authors

[FIG 7.VI] Plastic card model of the scheme that juxtaposes against the relic SOURCE: Authors 
[FIG 7.VII] Kelly Tarlton and the Napier aquaria were study resulting in analogy of the lighting

SOURCE: Authors site trip

[FIG 7.VIII] the mnemonic device weaves into the relic, the above images show an iterative process of weaving the intervention intothe relic

SOURCE: Authors, model on sketch up

[FIG 7.IX] montage of drawings and model making that show how the site is developed as a result of the analogic and metamorphic methods SOURCE: Authors

[FIG 7.X] Floor plans of the scheme that weaves with a relic SOURCE: Authors

[FIG 7.XI] Sections of the scheme that weaves with a relic SOURCE: Authors

[FIG 7.XII] Plastic card model of the scheme that weaves with a relic SOURCE: Authors

[FIG 7.XIII] Kelly Tarlton and the Napier aquaria were study resulting in analogy of the openess

SOURCE: Authors site trip

[FIG 7.XIV] the mnemonic device wraps around and over the relic, the above images show an iterative process of wrapping the intervention into the relic SOURCE: Authors, model on sketch up

[FIG 7.XV] montage of drawings and model making that show how the site is developed as a result of the analogic and metamorphic methods SOURCE: Authors

scheme that wraps around a relic SOURCE: Authors

[FIG 7.XVIII Sections of the scheme that wraps around a relic SOURCE: Authors

IFIG 7.XVIII] Plastic card model of the scheme that wraps around a relic SOURCE: Authors 
Adam, Robert. Does heritage dogma destroy living history? May 2003. http://ihbc.org.uk/context_archive/79/dogma/ adam.html

Adkin, G. Leslie. The Great Harbour of Tara. New Zealand: Whitcombe and Tombs Ltd, 1959. Print.

Anderson, Atholl. "In the foreign gaze, AD 1642-1820." Tangata whenua; an illustrative history. Ed. Anderson, Atholl, Judith Binney and Aroha Harris. Wellington: Bridget Williams Books, 2014. 132-160. Print.

Anderson, Stanford. "memory without monuments: vernacular architecture." Tradditional dwellings and Settlement Review 11:1 (Fall 1999): 13-22. JSTOR. Web. 27 July 2014

Aristotle. On the soul and on memory and recollection. Trans. Sachs, Joe. New Mexico: Green Lion Press, 2004. Print.

Ballara, Angela. "Te Whanganui-a-Tara: phases of Maor occupation of Wellington harbour c. 1800-1840." The making of Wellington 1800-1914. Ed. Hamer, David and Roberta Nicholls. Wellington: Victoria University Press, 1990. 9-34. Print.

Ballengee-Morris, Christine. "Cultures for sale: Perspectives on colonialism and self-Determination and the relationship to authenticity and tourism." Studies in Art education 43:3 (spring, 2002): 232-245. JSTOR. Web. 21 January 2014

Best, Elsdon. The pā Maori: an account of the fortified villages of the Māori in pre-European and modern times, illustrating methods of defence by means of ramparts, fosses, scarps and stockades. Wellington: Museum of New Zealand Te Papa Tongarewa, 1995. Print.

----- The Great Harbour of Tara: traditional Maori place names and sites of Wellington harbour and environs. Christchurch:
Whitcombe and Tombs, 1959. Print.

Binney, Judith. Stories without end, essays 1975-2010. Wellington: Bridget Williams Books Limited, 2010. Print

Bollack, Françoise Astorg. Old buildings, new forms; new directions in architectural transformations. United States: The Monacelli Press, 2013. Print.

Calvino, Italo. Invisible Cities. New York: Houghton Mifflin Harcourt Publishing Company, 1974. Print.

Crengle, Sue and Rhys Jones, Tim McCreanor "How Tikanga Guides and Protects the Research Process: Insights From the Hauora Tāne Project." Social policy journal of New Zealand Te puna whakaaro. 29-Nov. 2006. Ministry of social development https://www.msd.govt.nz/about-msd-and-ourwork/publications-resources/journals-and-magazines/index. html Web. 22 Sept. 2014.

Curtis, Barry. "That place where: some thoughts on Memory and the city." The unknown city, contesting architecture and social space. Ed. Borden, lain, Joe Kerr, Jane Rendell and Alicia Pivaro. Cambridge: MIT press, 2001.

Eades, Gwilym Lucas. Maps and Memes: redrawing culture, place, and identity in indigenous communities. London: McGill-Queen's University Press, 2015. Print.

Engel, Heino. Measure and construction of the Japanese house. Singapore: Berkeley Books Pte. Ltd. 1985. Print. Gosden, Chris. "What do objects want?" Journal of Archaeological Method and Theory 12:3 (Sept 2005): 193211. JSTOR. Web. 21 January 2014

Jones, Johnpaul. "Introduction: Remembering the Experience of past generations." The land has memory: indigenous knowledge, native landscapes and the national 
museum of the American Indian. Ed. Duane Blue Spruce and Tanya Thrasher. Chapel Hill: University of North Carolina press, 2008. 1-10

Love, Morrie "A Wharewaka for Wellington: keeping a Māori footprint in the city." Tāone Tupu Ora; indigenous knowledge and sustainable design. Ed. Keriata Stuart and Michelle Thompson-Fawcett. Wellington: Astra Print, 2010. 91-99.

-----“Te Āti Awa of Wellington." Te Ara the encyclopaedia of New Zealand. 24-Aug. 2014. Web. 22 Sept. 2014

Lowenthal, David. The Past is a Foreign Country. Cambridge: Cambridge university press, 2003. Print.

Lyndon Donlyn and Charles W Moore. Chambers for a memory palace. Massachusetts: the MIT press, 1994. Print.

Maclean, Chris. "Wellington Region". Te Ara - the encyclopaedia of New Zealand. 15 June 2015. Manatū Taonga Ministry for Culture and Heritage. 28 August. 2015. http://www.teara.govt.nz/en/wellington-region

Maria Stafford, Barbara. Visual analogy; consciousness as the art of connecting. England: the MIT Press, 1999. Print

McClean, Robert. Te Whanganui a Tara Foreshores reclamations report. WAI 145, Waitangi tribunal research. 1997. Report.

McEwen, Jock. Rangitane; a tribal history. Auckland: Reed Methuen Publishers LTD, 1986. Print.

Mehrotra, Rahul. "Constructing Cultural significance: looking at Bombay's Historic Fort area." Future Anterior: Journal of Historic Preservation, History, Theory, and Criticism 1:2 (Fall 2004): 24-31. JSTOR. Web. 12 April 2014.
Mitchell. J.H. (Tiaki Hikawera Mitira). Takitimu, A history of Ngati Kahungunu. Auckland: Libro International, 2014. Print.

Munoz-Vinas, Salvador. Contemporary theory of conservation. Oxford: Elsevier Butterworth-Heinemann, 2005. EBook.

Pallasmaa, Juhani. "Space, place, memory, an imagination: the temporal dimension of existential space." The unknown city, contesting architecture and social space. Ed. Borden, Iain, Joe Kerr, Jane Rendell and Alicia Pivaro. Cambridge: MIT press, 2001.

Panoho, Rangihiroa. "the harakeke- No place for the bellbird to sing: Western colonization of Maori art in Aotearoa." Cultural Studies 9:1 (01 Jan 1995): 11-25. Web.

Patterson, John. Exploring Maori values. Wellington: Dunmore Publishing LTD, 2009.

Pocock, J.G.A. "the treaty between histories." Histories power and loss; uses of the past-a New Zealand commentary. Ed. Sharp, Andrew and Paul McHugh. Wellington: Bridget Williams Books Limited, 2001. 75-95. Print.

Price, Nicholas Sanely, M. Kirby Talley Jr. And Alessandra Melucco Vaccaro. Historical and philosophical issues in the Conservation of Cultural Heritage. United States of America: The Getty Conservation institute, 1996. Print.

Ramsden, Irihapeti. "An existence in history". Growing up Maori. Ed. Witi Ihimaera. Auckland: Tandem press, 1998. 286-294.

Ranger, Terrence. "the past is a foreign country review". American journal of sociology 92.4. (Jan 1987): 1008-1009. J-Stor. Web. 21 sep 2015
Royal, Te Ahukaramū Charles. "Te Ao Mārama-the natural world." Te Ara The encyclopedia of New Zealand. (September 2012): 6 pars. 31 Aug. 2015. http://www.teara.govt.nz/en/ te-ao-marama-the-natural-world/page-1

Schumacher, Thomas L. Terragni's Danteum. New York: Princeton Architectural Press, 2003.

Schneider, Bernhard. Daniel Libeskind, Jewish Museum Berlin. Munich: Prestel, 1999.

Smith, Bruce and Yoshiko Yamamoto. The Japanese bath Layton: Gibbs Smith, 2001. Print.

Smith, Linda Tuhiwai. Decolonizing Methodologies; second edition. Dunedin: Otago University Press, 2012. Print.

Spruce, Duane Blue and Tanya Thrasher. The land has memory indigenous knowledge, native landscapes, and the National Museum of the American Indian. Chapel Hill: University of North Carolina Press, 2008. EBook.

Struthers, John. Miramar Peninsula; a historical and social study. Trentham: Wright \& Carman Limited, 1975.

Taylor, Micheal and Annette Sutton. "An archaeologica assessment for the New Zealand Defence Force at Watts Peninsula, Wellington." Archaeology North Ltd. April 2009. Paper.

Trapeznik, Alexander, ed. Common ground? Heritage and public places in New Zealand. Dunedin: University of Otago Press, 2000. Print.

Treib, Marc. Spatial Recall: memory in architecture and landscape. New York: Routledge, 2009. Print. 
Walker Wiki. "Tangata whenua me te Kāinga kanohi/tangata whenua and the landscape" Taone Tupu Ora Indigenous knowledge and sustainable urban design. Ed. Keriata Stuart and michelle Thompson-Fawcett. Wellington: Steele Roberts Aotearoa, 2010. 82-90. Print.

Waitangi Tribunal. Te Whanganui a Tara me ona Takiwa, report on the Wellington district. Wellington: Legislation Direct, 2003. Print.

Warden, Robert. "towards a new era of cultural heritage recording and documentation." APT Bulletin, 40:3 (2009): 5-10. JSTOR. Web. 28 February 2014.

Woodward, Christopher. In ruins. Great Britain: Chatto and Windus, 2001. Print.

Yates, Frances A. The art of memory. Harmondsworth Penguin Books,1969. Print. 
